\title{
CONTRIBUIÇÃO PARA A TEORIA TERMODINAMICAMENTE CONSISTENTE DA FRATURA
}

João Augusto de Lima Rocha

Tese apresentada à Escola de Engenharia de São Carlos, da Universidade de São Paulo, como parte dos requisitos para a obtenção do título de Doutor em Engenharia de Estruturas

ORIENTADOR: Prof. Tit. Wilson Sérgio Venturini

São Carlos

1999 


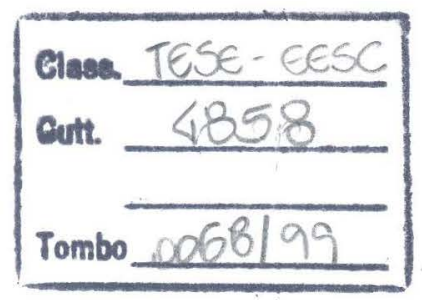

$5 / 5 \quad 1030639$

Ficha catalográfica preparada pela Seção de Tratamento da Informação do Serviço de Bíblioteca - EESC/USP

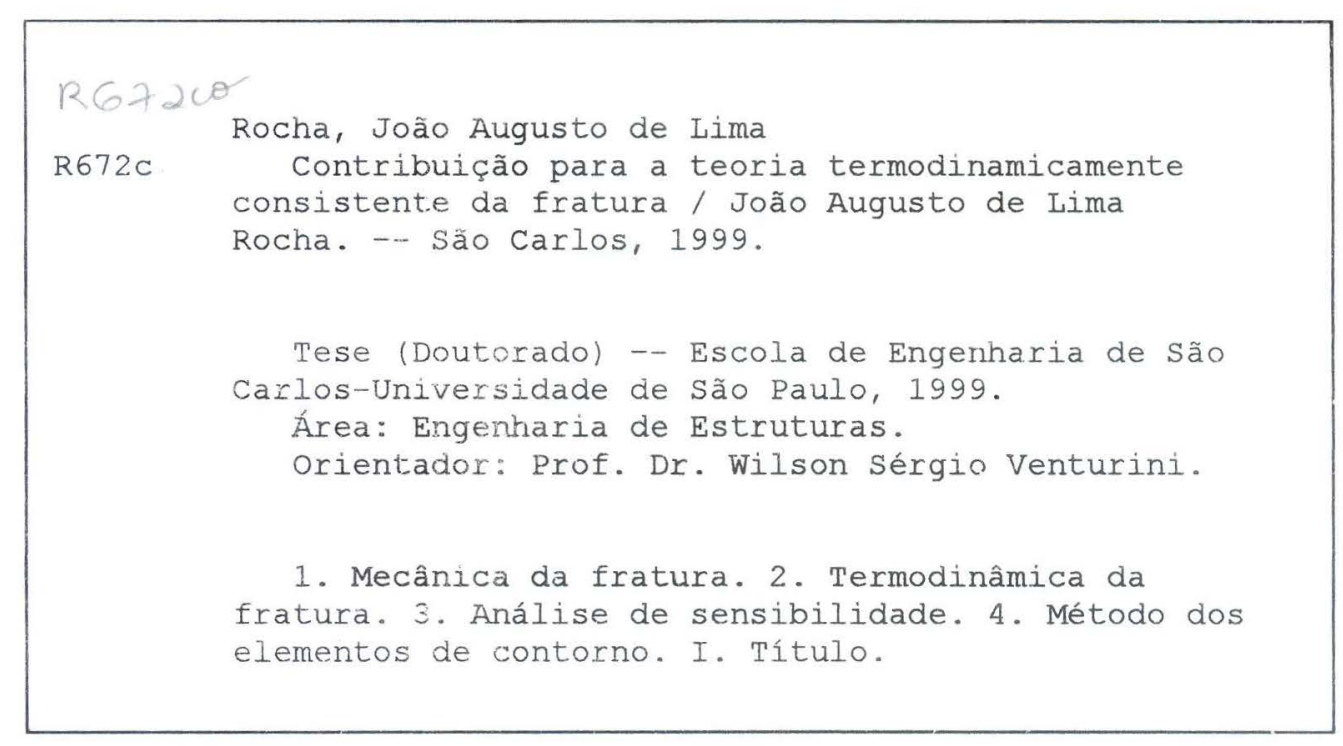




\section{Candidato: Engenheiro JOÃO AUGUSTO DE LIMA ROCHA}

Tese defendida e aprovada em 12-03-1999

pela Comissão Julgadora:

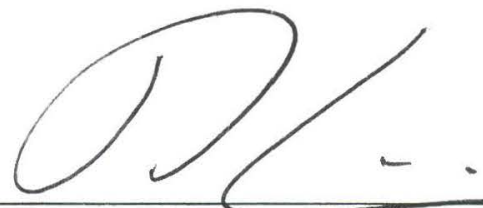

Prof. Titular WILSON SERGIO VENTURINI (Orientador)

(Escola de Engenharia de São Carlos - Universidade de São Paulo)

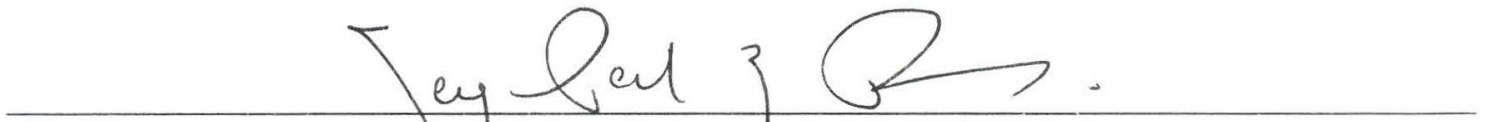

Prof. Associado SERGIO PERSIVAL BARONCINI PROENÇA

(Escola de Engenharia/de São Carlos - Universidade de São Paulo)

Prof. Doutor HUMBERTO BREVES CODA

(Escola de Engenharia de São Carlos - Universidade de São Paulo)

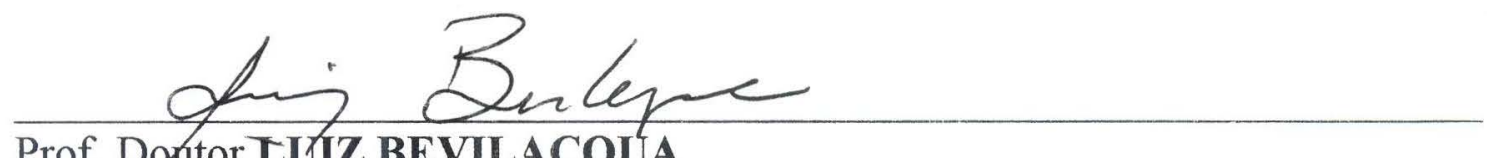

Prof. Doritor LUIZ BEVILACQUA

(COPPE - Universidade Federal do Rio de Janeiro)

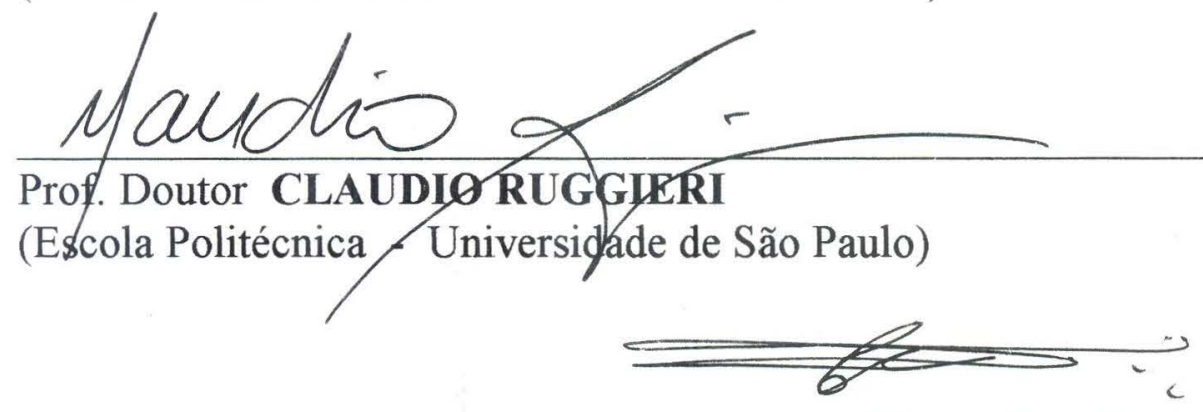

Prof. Titular CARLITO CALIL JUNIOR

Coordenador da Área de Engenharia de Estruturas

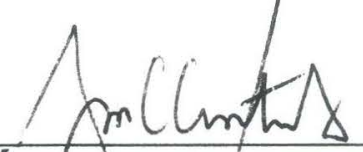

JOSÉ CARLOS A CINTRA

Presidente da Comissão de Pós-Graduação da EESC 
Com saudade, dedico este trabalho à memória de meu avô, Marcolino Fortes, e à de meu pai, Epaminondas Rocha, que conseguiram me convencer, cada um a seu modo, sobre a importância de avançar-se sempre no conhecimento do mundo.

Por semelhante motivo, também o dedico a Aydil, Leila, Vladimir e Pedro, cuja convivência, em família, nos faz solidariamente responsáveis pela continuidade da mesma tarefa. 


\section{AGRADECIMENTOS}

A convivência fraternal com os colegas, professores e funcionários do Departamento de Engenharia de Estruturas, e das bibliotecas da Escola de Engenharia da USP - São Carlos, particularmente reforçada nos momentos do congraçamento diário, esquentados pelo tradicional cafezinho, exigiria que este agradecimento não fizesse menção explícita a qualquer pessoa, isoladamente, porque seria injusto excluir alguma das tantas com quem estive em contato, durante os quatro proveitosos anos utilizados na organização deste trabalho. No entanto, é necessário que uma exceção se faça, para agradecer ao Prof. Tit. Wilson Sérgio Venturini, Orientador de Tese, por sua disponibilidade no atendimento, e pela confiança em mim depositada, fatores que muito me incentivaram a explorar possibilidades não convencionais do tema escolhido.

Agradeço também à CAPES e à Universidade Federal da Bahia, particularmente aos colegas e funcionários do Departamento de Construção e Estruturas da Escola Politécnica, pelo importante suporte durante o período do meu afastamento. 


\section{SUMÁRIO}

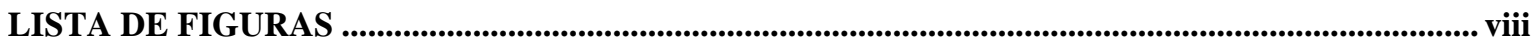

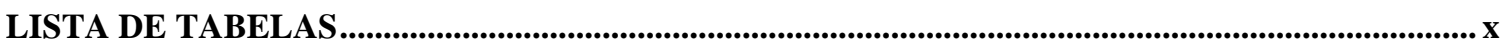

LISTA DE ABREVIATURAS E SIGLAS ............................................................................................

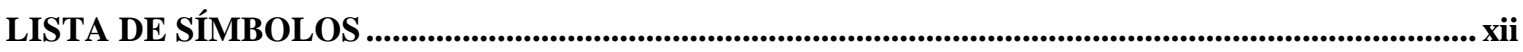

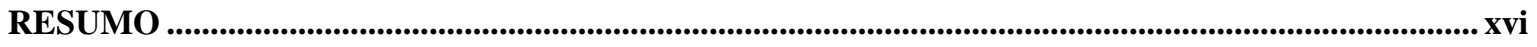

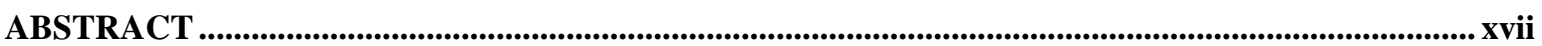

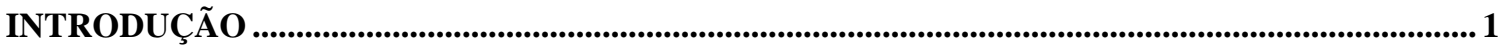

\section{CAPÍTULO 1}

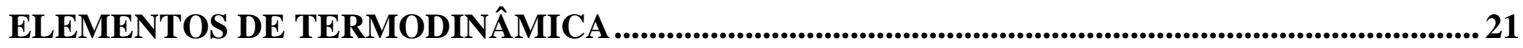

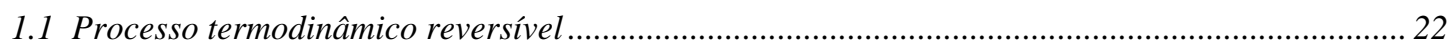

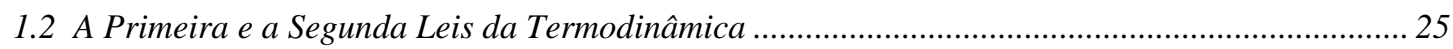

1.3 Interpretação termodinâmica do processo de deformaçãa de um sólido ......................................... 29

\section{CAPÍTULO 2}

O FENÔMENO DA FRATURA À LUZ DA MECÂNICA DO CONTÍNUO ...........................................31

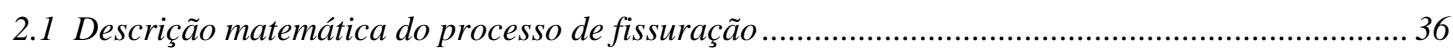

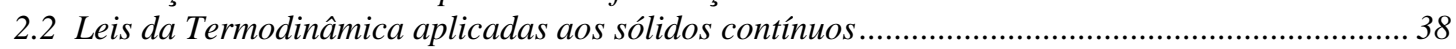

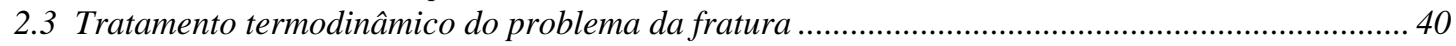

2.3.1 Passagem das equações de balanço global às equações de balanço local.................................... 40

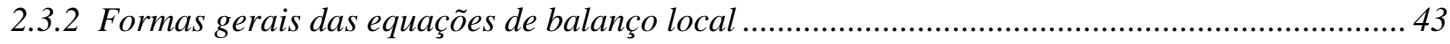

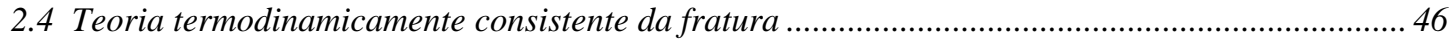

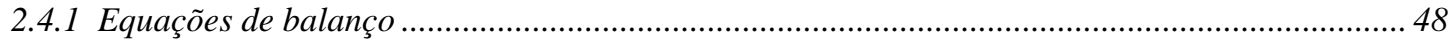

\section{CAPÍTULO 3}

CRITÉRIO TERMODINAMICAMENTE CONSISTENTE DE FRATURA.......................................60

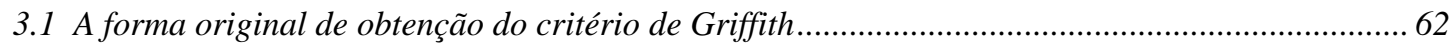

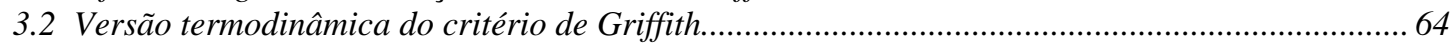

3.3 A dinâmica da propagação de uma fissura e o critério de Griffith ..................................................... 69

3.4 Critério termodinamicamente consistente de fratura …………………………............................. 71 


\section{CAPÍTULO 4}

A ANÁLISE DE SENSIBILIDADE APLICADA NA OBTENÇÃO DA DERIVADA MATERIAL DA ENERGIA DE DEFORMAÇÃ O .............................................................75

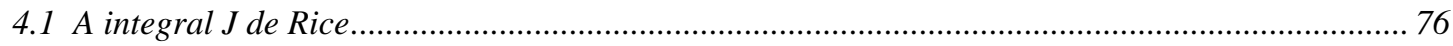

4.2 Derivada material da energia de deformação ............................................................................ 82

4.3 A simulação do avanço da fissura, via Análise de Sensibilidade ...................................................... 84

4.4 Discussão sobre o significado e a obtenção dos parâmetros J e Gt .............................................. 88

4.5 Particularização de Gt para o caso de uma chapa de espessura

constante contendo uma fissura iniciando-se no contorno ................................................................. 93

\section{CAPÍTULO 5}

\section{A INTEGRAL J E O PARÂMETRO TERMODINÂMICO DE FRATURA OBTIDOS COM O AUXÍLIO DO MÉTODO DOS ELEMENTOS DE CONTORNO 96}

5.1 Esquema teórico para a determinação aproximada de Gt no EPD......................................... 98

5.2 Obtenção da direção segundo a qual a fissura avançará........................................................... 102

5.3 Obtenção aproximada da energy release rate $G$ (integral $J$ ) no EPD......................................... 104

\section{CAPÍTULO 6}

\section{ASPECTOS EXPERIMENTAIS E NORMATIVOS SOBRE PARÂMETROS DE FRATURA 107}

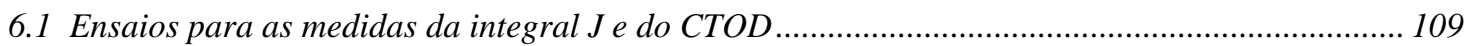

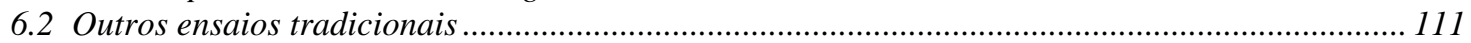

6.3 Os procedimentos normativos mais recentes de ensaios ........................................................... 111

6.4 Sugestão de experimentação para a determinação do

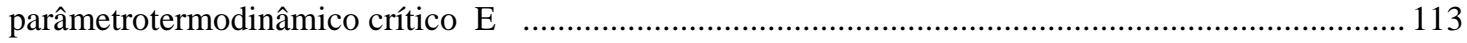

\section{CAPÍTULO 7}

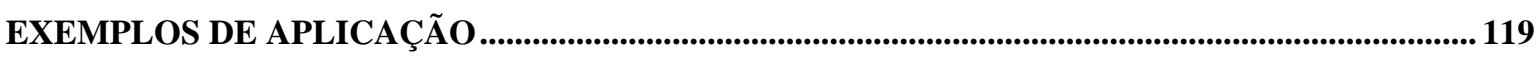

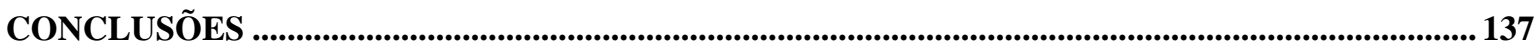

\section{ANEXOA}

ELEMENTOS DE ÁLGEBRA E DE ANÁLISE TENSORIAL ......................................................... 141

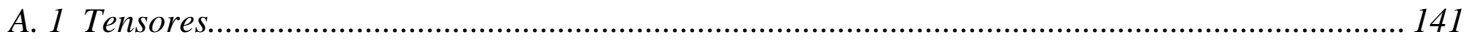

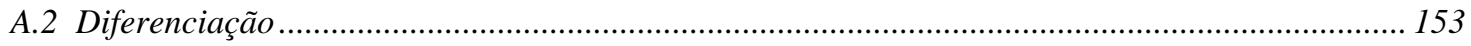

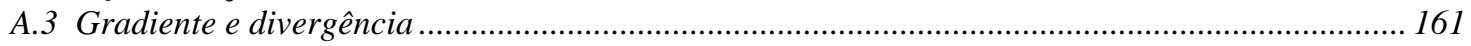

Teorema da Divergência (Gauss) .............................................................................................. 165

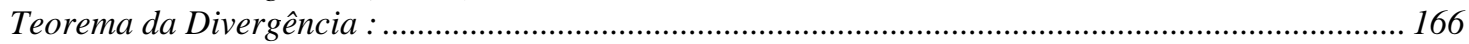

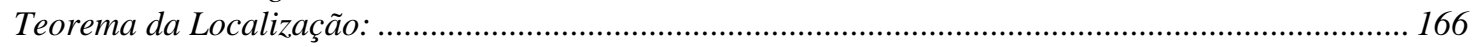

ANEXO B

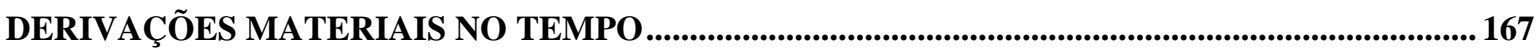

ANEXO C

ANÁLISE DE SENSIBILIDADE À MUDANÇA DE FORMA DO DOMÍNIO ...................................... 171

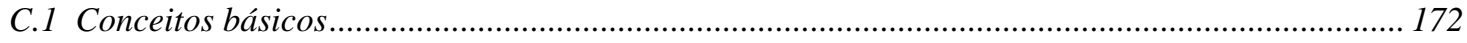

C.2 Cálculo de no caso em que vé arbitrado como uma

translação dos pontos do contorno. 
ANEXO D

MÉTODO DOS ELEMENTOS DE CONTORNO APLICADO A PROBLEMAS BIDIMENSIONAIS

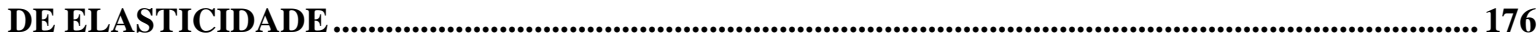

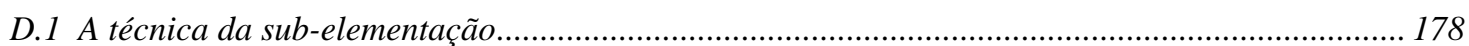

D.1.1 A integração numérica no sub-elemento.............................................................................. 181

ANEXO E

PROGRAMA ELCFRAT: CÁLCULO DA INTEGRAL J E DO PARÂMETRO TERMODINÂMICO

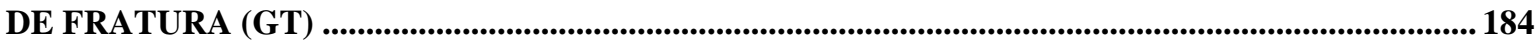

E.1 Descrição do programa automático e entrada de dados......................................................... 186

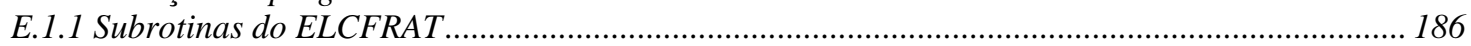

E.1.2 Entrada de dados............................................................................................................ 187

E.1.3 Saída do valor da integral J, do valor limite de Gt e do ângulo

formado pela direção do avanço da fissura com o eixo $x 1$.......................................................... 189

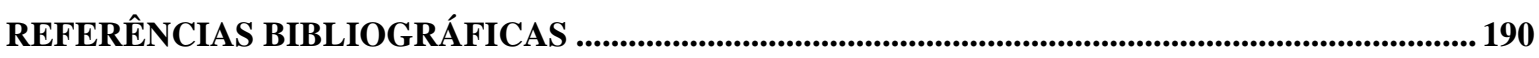

BIBLIOGRAFIA COMPLEMENTAR ......................................................................................................... 195 


\section{LISTA DE FIGURAS}

FIGURA 1- TRANSFERÊNCIA REVERSÍVEL DE CALOR A UM SISTEMA

(ADAPTADA DE NUSSENZVEIG (1990))

FIGURA 2- PROCESSO TERMODINÂMICO REVERSÍVEL

(ADAPTADA DE NUSSENZVEIG (1990)) .24

FIGURA 3- A DEFORMAÇÃO NO CASO DE UM SÓLIDO

NÃO FISSURADO (a) OU CONTENDO UMA FISSURA(b)

FIGURA 4- FISSURA RETA CRESCENDO NA DIREÇÃo $\mathbf{x}_{1}$ .77

FIGURA 5- A DELIMITAÇÃO DA PARTE $P$ E O AVANÇO DA FISSURA ......................................85

FIGURA 6- SIMULAÇÃO DO AVANÇO DA FISSURA...............................................................86

FIGURA 7- CONVENÇÕES DE EIXOS E DE ÂNGULOS...........................................................99

FIGURA 8- A EVOLUÇÃO DE UMA FISSURA TÍPICA DOS AÇOS

(ADAPTADA DE De AQUINO et al (1998)) .110

FIGURA 9- AJUSTE DE INICIALIZAÇÃO DE $\Delta$ a

(ADAPTADA DE DEAQUINO et al (1998))

FIGURA 10- ESBOÇO DA CHAPA A SER ENSAIADA PARA

A OBTENÇÃO DE $\gamma_{E}(F)$ .115

FIGURA 11- EXEMPLO 1 e FIGURA 12- EXEMPLO 2 120

FIGURA 13- HASTE DOS EXEMPLOS 1 E 2, INDICANDO OS PONTOS DE

INTEGRAÇÃO DO CONTORNO ELÍPTICO E OS NÓS DO CONTORNO. 120

FIGURA 14- COMPONENTES $\sigma_{22}, \sigma_{11}$ E $\tau_{12}$, COMO FUNÇÃO DE $r$, NO EXEMPLO 1....................121

FIGURA 15- COMPONENTES $\sigma_{11}, \sigma_{22}$ E $\tau_{12}$ COMO FUNÇÃO DE $r$, NO EXEMPLO 2.....................121

FIGURA 16- EXEMPLO 3: PEÇA COM FISSURA CENTRAL

FIGURA 17- EXEMPLO 3: SEMI-ELIPSE, METADE DO CAMINHO DA

INTEGRAL $\boldsymbol{J}$, EM TORNO DE UMA DAS EXTREMIDADES DA FISSURA .124

FIGURA 18- CHAPA COM GEOMETRIA E CARREGAMENTO PARAMETRIZADOS. 130

FIGURA 19- CASO DE DUAS FISSURAS: DISCRETIZAÇÃO PELO BEM

E CIRCUITO ELÍPTICO INTERNO. 
FIGURA 20- CONTORNO ELÍPTICO E CÉLULAS INTERNAS EM TORNO DA EXTREMIDADE DA FISSURA

FIGURA 21- CHAPA COM DESLOCAMENTOS

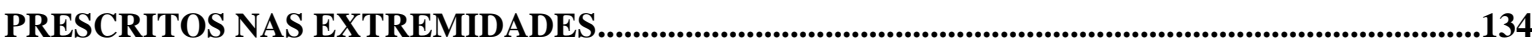

FIGURA 22- VARIAÇÃO DE FORMA DO DOMÍNIO E DE SEU CONTORNO .................................173

FIGURA 23- POSIÇÕES RELATIVAS DO PONTO DE COLOCAÇÃO

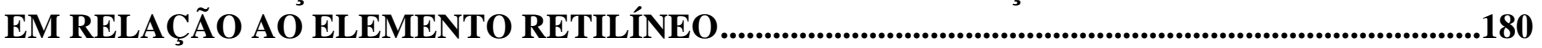

FIGURA 24- SUB-ELEMENTO DE UM ELEMENTO

DE CONTORNO RETILÍNEO ....................................................................................................................182 


\section{LISTA DE TABELAS}

TABELA 1-VALORES DA INTEGRAL $\boldsymbol{J}$, CALCULADA PELO BEM (ELCFRAT), PARA O CASO DE UMA HASTE COM ENTALHE EM ÂNGULO

$\left(\theta=11,42^{\circ} ;\right.$ abertura inferior $\left.=2 \times 10^{-2} \mathrm{~m}\right)$.

TABELA 2-VALORES DA INTEGRAL $J$, CALCULADA PELO BEM (ELCFRAT) QUANDO, NOS EXEMPLOS 1 E 2, O ENTALHE É RETANGULAR (abertura. $=10^{-4} \mathrm{~m}$, COMP. $\left.=10^{-1} \mathrm{~m}\right)$

TABELA 3- COMPARAÇÃO DO CÁLCULO DE $J$ (J/m)

PELO MEF E PELO BEM

TABELA 4- VALORES DE $J, G_{\mathrm{t}}$ E A DIREÇÃO DE

PROPAGAÇÃO DA FISSURA: EXEMPLO .4.

TABELA 5- VALORES DE $\boldsymbol{J} \boldsymbol{G}_{\mathrm{t}}$ E DA DIREÇÃO DE AVANÇO DA FISSURA: EXEMPLO 5

TABELA 6- ESTUDO DA VARIAÇÃO DE $J$ E $G_{t}$, COM AS ESCALAS GEOMÉTRICA E DE CARREGAMENTO.

TABELA 7- VALORES DE $\boldsymbol{J}$ E DE $\boldsymbol{G}_{\boldsymbol{t}}$, NO CASO DE UMA CHAPA CONTENDO DUAS FISSURAS

TABELA 8 - VALORES DE $G_{t}$ EM UM CASO DE ELASTOPLASTICIDADE PERFEITA 


\title{
LISTA DE ABREVIATURAS E SIGLAS
}

\author{
ASTM \\ American Standard for Testing and Materials. \\ BEM \\ Método dos Elementos de Contorno (Boundary Element. \\ Method). \\ $B S I$ \\ Britsh Standards Institute. \\ DIN \\ Deutsche Industrie Normen. \\ $E P D$ \\ Estado plano de tensão. \\ $E P T$ \\ Estado plano de deformação. \\ ISO \\ International Standard Organization. \\ $M E F$ \\ Método dos Elementos Finitos. \\ RILEM \\ Réunion International des Laboratoires d'Éssais et de \\ Recherches sur les Matériaux et les Constructions
}




\section{LISTA DE SÍMBOLOS}

Grandezas escalares são aqui representadas com auxílio de letras latinas, minúsculas ou maiúsculas, em itálico. Caracteres desse mesmo tipo são também utilizados para representar funções, coeficientes, conjuntos, sólidos, partes de sólidos ou pontos.

Letras latinas minúsculas, em negrito, indicam vetores (em $I R^{2}$, ou em $I R^{3}$ ); letras latinas maiúsculas, em negrito, indicam tensores de segunda ordem (transformações lineares de $I R^{2}$ em $I R^{2}$, ou de $I R^{3}$ em $I R^{3}$ ).

No texto, o significado de cada um dos símbolos utilizados é sempre indicado no primeiro lugar em que aparece. A seguir, são descritos os principais símbolos.

\section{CARACTERES LATINOS}

A

$a$

b

$b$

$B$

$C$

$C_{0}$

$C_{\mathrm{t}}$

D

e

$\mathbf{e}_{\mathrm{i}}$

E

$E_{\mathrm{d}}$

f

$F$

g

$G$

$G_{\mathrm{t}}$

$h$

I

$J$

$J_{\text {Ic }}$

Área da base de um cilindro, ou seção transversal.

Semi-eixo maior de uma elipse; parâmetro de fratura.

Densidade de forças de corpo, por unidade de volume.

Semi-eixo menor de uma elipse.

Corpo deformável.

Capacidade térmica de um sólido.

Configuração de referência de um sólido, no $I R^{3}$.

Configuração atualizada de um sólido, no instante $t$, no $I R^{3}$.

Tensor taxa de deformação.

Vetor unitário da direção de propagação da fissura.

Vetor unitário na direção de um eixo coordenado.

Energia interna; módulo de Young.

Energia de deformação.

Densidade de forças de corpo, por unidade de massa.

Força.

Densidade volumétrica genérica (de forças de corpo, de quantidade de calor trocada com o exterior etc.).

Energy release rate.

Parâmetro termodinâmico de fratura.

Espessura de uma chapa.

Tensor identidade.

Integral $J$ : parâmetro de fratura.

Parâmetro experimental: integral $J$, medida no ponto a partir 


\section{K}

$K_{\mathrm{I}}, K_{\mathrm{II}}, K_{\mathrm{III}}$

$K_{\text {Ic }}, K_{\text {IIc }}, K_{\text {III }}$

n

$N_{\rho}(P)$

$P, p^{\prime}$

$P_{\mathrm{j}}{ }^{*}$

$P$

$P_{0}$

$P_{\mathrm{t}}$

q

$Q$

$q$

$r$

S, s

$\mathbf{s}$

$S$

$S_{\mathrm{f}}(t)$

$s_{\mathrm{f}}(t)$

$t$

$\mathbf{t}$

$\overline{\mathbf{t}}$

$T$

T

$T_{\mathrm{ij}}$

u

$u_{\mathrm{j}}$

$u_{\mathrm{ij}}{ }^{*}$

$U$

V

V

V

W

W

$\mathbf{x}$

$x_{\mathrm{i}}$

$\mathbf{X}$ do qual a fissura passa a ter um crescimento estável.

Conjunto.

Fatores de intensidade de tensões.

Valores críticos dos fatores de intensidade de tensões.

Vetor normal unitário, em um ponto de uma superfície, ou curva regular.

Vizinhança de raio $\rho$, de um ponto $P$.

Pressão.

Componente de traction (BEM).

Componente de traction da solução fundamental (BEM).

Parte de um sólido; ponto fonte (BEM).

Representação da parte $P$, de um sólido, na configuração de referência.

Representação atualizada da parte $P$, de um sólido.

Vetor fluxo de calor.

Quantidade de calor.

Quantidade de calor, por unidade de volume.

Taxa de calor fornecido a um sólido, por unidade de massa; medida algébrica da distância entre um ponto fonte e um ponto de colocação (BEM).

Entropia

Densidade de força, por unidade de área.

Ponto de colocação (BEM).

Representação de referência, da superfície de avanço de uma fissura, relativa ao instante $t$

Representação atualizada, da superfície de avanço de uma

fissura, no instante $t$

Tempo.

Vetor de tensão de Cauchy (traction)

Valores de tractions aplicadas no contorno $\Omega_{\mathrm{t}}$

Temperatura absoluta.

Tensor tensão, de Cauchy

Componentes cartesianas do tensor $\mathbf{T}$.

Vetor deslocamento.

Componentes cartesianas do vetor deslocamento.

Componente de deslocamento da solução fundamental (BEM).

Energia potencial elástica.

Volume, na configuração atualizada do sólido.

Derivada material no tempo, do vetor posição (velocidade).

Volume, na configuração de referência do sólido.

Trabalho mecânico.

Quantidade de trabalho mecânico, por unidade de volume.

Vetor que define a posição de um ponto da configuração atualizada de um sólido.

componentes cartesianas do vetor $\mathbf{x}$; eixos coordenados. Vetor que define a posição de um ponto da configuração de referência, associado a $\mathbf{x}$. 


\section{OUTROS CARACTERES}

$\phi$

$\Phi(\mathbf{x}, t)$

$\Phi^{*}(\mathbf{x}, t)$

$\delta_{\mathrm{ik}}$

$\varepsilon$

$\varepsilon^{*}$

$\varepsilon$

$\varepsilon_{\mathrm{ij}}$

$\gamma$

$\gamma^{*}$

$\mu$

$\gamma_{\mathrm{E}}$

$\Gamma$

$\Gamma_{\mathrm{T}}$

$\Gamma^{+}, \Gamma^{-}$

$\eta$

$\eta^{*}$

$\Lambda$

$v$

$\rho$

$\rho^{*}$

$\sigma_{\text {ap }}$

$\Sigma$

$\tau$

$\xi$

$\psi$

$\psi^{*}$

$\Psi$

$\Omega$

$\Omega_{\mathrm{t}}$

$\Omega_{\mathrm{u}}$
Densidade de energia de deformação, por unidade de volume.

Campo genérico, escalar, ou vetorial, da equação geral de balanço termomecânico (definido no volume da configuração atualizada do sólido).

Campo genérico, escalar, ou vetorial, da equação geral de balanço termomecânico (definido nas superfícies de avanço da fissura).

Delta de Kronecker.

Energia interna por unidade de massa, ou energia interna, por unidade de volume.

Energia interna superficial, por unidade de massa.

Tensor deformação.

Componentes cartesianas do tensor deformação.

Energia superficial, por unidade de área de avanço da fissura.

Energia superficial termodinâmica de fratura, por unidade de área.

Módulo de elasticidade transversal.

Valor crítico do parâmetro termodinâmico de fratura.

Fronteira de uma região plana.

Fronteira da zona de processo da fissura.

Faces planas de uma fissura.

Entropia por unidade de massa.

Entropia superficial, por unidade de massa

Taxa de dissipação de energia, por unidade de volume.

Coeficiente de Poisson.

Densidade de massa, ou massa específica. Raio de uma vizinhança

Massa superficial, por unidade de área.

Tensão de tração, aplicada no infinito, no contorno de uma chapa.

Tensor de Eshelby

Parâmetro escalar, da Análise de Sensibilidade.

Taxa de produção de entropia, por unidade de massa.

Energia livre de Helmholtz, por unidade de massa.

Energia livre de Helmholtz superficial, por unidade de massa.

Energia livre de Helmholtz, de um sólido.

Região plana fechada.

Região do contorno de um sólido, com tractions prescritas.

Região do contorno de um sólido, com deslocamentos 
prescritos.

$\partial \Omega$

$\Upsilon$

$\partial P_{\mathrm{t}}$

$\partial P_{0}$

$\nabla$

$\operatorname{grad}$
Fronteira da região plana $\Omega$.

Indica uma grandeza genérica, para qual faz sentido sua aplicação ao vetor $\mathbf{n}$ (tensor tensão, vetor fluxo de calor etc.)

Fronteira de $P_{\mathrm{t}}$.

Fronteira de $P_{0}$.

Gradiente material.

Gradiente espacial. 


\section{RESUMO}

ROCHA, J. A. de L (1998). Contribuição para a teoria termodinamicamente consistente da fratura. São Carlos, 1998. 201p. Tese (Doutorado) - Escola de Engenharia de São Carlos, Universidade de São Paulo

Como ponto de partida para a formulação da teoria termodinamicamente consistente da fratura, parte-se das cinco equações globais do balanço termomecânico (massa, momentum linear, momentum angular, energia e entropia), aplicadas ao caso de um sólido dentro do qual superfícies internas regulares podem evoluir, continuamente, com o processo de deformação, simulando fissuras. Faz-se a passagem das equações globais às correspondentes equações locais de balanço, inclusive nos pontos das superfícies de avanço das fissuras, e chega-se ao critério termodinâmico geral de fratura. Fazendo-se uso da noção de energia livre de Helmholtz, particulariza-se o critério para o caso isotérmico. $\mathrm{Na}$ seqüência, contando-se com o auxílio da Análise de Sensibilidade à variação de forma, da Otimização Estrutural, aplicada ao caso da fratura, obtém-se o parâmetro termodinâmico de fratura, válido para uma parte arbitrária do sólido contendo uma fissura. Assim, o problema fica reduzido à obtenção do valor de uma integral sobre a fronteira da parte do sólido considerada. O Método dos Elementos de Contorno é utilizado para a obtenção de resultados aproximados desse parâmetro, que é alternativo à integral $J$ de Rice. Conclui-se, com uma proposta de experimento de laboratório, acoplado a um experimento numérico, para o caso de um problema bidimensional. A partir da comparação entre resultados do experimento de laboratório e do correspondente experimento numérico, sugere-se que será possível a calibração de parâmetros associados ao comportamento não linear do material nas proximidades da extremidade de uma fissura.

Palavras-chave: Mecânica da Fratura; Termodinâmica da Fratura; Fratura, Teoria da Fratura, Método dos Elementos de Contorno, Análise de Sensibilidade. 


\section{ABSTRACT}

ROCHA, J. A . de L (1998). Contribution to the thermodynamically consistent theory of fracture. São Carlos, 1998. 201p. Tese (Doutorado) - Escola de Engenharia de São Carlos, Universidade de São Paulo.

The construction of a thermodynamically consistent theory of fracture, is here proposed assuming that the five global equations of the thermomechanical balance (mass, linear momentum, angular momentum, energy and entropy), of Continuum Mechanics, are valid in the case of a solid containing flaws, simulating initial cracks. Considering the possibility of crack advances, the passage from global equations to local ones conducted to local balance, also for points taken over the crack advancing surfaces. As consequence, a general thermodynamic fracture criterion is obtained. Then, using the concept of Helmholtz Free Energy, this fracture criterion is particularised to the isothermal case. The Shape Sensitivity Analysis, used as a tool of Fracture Mechanics, conducted to a fracture thermodynamic parameter $G_{\mathrm{t}}$, whose physical meaning is analogous to the Griffith's energy release rate (or the Rice's $J$ integral) but that parameter is based on the strain energy instead potential total energy. The Boundary Element Method is used in the construction of a strategy of coupling numerical and experimental tests, viewing the construction of a particular fracture criterion, valid to plane problems. In conclusion, one proposes that this numerical and experimental coupling be adopted for calibration of non-linear models of material behaviours, valid in the neighbouring of crack's onset.

Keywords: Fracture Mechanics, Fracture Thermodynamics, Fracture, Fracture Theory, Boundary Element Method, Sensitivity Analysis. 


\section{INTRODUÇÃO}

O objetivo do presente trabalho é contribuir para a organização de uma teoria termodinamicamente consistente da fratura, fundamentando-se na idéia chave da Termomecânica do Contínuo, que é a passagem das equações de balanço global (massa, quantidade de movimento linear, quantidade de movimento angular, energia, princípio da irreversibilidade ou desigualdade de Clausius-Duhem), tomadas como axiomas, para as respectivas equações locais, nos pontos interiores do sólido. A novidade está em examinar-se a extensão desse procedimento, ao caso de um sólido contendo vazios, isto é, fissuras cujas superfícies internas tenham a possibilidade de evoluir de maneira irreversível.

A presente proposta é de natureza essencialmente teórica, embora nela também se inclua uma proposta de verificação de sua validade prática, com o auxílio de uma metodologia que associa a experimentação de laboratório com a experimentação numérica.

Para evitar dubiedade na aplicação de duas palavras que aparecem com bastante freqüência no texto, e que, na língua portuguesa, costumam ter aplicação ambígua, definem-se inicialmente:

1. FRATURA (fracture) é o fenômeno irreversível caracterizado pelo crescimento das áreas das superfícies internas dos vazios de um sólido em processo de deformação.

2. FISSURA é um ente cuja extensão física é caracterizada somente pela medida de sua fronteira, possuindo uma dimensão a menos que qualquer conjunto formado por pontos materiais do sólido em que está inserida. Nesse sentido é que se identifica com o vazio. A medida de seu crescimento irreversível, é dada pelo acréscimo da área de sua fronteira 
ocorrido no processo de fratura. O valor da área da superfície de uma fissura é sempre, por hipótese, diferente de zero. Existem fissuras que ficam totalmente imersas no interior do sólido (cracks), e outras que adentram a partir da fronteira do sólido (notches).

\section{CARACTERÍSTICAS ESSENCIAIS DA TEORIA TERMODINAMICAMENTE CONSISTENTE DA FRATURA:}

a) É considerada a parcela dissipada nas superfícies de avanço das fissuras; para efeito do balanço de energia;

b) associada ao processo de avanço de uma fissura incluída em uma parte arbitrária do sólido, aparece uma grandeza, a densidade termodinâmica superficial de fratura, definida em cada ponto dessa superfície de avanço, através da qual podese verificar se como o acoplamento de influências entre a temperatura absoluta e a velocidade de propagação, influencia a estabilidade do processo.

c) no caso do regime quase estático e isotérmico, resulta o parâmetro termodinâmico de fratura, grandeza cuja determinação, através da Análise de Sensibilidade, decorre da consideração das Leis da Termodinâmica, em lugar do Princípio da Mínima Energia Potencial Elástica estendido por Griffith para o estudo da fratura.

\section{MODELO FÍSICO:}

a) Tal como na Mecânica do Contínuo, parte-se do pressuposto que, para um sólido sujeito à fratura, são sempre atendidas as cinco equações termomecânicas de balanço global, inclusive nas superfícies de avanço das fissuras.

b) a Primeira e a Segunda Leis da Termodinâmica fornecem a base para a construção de um critério de fratura termodinamicamente consistente;

c) no caso particular em que o regime de deformação é quase estático e isotérmico, o processo termodinâmico só progredirá, espontaneamente, entre dois estados, se a função energia livre de Helmholtz $\Psi$ (para todo o sólido) sofrer um decréscimo, de um estado para o outro. O crescimento das fissuras é, portanto, 
irreversível. Mas a simples ocorrência de um decréscimo na função $\Psi$ não é condição suficiente para indicar que ele tenha sido provocado pelo avanço de uma fissura. $\mathrm{O}$ decréscimo da energia livre de Helmholtz é, pois, uma condição necessária, mas não suficiente, para a ocorrência de fissuração no sólido. Isto porque podem ocorrer outros fenômenos dissipativos durante a deformação dos sólidos, tais como a plasticidade e o dano.

d) a evolução do processo de fissuração pode ser modelada como se estivesse ocorrendo uma seqüência de iniciações de fratura, após cada uma das quais o domínio do problema precisaria ser atualizado.

\section{MODELO MATEMÁTICO:}

a) Ditado pela física do problema, esse modelo busca acompanhar, nas sucessivas representações atualizadas do corpo, a interação contínua entre fenômenos que ocorrem no $I R^{3}$ (pontos interiores não atingidos pela fissuração) $e$ aqueles que ocorrem no $I R^{2}$ (superfícies de avanço das fissuras);

b) A alternativa à energy release rate, de Griffith-Irwin, será o parâmetro termodinâmico de fratura, calculado como a derivada material da energia de deformação do sólido, em relação a um parâmetro geométrico de fratura. A Análise de Sensibilidade á variação de forma, da Otimização Estrutural, será utilizada como ferramenta, no cálculo dessa derivada.

Como orientação básica para o aprofundamento no tema, procurou-se examinar, diretamente, as publicações tidas como fundamentais no estudo da fratura, a partir do trabalho pioneiro de GRIFFITH (1920). E a pesquisa do instrumental adequado aos objetivos propostos, exigiu um aprofundamento teórico geral nos campos da Mecânica do Contínuo, da Análise de Sensibilidade, e dos métodos numéricos da Física Matemática, com destaque para o Método dos Elementos de Contorno $(B E M)$. 
No Capítulo 1 apresenta-se um apanhado dos conceitos básicos da Termodinâmica, aplicados à interpretação dos processos que se desenvolvem nos sólidos deformáveis.

No Capítulo 2, que contém a principal contribuição trazida pelo presente trabalho, desenvolve-se a pesquisa da possibilidade da extensão, ao caso da fratura, do procedimento da passagem das equações globais às locais, procedimento que é o típico do balanço termomecânico da Mecânica do Contínuo. O desenvolvimento apresentado nesse capítulo é uma alternativa ao proposto por ZHANG \& KARIHALOO (1993), baseado no Teorema de Transporte de Reynolds. Aqui, optouse por um caminho pelo qual se chega a uma equação geral de balanço local, válida para cada ponto das superfícies de avanço das fissuras. De posse desse resultado, parte-se para a interpretação, uma a uma, das cinco equações locais. Assim, consegue-se completar algumas lacunas contidas no trabalho antes citado, ensejando a perspectiva de aplicação a objetivos de interesse prático, dos resultados da teoria termodinamicamente consistente.

O Capítulo 3 centra-se exatamente em tal perspectiva, através da busca de conexão entre a metodologia aqui proposta e a sugerida por GRIFFITH $(1920,1924)$, cujo conhecido critério de iniciação da fratura considera somente a Primeira Lei da Termodinâmica (conservação da energia). Com o auxílio da Primeira e da Segunda Leis, no caso em que o fenômeno se desenvolve em regime quase estático e isotérmico, é feita a interpretação termodinâmica do critério de Griffith, chegando-se a formulações que se desdobram em critérios de fratura que, a despeito de certa semelhança de forma, são, em essência, diferentes do original, por conta da consistência termodinâmica.

No caso geral, não isotérmico, embora tenha sido completamente desenvolvida a teoria, não foi explorada a possibilidade de aplicações práticas, ficando na dependência de desenvolvimentos posteriores, em razão da aparecimento de parâmetros cuja determinação exigiria uma nova filosofia experimental. 
No Capítulo 4 apresenta-se a ferramenta cuja utilização veio facilitar a generalização, para os casos de problemas tridimensionais, tanto do cálculo da integral $J$, de RICE (1968), baseada na noção de energy release rate (Griffith-Irwin), quanto da obtenção do parâmetro termodinâmico de fratura, surgido com o presente trabalho. Trata-se da Análise de Sensibilidade à variação de forma, um campo de estudos cujas aplicações tradicionais são na área da Otimização Estrutural, mas que vem sendo recentemente aplicado, com sucesso, à Mecânica da Fratura, principalmente por TAROCO (1996). Nesse particular, a contribuição trazida pelo presente trabalho, contida no Capítulo 4, é o cálculo da derivada material da energia de deformação, em relação a um parâmetro geométrico de fratura, base para a simulação da deflagração do avanço de uma fissura no sólido. Decorre desse processo de derivação, a possibilidade do emprego de um método numérico, visando ao cálculo aproximado do parâmetro termodinâmico de fratura.

No Capítulo 5 desenvolve-se, com o auxílio do Método dos Elementos de Contorno, uma aplicação simples, que permite a programação automática do esquema de cálculo aproximado do parâmetro termodinâmico e também da integral $J$. Trata-se do problema de fratura em uma chapa. Ë uma mera demonstração da possibilidade de uma alternativa numérica que, com bastante simplicidade, poderá dar bons frutos, no que se refere à aplicação tecnológica. O programa automático (em FORTRAN), desenvolvido com base no conteúdo desse capítulo, denominado ELCFRAT (v. Anexo E), apresenta um elemento de contorno retilíneo, isoparamétrico, com interpolação linear, sub-elementação automática e a possibilidade de colocação de nós duplos.

No Capítulo 6, discorre-se sobre a Análise Experimental na Mecânica da Fratura, destacando-se as metodologias correntes de ensaio e análise, basicamente as propostas pela $A S T M$, para os aços. Apresenta-se aí, um esboço de proposta de ensaio de laboratório que, em associação com a experimentação numérica, realizada sobre um modelo do mesmo corpo de prova ensaiado, é capaz de fornecer um critério de fratura, baseado no valor crítico do parâmetro termodinâmico. 
No Capítulo 7, apresentam-se exemplos de aplicação, sendo calculados a integral $J$ e o parâmetro $G_{\mathrm{t}}$, com o auxílio do programa ELCFRAT. Além desses resultados, que visam demonstrar as possibilidades da metodologia aqui proposta, são também apresentados alguns outros, com base em outro programa automático, em desenvolvimento pelo Prof. Humberto Coda, do Departamento de Engenharia da Escola de Engenharia de São Carlos - USP. Nesse caso, como o programa inclui modelos elastoplásticos, permite que a metodologia proposta seja explorada de maneira mais completa, particularmente na calibração de parâmetros associados ao estado da região de processo da fissura.

No Anexo A, apresentam-se alguns resultados úteis, de Álgebra e de Análise Tensorial. Do Anexo B constam os conceitos básicos da Mecânica do Contínuo, sobre a aplicação deformação, e sobre a derivação material. No Anexo C, são mostrados alguns resultados úteis à aplicação da Análise de Sensibilidade ao problema da fratura. No Anexo D, apresentam-se alguns desenvolvimentos essenciais à compreensão das particularidades do Método dos Elementos de Contorno, aplicado a problemas bidimensionais. Inclui-se aí o desenvolvimento de uma técnica de sub-elementação, especialmente desenvolvida para este trabalho, que aumenta sensivelmente a precisão dos resultados do programa ELCFRAT. Finalmente, no Anexo E, encontra-se a descrição do programa ELCFRAT, assim como observações sobre a entrada de dados e a saída dos resultados.

\section{SÍNTESE HISTÓRICA:}

Visando prever o limite da capacidade resistente dos materiais, o homem vem buscando compreender, desde os primórdios, o mecanismo do rompimento das ligações interiores, responsável pela perda da integridade dos corpos sólidos submetidos a ações externas.

Se o acompanhamento da evolução dos procedimentos utilizados nesse tipo de previsão começa na fase mais recente da história, marcada pela aplicação do conhecimento científico à compreensão dos fenômenos da resistência dos materiais, verifica-se que Galileo Galilei (1564-1642) foi pioneiro também nesse terreno. Tido 
como um dos precursores da Mecânica dos Materiais, Galileo destaca em sua obra Duas Novas Ciências a preocupação com "a coerência das partes nos corpos sólidos" e com a "resistência dos sólidos à fratura", temas sobre os quais desenvolve a conversação entre os personagens Salviati, Sagredo e Símplício, nas duas primeiras jornadas de seu famoso livro, GALILEI (1945). Aí apresenta proposições que já revelam uma clara compreensão dos mecanismos da resistência dos materiais, alimentada certamente pela necessidade prática imediata de resolver os problemas surgidos na atividade de projeto e construção que então desenvolvia no arsenal de Veneza. A ênfase de Galileo foi colocada na busca da resistência à fratura, isto é, na obtenção de informações sobre a capacidade resistente do material no momento da ruptura.

Diferente foi a orientação decorrente das experiências de Robert Hooke (1635-1703) com molas. Baseado na analogia que intuiu entre elas e o comportamento dos materiais, Hooke levou a então incipiente Mecânica dos Materiais a optar pela hipótese da linearidade da relação força x deslocamento nas peças e estruturas, cujo reflexo é evidente na simplificação dos modelos para o estudo dos fenômenos dessa área. Isso parece ser a razão fundamental para o abandono da ênfase na questão da fratura, ou na resistência limite dos materiais, prevalecendo, até recentemente, a opção pelo limite elástico como referência básica no estudo do comportamento mecânico dos materiais.

A despeito de Saint-Venant (1797-1886), com sua plasticodinâmica, segundo TIMOSHENKO (1953), ter dado os primeiros e seguros passos no sentido do desenvolvimento da teoria da plasticidade, seguindo-se a ele um grande número de contribuições relevantes, a volta à ênfase original de Galileo, centrada no comportamento limite dos materiais, reforça-se bastante a partir da década de 20 do presente século com a contribuição de Griffith (1893-1963), a quem se deve o início da Mecânica da Fratura.

É curioso verificar-se que a idéia fundamental, base para a retomada da ênfase na resistência limite de fratura, GRIFFITH (1924), decorre do aproveitamento criativo de resultados da própria elasticidade linear, a saber, da análise de problemas sobre concentração de tensão em torno de reentrâncias e orifícios, divulgados num 
trabalho de INGLIS (1913) inspirado em problemas práticos da indústria naval. A proposta teórica de Griffith parte do pressuposto de que não se criam fissuras no interior de um sólido, e sim que elas crescem a partir de vazios preexistentes na matéria. Assim, em seu modelo plano, a fissura é assimilada a um furo elíptico cujas dimensões lineares variam, no processo de deformação, de acordo com um único parâmetro o comprimento $a$ do semi-eixo maior da elipse. Admitindo o carregamento externo constante, Griffith calcula a variação da energia potencial elástica da chapa contendo o furo elíptico, quando $a$ aumenta para $a+\mathrm{d} a$. Obtém, assim, a expressão $\mathrm{d} U / \mathrm{d} a$, que revela a sensibilidade da energia potencial elástica em relação à variação ocorrida no comprimento $a$, quando o furo se amplia. A grandeza $G=\mathrm{d} U / \mathrm{d} a$, denominada mais tarde strain-energy release rate, é considerada, desde Griffith, um parâmetro chave na caracterização do fenômeno da fratura. O problema, portanto, é reduzido à verificação da estabilidade de uma fissura.

Quando ocorre o crescimento da fissura, alguma quantidade de energia deve estar associada à área da superfície do furo acrescida nesse processo. Griffith propõe quantificar essa energia com base em um parâmetro que denomina densidade superficial de energia $\gamma$, que seria, segundo sua compreensão, uma propriedade intrínseca do material.

Em função dos resultados dessa análise, concluiu que, se fosse possível uma intervenção no processo de produção do material, com o intuito de diminuir o tamanho médio dos vazios num sólido, então a tensão limite de fratura poderia ser artificialmente aumentada. Devido ao sucesso tecnológico representado pela síntese de um material de alta resistência, a fibra de vidro, com base nessa idéia, é que se deu a grande difusão do critério de iniciação de fratura por ele proposto. Ao diminuir as dimensões dos vazios interiores no vidro, Griffith conseguiu aumentar bastante o valor da tensão limite de ruptura. Chegou a esse objetivo através da produção de finíssimas fibras desse material, que seriam depois aglomeradas em uma matriz de resina, para formar painéis de fácil moldabilidade e grande resistência. Em síntese, como conseqüência da formulação do critério que leva o seu nome, Griffith chamou atenção para o fato muito relevante de que a resistência dos materiais não está relacionada somente com a capacidade de coesão das moléculas mas, também, com a 
presença de espaços vazios entre elas. Assim, segundo ele, para bem caracterizar mecanicamente os materiais, não basta apenas o conhecimento dos limites de resistência, mas também a determinação experimental de alguma(s) grandeza(s) capaz(es) de dar conta da tenacidade (toughness, ou fracture toughness) do material, uma propriedade associada à capacidade de impedir o crescimento de fissuras. Para isso seria fundamental, em um sólido sujeito a ações e restrições a seu deslocamento, a determinação da energy release rate $G$. Na visão de Griffith, a comparação dessa grandeza com a tenacidade do material ( uma característica associada à densidade superficial de energia $\gamma$ ) forneceria um critério para aferir a integridade do sólido .

Paralelamente à Mecânica da Fratura, a Física também tem contribuído na busca de modelos para explicar, do ponto de vista microscópico, particularmente a resistência dos sólidos cristalinos, VOLTERRA (1907). As imperfeições detectadas na rede cristalina (discordâncias) são utilizadas para explicar os fenômenos da resistência e da fratura nesse tipo de sólido. $\mathrm{O}$ movimento das discordâncias no interior da rede cristalina, ocasionado pela aplicação de esforços, faz com que elas aflorem na superfície. O número de discordâncias contadas na superfície externa do sólido está diretamente relacionado com o estado de tensão no interior. Foram desenvolvidos métodos para a contagem dessas discordâncias e isso permitiu importantes interpretações úteis ao interesse tecnológico, particularmente no campo da metalurgia. O comportamento dúctil (tomado como distinto do comportamento frágil de um material), particularmente na extremidade de fissuras, tem merecido um sem número de interpretações à base do conceito de discordância, RICE \& THOMSON (1974).

Com o objetivo de estender a aplicação do critério de Griffith aos materiais dúcteis, OROWAN (1952) sugeriu que, além da grandeza $\gamma$, deveria ser considerado uma outra, $\gamma_{\mathrm{pl}}$, que faria as vezes de uma espécie de componente plástica da densidade de energia superficial, servindo para corrigir o critério de Griffith nesses casos. A experiência mostra que tal parcela assume valores muito maiores que $\gamma$. A rigor, a soma dos dois parâmetros produziria um valor crítico, que seria uma característica do material. Assim: 
$G_{\text {crit }}=2 \gamma+\gamma_{\mathrm{p}}$

onde $G_{\text {crit }}$ serviria para caracterizar o material, sendo uma grandeza macroscópica capaz de permitir a ampliação das aplicações da Mecânica da Fratura à análise dos problemas correntes da engenharia estrutural, principalmente no caso daqueles em que os materiais utilizados tivessem um comportamento mais predominantemente dúctil.

O passo seguinte ao de Griffith, no sentido do aperfeiçoamento da utilização da Mecânica da Fratura na caracterização da integridade das estruturas e na síntese de novos materiais, deve-se Irwin, e está baseado numa série de trabalhos por ele realizados na década de 1950, IRWIN (1957). Embora tendo o mesmo sentido da contribuição de Orowan, que era estender as possibilidades da Mecânica da Fratura para além do estudo dos materiais frágeis, a idéia central de Irwin conduz a uma nova interpretação da energy release rate, a qual, por possuir dimensão de força por unidade de área, permitiria ser interpretada da seguinte maneira: "Quando a fissura cresce, alguma energia passa de mecânica (ou de deformação) para outras formas, na vizinhança da fissura. O processo é tal que predomina a energia calorífica.A grandeza $G$ dá a medida dessa energia externa associada com a extensão unitária da fissura e pode ser considerada como a força tendente a causar o crescimento da fissura”, IRWIN (1957).

Utilizando as expressões das componentes de tensão e de deslocamento apresentadas por WESTERGAARD (1939), Irwin analisa o caso de uma chapa de espessura unitária, em estado plano, através da aplicação da teoria das funções de variável complexa à elasticidade plana, sendo a(s) fissura(s) simulada(s) através de segmento(s) de reta contido(s) no plano médio da chapa. Tal análise também facilitou a simulação geométrica de uma faixa com dimensões finitas, sendo apresentado, em seu citado trabalho, a solução para um exemplo muito útil, o de uma faixa de comprimento infinito, porém com largura finita e submetida a uma tração uniforme, aplicada no infinito. 
O problema tratado por Irwin, embora sofrendo da mesma limitação do de Griffith, por situar-se no âmbito da elasticidade linear, revelou uma característica que passou a influenciar grandemente o estudo da fratura. Trata-se da observação da ocorrência de um tipo especial de singularidade nas componentes do tensor tensão, em problemas planos de fratura (da ordem de $1 / \sqrt{r}$, onde $r$ é a distância do ponto considerado à extremidade da fissura), evidenciada em todos cinco exemplos apresentados no seu mais citado trabalho sobre o tema.

Ora, se as expressões das componentes de tensão apresentam alguma parcela singular, então elas tendem para infinito quando $r$ tende para zero. Mas, obviamente, no tratamento matemático do problema só é possível trabalhar-se com as hipóteses da elasticidade linear enquanto as componentes de tensão estiverem abaixo do limite elástico. Esse fato conduz a uma contradição, que só pode ser resolvida se excluir do domínio, zonas de acomodação plástica, situadas próximas das extremidades das fissuras. A consideração dessas zonas passou a ser, então, um novo problema, porque elas só poderiam ser incluídas se o modelo constitutivo previsse a dissipação de energia associada ao avanço das fissuras. Irwin procurou fugir dessa exigência, elaborando o seguinte raciocínio: Se os deslocamentos calculados são da ordem de $\sqrt{r}$, então o trabalho empregado na abertura da fissura é finito, na medida em que ele é calculado através de uma integral cujo integrando envolve o produto de força (que teria o mesmo tipo de singularidade da tensão) por deslocamento, na vizinhança das extremidades das fissuras. É certo que isso elimina a questão da singularidade, o que ele desejava, mas não elimina a existência de dissipação, por ele considerada simplesmente como trabalho. Vê-se, portanto, que Irwin recorre à mesma simplificação de Griffith cuja idéia de energia superficial equivale à de trabalho desenvolvido na zona próxima à extremidade da fissura. Isto quer dizer que, usando a elasticidade linear, Irwin intuiu um resultado que dá conta da plastificação local, na vizinhança da extremidade da fissura, o que, a despeito de ser coerente com a idéia de Orowan, é inconsistente, do ponto de vista teórico, porque a dissipação de energia desenvolvida no processo não foi considerada. 
A partir da hipótese de que a região plastificada em torno da extremidade da fissura é muito pequena, Irwin introduz os fatores de intensidade de tensão, $K_{\mathrm{I}}, K_{\mathrm{II}} \mathrm{e}$ $K_{\text {III }}$ grandezas-chave da chamada Mecânica da Fratura Linear, que são os coeficientes das parcelas não-lineares, presentes nos respectivos desenvolvimentos em séries, que aproximam os valores das componentes planas do tensor tensão, em cada um dos três modos sugeridos por Irwin, denominados: de abertura, de deslizamento e de rasgamento. Os fatores de intensidade de tensão estão funcionalmente relacionados com os respectivos valores da energy release rate, $G$, associados a esses três modos, e com o módulo de elasticidade, $E$, do material. Tais grandezas, segundo Irwin, seriam capazes de caracterizar, do ponto de vista da fratura, o estado de uma peça submetida a esforços, desde que a zona de acomodação plástica próxima à extremidade da fissura não fosse relevante. Para a finalidade de avaliação da integridade de um sólido contendo fissuras, seria feita comparação dessas grandezas, calculadas para determinada configuração de ações aplicadas e deslocamentos prescritos no contorno do sólido, com os respectivos valores críticos, $K_{\text {Ic }}, K_{\text {IIc }}$ e $K_{\text {IIIc }}$, determinados experimentalmente.

Segundo KNOTT (1993), a contribuição de Irwin deu vez ao surgimento da Engenharia da Fratura, enquanto Griffith seria, para ele, o criador da Ciência da Fratura. No entanto, como antes já foi comentado, a introdução dos fatores de intensidade de tensão, por Irwin, faz uso da mesma base física utilizada por Griffith, isto é o recurso à elasticidade linear, que não dá conta do caráter irreversível do fenômeno da fissuração. A diferença dos dois enfoques está somente em que, para simular a fissura Irwin substituiu o orifício elíptico por um segmento de reta, tirando daí conclusões sobre a interpretação da energy release rate como sendo uma força por unidade de área da superfície de avanço da fissura. Embora possa parecer que os valores críticos dos $K$ 's, obtidos experimentalmente, sejam capazes de caracterizar os materiais do ponto de vista da fratura, diferentemente da densidade de energia superficial de Griffith, isso não é verdade, pelo fato de que sua determinação também depende de uma série de variáveis, tais como a escala da peça ensaiada, e outras de natureza ambiental. 
Uma importante vertente teórica na interpretação do fenômeno da fratura deve-se à Escola Russa, liderada por G. I. Barenblatt que, entre 1959 e 1961, apresentou uma série de trabalhos nos quais elabora um princípio geral (válido, segundo ele, para uma série de fenômenos da Mecânica do Contínuo), aplicável ao fenômeno da fratura. Aí ele busca adaptar a idéia de Griffith à consideração de aspectos microscópicos do fenômeno, presentes nas extremidades das fissuras. $\mathrm{O}$ princípio é baseado, segundo seu autor, na formulação de hipóteses físicas, fundadas em observações experimentais capazes de assegurar a unicidade da solução de problemas dependentes de parâmetros.

No caso da Mecânica da Fratura, a busca de tais hipóteses físicas teria, segundo Barenblatt, a finalidade de assegurar a finitude da tensão nas extremidades das fissuras. Tais ações caracterizariam um efeito coesivo, capaz de produzir uma variação gradual da tensão em uma minúscula zona especial de interação entre as duas faces da fissura, próximo à extremidade. A exigência da finitude da tensão induziria, inclusive, a necessidade de uma concordância tangencial entre as duas faces, na extremidade da fissura, conformando algo com o aspecto de uma cúspide. É importante observar-se também, que outra das preocupações de Barenblatt é a formulação de uma Mecânica da Fratura capaz de dar conta do problema da pressão de fluidos no interior de maciços rochosos. Essa exigência de concordância tangencial entre as faces, nas extremidades da fissura também está relacionada com sua observações experimentais nesse campo, BARENBLATT $(1959,1960,1964)$. A contribuição de Barenblatt lança novos elementos na discussão a respeito do caráter do fenômeno da fissuração, se reversível ou irreversível. Conhecedor que era das contribuições de Westergaard e de Irwin, a respeito das distribuições de tensão e de deslocamento típicas dos modelos matemáticos do problemas de fratura, introduz fatos exteriores à teoria da elasticidade, a saber a interação material ao nível microscópico nas extremidades de fissuras, para justificar a reversibilidade. Não há dúvida que o aproveitamento de suas idéias, na formulação de modelos adequados a materiais caracterizados pela grande presença de microfissuras durante a evolução do fenômeno da fratura, permitiu o desenvolvimento paralelo de uma interpretação que associa a reversibilidade ao comportamento coesivo do material na vizinhança das extremidades de fissuras. 
Essa interpretação deu origem a modelos aplicados principalmente ao concreto, dentre os quais se destaca o da fissura fictícia, assim denominado por seu principal autor, Hillerborg. Segundo ele, "Uma vantagem do modelo da fratura fictícia sobre o convencional da Mecânica da Fratura é que, além de ele ser usado para analisar a estabilidade do crescimento de fissuras, pode também ser usado para a análise da formação de fissuras", HILLERBORG (1990). Isto significa a introdução de uma hipótese essencialmente distinta da tradicional, devida a Griffith que não admite a possibilidade de a fissura surgir no sólido, só podendo crescer a partir de um vazio preexistente. Segundo o próprio Hillerborg, no artigo antes citado: "Como uma fissura real não pode transferir tensão entre suas faces, a fissura que admite transferência de tensão foi chamada de fissura fictícia - daí o nome do modelo". E continua: "A expressão modelo de fissura fictícia tem sua origem derivada nas aplicações do método dos elementos finitos onde tem sido adotado, nas quais não se admite nem fissura fictícia nem zona de fissuração infinitamente estreita, adotandose, no entanto, que a deformação adicional ocorrida dentro da zona de fissuração tem de ser considerada como derivada de uma relação tensão-deslocamento"

Pelo que se percebe, o modelo da fissura fictícia parece ficar mais adequadamente incluído em um outro campo da Mecânica dos Materiais, a Mecânica do Dano, segundo a qual a interpretação do fenômeno da fratura ganha sentido enquanto considerado em uma seqüência, no processo deformação dos sólidos, até a ruptura, que, em geral, inicia-se pelo comportamento elástico, passando pelo plástico (ou elastoplástico), seguindo-se o regime de dano e, finalmente, o de fratura. A passagem do regime de dano para o de fratura decorreria da exaustão de um estado de microfissuração distribuída (dano), a partir do qual ocorreria a localização do fenômeno em uma região limitada do sólido na qual se instalaria uma macrofissura preferencial, caracterizadora da bifurcação do equilíbrio local, gerando uma bem determinada porção amolecida do material, por onde a ruptura, finalmente, teria curso, LEMAITRE \& CHABOCHE (1990). 
A partir da década de 1960, as investigações no campo da Mecânica da Fratura intensificam-se bastante, estendendo-se para uma ampla gama de materiais, que vai dos materiais metálicos aos materiais derivados de polímeros e aos compósitos, particularmente o concreto, passando a desenvolver-se segundo duas grandes vertentes. A primeira, no campo experimental, orienta-se para a pesquisa de parâmetros, e sua conseqüente determinação em laboratório, visando a quantificação da tenacidade dos materiais. Destaca-se, neste particular, os métodos da ASTM para a determinação dos valores críticos dos fatores de intensidade de tensão em materiais metálicos, e para a determinação da energia de fratura, aplicada ao concreto, com o método normalizado pela RILEM.

A segunda vertente é a da pesquisa de métodos numéricos visando à determinação aproximada de parâmetros caracterizadores da iniciação e da evolução do fenômeno da fratura, todos eles de certa forma relacionados, ou com a metodologia de Irwin, dos fatores de intensidade de tensão, ou com a metodologia de RICE (1968), que introduz a integral $J$, uma integral independente do caminho cuja utilização vem crescendo amplamente.

Na aplicação dos métodos numéricos no cálculo aproximado dos fatores de intensidade de tensão ou da integral $J$, tem sido destacada a utilização do Método dos Elementos Finitos $(M E F)$. Mais recentemente, a partir da década de 1980, no entanto, o Método dos Elementos de Contorno (BEM) passou a ser também aplicado intensamente, a partir de grande uma variedade de modelos matemáticos que, muitas vezes padecem de uma perigosa inversão, que é a de colocá-los à frente do modelo físico. As principais contribuições nesse campo estão sintetizadas em VENTURINI (1995a) e VENTURINI (1995b).

Um dos mais difíceis problemas da Mecânica da Fratura é a obtenção, por via analítica, da energy release rate $G$, particularmente porque, para ser feita de forma direta, é necessário o conhecimento da expressão que fornece a energia potencial elástica (ou total) do sólido fissurado, em função de parâmetros de fissura, já que, em geral, os métodos da Mecânica da Fratura partem da análise da evolução de vazios preexistentes no meio, sejam eles contidos inteiramente no sólido, ou se iniciando no contorno, cujas dimensões estão associadas a esses parâmetros. 
Mesmo que para um número ainda limitado de casos, tal dificuldade pode ser superada através do cálculo da integral $J$, que se realiza sobre um contorno regular contendo uma extremidade de fissura em seu interior. O método da integral $J$ foi inspirado, segundo revela seu próprio criador, "na componente estática do tensor momentum-energia, uma grandeza introduzida por ESHELBY (1956) para caracterizar forças generalizadas atuando sobre discordâncias e defeitos pontuais em meios elásticos". O significado físico dessa integral (originalmente com dimensão de $\mathrm{J} / \mathrm{m}^{2}$ ) é, segundo ele, o de uma grandeza associada ao estado médio da deformação na vizinhança da extremidade da fissura. Além disso, possui a seguinte propriedade: Se realizada em qualquer contorno de um meio contínuo não contendo fissura passível de avançar, o valor da integral J é nulo.

Recentemente, a aplicação da integral $J$ ganhou um engenhoso suporte matemático, com o qual é possível calculá-la como a energy release rate (derivada da energia potencial elástica em relação a um parâmetro geométrico de fratura), sem que seja necessário conhecer-se uma expressão explícita da expressão dessa energia em função de parâmetro(s) de fratura, TAROCO (1996). Isso está baseado em uma adaptação, ao problema da fratura, da Análise de Sensibilidade à variação de forma, do domínio e fronteira do sólido. Com o auxílio dessa técnica, advinda da área de Otimização Estrutural, pode-se construir um modelo teórico do problema da fratura, a partir de uma analogia deste com o problema da deformação, da Mecânica do Contínuo, num caso em que se considera que a evolução de uma fissura configura uma variação de forma do domínio e do contorno do sólido. Isso permite que o cálculo da energy release rate (ou integral $J$ ) seja feito na configuração atualizada do sólido, na qual torna-se nulo o parâmetro que controla a variação do domínio e do contorno do sólido. A integral $J$, segundo essa interpretação, portanto, pode ser calculada com o auxílio da derivada material da energia potencial elástica associada ao sólido fissurado, em relação a um parâmetro que tem a propriedade de poder simular uma especial alteração geométrica do domínio e da fronteira do sólido, que imita o movimento relativo entre uma fissura que avança, e a fronteira distante de uma região que contém essa fissura. Foi com o auxílio dessa ferramenta que tornouse possível, mesmo que somente para problemas isotérmicos, conseguiu-se, no presente trabalho, chegar-se a algum resultado numérico, o que serve para aquilatar- 
se a potencialidade prática do desenvolvimento, essencialmente teórico, a seguir explicitado.

O objetivo principal desta tese é contribuir para a formulação de uma teoria termodinamicamente consistente da fratura, a partir da qual busca-se construir uma base para a elaboração de critérios de iniciação e propagação de fratura, utilizando-se a Análise de Sensibilidade como instrumento para a construção de um esquema de resolução numérica aproximada, de um caso particular do problema da fratura.

Inicialmente, estabelecem-se as condições para a aplicação dos princípios da Mecânica do Contínuo à Mecânica da Fratura, ,propondo-se a introdução, em cada uma das cinco equações clássicas do balanço termomecânico global, de uma parcela nova, referente ao que ocorre na superfície de avanço das fissuras. Surge então, em decorrência da operação de passagem da equação de balanço global da energia para a correspondente equação local, nos pontos da superfície de avanço da fissura, ROCHA \& VENTURINI (1997), um critério termodinâmico generalizado de fratura.

Na seqüência, adotando-se a metodologia de Griffith (mais em sua forma do que na sua essência), faz-se a utilização da Análise de Sensibilidade para chegar-se a um critério de fratura válido para casos em que o processo é quase estático e isotérmico. Já orientando-se para o uso do BEM, chega-se à da variação da energia de deformação do sólido fissurado, que pode ser reduzida a uma função definida na fronteira regular, por partes, de uma região interior arbitrária contendo a extremidade de uma fissura iniciada no contorno do sólido. É um procedimento em tudo semelhante ao desenvolvido por TAROCO (1966) para a integral $J$, só que naquele caso, como dito anteriormente, foi usada a energia potencial elástica, e não a energia de deformação aqui adotada.

A opção de método aproximado, para o cálculo do novo parâmetro alternativo à integral $J$, ora denominado parâmetro termodinâmico de fratura, $G_{\mathrm{t}}$, recaiu, como já foi dito, sobre o BEM. A opção de se realizar o cálculo automático, tanto desse parâmetro, quanto da integral $J$, obedeceu ao interesse da comparação com resultados existentes na literatura, dessa última, obtidos através do $M E F$, 
particularmente o de CUNHA et al. (1995), que também utiliza o recurso da Análise de Sensibilidade aplicada à fratura.

No caso da fratura frágil, à semelhança do que ocorre também com a fadiga e com o impacto, manifesta-se a dependência do fenômeno em relação ao tamanho (volume) do sólido. Uma discussão sobre esse fato foi realizada com o apoio da interpretação estatística, fundada na conjectura conhecida como hipótese do elo mais fraco, introduzida no estudo da resistência dos materiais por WEIBULL (1939). Baseado na hipótese do caráter aleatório da resistência, ponto a ponto, nos sólidos, Weibull mostrou que, para um dado material, se são feitas duas séries de ensaios de tração, em corpos de prova com os volumes, respectivamente, $V_{1}$ e $V_{2}$, por exemplo, os correspondentes valores da resistência última obedecem à seguinte relação:

$$
\frac{\left(\sigma_{u l t}\right)_{1}}{\left(\sigma_{u l t}\right)_{2}}=\left(\frac{V_{2}}{V_{1}}\right)^{1 / m},
$$

onde $m$ é uma constante do material, qualquer que seja o tamanho dos corpos de prova. Os experimentos sugeridos por Weibull, foram realizados por DAVIDENKOV (1947), que obteve resultados bastante concordantes com a teoria.

Uma abordagem recente e promissora do problema da fratura busca recuperar essa importante contribuição de Weibull. A chave dessa vertente é a articulação do comportamento local (na vizinhança da extremidade da fissura), com o comportamento à distância, medido em um caminho, situado no interior do sólido contendo a fissura, com auxílio da integral $J$.

Enfatizada por BEREMIN (1983), MINAMI et al. (1992), RUGGIERI \& DODDS (1996a) e RUGGIERI \& DODDS (1996b), o essencial dessa abordagem parte da constatação de que os problemas práticos de verificação da integridade de componentes de estruturas, não podem se valer diretamente dos resultados de ensaios de laboratório, tais como foram projetados e incorporados às normas técnicas correntes, devido ao que denominam, diferença do nível de restrição, do campo de tensão, entre o ensaio de laboratório e as estruturas reais. 
Distribuições de Weibull, de dois ou de três parâmetros, costumam ser utilizadas nessas análises, cujo objetivo é estabelecer a correlação entre a tensão $\left(\sigma_{\mathrm{w}}\right)$ e o parâmetro $m$, de Weibull, determinados em função de uma interpretação estatística do fenômeno localizado, na vizinhança da fratura, e a integral $J$, associada ao carregamento atuante e à configuração física do sólido, considerado o regime elastoplástico na vizinhança da extremidade da fissura. RUGGIERI et. al (1997) desdobra ainda mais a análise, em relação ao significado do parâmetro de escala $m$, questionando sobre se, de fato, pode, ou não, ser ele considerado um parâmetro característico do material, no contexto do estudo da dependência de $m$ em relação à temperatura, no regime de transição dúctil-frágil dos aços.

Tudo leva a crer que o resultado almejado pelo presente trabalho poderá ser muito útil ao aperfeiçoamento, principalmente da vertente que acaba de ser analisada, principalmente pelo fato de que o tratamento estatístico parece ser o mais adequado para a análise de um fenômeno, tal como o da fratura, em que está tão fortemente presente a interação entre os níveis micro e macroscópico, ressaltando-se as heterogeneidades e as singularidades ao nível local, e a possibilidade do uso da hipótese da continuidade, a nível global do sólido. Neste sentido, o presente trabalho pode contribuir para o aperfeiçoamento do modelo físico do fenômeno da fratura, já que centra-se na consideração da presença de dissipação de energia durante o crescimento da fissura.

A despeito de todo o grande desenvolvimento até agora experimentado pela Mecânica da Fratura, as teorias em voga só consideram, explícita (como em Griffith), ou implicitamente (como em Irwin e Rice), o Princípio de Conservação da Energia (Primeira Lei da Termodinâmica). Por isso, há muito que que o estudo da fratura necessita de um tratamento teórico capaz de dar conta dos aspectos termodinâmicos envolvidos com a irreversibilidade do fenômeno. Sabe-se que nem a Teoria de Griffith, nem a de Irwin ou a da integral $J$, de Rice, cogitam da Segunda Lei da Termodinâmica e, por essa razão, não podem refletir o fato de que a fissuração é um processo irreversível. 
Espera-se, portanto, que a contribuição teórica trazida pelo presente trabalho, centrada essencialmente no aperfeiçoamento do modelo físico do fenômeno da fratura, possa ser desdobrada em novas metodologias de ensaio de materiais, e no aperfeiçoamento de uma base conceitual útil, tanto à concepção de novos modelos matemáticos, quanto ao melhor aproveitamento dos métodos matemáticos aproximados, no estudo da fratura dos materiais. 


\section{CAPÍTULO 1}

\section{ELEMENTOS DE TERMODINÂMICA}

A Termodinâmica é a parte da Física que trata do calor e da temperatura, fazendo a ponte com a Mecânica através da equivalência entre calor e trabalho, cujo fator de conversão foi determinado por Joule, em meados do século XIX. A obtenção precisa desse fator de conversão é um marco fundamental na construção conceitual da Termodinâmica, reforçando-a enquanto instrumento na busca da interpretação das possibilidades de interação entre trabalho e energia. Tanto que as Leis nas quais se fundamenta, a partir da sistematização de Clausius, em torno do ano de 1850, dão-lhe uma característica bastante geral e de grande importância filosófica na interpretação dos fenômenos do Universo. É através da Termodinâmica que se chega, por exemplo, a uma explicação, ao nível macroscópico da matéria, sobre a origem física da flecha do tempo, isto é, sobre a razão pela qual os fenômenos físicos parecem caminhar em um só sentido, marcando com isso a distinção entre passado e futuro, NUSSENZVEIG (1990).

São quatro as Leis da Termodinâmica: a chamada Lei Zero, é a que dá sentido ao conceito de temperatura, baseado no equilíbrio térmico, segundo o qual, dois corpos estão à mesma temperatura somente se estão em equilíbrio térmico com um terceiro. A Primeira e a Segunda Leis, em geral as de maior utilização prática, serão discutidas em detalhes, a seguir. E a Terceira é aquela segundo a qual a temperatura possui um limite inferior, o chamado zero absoluto.

Em geral, a aplicação da Termodinâmica é útil quando há interesse na caracterização de sistemas com um grande número de partículas, com o auxílio de variáveis tais como pressão e temperatura, que representam o estado médio dessas partículas, refletindo, no fundo, uma abordagem estatística dos fenômenos da natureza. Daí a razão de sua grande utilização no estudo dos fluidos e, mais 
recentemente, também na Mecânica dos Sólidos. Nesse último caso, o interesse concentra-se na busca da resposta do sólido às ações externas, tanto as exercidas à distância quanto as que derivam do contato direto com outros corpos. O estudo com base na Termodinâmica é uma opção que, além de permitir a consideração do calor como uma forma de energia presente nas interações entre os sólidos, também permite uma interpretação mais rigorosa da aplicação dos conceitos de trabalho e energia, fundamentais para a compreensão das transformações sofridas pelos corpos deformáveis.

De acordo com BROPHY et al. (1972) : “As leis da Termodinâmica são generalizações da experiência comum. Podemos tomar medidas simples de pressão, volume, temperatura, composição química e outras quantidades apropriadas; tais dados determinam o estado do objeto ou região de interesse (sistema) e todas suas propriedades. Se um sistema não estiver sujeito a perturbações, ele atingirá, depois de certo tempo, o equilíbrio, e todas as suas propriedades não mais variarão em função do tempo" (BROPHY et al., 1972, p. 1).

\subsection{Processo termodinâmico reversível ${ }^{1}$}

A capacidade térmica, $C$, de um corpo, é definida como a relação entre variação de calor a ele transferido, $\Delta Q$, e a variação de temperatura, $\Delta T$, por ele sofrida nesse processo. Como $C$ é uma grandeza proporcional à massa do corpo, e a variação da temperatura é dada por $\Delta T=\Delta Q / C$, tal variação pode-se tornar muito pequena, se for bastante grande o corpo que transfere calor para o sistema em estudo. No caso limite, quando esse corpo tiver massa infinita, o sistema observado não sofre qualquer aumento de temperatura. Um corpo infinito com essa caraterística, denomina-se reservatório térmico. A atmosfera e o oceano são exemplos de reservatórios térmicos. No entanto, para fins práticos, até corpos menores podem ser também considerados reservatórios térmicos.

A Figura 1 ilustra como é possível ser feita a transferência de calor, de maneira reversível, a um sistema. $\mathrm{O}$ tracejado em torno do corpo, indica que as 
paredes estão isoladas termicamente. A inferior é uma parede diatérmica, em contato com o reservatório térmico, através da qual a transferência de calor é livremente permitida. $T_{\mathrm{i}}$ é a temperatura inicial do sistema (representado em contato com um reservatório térmico, a essa temperatura). Em seguida submete-se o sistema a um reservatório térmico de temperatura $T_{\mathrm{i}}+\mathrm{d} T$, aguardando-se até que se estabeleça o equilíbrio térmico. Daí, nova transferência é feita, agora para um reservatório térmico de temperatura $T_{\mathrm{i}}+2 \mathrm{~d} T$, aguardando-se mais uma vez, até que o novo equilíbrio térmico se estabeleça. E assim sucessivamente, até que seja atingida a temperatura final $T_{\mathrm{f}}$, completando-se assim a transferência de calor desejada.

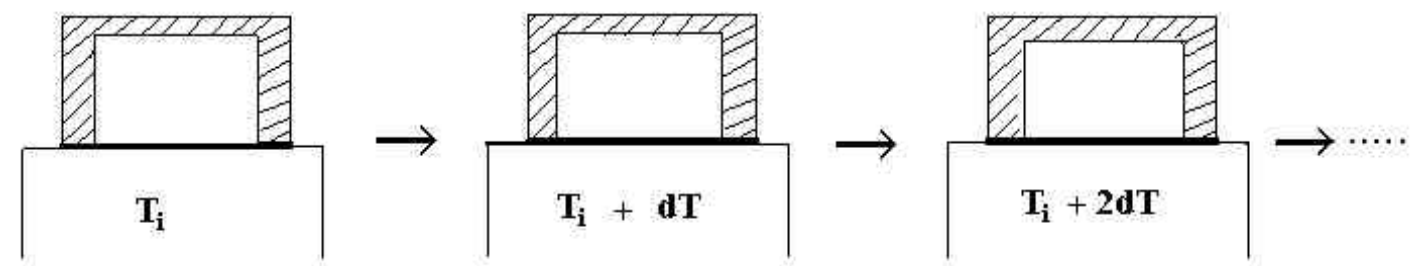

Figura 1 - TrANSFERÊNCIA REVERSÍVEL DE CALOR A UM SISTEMA (ADAPTADA DE NUSSENZVEIG (1990))

No sentido de exemplificar a possibilidade concreta de um processo termodinâmico reversível, a Figura 2 ilustra o caso de um gás em equilíbrio térmico, ocupando um recipiente cilíndrico de área da base $A$ e altura $x$, sendo o volume, portanto, $V=A x$, sujeito a uma pressão $p$. A base superior é um pistão, que supõe-se poder deslocar sem atrito, no contato com as parede lateral do reservatório. Imaginando-se que a força, $F=p A$, esteja equilibrada pelo peso de um monte de areia colocado sobre o pistão, suponha-se que o gás sofra uma expansão, decorrente de um deslocamento $\mathrm{d} x$, do pistão, para cima (devido à retirada de um grão de areia do monte, por exemplo). O trabalho realizado pelo gás, nessa expansão, é: $\mathrm{d}^{\prime} W=F \mathrm{~d} x=p A \mathrm{~d} x=p \mathrm{~d} V$. Conforme será retomado adiante, a razão de usar-se a notação d'W em lugar de $\mathrm{d} W$, é para enfatizar que a função $W$ não é uma diferencial exata.

\footnotetext{
${ }^{1}$ A elaboração do texto e das ilustrações dessa seção, baseia-se em NUSSENZVEIG (1990), texto recomendado para quem desejar maiores detalhes acerca da Termodinâmica..
} 
Se esse procedimento for repetido, pode-se, gradativamente, atingir a expansão finita desejada para o gás. Com a recolocação da areia, grão a grão, pode-se voltar, pelo caminho inverso, ao estado inicial. Um processo assim realizado é chamado de reversível. Em síntese, para que o processo termodinâmico seja considerado como reversível, é necessário que as seguintes condições sejam satisfeitas: a) deve realizarse muito lentamente; b) $\mathrm{O}$ atrito deve ser desprezível.

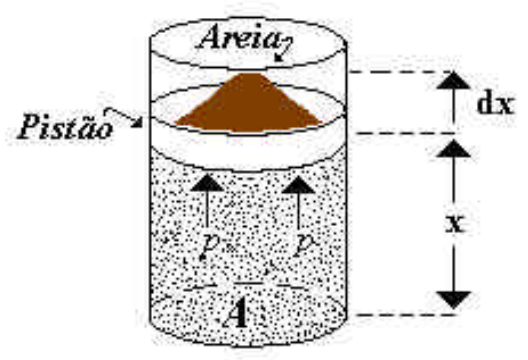

Figura 2 - PROCESSO TERMOdINÂMICO REVERSível ( ADAPTADA DE NUSSENZVEIG (1990))

Para que a condição (a) seja atendida, o lapso de tempo entre o estado do sistema e um estado de equilíbrio termodinâmico deve ser um infinitésimo, o que caracteriza o processo denominado quase-estático. Imaginando-se que a condição (b) não seja atendida, isto é, que haja atrito entre o pistão e as paredes, então a pressão do gás seria $p^{\prime}<p$, sendo o trabalho realizado na expansão igual a $p^{\prime} \mathrm{d} V<p \mathrm{~d} V$, a diferença representando o calor gerado por atrito.

Na reversão de processo de expansão quase-estático e sem atrito, chega-se à situação inicial, realizando um trabalho positivo igual a $-p \mathrm{~d} V$ (isso porque o volume sofre uma diminuição, nesse caso). Obviamente, no caso de haver atrito entre o pistão e as paredes do cilindro, mesmo que o processo inverso seja conduzido lentamente, ele não atingirá a situação inicial

\subsection{A Primeira e a Segunda Leis da Termodinâmica}

A Primeira Lei da Termodinâmica é uma generalização do Princípio de Conservação da Energia, sendo sua característica marcante a consideração do calor como uma forma de energia, em certo sentido distinta das demais porque é para ela que todas as outras parecem tender. Por essa razão, o calor é a forma de energia cuja 
observação permite uma oposição mais nítida entre energia e trabalho, este entendido como a outra categoria em que se desdobra a possibilidade de interação entre os sistemas físicos. Útil à formulação da Primeira Lei da Termodinâmica, concebe-se a energia interna de um sistema como uma função de estado (isto porque não depende de qualquer processo), correspondendo à soma do trabalho realizado sobre esse sistema, com a diferença entre o calor cedido e o produzido no processo.

Citando ainda BROPHY et al.: "De acordo com a Segunda Lei, o calor jamais poderá ser inteiramente convertido em trabalho ${ }^{2}$, e ele nunca se transforma espontaneamente em trabalho. Um tal comportamento é descrito pela maximização de uma nova função de estado, a entropia, que cresce à medida que o sistema se aproxima do equilíbrio, e se torna máxima no equilíbrio. Calor e trabalho são quantidades relativamente fáceis de se medir e permitem a previsão do estado de equilíbrio de qualquer sistema termodinâmico. A ocorrência espontânea de um evento natural pode ser descrita em termos da diminuição na função energia livre ${ }^{3}$ apropriada”. (BROPHY et. al., 1972, p.3)

Entropia é uma palavra cunhada por Clausius, a partir do grego, significando transformação. Para compreender seu significado, é necessário o conhecimento dos processos em que é possível a transformação de calor em trabalho, dos quais pode-se tirar proveito para a construção de máquinas térmicas, tais como a máquina a vapor, os motores térmicos e o refrigerador. A prática comprova que só é possível construirse uma máquina térmica se ela for composta de uma fonte quente e de uma fonte fria. Para que se possa realizar trabalho com o auxílio de um sistema denominado motor térmico, por exemplo, é preciso que se forneça a esse sistema uma quantidade de calor $Q_{1}$, a uma temperatura absoluta $T_{1}$, e seja retirada uma quantidade $Q_{2}$, a uma temperatura absoluta $T_{2}$. Admitidas as quantidades $Q_{1}$ e $Q_{2}$ com sinal positivo, para que o motor possa funcionar é necessário que o valor do trabalho mecânico

\footnotetext{
${ }^{2}$ A respeito dessa afirmação, de que é impossível a transformação total de calor em trabalho, convém observar que ela só é verdadeira se for aplicada a um processo cíclico. V. páginas 332 e 333 de NUSSENZVEIG [1983 ].

${ }^{3}$ Essa grandeza, que será logo adiante definida, segundo a versão de Helmholtz, tem importante papel no desenvolvimento da interpretação termodinâmica da fratura aqui proposta.
} 
$W=Q_{1}-Q_{2}$, produzido no processo, seja maior que zero. Portanto, $Q_{1}$ tem de ser maior do que $Q_{2}$. A experiência mostra que, para isso, $T_{1}$ tem de ser, obrigatoriamente, também maior do que $T_{2}$. O principal responsável por essa descoberta é o engenheiro francês Sadi Carnot que, ao pesquisar a máquina térmica de máxima eficiência, concluiu que tal situação ideal só poderia ocorrer se a relação de entrada, $Q_{1} / T_{1}$, fosse igual à relação de saída, $Q_{2} / T_{2}$. Esse seria o caso da máquina ideal, na qual não ocorresse qualquer perda de energia interna. Adotando-se, nesse exemplo da máquina térmica, uma outra convenção de sinal, segundo a qual o calor será positivo quando fornecido ao sistema, então $Q_{1}$ terá sinal positivo e $Q_{2}$, sinal negativo. Usando essa convenção, e sintetizando a contribuição de Carnot, Clausius mostrou que, em cada ciclo reversível desse processo, na máquina térmica ideal, a condição para a produção do trabalho $W$ exige a que a seguinte condição seja satisfeita:

$\frac{Q_{1}}{T_{1}}+\frac{Q_{2}}{T_{2}}=0$

Generalizando o resultado, na forma de um teorema que hoje leva seu nome, Clausius mostrou que, em um ciclo contínuo de uma máquina térmica qualquer, real ou ideal, no qual o calor seja fornecido em parcelas infinitesimais, impondo ao sistema sucessivos estados de equilíbrio, vale a seguinte expressão:

$\oint \frac{\mathrm{d} Q}{T} \leq 0$

que é a síntese do chamado Teorema de Clausius, segundo o qual não é possível um processo termodinâmico cujo único efeito seja a conversão de calor em trabalho. $\mathrm{Na}$ expressão (1.2), a igualdade vale para os ciclos reversíveis, como, por exemplo, o da máquina térmica ideal, explicitado pela eq.(1.1). Já a desigualdade aplica-se a ciclos irreversíveis, que é o caso da máquina térmica real, e de todos os fenômenos que ocorrem espontaneamente na natureza. A eq.(1.2) pretende dar uma descrição, ao invés de uma explicação, dos fenômenos abordados à luz da Termodinâmica. Para o cumprimento dessa finalidade, introduz-se a noção de entropia, uma variável termodinâmica que permite tornar mais clara a interação entre calor e trabalho, 
principalmente no caso dos fenômenos caracterizados pela irreversibilidade. A análise da máquina térmica ideal de Carnot permite uma boa compreensão do significado da entropia: no processo nela realizado, como se viu, vale tanto o princípio de conservação da energia, quanto também se conserva a relação $Q / T$, na entrada e na saída. A relação $\left(Q_{1} / T_{1}\right)$, correspondente à entrada, isto é, ao que foi fornecido pelo exterior à máquina térmica, seria a entropia de entrada, e ao final, a relação $\left(Q_{2 / T 2}\right)$, referente ao que foi devolvido por ela, seria a entropia de saída da máquina. Se, ao invés de uma máquina ideal, ela fosse uma máquina real, haveria algum calor gerado pelo atrito interno, o que faria aumentar a entropia de saída, justificando assim a afirmação básica da Segunda Lei da Termodinâmica, segundo a qual a entropia do conjunto formado pelo exterior e pela máquina térmica, sempre tende a crescer, quando qualquer processo termodinâmico é levado a efeito no Universo.

Para o caso de um ciclo reversível, como já foi dito, vale a igualdade na expressão (1.2). No caso em que a análise é feita entre dois estados $A$ e $B$ quaisquer, do caminho seguido pelo processo termodinâmico, vale analisar a integral:

$$
\int_{A}^{B} \frac{\mathrm{d} Q_{r e v}}{T}
$$

que, em razão da hipótese de reversibilidade, só deve depender dos estados inicial e final, e não do caminho. O integrando de (1.3) é, portanto, uma diferencial exata, a saber:

$$
\mathrm{d} s=\frac{\mathrm{d} Q_{r e v}}{T},
$$

onde $s$, é definida como a entropia, que se caracteriza por ser uma função de estado, na medida em que só depende dos estados inicial e final.

Pela eq.(1.2), e de acordo com a discussão acima, conclui-se que, para uma mesma mudança de estado: 
$\mathrm{d} Q_{\text {rev }}>\mathrm{d} Q_{\text {irrev }}$.

Considerando-se uma mudança de estado arbitrariamente pequena, na qual é transferida a quantidade de calor $\mathrm{d} Q$ ao sistema, então, de acordo com a eq.(1.5):

$\mathrm{d} Q \leq \mathrm{d} Q_{\text {rev }}$

Pelo fato de ser determinada apenas pelos estados inicial e final, a variação de entropia do sistema independe de o processo ser reversível ou irreversivel. Daí:

$\mathrm{d} s_{\text {sist. }}=\frac{\mathrm{d} Q_{\text {rev }}}{T}$.

Como $\mathrm{d} Q$ é infinitesimal, a vizinhança do sistema pode voltar a seu estado inicial mediante a reposição do calor d $Q$. Então, a variação da entropia dessa vizinhança (que a ele havia fornecido o calor $\mathrm{d} Q$ ) é:

$\mathrm{d} s_{v i z .}=\frac{-\mathrm{d} Q}{T}$.

Assim sendo, a variação líquida de entropia, ocorrida em consequência de uma mudança diferencial de estado tal como o acima, será:

$\mathrm{d} s_{\text {liq. }}=\mathrm{d} s_{\text {sist }}+\mathrm{d} s_{\text {viz. }}=\frac{\mathrm{d} Q_{r e v .}-\mathrm{d} Q}{T} \geq 0$

onde a igualdade, uma vez mais, refere-se à reversibilidade. Um processo que ocorre espontaneamente, é irreversível por natureza. Do contrário, não ocorreria. A reversibilidade só pode ser atingida quando o equilíbrio está tão próximo, que nenhuma mudança observável possa acontecer. A eq.(1.9) revela, portanto, que há sempre um aumento da entropia líquida, quando ocorre um evento espontâneo. E a igualdade, naquela equação, revela que a entropia torna-se máxima no equilíbrio.

A conseqüência mais importante do que acima foi dito, liga-se à constatação de que a parte da energia que não pode ser transformada em trabalho, em um dado processo, está associada à variação líquida da entropia (do conjunto formado pelo sistema e sua vizinhança). Mas, na maioria das vezes, quando se procura calcular a 
variação total da entropia que acompanha um evento determinado, verifica-se que a união do sistema com sua vizinhança é algo tão complicado, que tais cálculos são muito trabalhosos, senão impossíveis. Daí surge a necessidade da introdução de uma função, denominada energia livre de Helmholtz, $\Psi$, que retira da energia interna o produto temperatura absoluta $T \times$ entropia s do sistema, como forma de evidenciar a parcela da energia interna disponível para a transformação em trabalho:

$\Psi=E-T s$.

De fato, a afirmação de que a entropia do conjunto exterior-sistema tende sempre a crescer, é o mesmo que dizer-se que a energia livre do sistema isolado tende sempre para um valor mínimo. Com maior rigor, e no interesse do propósito deste trabalho, $\Psi$ pode ser também definida como a máxima quantidade de energia interna do sistema que, num processo irreversível, está disponível para a realização de trabalho.

1.3 Interpretação termodinâmica do processo de deformação de um sólido

Com o intuito de fixar conceitos, será apresentada, a seguir, uma ilustração do uso da Termodinâmica na interpretação do processo de deformação de um sólido, supondo-se que nele ainda não se encontre instalado qualquer processo dissipativo, seja de plasticidade, dano ou fratura. Admitindo-se que as grandezas aqui tratadas, referentes ao sólido deformável, estejam associadas exclusivamente a volume, a expressão do balanço energético (Primeira Lei da Termodinâmica), tomada entre dois estados infinitesimalmente próximos, equivale a:

$\mathrm{d} E=\mathrm{d}^{\prime} Q+\mathrm{d}^{\prime} W$

onde $E$ corresponde à energia interna do sólido; $Q$, à quantidade de calor trocada entre o sólido e o exterior e $W$, ao trabalho mecânico realizado no processo. Aqui, o valor de $W$ será tomado como positivo quando se referir a trabalho fornecido ao sistema (e não pelo sistema, como normalmente se considera no caso de máquinas 
térmicas), e $Q$ será positiva quando corresponder a calor fornecido ao sistema, pelo ambiente. Observe-se que $W$ eqüivale à energia de deformação armazenada no sólido. Como antes já foi observado, d' $Q$ e d' $W$ indicam diferenciais inexatas, e elas de fato o são, porque nem calor nem trabalho são funções de estado, e sim funções do caminho seguido pelo processo, que inclui a deformação, e a troca de calor com o ambiente. Sua soma, no entanto, eq. (1.11), é uma diferencial exata, porque a energia interna, por definição, é uma função de estado.

Diferenciando-se a eq. (1.10), no mesmo sentido anterior, em que a diferencial de uma variável é entendida como a variação por ela sofrida, entre estados infinitesimalmente próximos, e considerando a eq. (1.11), tem-se:

$\mathrm{d} \Psi=\mathrm{d}^{\prime} Q+\mathrm{d}^{\prime} W-T \mathrm{~d} s-s \mathrm{~d} T$

Na hipótese de um processo de deformação reversível, i. e., em que não há dissipação interna, e o regime é quase-estático, a entropia será dada por $\mathrm{d}^{\prime} Q=T \mathrm{~d} s$. Então:

$\mathrm{d} \Psi=\mathrm{d}^{\prime} W-s \mathrm{~d} T$.

Como o fenômeno de deformação ocorre no meio ambiente, e este é um reservatório térmico, então o equilíbrio térmico sempre se estabelece, de tal forma que a variação de $T$ é desprezível. Diz-se, portanto que o fenômeno ocorre em condições isotérmicas e, assim sendo, $\mathrm{d} T=0$ e, então, a eq. (1.13) fica:

$\mathrm{d} \Psi=\mathrm{d}^{\prime} W$.

Isso quer dizer que, na ausência de fenômenos dissipativos, um sólido sujeito a deformação e troca de calor com o seu entorno, apresenta uma variação de energia livre, entre dois estados de equilíbrio termodinâmico, equivalente á variação de sua energia de deformação. A eq. (1.14) confirma, portanto, a definição de energia livre como a parcela da energia interna disponível para a realização de trabalho.

No capítulo seguinte, os conceitos termodinâmicos aqui apresentados, serão utilizados, em um grau mais avançado de generalidade, no exame das condições para a aplicação da Mecânica do Contínuo à Mecânica da Fratura. 


\section{CAPÍTULO 2}

\section{O FENÔMENO DA FRATURA À LUZ DA MECÂNICA DO CONTÍNUO}

Desde quando Irwin, a partir do final da década de 1940 e durante a seguinte, passou a divulgar sua importante contribuição ao estudo do fenômeno da fratura, generalizou-se a idéia de que o modelo da elasticidade plana, resolvido com o auxílio das funções de variável complexa, forneceria a base metodológica adequada para o ataque ao problema do surgimento e da propagação de fissuras nos sólidos. Assim nascia a Mecânica da Fratura Elástica Linear, com a esperança de que fosse um importante passo na superação das deficiências crônicas identificadas no modelo de GRIFFITH (1920). A principal dessas deficiências, considerada naquele momento, era a limitação da validade do critério de Griffith, para a previsão do início da fratura, aos casos de sólidos formados por materiais de comportamento frágil. Outra deficiência residia na verificação de que o parâmetro experimental proposto por Grifith para compor seu critério, a energia superficial específica, não era, de fato, uma característica tecnológica do material.

Com base em resultados obtidos por WESTERGAARD (1939), com auxílio dos potenciais complexos introduzidos por Kolossov-Muskhelishivili (uma alternativa às funções de Airy), no estudo dos problemas da elasticidade bidimensional, IRWIN (1957) introduz os fatores de intensidade de tensão, identificando-os, então, com a energy release rate (grandeza cuja denominação a ele se deve), identificada como a força responsável pelo avanço da fissura. Tal grandeza que, embora ainda sem essa denominação, fora usada por GRIFFITH (1920) na formulação de seu critério, corresponde à variação da energia potencial elástica do 
sólido contendo uma fissura, em relação a um parâmetro geométrico (metade do comprimento) dessa fissura.

Os resultados de Westergaard, baseados na elasticidade linear, são obtidos na forma de séries de funções, uma para cada componente do tensor tensão plano, e apresentam (em todos os cinco casos tratados no citado trabalho de Irwin) uma característica comum: Cada uma das séries de funções contém uma parcela singular do tipo $1 / \sqrt{r}$, onde $r$ é a distância de um ponto genérico do plano médio da chapa, à extremidade da fissura contida no mesmo plano. $O$ surgimento de tal tipo de singularidade, em problemas da elasticidade linear, ocorre, simplesmente, porque a fissura é simulada como um segmento de reta (algo que pode ser entendido como o caso limite da elipse usada por Griffith, quando o eixo menor tende para zero).

A razão para a difusão da idéia de que a fratura envolve, necessariamente, singularidade nas expressões das componentes de tensão, decorre dessa idealização de Irwin que, seguramente, não simula melhor a realidade, do que a proposta de Griffith segundo a qual os raios de curvatura na extremidade da fissura devem ser diferentes de zero, tal como em uma elipse achatada. Como conseqüência de seu modelo, Irwin identificou nos coeficientes das parcelas singulares, nas diversas representações em série das componentes de tensão, em três casos simples, grandezas que passou a denominar de fatores de intensidade de tensão. Em síntese, os fatores de intensidade de tensão podem ser entendidos como conseqüência da simulação da fissura como um vazio preexistente, localizado no plano médio de uma chapa de material elástico-linear, submetida a cargas nesse mesmo plano. Sua utilização prática, portanto, teria que ser feita com base na consciência precisa da limitação da teoria que lhe dá suporte. Essa teoria, elástico-linear, fornece expressões para as componentes do tensor tensão, contendo parcelas singulares, as quais encerram em si mesmas uma contradição, pois, naturalmente, na vizinhança do extremo do segmento de reta representativo da fissura, as componentes de tensão tendem ao infinito, caracterizando, assim, uma impossibilidade física, diante da hipótese do comportamento linear do material. 
A rigor, a idealização de Irwin, do segmento de reta, ou corte matemático, para simular o vazio (fissura) preexistente, exigiria a delimitação, a priori, de um entorno da extremidade do segmento, onde uma hipótese de plasticidade teria de ser adotada, para assim poder-se proceder a uma análise mais realista. Nesse caso, os resultados não mais envolveriam singularidade e, em conseqüência, não mais apareceriam os fatores de intensidade de tensão! Entretanto, a justificativa para atenuar, na metodologia de Irwin, a não consideração da acomodação plástica na extremidade da fissura, como necessidade, está em admitir-se que é muito pequena a região onde ocorre a plastificação, sendo, portanto, desprezível a quantidade de energia nela dissipada. O problema está em que, para uma teoria ser consistente, é necessário que nela esteja incluída algo que torne possível a delimitação de seu campo de validade. Para isso, deveriam estar claros os instrumentos conceituais capazes de especificar a medida da região, na vizinhança da extremidade da fissura, além da qual a hipótese de comportamento linear do material não mais seria recomendada. Isso, entretanto, não é cogitado na metodologia de Irwin, o que afeta sua objetividade.

Para complementar a metodologia de Irwin, é exigida a determinação experimental dos valores críticos dos fatores de intensidade de tensão, cuja comparação com os respectivos valores calculados, para um sólido elástico qualquer, serviria para aferir sua integridade, no que diz respeito à fratura. Muito foi feito nesse terreno, visando a determinação desses parâmetros em laboratório, ao tempo em que sua validade científica ainda é motivo de grande controvérsia.

De fato, a metodologia de Irwin instalou-se muito fortemente entre os estudiosos, e mais ainda entre os usuários da Mecânica da Fratura, como se fosse uma verdade imutável, acabando por cristalizar uma cultura tecnológica que, do ponto de vista da Mecânica dos Materiais, apresenta graves deficiências. Isso porque, além de o fenômeno da fratura ser essencialmente não linear e irreversível, o que a metodologia de Irwin, evidentemente, não pretende captar, a complexidade do fenômeno da deformação não pode ser abarcada somente com o auxílio de três modos simples de fratura, pois, pelo menos do ponto de vista do modelo de tensão de 
Cauchy, o problema do acoplamento de influências entre componentes tangenciais e componentes normais, em tensão e em deformação, é muito complexo para ser tratado somente com o auxílio dos três tradicionais modos de fratura.

Na elaboração dos modelos físico e matemático do fenômeno, duas opções principais foram feitas. A primeira, é sobre a questão do início do processo de fissuração: inicia-se a partir de um vazio preexistente, tal como Griffith e Irwin consideram, ou pode surgir a partir do estado de continuidade, como quer Hillerborg, por exemplo?

Do ponto de vista físico, dado que qualquer sólido é composto por uma quantidade imensamente maior de vazios do que de matéria compacta, a hipótese do vazio preexistente parece ter mais sentido. O problema estaria ao nível do modelo matemático, para considerar adequadamente tantos, e tão irregulares, vazios contidos no sólido real, de onde, potencialmente, o processo poderia avançar. $\mathrm{O}$ tratamento da questão do surgimento de uma descontinuidade no sólido é, no entanto, mais complexo do que o exigido para o caso de uma fissura que cresce a partir de um vazio preexistente, mesmo que o estudo se faça com o auxílio de um modelo não determinista. Mesmo assim, o tratamento descontínuo envolve dificuldades superáveis. Adota-se aqui, portanto, a hipótese do vazio preexistente, com base em um modelo determinista.

A segunda opção ganha maior destaque, por dizer respeito a algo que ainda não foi avaliado em todas as suas conseqüências. Trata-se da questão da irreversibilidade da fratura. Admite-se, aqui, que ocorre, necessariamente, dissipação de energia na superfície de avanço da fissura, o que implica na adoção da hipótese da irreversibilidade do processo de fissuração. Esse é o ponto essencial de divergência ente os modelos anteriores e o aqui é proposto, sendo que a crítica a eles feita, só tem o sentido de acrescentar uma outra visão do problema que, espera-se, poderá contribuir para aperfeiçoá-los.

A pioneira contribuição de Griffith, para a compreensão do problema da fratura, é responsável pela opinião unânime segundo a qual foi ele o iniciador da 
ciência hoje denominada Mecânica da Fratura. A sua refinada intuição do fenômeno físico, ao admitir que tudo ocorreria como se as fissuras crescessem a partir de vazios preexistentes, mais tarde também adotada por Irwin, permitiu a justificativa para a observação separada entre fenômenos associados a volume, e outros que ocorrem nas superfícies de avanço, após iniciado o processo de fissuração. Isso é aqui retomado, em outra perspectiva, na intenção de organizar-se uma teoria da fratura cuja característica básica reside no recurso à Mecânica do Contínuo e à Termodinâmica.

O exame minucioso dessa possibilidade é o objeto do presente capítulo, que apresenta a formulação de um modelo matemático do problema da fissuração, em um sólido considerado inicialmente como um meio contínuo contendo vazios a partir dos quais fissuras poderão se desenvolver. A compatibilização aqui buscada, da Mecânica da Fratura com a Mecânica do Contínuo e a Termodinâmica, visa aproveitar as vantagens do status científico dessas últimas, em proveito da primeira.

As bases para a linha de investigação aqui desenvolvida situam-se no pioneiro estudo de EFTIS \& LIEBOWITZ (1976), que afirma a insuficiência da formulação original de Griffith (na perspectiva de aperfeiçoá-la), a saber, que a energia superficial específica não é uma propriedade do material, mas sim uma grandeza mais complexa, dotada das seguintes características: função de ponto, composta de três parcelas, associadas, respectivamente, à energia livre, à temperatura e à energia cinética nas faces de avanço das fissuras. Com essa interpretação criam-se as condições para a construção de modelos não lineares e termodinamicamente consistentes, na Mecânica da Fratura.

O trabalho de ZHANG \& KARIHALOO (1993) segundo o qual "a condição necessária para o crescimento de fissuras em um meio é o cumprimento das leis de balanço, não somente no volume do corpo mas também nas superfícies das fissuras que vão sendo irreversivelmente criadas", também representa uma considerável contribuição no sentido da linha aqui adotada. Ao provar que tal condição é satisfeita, fazendo uso da equação de transporte generalizada de Reynolds (aqui, uma outra alternativa é desenvolvida), encontra-se, naquele trabalho, o instrumental metodológico básico para a passagem das equações de balanço global às de balanço 
local, inclusive nos pontos das superfícies de avanço das fissuras. Esse último constitui-se em significativo avanço, em relação ao citado trabalho de EFTIS \& LIEBOWITZ (1976), porquanto naquele ainda era negada, a priori, a possibilidade do tratamento do problema da fratura com o auxílio da Mecânica do Contínuo.

A saída para a nova interpretação, no entanto, só foi possível em razão do exaustivo esforço científico desenvolvido no citado trabalho de Eftis \& Liebowitz, para justificar a introdução, nas equações globais de balanço termomecânico, de uma expressão própria das grandezas associadas às superfícies de avanço das fissuras criadas durante o processo, ensejando assim a possibilidade da contribuição aqui lançada.

\subsection{Descrição matemática do processo de fissuração}

O pressuposto da continuidade de um corpo sólido $B$, permite que se faça uma associação dele com um conjunto limitado, fechado e de fronteira suave, denominado configuração de referência $\left(C_{0} \subset I R^{3}\right)$. Imagina-se que a evolução desse corpo deformável poderá ser acompanhada mediante uma seqüência de aplicações biunívocas, capazes de associar, instante a instante, cada ponto $X \in C_{0}$ a um e um só ponto $x \in C_{\mathrm{t}}$ onde $C_{\mathrm{t}} \subset I R^{3}$ é a configuração atualizada do corpo $B$, no instante $t$. Cada aplicação dessa seqüência (também chamada de deformação) é biunívoca, contínua, inversível e com inversa também contínua, isto é, um homeomorfismo.

No presente modelo, nada impede que haja mais de uma fissura no interior de $B$ (o número delas sendo naturalmente finito). Sem perda de generalidade, no entanto, a análise estará concentrada numa parte $P \subseteq B$ que, para facilitar, supõe-se conter somente uma fissura. Na configuração de referência, tal parte será representada por $P_{0}$, e $P_{\mathrm{t}}$ é sua representação na configuração atualizada correspondente ao instante $t$. Portanto, $P_{0} \subseteq C_{0}$ e $P_{\mathrm{t}} \subseteq C_{\mathrm{t}}$.

Diz-se que um ponto pertence à fronteira de um conjunto genérico $\mathrm{K}$, se qualquer vizinhança desse ponto possuir ao menos um ponto do interior e outro do exterior de $\mathrm{K}$. Define-se, então, como contorno $\partial P_{\mathrm{t}}$, a fronteira da configuração 
atualizada $P_{\mathrm{t}}\left(\partial P_{0}\right.$, no caso da configuração de referência $\left.P_{0}\right)$. Considera-se, também, que as representações de referência e atualizada, do contorno de um vazio preexistente em $P$, só pertencem, respectivamente, a $\partial P_{0}$ e a $\partial P_{\mathrm{t}}$, enquanto não ocorre o crescimento irreversível da fissura. Essa é uma opção que será adiante justificada, pois no presente modelo, excluem-se, deliberadamente, de $\partial P_{0}$ e de de $\partial P_{\mathrm{t}}$ os pontos representantes do avanço da fissura.

Em razão dessa exclusão, supõe-se a existência de um conjunto, $\subset P_{0}$, com o auxílio do qual registra-se o crescimento da fissura com o tempo, mediante uma seqüência de aplicações $g^{*}$, que leva pontos de $S_{\mathrm{f}}(t)$ a pontos do conjunto $S_{\mathrm{f}}(t) \subset P_{\mathrm{t}}$. Vale enfatizar que $S_{\mathrm{f}}(t)$ está contido em $P_{0}$, e não em $\partial P_{0}$.

FIGURA 3.- A DEFORMAÇÃo NO CASO DE UM SÓLIDO NÃO FISSURADO (a) OU CONTENDO UMA FISSURA (b)

Insiste-se que, no presente modelo, por princípio, uma fissura nunca poderá surgir no sólido, podendo apenas crescer, a partir de um vazio preexistente. A Figura 3 ilustra o modelo clássico da Mecânica do Contínuo, quando no interior do corpo existe um vazio. Enquanto o movimento do corpo é realizado, em condições sob as quais existe a reversibilidade (regime elástico, por exemplo), Figura $3 a$, as alterações das dimensões do vazio são conseqüência de fenômenos associados a volume. No estudo dos fenômenos espontâneos, tais como a fissuração, na hipótese do avanço de 
uma fissura, a superfície do vazio preexistente, a partir do qual a fissura pode evoluir, sofre um acréscimo irreversível em sua área, Figura 3b.

Do ponto de vista da termodinâmico, a incoerência do modelo de Griffith (v. Capítulo 1), por exemplo, está relacionada com o fato de o ponto de partida para sua formulação ser um problema da elasticidade linear, que não comporta, obviamente, a possibilidade de uma associação entre a energia superficial e a dissipação de energia ocorrida na superfície de avanço das fissuras.

A aplicação das Leis da Termomecânica a $P$, conduz a que se postulem as equações de balanço global (da massa, da quantidade de movimento linear, da quantidade de movimento angular, da energia e do Princípio da Irreversibilidade, ou desigualdade de Clausius-Duhem). No caso do problema clássico da Mecânica do Contínuo é sempre possível partir-se das equações de balanço global e chegar-se a relações diferenciais válidas ao nível local, isto é, ao nível de cada ponto, em $P_{\mathrm{t}}$. A possibilidade da generalização desse procedimento, para o caso de meios fissurados, é o que será discutido a seguir.

\subsection{Leis da Termodinâmica aplicadas aos sólidos contínuos}

Definem-se os campos escalares $\varepsilon$ e $\eta$, denominados de energia interna e entropia, por unidade de massa, respectivamente. Daí, a entropia e a energia interna, numa parte genérica $P$ do sólido, são dadas, no instante $t$, por:

$$
\int_{\mathrm{P}_{t}} \rho \varepsilon \mathrm{d} v \quad \int_{\mathrm{P}_{\mathrm{t}}} \rho \eta \mathrm{d} v
$$

onde $\rho$ é a massa específica, uma função de ponto, e $\mathrm{d} v$ é o elemento de volume, na representação atualizada $P_{\mathrm{t}}$. A energia total $E(P, t)$, dessa parte, é definida como:

$$
E(P, t)=\int_{\mathrm{P}_{t}} \rho \varepsilon \mathrm{d} v+\frac{1}{2} \int_{\mathrm{P}_{\mathrm{t}}} \rho \mathbf{v} \cdot \mathbf{v d} v,
$$

sendo $\mathbf{v}$ a velocidade do ponto $\mathbf{x}=\mathbf{x}(\mathbf{X}, t)$, com $\mathbf{x} \in P_{\mathrm{t}}$. 
Admitindo-se que, de alguma maneira, seja fornecido ou retirado calor de $P_{\mathrm{t}}$, numa troca entre essa parte e seu exterior, quantifica-se essa possibilidade através de uma taxa $r$, de calor fornecido, por unidade de massa, em $P_{\mathrm{t}}$, e pelo vetor fluxo calorífico $\mathbf{q}$, em $\partial P_{\mathrm{t}}$. Daí, obtêm-se as grandezas:

$\int_{\mathrm{P}_{\mathrm{t}}} \rho r \mathrm{~d} v \quad$ e $\quad-\int_{\partial \mathrm{P}_{\mathrm{t}}} \mathbf{q} \cdot \mathbf{n} \mathrm{d} s$,

ambas com dimensão de potência mecânica, correspondendo às taxas temporais de variação da energia, no interior e na fronteira de $P_{\mathrm{t}}$, respectivamente. Observe-se que o sinal negativo na segunda expressão decorre da convenção para o vetor unitário normal $\mathbf{n}$, positiva quando dirigido para fora, em cada ponto do contorno $\partial P_{\mathrm{t}}$. Isso significa que a quantidade de calor ) é convencionada positiva, quando fornecida á parte considerada do sólido (sistema).

A partir das potências das forças aplicadas (b.v, por unidade de volume e s.v, por unidade de área), onde b é a densidade das forças de corpo, por unidade de volume, e $\mathbf{s}$ é a densidade das forças, por unidade de superfície, tem-se a seguir a expressão matemática da Primeira Lei da Termodinâmica, que equivale à Lei de Conservação da Energia:

$$
\frac{D}{D t} E(P, t)=\int_{\mathrm{P}_{\mathrm{t}}}(\rho r+\mathbf{b . v}) \mathrm{d} v+\int_{\partial \mathrm{P}_{\mathrm{t}}}(\text { s.v-q.n }) \mathrm{d} s
$$

onde a expressão $D / D t$ indica derivada material no tempo.

Substituindo na eq. (2.1) o valor de $E(P, t)$ da eq. (2.2), tem-se:

$$
\frac{D}{D t} \int_{\mathrm{P}_{t}} \rho\left(\varepsilon+\frac{1}{2} \mathbf{v} \cdot \mathbf{v}\right) \mathrm{d} v=\int_{\mathrm{P}_{t}}(\rho r+\mathbf{b . v}) \mathrm{d} v+\int_{\partial \mathrm{P}_{\mathrm{t}}}(\mathbf{s . v}-\mathbf{q} \cdot \boldsymbol{n}) \mathrm{d} s
$$

A taxa de calor trocado com o exterior, correspondente a $P_{\mathrm{t}}$, é:

$$
Q(P, t)=\int_{\mathrm{P}_{\mathrm{t}}} \rho r d v-\int_{\partial \mathrm{P}_{\mathrm{t}}} \mathbf{q} \cdot \mathbf{n} \mathrm{d} s
$$


De acordo com a Segunda Lei da Termodinâmica, a taxa de entropia produzida em $P_{\mathrm{t}}$ é sempre maior ou igual à taxa de energia trocada entre essa parte e o exterior, dividida pela temperatura absoluta, no volume e no contorno. Daí:

$$
\frac{\mathrm{D}}{\mathrm{Dt}} \int_{\mathrm{P}_{\mathrm{t}}} \rho \eta \mathrm{d} v=\int_{\mathrm{P}_{\mathrm{t}}} \rho \dot{\eta} \mathrm{d} v \geq \int_{\mathrm{P}_{\mathrm{t}}} \rho \frac{r}{T} \mathrm{~d} v-\int_{\partial \mathrm{P}_{\mathrm{t}}} \frac{\mathbf{q}}{T} \cdot \mathbf{n} d s,
$$

onde o ponto sobre a variável também indica derivada material no tempo.

Observe-se, na eq (2.5), que a passagem da derivada material D/Dt para dentro da integral só afetou a variável $\eta$. Essa propriedade da derivada material, que adiante será usada, tanto para a integração no volume quanto na superfície, pode ser demonstrada com o auxílio da eq. (B.12), do Anexo B, levada em conta a conservação da massa.

\subsection{Tratamento termodinâmico do problema da fratura}

O tratamento clássico dos problemas da Mecânica da Fratura, baseado nas contribuições de Griffith e de Irwin, considera, ainda que não explicitamente, a Primeira Lei da Termodinâmica. Segundo ZHANG \& KARIHALOO (1993), tal tratamento é insuficiente, merecendo que se adote o tratamento termodinamicamente consistente, isto é, aquele em que se leva em consideração tanto a Primeira quanto a Segunda Lei da Termodinâmica. A justificativa para o tratamento termodinamicamente consistente do problema da fratura, decorre, portanto, do caráter irreversível do fenômeno, cuja análise exige a consideração de aspectos relacionados com a evolução da entropia.

\subsubsection{Passagem das equações de balanço global às equações de balanço local}

Ao nível global, de uma parte $P$ do sólido (este considerado como um meio contínuo), postulam-se cinco princípios, denominados princípios de balanço termomecânico, cuja validade, a priori, é o ponto de partida para a construção de qualquer modelo capaz de enquadrar o estudo do movimento de um corpo, no caso 
em que esse movimento inclui a deformação como possibilidade. Os cinco balanços globais são: de massa, de momentum linear, de momentum angular, de energia, e de entropia (Desigualdade de Clausius-Duhem, ou Princípio da Irreversibilidade).

Para o estudo de um sólido contendo vazios, e estando prevista a possibilidade de um processo de crescimento irreversível das superfícies internas desses vazios, assimilados a fissuras, é preciso uma adaptação do modelo tradicional da Mecânica do Contínuo, para que ele possa dar conta da análise do fenômeno. A saída, advém da proposta original de EFTIS \& LIEBOWITZ (1976), e consiste na inclusão de uma nova parcela, em cada uma das cinco equações de balanço global, uma integral de área, para cada caso, a ser calculada sobre as superfícies de avanço das fissuras, isto é, sobre a parte irreversível da expansão sofrida pelos vazios no curso movimento.

Somente com o sentido de síntese, será desenvolvido, a seguir, um procedimento geral, capaz de enquadrar, formalmente, os cinco princípios termomecânicos clássicos, estendidos agora da Mecânica do Contínuo para a Mecânica da Fratura. Quatro deles são princípios de conservação: da massa, da quantidade de movimento linear, da quantidade de movimento angular, e da energia. O quinto, é o Princípio da Irreversibilidade que, embora seja expresso por meio de uma desigualdade, pode, mediante um artifício, desenvolvido logo mais, ser colocado em forma de igualdade. Assim, a expressão geral, a seguir desenvolvida na forma de uma igualdade, poderá ser especializada para cada um dos cinco princípios.

Sejam $\Phi$ e $\Phi^{*}$ dois campos (ambos escalares ou ambos vetoriais) definidos em $P_{\mathrm{t}}$ e em $s_{\mathrm{f}}(t)$ respectivamente. O balanço global, em sua forma geral, expressa-se por:

$\frac{D}{D t} \int_{P_{t}} \Phi d v+\frac{D}{D t} \int_{s_{f(t)}} \Phi^{*} d s=\int_{\partial P_{t}} \mathbf{r} \cdot \mathbf{n} d s+\int_{P_{t}} \mathbf{g} d v$

A novidade, repita-se, é que o primeiro membro dessa equação geral desdobra-se em duas parcelas, uma associada ao volume e outra à superfície de avanço da fissura. $\mathrm{O}$ segundo membro, que expressa a interação de $P_{\mathrm{t}}$ com o exterior, tem duas parcelas, a 
primeira é uma integral tomada na fronteira da parte e a segunda é uma integral no volume. $D / D t$ representa a derivada material no tempo; $\Upsilon$ representa grandezas para as quais faz sentido a aplicação ao vetor $\mathbf{n}$, podendo ser um vetor, ou um tensor de segunda ordem, tais como o tensor de Cauchy, o fluxo de calor, etc. E $\mathbf{g}$ expressa uma densidade volumétrica (de forças de corpo, de quantidade de calor trocada com o exterior, etc.), todos tomados na configuração atualizada $P_{\mathrm{t}} . \mathbf{n}$ é o vetor normal unitário externo, em pontos de $\partial P_{\mathrm{t}}$, contorno considerado regular o suficiente para que só exista um único valor de $\mathbf{n}$ em cada ponto. Os elementos infinitesimais $\mathrm{d} v$ e $\mathrm{d} s$ são relativos, respectivamente, ao volume de $P_{\mathrm{t}}$ e às fronteiras $\left[\partial P_{\mathrm{t}} \cup s_{\mathrm{f}}(t)\right]$. Como se vê, a diferença que surge, no caso do meio fissurado, em relação ao tradicional da Mecânica do Contínuo, é a inclusão de uma segunda parcela no primeiro membro da eq. (2.6), cuja justificativa física, conforme já foi dito, encontra-se em EFTIS \& LIEBOWITZ (1976).

A seguir, será desenvolvido o artifício algébrico que transforma em uma igualdade o quinto princípio, o da Irreversibilidade que, de fato, tem a forma de uma desigualdade. Assim, será possível enquadrá-lo na expressão geral da eq.(2.6).

Tome-se como referência a inequação (2.5), válida para a Mecânica do Contínuo tradicional, e adicione-se a seu primeiro membro uma integral, a ser realizada numa possível superfície de avanço da fissura, na qual aparecem as densidades $\rho *$ e $\eta *$, análogas às que aparecem na integral de volume, só que agora definidas por unidade de superfície. Então, a equação de balanço de entropia, na parte considerada, supondo que nela haja pelo menos uma fissura em crescimento, será:

$$
\frac{D}{D t} \int \underset{\mathrm{P}_{\mathrm{t}}}{ } \rho \eta \mathrm{d} v+\frac{D}{D t} \underset{\mathrm{s}_{\mathrm{f}}(t)}{\int \rho^{*} \eta} \eta^{*} \mathrm{~d} s-\int_{\mathrm{P}_{\mathrm{t}}} \rho \frac{r}{T} \mathrm{~d} v+\int_{\partial \mathrm{P}_{\mathrm{t}}} \frac{\mathbf{q}}{T} \cdot \mathbf{n} d s \geq 0 .
$$

Definindo-se, em seguida, uma taxa $\xi(\geq 0)$ de produção de entropia por unidade de massa, associada a $P_{\mathrm{t}}$, tal que:

$$
\int_{P_{t}} \rho \xi \mathrm{d} v=\int_{P_{t}} \rho\left(\frac{D}{D t} \eta-\frac{r}{T}\right) \mathrm{d} v+\int_{s_{f}(t)} \rho^{*}\left(\frac{D}{D t} \eta^{*}\right) \mathrm{d} s+\int_{\partial P_{t}} \frac{\mathbf{q} \cdot \mathbf{n}}{T} \mathrm{~d} s \geq 0,
$$


chega-se ao Princípio da Irreversibilidade que, passa a enquadrar-se na forma da eq. (2.6):

$\frac{D}{D t} \int_{P_{t}} \rho \eta d v+\frac{D}{D t} \int_{S_{f}(t)} \rho^{*} \eta^{*} d s=\int_{P_{t}} \rho\left(\frac{r}{T}+\xi\right) d v-\int_{\partial P_{t}} \frac{\mathbf{q} \cdot \mathbf{n}}{T} d s$.

O próximo passo, no caso da Mecânica do Contínuo tradicional, é a passagem das equações de balanço global (na forma integral), para as respectivas equações de balanço local (na forma diferencial). Essa processo de passagem é um importante recurso, que atesta a versatilidade da metodologia da Mecânica do Contínuo, porquanto evidencia a presença das Leis de Newton, da Mecânica, e da Primeira e Segunda Leis da Termodinâmica, como os fundamentos básicos da formulação.

O que será feito a seguir, inspirado em ZHANG \& KARIHALOO (1993), embora por um caminho alternativo, é o desenvolvimento matemático que conduz à passagem das equações de balanço global para as correspondentes equações de balanço local, a partir da forma geral dada por (2.6), válidas para o caso em que há vazios podendo crescer, irreversivelmente, dentro do meio contínuo. Esse caminho alternativo é vantajoso porque conduz a uma equação geral, de caráter local, muito útil na obtenção das conclusões aqui apresentadas em primeira mão, particularmente nos pontos situados nas superfícies de avanço das fissuras.

\subsubsection{Formas gerais das equações de balanço local}

Supondo-se $\Phi(x, t)$ limitado e contínuo em todo ponto $x \in P_{\mathrm{t}}$, onde $x=x(X, t) \mathrm{e}$ $X \in P_{0}$, então a integral de volume, no sentido de Riemann, será:

$$
\int_{P_{t}} \Phi(x, t) d \mathrm{v}=\lim _{n \rightarrow \infty} \sum_{i=1}^{n} \Phi\left(x\left(X_{i}, t\right), t\right) \Delta \mathrm{v}_{i} .
$$

O segundo membro da eq.(2.10) expressa que a integral pode ser obtida através da partição de $P_{\mathrm{t}}$ em subdomínios de medidas $\Delta v_{i}(i=1 \ldots n)$, sendo cada ponto $x_{i}=x\left(X_{i}, t\right)$, obrigatoriamente, um ponto interior do correspondente subdomínio de $P_{\mathrm{t}}$. Para as condições em que $\Phi(x, t)$ foi acima definido, obtém-se, portanto, segundo 
Riemann, um e um só valor para o limite do segundo membro da eq.(2.10), independentemente da partição, do volume de $P_{\mathrm{t}}$, utilizada.

Por definição, a derivada material no tempo, da integral de volume do primeiro membro da eq.(2.6) é:

$$
\frac{D}{D t} \int_{P_{t}} \Phi(x, t) d v=\lim _{\Delta t \rightarrow 0} \frac{\Delta\left(\int_{P_{t}} \Phi(x, t) d v\right)}{\Delta t}
$$

que resulta em, (v. Anexo B ):

$$
\frac{D}{D t} \int_{P_{t}} \Phi d v=\int_{P_{t}}\left[\frac{D \Phi}{D t}+\Phi \operatorname{div} \mathbf{v}\right] d v
$$

Na seqüência, será calculada a derivada material no tempo da segunda parcela do primeiro membro da eq. (2.6), através de um procedimento em tudo semelhante ao anterior (v. Anexo B), a partir da definição:

$$
\frac{D}{D t} \int_{s_{f}(t)} \Phi^{*}(x, t) d s=\lim _{\Delta t \rightarrow 0} \frac{\Delta\left(\int_{s_{f}(t)} \Phi^{*}(x, t) d s\right)}{\Delta t},
$$

que resulta em:

$$
\frac{D}{D t} \int_{s_{f}} \Phi^{*} d s=\int_{s_{f}}\left[\frac{D \Phi^{*}}{D t}+\Phi^{*} d i v \mathbf{v}\right] d s
$$

Levando as eqs.(2.12) e (2.14) à eq.(2.6), tem-se:

$$
\int_{P_{t}}\left[\frac{D \Phi}{D t}+\Phi \operatorname{div} \mathbf{v}\right] \mathrm{d} v+\int_{s_{f}}\left[\frac{D \Phi^{*}}{D t}+\Phi^{*} \operatorname{div} \mathbf{v}\right] \mathrm{d} \mathrm{s}=\int_{\partial P_{t}} \mathbf{r} \cdot \mathbf{n d s}+\int_{P_{t}} \mathbf{g d} v
$$

No caso de não haver crescimento da fissura, desde o instante inicial até o instante $t$, a função $\Phi^{*}$ será identicamente nula, e a eq.(2.15) corresponderá à tradicional expressão do balanço global da Mecânica do Contínuo. Para examinar o que ocorre numa vizinhança infinitesimal $V\left(a_{1}\right)$, de um ponto qualquer $a_{1} \in P_{\mathrm{t}}$, será 
aplicado o Teorema de Gauss (da divergência) à primeira parcela do segundo membro da eq.(2.15) que, reorganizada, fica:

$\int_{\mathrm{V}\left(\mathrm{a}_{1}\right)}\left[\frac{D \Phi}{D t}+\Phi \operatorname{div} \mathbf{v}\right] d v-\int_{\mathrm{V}\left(a_{1}\right)}^{\Upsilon} \nabla d v-\int_{\mathrm{V}\left(a_{1}\right)} \mathbf{g d} v=\mathbf{0}$.

Como o ponto $a_{1}$ é genérico, tem-se a expressão do balanço local em pontos não atingidos pela passagem da fissura:

$\frac{D \Phi}{D t}+\Phi \operatorname{div} \mathbf{v}-\Upsilon . \nabla-\mathbf{g}=0, \quad \forall a_{1} \in P_{\mathrm{t}}$

Observação: A grandeza genérica $\Upsilon$ pode ser, ou um vetor, ou um tensor de segunda ordem, e a notação usada tem o seguinte significado: a) $\Upsilon . \nabla$ sempre equivale a div $\Upsilon$; b) $\Upsilon$.n equivale ao produto interno dos dois vetores, quando $\Upsilon$ for um vetor $\mathrm{e}$ c) Quando $\Upsilon$ for um tensor de segunda ordem, $\Upsilon$.n equivale à aplicação de um tensor a um vetor. O símbolo $\nabla$ indica o gradiente espacial, entendido como um vetor, cujas componentes são, respectivamente, as derivadas parciais nas direções dos três eixos do sistema cartesiano ortogonal.

Caso haja crescimento da fissura, contida por hipótese na parte $P_{\mathrm{t}}$, então, para cada ponto $a \in P_{\mathrm{t}}$, pode-se construir uma vizinhança de raio tão pequeno que a fissura passará por fora dela. Essa situação configura-se idêntica à anterior. Imagine-se agora um ponto $a_{2} \in P_{\mathrm{t}}$, que possua uma vizinhança $V\left(a_{2}\right)$ cuja fronteira possua intercessão com a superfície de uma das faces da fissura que avança, no instante $t$. Então, $\partial V\left(a_{2}\right)=\partial_{1} V\left(a_{2}\right) \cup s_{\mathrm{f}}(t)$, em que $\partial_{1} V\left(a_{2}\right)$ é a parte da fronteira de $V\left(a_{2}\right)$ onde a fissura não penetrou, e $s_{\mathrm{f}}=s_{\mathrm{f}}(t)$ é a intercessão da fronteira dessa vizinhança com uma das faces da fissura que avança. Também nesse caso, haverá pelo menos uma outra vizinhança infinitesimal $U\left(a_{2}\right)$, de $a_{2}$, toda contida em $P_{\mathrm{t}}$, o que implica na validade da eq.(2.17) para esse ponto. Substituindo-se a eq.(2.17) na eq.(2.15), esta particularizada para a vizinhança $V\left(a_{2}\right)$, tem-se: 


$$
\int_{V\left(a_{2}\right)}(\Upsilon . \nabla) d v+\int_{\Delta s_{f}}\left[\frac{D \Phi^{*}}{D t}+\Phi^{*} \operatorname{div} \mathbf{v}\right] d s=\int_{\partial_{1} V\left(a_{2}\right)}(\Upsilon \cdot \mathbf{n}) \mathrm{d} s .
$$

Aplicando-se o Teorema da Divergência à primeira integral do primeiro membro, desdobrando-a em duas parcelas, sendo uma em $\partial_{1} V\left(a_{2}\right)$ e outra em $\Delta s_{\mathrm{f}}$, tem-se:

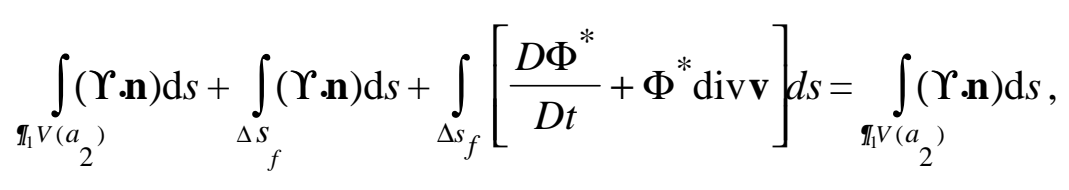

cuja simplificação, leva à seguinte equação, ainda na forma integral, válida na superfície de avanço da fissura:

$$
\int_{\Delta s_{f}} \Upsilon . n d s=-\int_{\Delta s_{f}}\left[\frac{D \Phi^{*}}{D t}+\Phi^{*} \operatorname{div} \mathbf{v}\right] d s
$$

Finalmente, como é genérico o ponto $a_{2}$, escolhido na vizinhança da face da fissura em crescimento, chega-se à expressão diferencial que corresponde ao balanço local na superfície de avanço da fissura:

$$
\Upsilon . \mathrm{n}=-\left(\frac{D \Phi^{*}}{D t}+\Phi^{*} \operatorname{div} \mathbf{v}\right)
$$

Essa equação, cujos desdobramentos serão explorados adiante, sintetiza um dos principais objetivos do presente trabalho, que é demonstrar a possibilidade de utilização da Mecânica do Contínuo na análise do fenômeno da fratura.

\subsection{Teoria termodinamicamente consistente da fratura}

De posse do resultado acima, pode-se partir para a elaboração de uma teoria termodinamicamente consistente, desenvolvida com base no suporte conceitual da Mecânica do Contínuo. Como adiante se verá, o presente trabalho não esgota toda a generalidade aberta pelos resultados aqui obtidos, porque, em decorrência do desenvolvimento teórico, algumas grandezas surgirão que, para serem 
completamente caracterizadas, acredita-se, exigirão um trabalho adicional em laboratório, o que está fora dos objetivos do presente trabalho. Tais grandezas são: a densidade $\rho^{*}$, com dimensão de massa por unidade de superfície; e $\eta^{*}$ e $\varepsilon^{*}$, entropia e energia interna, ambas por unidade de massa, respectivamente, definidas em pontos da superfície de avanço da fissura, $s_{\mathrm{f}}(t)$. O fato de serem grandezas definidas, ponto a ponto, na superfície de avanço das fissuras, é o aspecto curioso que as envolve.

Vale destacar que o aparecimento de tais grandezas já havia sido previsto no trabalho inovador de EFTIS \& LIEBOWITZ (1976). Aproveitadas por ZHANG \& KARIHALOO (1993), em outra perspectiva, o surgimento delas foi apresentado como base para uma nova interpretação da energia superficial específica, $\gamma$, de Griffith. A nova grandeza, $\gamma^{*}$, seria denominada densidade de energia superficial termodinâmica de fratura, e dada por: $\gamma^{*}=\rho^{*}\left[\psi^{*}+T \eta^{*}+(1 / 2) . \mathbf{v . v}\right]$, onde $T$ é a temperatura absoluta e $\psi^{*}$ é a densidade superficial de energia livre (por unidade de massa), conseqüência da definição da energia livre de Helmholtz, sendo dada por $\psi^{*}=\varepsilon^{*}-T \eta^{*}$. No presente trabalho, como à frente será mostrado, surge uma nova interpretação, segundo a qual $\rho^{*}, \eta^{*}$ e $\varepsilon^{*}$ não são independentes, podendo reduzir-se a somente duas.

Sejam, definidas em $P_{\mathrm{t}}$, as grandezas $\rho$, massa específica; e $\varepsilon, \eta, r, \xi, T$ e $\Lambda$ a energia interna , a entropia; a taxa de fornecimento de calor e a taxa de produção de entropia, todas por unidade de massa; a temperatura absoluta e a dissipação interna por unidade de volume, respectivamente. Sejam também, $\mathbf{x}, \mathbf{v}, \mathbf{f}, \boldsymbol{n}$ e $\boldsymbol{q}$ os vetores de posição, velocidade, força de corpo por unidade de massa, vetor normal unitário externo e fluxo de calor; e T, D, os tensor tensão de Cauchy e o tensor taxa de deformação, respectivamente.

$\mathrm{Na}$ seqüência, com o auxílio das grandezas acima definidas, serão particularizadas as equações globais e as equações locais de balanço, de acordo com os resultados do desenvolvimento geral realizado na Seção 2.3, mediante a especialização da eq. (2.6) para cada um dos cinco princípios do balanço 
termomecânico. Assim, serão adotados os campos $\Phi$ e $\Phi^{*}$ válidos, respectivamente, para os casos das leis de conservação da massa, da quantidade de movimento linear, da quantidade de movimento angular, da energia e do Princípio da Irreversibilidade.

Se cada conjunto de tais grandezas for levado à eq.(2.6), obtém-se a respectiva equação de balanço global. Se levado na eq.(2.17), chega-se à equação de balanço local em cada ponto de $P_{\mathrm{t}}$. Finalmente, se substituído na eq. (2.20), será obtida a equação de balanço local, em cada ponto da superfície de avanço da fissura.

\subsubsection{Equações de balanço}

a) Princípio de conservação da massa

$$
\Phi=\rho, \quad \Phi^{*}=\rho^{*}, \quad \Upsilon=\mathbf{0} \quad \text { e } \quad \mathbf{g = 0} .
$$

Equação global:

$$
\frac{D}{D t} \int_{P_{t}} \rho \mathrm{d} v+\frac{D}{D t} \int_{s_{f}(t)} \rho^{*} \mathrm{~d} s=0 .
$$

Equação local, nos pontos do interior do corpo:

Usando-se a eq.(2.17), com as grandezas particularizadas pelas eqs.(2.21), tem-se:

$\dot{\rho}+\rho \operatorname{div} \mathbf{v}=0$.

Equação local, nos pontos situados nas faces das fissuras:

Usando-se a eq.(2.20), com as grandezas particularizadas pela eq.(2.21), temse:

$\dot{\rho}^{*}+\rho^{*} \operatorname{div} \mathbf{v}=0$.

b) Princípio de conservação da quantidade de movimento linear:

$\Phi=\rho \mathbf{v}, \quad \quad \quad \Phi^{*}=\rho^{*} \mathbf{v}, \quad \mathbf{T}=\mathbf{T} \quad$ e $\quad \mathbf{g}=\rho \mathbf{b}$. 


\section{Equação global:}

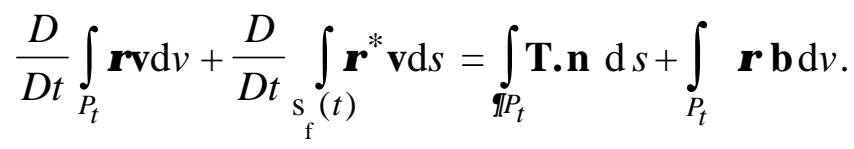

\section{Equação local, nos pontos do interior do corpo:}

Fazendo-se uso da eq.(2.17), particularizada para o caso, usando-se as grandezas definidas pelas eqs (2.25), tem-se:

$$
\frac{D(\rho \mathbf{v})}{D t}+\rho \mathbf{v d i v} \mathbf{v}-\mathrm{T} . \nabla-\rho \mathbf{f}=0
$$

ou

$\dot{\rho} \mathbf{v}+\rho \dot{\mathbf{v}}+\rho \mathbf{v d i v} \mathbf{v}-\mathbf{T} \cdot \nabla-\rho \mathbf{f}=\mathbf{0}$,

ou ainda:

$\rho \dot{\mathbf{v}}+(\dot{\rho}+\rho \operatorname{div} \mathbf{v}) \mathbf{v}-\mathbf{T} \cdot \nabla-\rho \mathbf{f}=\mathbf{0}$.

Considerando-se a eq. (2.23), que expressa o princípio de conservação da massa, vem:

$$
\mathbf{T} \cdot \nabla+\rho(\mathbf{f}-\dot{\mathbf{v}})=\mathbf{0},
$$

que corresponde à equação de equilíbrio dinâmico, num ponto do interior do sólido.

\section{Equação local, nos pontos situados nas faces das fissuras}

Levando-se em conta a eq.(2.20), utilizados os valores das eqs.(2.25), tem-se:

$\mathbf{T} . \mathbf{n}=-\left(\frac{D\left(\rho^{*} \mathbf{v}\right)}{D t}+\rho^{*} \mathbf{v d i v} \mathbf{v}\right)$

ou: 
T.n $=-\left(\rho^{*}+\rho^{*} \operatorname{divv}\right) \mathbf{v}-\rho^{*} \dot{\mathbf{v}}$

Considerando-se o princípio de conservação da massa nas superfícies de fissuras, expresso pela eq.(2.24), chega-se, finalmente, a:

T. $\mathbf{n}=-\rho^{*} \dot{\mathbf{v}}$.

Esse é resultado importante, que pode ser interpretado como uma espécie de Teorema de Cauchy para superfícies fissuradas, segundo o qual, quando a fissura está se propagando, a traction que surge em um ponto da superfície de avanço, no instante em que se dá a abertura, equivale a uma força de inércia por unidade de área.

c) Princípio de conservação da quantidade de movimento angular

$\Phi=\rho \mathbf{p} \times \mathbf{v}, \quad \Phi^{*}=\rho^{*} \mathbf{p} \times \mathbf{v}, \quad \Upsilon=\mathbf{p} \times \mathbf{T} \quad$ e $\quad \mathbf{g}=\rho \mathbf{p} \times \mathbf{f}$,

onde $\mathbf{p}=\mathbf{x}-\mathbf{x}_{\mathbf{0}}$.

Equação global:

$\frac{D}{D t} \int_{P_{t}} \rho \mathbf{p} \times \mathbf{v} \mathrm{d} v+\frac{D}{D t} \int_{s_{f}(t)} \rho^{*} \mathbf{p} \times \mathbf{v} \mathrm{d} s=\int_{\partial P_{t}}(\mathbf{p} \times \mathbf{T}) . \mathbf{n} \mathrm{d} s+\int_{P_{t}} \rho \mathbf{p} \times \mathbf{f} \mathrm{d} v$.

Observação: A notação $\Upsilon \mathbf{\Upsilon}=\mathbf{p} \times \mathbf{T}$ tem sentido quando se faz $(\mathbf{p} \times \mathbf{T}) . \mathbf{n}$, como equivalente a $\mathbf{p} \times($ T.n) .

\section{Equação local, nos pontos do interior do corpo}

Usando-se a eq.(2.17), com os valores particulares da eq.(2.34), tem-se:

$\frac{D(\rho \mathbf{p} \times \mathbf{v})}{D t}+(\rho \mathbf{p} \times \mathbf{v}) \operatorname{div} \mathbf{v}-(\mathbf{p} \times \mathbf{T}) . \nabla-\rho(\mathbf{p} \times \mathbf{f})=0$,

ou:

$\dot{\rho}(\mathbf{p} \times \mathbf{v})+\rho(\dot{\mathbf{p}} \times \mathbf{v}+\mathbf{p} \times \dot{\mathbf{v}})+\rho(\mathbf{p} \times \mathbf{v}) \operatorname{div} \mathbf{v}-(\mathbf{p} \times \mathbf{T}) . \nabla-\rho(\mathbf{p} \times \mathbf{f})=0$. 
Reagrupando convenientemente e levando em conta que $\dot{\mathbf{p}} \times \mathbf{v}=\mathbf{0}$, então:

$(\mathbf{p} \times \mathbf{v})(\dot{\rho}+\rho \operatorname{div} \mathbf{v})-(\mathbf{p} \times \mathbf{T}) \cdot \nabla-\rho \mathbf{p} \times(\mathbf{f}-\dot{\mathbf{v}})=\mathbf{0}$.

Levando-se em conta o princípio de conservação da massa, expresso pela eq.(2.23) e o princípio de conservação do quantidade de movimento linear, expresso pela eq.(2.30), tem-se, daí, a expressão representativa do princípio de conservação da quantidade de movimento angular:

$(\mathbf{p} \times \mathbf{T}) \cdot \nabla=\mathbf{p} \times(\mathbf{T} \cdot \nabla)$.

Para provar-se que tal expressão responde pela simetria do tensor tensão de Cauchy, inicialmente premultiplicam-se (produto interno) ambos os membros dessa igualdade por um deslocamento infinitesimal rígido arbitrário, w, integrando-se após, isto é:

$$
\int_{P_{t}} \mathbf{w} \cdot[(\mathbf{p} \times \mathbf{T}) \cdot \nabla] \mathrm{d} v=\int_{P_{t}} \mathbf{w} \cdot[\mathbf{p} \times(\mathbf{T} \cdot \nabla)] \mathrm{d} v
$$

Mediante a aplicação do Teorema da Divergência (Gauss), o primeiro membro dessa equação fica:

$$
\int_{P_{t}} \mathbf{w} \cdot[(\mathbf{p} \times \mathbf{T}) \cdot \nabla] \mathrm{d} v=\int_{\partial P_{t}} \mathbf{w} \cdot[(\mathbf{p} \times \mathbf{T}) \cdot \mathbf{n}] \mathrm{d} s
$$

Usando a propriedade do produto misto, tem-se:

$$
\int_{\partial P_{t}} \mathbf{w} \cdot[(\mathbf{p} \times \mathbf{T}) \cdot \mathbf{n}] \mathrm{d} s=\int_{\partial P_{t}} \mathbf{w} \cdot[\mathbf{p} \times(\mathbf{T} \cdot \mathbf{n})] \mathrm{d} s=\int_{\partial P_{t}}(\mathbf{T} \cdot \mathbf{n}) \cdot(\mathbf{w} \times \mathbf{p}) d s .
$$

Aplicando-se, à última expressão, a definição de tensor transposto, e reutilizando o Teorema da Divergência para fazer a integral voltar ao volume, tem-se:

$$
\int_{\partial P_{t}}(\mathbf{T} \cdot \mathbf{n}) \cdot(\mathbf{w} \times \mathbf{p}) \mathrm{d} s=\int_{\partial P_{t}}\left[\mathbf{T}^{\mathrm{T}}(\mathbf{w} \times \mathbf{p}) \cdot \mathbf{n}\right] \mathrm{d} s=\int_{P_{t}}\left[\mathbf{T}^{\mathrm{T}}(\mathbf{w} \times \mathbf{p})\right] \cdot \nabla \mathrm{d} v,
$$

que é a nova forma do primeiro membro da eq. (2.40). Isso faz com que aquela equação fique: 


$$
\int_{P_{t}}\left[\mathbf{T}^{\mathrm{T}}(\mathbf{w} \times \mathbf{p})\right] \cdot \nabla \mathrm{d} v=\int_{P_{t}} \mathbf{w} \cdot[\mathbf{p} \times(\mathbf{T} \cdot \nabla)] \mathrm{d} v .
$$

Porém, de acordo com a sexta propriedade das eqs.(A 89), Anexo A, tem-se:

$$
\left[\mathbf{T}^{\mathrm{T}}(\mathbf{w} \times \mathbf{p})\right] \cdot \nabla=\mathbf{T}: \nabla(\mathbf{w} \times \mathbf{p})+(\mathbf{w} \times \mathbf{p}) \cdot(\mathbf{T} \cdot \nabla) .
$$

De acordo com a propriedade de circularidade do produto misto, verifica-se que a segunda parcela do segundo membro dessa última expressão é o integrando do segundo membro da eq. (2.44). Daí, a substituição desse resultado na eq. (2.44) dá:

$$
\int_{P_{t}} \mathbf{T}: \nabla(\mathbf{w} \times \mathbf{p}) \mathrm{d} v=0
$$

Mas, o deslocamento infinitesimal rígido, w, possui uma propriedade segundo a qual existe um único tensor $(\mathbf{W})$ a ele associado, que é anti-simétrico, tal que $\mathbf{w} \times \mathbf{p}=\mathbf{W} \mathbf{p}$, qualquer que seja p. Isso levado à eq.(2.45), junto com o fato de que, no caso, $\nabla(\mathbf{W p})=\mathbf{W} \nabla \mathbf{p}$, conduz a:

$$
\int_{P_{t}} \mathbf{T}:(\mathbf{W} \nabla \mathbf{p}) \mathrm{d} v=0
$$

Levando-se em conta que $\nabla \mathbf{p}$ é o tensor identidade, e que o deslocamento infinitesimal rígido, w, é arbitrário, tem-se:

$$
\mathbf{T}=\mathbf{T}^{\mathrm{T}}
$$

em razão da propriedade segundo a qual, ao ser nulo o produto interno de um tensor genérico por um tensor anti-simétrico $(\mathbf{W})$, então esse tensor é obrigatoriamente simétrico. Ver eq. (A52), no Anexo A.

Equação local, nos pontos situados nas faces das fissuras:

Levando-se em conta a eq.(2.20), com as variáveis definidas pela eq.(2.34), tem-se: 
$(\mathbf{p} \times \mathbf{T}) \cdot \mathbf{n}=-\frac{D\left(\rho^{*} \mathbf{p} \times \mathbf{v}\right)}{D t}-\left(\rho^{*} \mathbf{p} \times \mathbf{v}\right) \operatorname{div} \mathbf{v}$

Desenvolvendo-se o segundo membro de maneira análoga ao realizado com a eq. (2.36), obtém-se:

$$
(\mathbf{p} \times \mathbf{T}) \cdot \mathbf{n}=-\rho^{*} \mathbf{p} \times \dot{\mathbf{v}}
$$

Levando-se em conta a eq. (2.33), tem-se:

$$
(\mathbf{p} \times \mathbf{T}) \cdot \mathbf{n}=\mathbf{p} \times(\mathbf{T} \cdot \mathbf{n}) .
$$

Ao revelar uma mera definição de notação aqui utilizada, o resultado expresso pela eq. (2.50) não acrescenta qualquer informação especial sobre o tensor T, nas superfícies fissuradas. Convém observar que a propriedade de simetria desse tensor, já foi revelada, anteriormente, para pontos do interior do corpo, por meio do desenvolvimento que conduziu à eq.(2.47). Como a eq. (2.50) não impõe qualquer nova restrição ao tensor de tensão T, o teorema de Cauchy aí se aplica normalmente, revelando, simplesmente, que a traction em cada ponto, corresponde ao respectivo valor de contorno.

\section{d) Princípio de conservação da energia}

$$
\Phi=\rho \varepsilon+\frac{1}{2} \rho \mathbf{v} . \mathbf{v}, \quad \Phi^{*}=\rho^{*} \varepsilon^{*}+\frac{1}{2} \rho^{*} \mathbf{v} . \mathbf{v}, \quad \Upsilon=\mathbf{v} . \mathbf{T}-\mathbf{q} \quad \text { e } \quad \mathbf{g}=\rho \mathbf{v} . \mathbf{f}+\rho \mathrm{r}
$$

\section{Equação global:}

$$
\begin{aligned}
\frac{D}{D t} \int_{P_{t}}\left(\rho \varepsilon+\frac{1}{2} \rho \mathbf{v} \cdot \mathbf{v}\right) \mathrm{d} v & +\frac{D}{D t} \int_{s_{f}(t)}\left(\rho \varepsilon^{*}+\frac{1}{2} \rho^{*} \mathbf{v} \cdot \mathbf{v}\right) \mathrm{d} s= \\
& =\int_{\partial P_{t}}(\mathbf{v} \cdot \mathbf{T}-\mathbf{q}) \cdot \mathbf{n} \mathrm{d} s+\int_{P_{t}}(\rho \mathbf{v} \cdot \mathbf{f}+\rho r) \mathrm{d} v
\end{aligned}
$$

Equação local, nos pontos do interior do corpo

De acordo com as eqs.(2.17) e (2.51): 


$$
\frac{D}{D t}\left(\rho \varepsilon+\frac{1}{2} \rho \mathbf{v} \cdot \mathbf{v}\right)+\left(\rho \varepsilon+\frac{1}{2} \rho \mathbf{v} \cdot \mathbf{v}\right) \operatorname{divv}-(\mathbf{v} \cdot \mathbf{T}-\mathbf{q}) \cdot \nabla-\rho(\mathbf{v} . \mathbf{f}+\mathbf{r})=0
$$

Desenvolvendo-se as derivações e agrupando-se adequadamente, obtém-se:

$$
\rho \dot{\varepsilon}+\left(\varepsilon+\frac{1}{2} \mathbf{v} \cdot \mathbf{v}\right)(\dot{\rho}+\rho \operatorname{div} \mathbf{v})-(\mathbf{v} \cdot \mathbf{T}-\mathbf{q}) \cdot \nabla-\rho \mathbf{v}(\mathbf{f}-\dot{\mathbf{v}})-\rho r=0
$$

Levando-se em conta as eqs. (2.23) e (2.30), de conservação da massa e de conservação da quantidade de movimento linear, respectivamente, a equação anterior fica:

$$
\rho \dot{\varepsilon}-(\mathbf{v} \cdot \mathbf{T}) \cdot \nabla+\mathbf{q} \cdot \nabla+\mathbf{v} \cdot(\mathbf{T} \cdot \nabla)-\rho r=0 .
$$

Porém, de acordo com a sexta propriedade das eqs.(A 89), Anexo A, tem-se:

$$
(\mathbf{v} \cdot \mathbf{T}) \cdot \nabla=\mathbf{T}:(\mathbf{v} \cdot \nabla)+\mathbf{v} \cdot(\mathbf{T} \cdot \nabla)
$$

que substituída na equação anterior, fornece:

$$
\rho \dot{\varepsilon}-\mathbf{T}:(\mathbf{v} \cdot \nabla)+\operatorname{divq}-\rho r=0
$$

Em razão da simetria de $\mathbf{T}$, somente a parte simétrica do tensor $\mathbf{v} . \nabla$, que é o tensor taxa de deformação D, interfere nos cálculos. Obtém-se assim, finalmente, a forma local do princípio de conservação da energia, nos pontos do interior do corpo:

$$
\rho \dot{\varepsilon}-\mathbf{T}: \mathbf{D}+\mathbf{q} \cdot \nabla-\rho r=0
$$

\section{Equação local, nos pontos situados nas faces das fissuras}

De acordo com a eq.(2.20), e com a particularização das variáveis, feita através da eq.(2.51), tem-se:

$(\mathbf{v} \cdot \mathbf{T}-\mathbf{q}) \cdot \mathbf{n}=-\frac{D\left(\rho^{*} \varepsilon^{*}+\frac{1}{2} \rho^{*} \mathbf{v} \cdot \mathbf{v}\right)}{D t}-\left(\rho^{*} \varepsilon^{*}+\frac{1}{2} \rho^{*} \mathbf{v} \cdot \mathbf{v}\right) \operatorname{div} \mathbf{v}$ 
cujo desenvolvimento leva a:

$$
(\mathbf{v} \cdot \mathbf{T}-\mathbf{q}) \cdot \mathbf{n}=-\rho^{*} \dot{\varepsilon}^{*}-\rho^{*} \mathbf{v} \cdot \dot{\mathbf{v}}-\left(\varepsilon *+\frac{1}{2} \mathbf{v} \cdot \mathbf{v}\right)\left(\dot{\rho} *+\rho^{*} \operatorname{div} \mathbf{v}\right)
$$

A consideração do princípio de conservação da massa leva à anulação da última parcela do segundo membro, ficando então:

$$
(\mathbf{v} \cdot \mathbf{T}-\mathbf{q}) \cdot \mathbf{n}=-\rho^{*} \dot{\varepsilon} *-\rho^{*} \mathbf{v} \cdot \dot{\mathbf{v}}
$$

Considerando-se agora, a identidade:

$$
-\rho^{*} \varepsilon^{*}-\rho^{*} \mathbf{v} \cdot \dot{\mathbf{v}}=-\rho^{*} \frac{D}{D t}\left(\varepsilon^{*}+\frac{1}{2} \mathbf{v} \cdot \mathbf{v}\right)
$$

e nela substituindo $\varepsilon^{*}$ pela expressão que relaciona esta grandeza com a temperatura absoluta e com as densidades superficiais de entropia e de energia livre de Helmholtz, isto é, $\varepsilon^{*}=\psi^{*}+\mathrm{T} \eta^{*}$, a eq. (2.61), tem-se, finalmente:

$$
(\mathbf{v} \cdot \mathbf{T}-\mathbf{q}) \cdot \mathbf{n}=-\rho^{*} \frac{D}{D t}\left(\psi^{*}+T \eta^{*}+\frac{1}{2} \mathbf{v} \cdot \mathbf{v}\right)
$$

Se colocada na forma de uma integral, sobre a representação atualizada, $\mathrm{s}_{\mathrm{f}}(\mathrm{t})$, da superfície de avanço da fissura, a eq.(2.63) fornece uma boa base de informações acerca do processo de fissuração. Assim:

$-\int_{s_{f(t)}}(\mathbf{v} \cdot \mathbf{T}-\mathbf{q}) \cdot \mathbf{n} d s=\dot{\Gamma}, \quad \Gamma=\int_{s_{f(t)}} \rho^{*}\left(\psi^{*}+\eta^{*} T+\frac{1}{2} \mathbf{v} \cdot \mathbf{v}\right) \mathrm{d} s$,

onde

$$
\rho^{*}\left(\psi^{*}+T \eta^{*}+\frac{1}{2} \mathbf{v} \cdot \mathbf{v}\right)=\gamma^{*}
$$

define-se como a densidade de energia superficial termodinâmica de fratura, por unidade de área, a mesma obtida por EFTIS \& LIEBOWITZ (1976). Segundo esse trabalho, no entanto, o desenvolvimento da Mecânica da Fratura nunca poderia se apoiar na metodologia da Mecânica do Contínuo, porque o acompanhamento do 
processo de deformação, mediante uma seqüência de aplicações contínuas, com inversas contínuas, a base da Mecânica do Contínuo, seria prejudicado por conta das descontinuidades impostas ao meio, quando uma fissura viesse a avançar. Retomando as contribuições essenciais daquele trabalho, ZHANG \& KARIHALOO (1993) negam, entretanto, essa argumentação, resolvendo o problema mediante a inclusão de uma parcela exclusiva da superfície de avanço da fissura, no primeiro membro da equação geral de balanço (2.6).

\section{e) Princípio da Irreversibilidade}

$\Phi=\rho \eta, \quad \Phi^{*}=\rho^{*} \eta^{*}, \quad \Upsilon=-\mathbf{q} / T \quad$ e $\quad \mathbf{g}=\rho\left(\frac{r}{T}+\xi\right)$.

\section{Equação global}

$$
\frac{D}{D t} \int_{P_{t}} \rho \eta \mathrm{d} v+\frac{D}{D t} \int_{s_{f}(t)} \rho^{*} \eta^{*} \mathrm{~d} s=\int_{P_{t}} \rho\left(\frac{r}{T}+\xi\right) \mathrm{d} v-\int_{\partial P_{t}} \frac{\mathbf{q} \cdot \mathbf{n}}{T} \mathrm{~d} s .
$$

\section{Equação local, nos pontos do interior do corpo}

De acordo com a eq.(2.17), e levando-se em conta a definição de variáveis dada através da eq.(2.66):

$$
\frac{D(\rho \eta)}{D t}+\rho \eta \operatorname{div} \mathbf{v}+\left(\frac{\mathbf{q}}{T}\right) \cdot \nabla-\rho\left(\frac{r}{T}+\xi\right)=0
$$

Desenvolvendo-se a derivação material no tempo e agrupando adequadamente, vem:

$$
\eta(\dot{\rho}+\rho \operatorname{div} \mathbf{v})+\rho \dot{\eta}+\left(\frac{\mathbf{q}}{T}\right) \cdot \nabla-\rho \frac{r}{T}-\rho \xi=0 .
$$

Levando-se em conta o Princípio de Conservação da Massa, eq. (2.23), e a identidade:

$$
\left(\frac{\mathbf{q}}{T}\right) \cdot \nabla=\operatorname{div}\left(\frac{\mathbf{q}}{T}\right)=\frac{1}{T} \operatorname{div} \mathbf{q}-\frac{1}{T^{2}} \mathbf{q} \cdot \operatorname{grad} T,
$$


a eq.(2.66) torna-se:

$\rho \xi T=\rho \dot{\eta} T+\operatorname{divq}-\frac{1}{T} \mathbf{q} \cdot \operatorname{grad} T-\rho r$

Mas, levando-se em conta a eq.(2.58), expressão local da Primeira Lei da Termodinâmica, tem-se que:

$\operatorname{divq}-\rho r=-\rho \dot{\varepsilon}+\mathbf{T}:(\mathbf{v} \cdot \nabla)$

cuja substituição na eq.(2.68) conduz finalmente à equação que exprime localmente o Princípio da Irreversibilidade:

$\rho \xi T=\Lambda-\frac{1}{T} \mathbf{q} \cdot \operatorname{grad} T \geq 0$

$\Lambda=\rho \dot{\eta} T+\mathbf{T}: \mathbf{D}-\rho \dot{\varepsilon}$,

que corresponde à taxa de dissipação de energia por unidade de volume. A eq. (2.73) revela, portanto, que a taxa de produção de entropia em $P_{\mathrm{t}}$, quando dentro dela uma fissura está avançando, é dada por:

$\xi=\frac{\Lambda}{\rho T}-\frac{1}{\rho T^{2}} \mathbf{q} \cdot \operatorname{grad} T \geq 0$.

Equação local, nos pontos situados nas faces das fissuras

Levando-se em conta a eq.(2.20) e considerando as variáveis definidas através da eq.(2.66), tem-se:

$$
\begin{aligned}
& -\frac{\mathbf{q}}{T} \cdot \mathbf{n}=-\frac{D\left(\rho^{*} \eta^{*}\right)}{D t}-\rho * \eta^{*} \operatorname{divv} \text {. } \\
& \text { Realizando-se a derivação material no tempo e reunindo os termos } \\
& \text { adequadamente, tem-se: }
\end{aligned}
$$


$-\frac{\mathbf{q}}{T} \cdot \mathbf{n}=-\rho^{*} \dot{\eta}^{*}-\eta^{*}\left[\dot{\rho}^{*}+\rho^{*} \operatorname{div} \mathbf{v}\right]$

Levando-se em conta o princípio de conservação da massa, chega-se, finalmente, à equação que exprime o Princípio da Irreversibilidade, nos pontos das faces das fissuras:

$$
\frac{\mathbf{q} \cdot \mathbf{n}}{T}=\rho^{*} \dot{\eta}^{*}
$$

Observe-se que, se o resultado representado pela eq. (2.78) for levado à segunda integral do segundo membro da igualdade, na expressão (2.8), então:

$$
\int_{P_{t}} \rho \xi \mathrm{d} v=\int_{P_{t}} \rho\left(\dot{\eta}-\frac{r}{T}\right) \mathrm{d} v+\int_{\partial P_{t}} \frac{\mathbf{q} \cdot \mathbf{n}}{T} \mathrm{~d} s+\int_{s_{f}(t)} \frac{\mathbf{q} \cdot \mathbf{n}}{T} \mathrm{~d} s \geq 0
$$

A expressão (2.79) revela, portanto, que a produção de entropia é positiva, consideradas as fontes de fornecimento de calor a $P_{\mathrm{t}}$ : radiação (calor por unidade de massa, $r$ ); condução (fluxo de calor q, trocado com o exterior, através do contorno $\left.\partial P_{\mathrm{t}}\right)$ e, finalmente, calor gerado pelo avanço da fissura, no instante $t$, dado pelo fluxo q na superfície $s_{\mathrm{f}}(t)$, através da qual a troca com o exterior passa a ocorrer, à medida que a fissura se abre.

À luz do conjunto dos resultados acima obtidos, decorrente da passagem das equações de balanço global para as de balanço local, é possível uma útil reinterpretação do parâmetro $\gamma^{*}$, dado pela eq. (2.65). Para isso, parte-se da eq. (2.61). Mediante a aplicação da definição de tensor transposto, ao integrando do primeiro membro dessa equação, e devido à simetria do tensor $\mathbf{T}$, tem-se:

$$
(\mathbf{v} \cdot \mathbf{T}-\mathbf{q}) \cdot \mathbf{n}=\mathbf{n} \cdot \mathbf{T}^{T} \mathbf{v}-\mathbf{q} \cdot \mathbf{n}=\mathbf{n} \cdot \mathbf{T} \mathbf{v}-\mathbf{q} \cdot \mathbf{n}=-\rho^{*} \dot{\varepsilon}^{*}-\rho^{*} \mathbf{v} \cdot \dot{\mathbf{v}}
$$

onde $\mathbf{n} . \mathbf{T}=\mathbf{t}$ é o vetor de Cauchy, ou traction, em um ponto da superfície de avanço da fissura. 
Como conseqüência dos balanços de quantidade de movimento linear e de entropia, nos pontos da superfície de avanço da fissura tem-se, levando-se as eq. (2.33) e (2.78) à eq. (2.80), tem-se:

$$
\dot{\varepsilon} * T \dot{\eta}^{*}
$$

Considerando-se agora a relação $\varepsilon^{*}=\psi^{*}+\mathrm{T} \eta^{*}$, de Helmholtz, em sua forma local, válida na superfície de avanço da fissura, tem-se que $\psi^{*}=0$. Então, a eq. (2.63) simplifica-se para:

$$
(\mathbf{v} \cdot \mathbf{T}-\mathbf{q}) \cdot \mathbf{n}=-\rho^{*} \frac{D}{D t}\left(T \eta^{*}+\frac{1}{2} \mathbf{v} \cdot \mathbf{v}\right)
$$

o que conduz, conseqüentemente, a uma mudança na expressão definidora de $\gamma^{*}$, que não mais inclui uma parcela relativa à energia livre. Assim, a eq. (2.65), simplifica-se para::

$$
\gamma^{*}=\rho^{*}\left(T \eta^{*}+\frac{1}{2} \mathbf{v} \cdot \mathbf{v}\right)
$$

Verifica-se, portanto, que $\gamma^{*}$, na verdade, é constituído de duas parcelas, uma relacionada com dissipação de energia na superfície de avanço da fissura, e outra com a velocidade de fissuração. Comprovada, assim, a possibilidade de aplicação da Mecânica do Contínuo à Mecânica da Fratura, os capítulos seguintes serão dedicados à formulação de uma metodologia envolvendo a experimentação numérica e de laboratório, em busca de um critério de fratura termodinamicamente consistente. 


\section{CAPÍTULO 3}

\section{CRITÉRIO TERMODINAMICAMENTE CONSISTENTE DE FRATURA}

O estudo da previsão do início da fratura nos sólidos mereceu, na Inglaterra, a elaboração de dois trabalhos, GRIFFITH (1920, 1924), que são considerados, unanimemente, como os marcos iniciais do campo de estudos a partir daí denominado Mecânica da Fratura. Neles, o autor formula um critério, com o uso do qual pode-se prever, a partir de um vazio (elíptico) preexistente em uma chapa, se haverá, ou não, o seu crescimento.

$\mathrm{Na}$ fundamentação de tal critério, no primeiro dos citados trabalhos, afirma Griffith: "According to the well-known 'theorem of minimum energy', the equilibrium state of an elastic solid body, deformed by specified surface forces, is such that the potential energy of the whole system is a minimum. The new criterium of rupture is obtained by adding to this theorem the statement that the equilibrium position, if equilibrium is possible, must be one in which rupture of the solid has occurred, if the system can pass from the unbroken to the broken condition by a process involving a continuous decrease in potential energy." E continua: "In order, however, to apply this extended theorem to the problem of finding the breaking loads of real solids, it is necessary to take account of the increase in potential energy which occurs in the formation of new surfaces in the interior of such solids. It is known that, in the formation of a crack in a body composed of molecules which attract one another, work must be done against the coesive forces of the molecules on either side of the crack". E agora a conclusão: "This work appears as potential surface energy, and if the width of the crack is greater than the very small distance 
called the 'radius of molecular action', the energy per unit area is a constant of the material, namely, its surface tension.” (GRIFFITH, 1920, p. 165)

Vê-se na citação acima que a proposta de Griffith é de que o trabalho associado ao crescimento da fissura, seja quantificado com auxílio de um parâmetro, por ele denominado energia superficial específica, que seria uma constante do material. De acordo com esse raciocínio, uma certa quantidade de trabalho é realizada no processo de abertura da fissura, cujo valor é proporcional ao acréscimo de área das faces da fissura, ocorrido durante o crescimento. Ressalte-se também, que o critério é formulado dentro do pressuposto de que o material é elástico linear, já que o ponto de partida de Griffith é o trabalho de INGLIS (1913), no qual é examinado o problema da concentração de tensões em uma chapa infinita, decorrente da presença de orifícios.

Neste capítulo são examinados os pressupostos admitidos por Griffith para a formulação de seu critério, a partir, basicamente, do conteúdo das citações acima apresentadas. Na seqüência, o critério de Griffith é examinado com o auxílio da interpretação termodinâmica, tomando por base o que foi apresentado nos dois capítulos anteriores. O objetivo é a obtenção de um critério termodinâmico de fratura, usando-se o de Griffith, em certo sentido, como modelo. Embora a interpretação termodinâmica da fratura, que aqui se propõe, negue veementemente a idéia utilizada por Griffith, de estender o Princípio da Mínima Energia Potencial ao problema da fratura, aproveita-se sua idéia de fundamentar o estudo do fenômeno da fratura no exame do balanço de energia, entre um estado anterior e outro posterior ao avanço da fissura. Além disso, e principalmente, a idéia de uma parcela de energia associada às superfícies de avanço da fissura, concebida por Griffith, embora em sentido distinto do que aqui se usa, pode ser considerada a sua grande contribuição metodológica para o desenvolvimento da teoria termodinamicamente consistente da fratura. 


\subsection{A forma original de obtenção do critério de Griffith}

Aproveitando os resultados do citado trabalho de Inglis, Griffith considera o caso em que a chapa contendo um furo elíptico achatado (livre de forças no contorno) de eixo maior $2 a$, é submetida a uma tração $\sigma_{\text {ap }}$, no infinito, uniformemente distribuída nas bordas paralelas ao eixo maior da elipse. Com as expressões das tensões, ele calcula a redução da energia potencial elástica, entre o caso da chapa infinita sem furo e o da mesma chapa com furo, mantido o carregamento. $\mathrm{O}$ valor da variação da energia potencial elástica, $U$, é:

$$
U=-\frac{\sigma_{\mathrm{ap}}^{2} \pi a^{2}}{E^{\prime}},
$$

onde $E^{\prime}$ é igual ao módulo de elasticidade $E$ do material, no estado plano de tensão. Já no estado plano de deformação $E^{\prime}=E /\left(1-\mathrm{v}^{2}\right)$, onde $v$ é o coeficiente de Poisson do material.

Griffith supõe que, no processo de deformação, as dimensões lineares do furo elíptico achatado variam de acordo com um único parâmetro, o comprimento do semi-eixo maior da elipse, de valor $a$. Assim sendo, para o caso de uma chapa de espessura unitária, a superfície interna do furo é aproximadamente igual a $4 a$, as semi-elipses superior e inferior fazendo as vezes da face superior e da face inferior da fissura, respectivamente. Introduzindo o parâmetro $\gamma$, por ele denominado energia superficial específica, e admitindo o aumento da área da superfície interna do furo que simula a fissura, à medida que esta cresce, Griffith calcula, então, a variação da energia potencial associada ao aumento da fissura, mediante a suposição que é proporcional à área acrescida da fissura. Somando as duas contribuições infinitesimais chega à a diferencial de uma grandeza, também por ele assim denominada: a energia potencial total ${ }^{1}$ da chapa:

\footnotetext{
${ }^{1}$ A expressão energia potencial total é usada por Griffith para indicar a soma da energia potencial da chapa com um furo elíptico, mais a energia superficial, associada à superfície da fissura.
} 


$$
\frac{d U}{d a}+4 \gamma d a=0 \Rightarrow \frac{-2 a \sigma_{\text {ap }}^{2} \pi}{E^{\prime}}+4 \gamma d a=0
$$

que permite a obtenção de seu critério:

$$
\sigma_{\mathrm{ap}}=\sqrt{\frac{2 \gamma E^{\prime}}{\pi a}} .
$$

O valor absoluto, $G$, da grandeza $\mathrm{d} U / \mathrm{d} a$ utilizada por Griffith no desenvolvimento acima, corresponde à strain-energy release rate, assim denominada por IRWIN (1957), que a interpretou como sendo a força capaz de provocar o crescimento da fissura.

A eq. (3.3) revela que a tensão aplicada, $\sigma_{\text {ap }}$, comporta-se como se estivesse em uma espécie de equilíbrio com a fissura de comprimento $2 a$. Isto significa que, se o valor de $a$ decresce, a tensão de fratura, em equilíbrio com esse tamanho de fissura, cresce, como mostra a eq. (3.3).

Em função do resultado expresso pela eq.(3.3), Griffith concluiu que, se fosse possível, mediante intervenção no processo de produção do material, diminuir o tamanho médio dos vazios num sólido, tamanho esse parametrizado por um comprimento tipo $a$, então a tensão limite de fratura, $\sigma_{\mathrm{ap}}$, poderia ser artificialmente aumentada. Devido ao sucesso tecnológico representado pela síntese de um material de alta resistência, a fibra de vidro, com base nesse raciocínio, é que se deu a grande difusão do original critério de Griffith.

Ao diminuir as dimensões dos vazios interiores no vidro, ele conseguiu aumentar bastante o valor de $\sigma_{\text {ap. }}$. Chegou a esse objetivo através da produção de finíssimas fibras constituídas desse material, que seriam depois aglomeradas em uma matriz de resina, para formar painéis de fácil moldabilidade e grande resistência. Em síntese, como conseqüência da formulação do critério que leva seu nome, Griffith chamou atenção para o fato muito relevante de que a resistência dos materiais não está relacionada somente com a capacidade de coesão das moléculas, sendo que a presença de espaços vazios entre elas é também muito importante para a definição da 
capacidade resistente. A partir daí passou-se ao entendimento de que, para bem caracterizar os materiais, do ponto de vista de seu comportamento mecânico, não basta apenas o conhecimento de tensões limites de resistência, mas também a determinação experimental de uma grandeza capaz de dar conta da tenacidade do material (toughness, ou fracture toughness), isto é, a capacidade do material de se opor à fratura.

\subsection{Versão termodinâmica do critério de Griffith}

Embora não tenha justificado seu critério a partir dos princípios da Termodinâmica, não resta dúvida que Griffith, para formulá-lo, realizou um balanço de energia entre dois estados próximos, um anterior e outro posterior ao crescimento da fissura, como fica claro na citação apresentada no início deste capítulo.

Numa reconstituição da essência de seu raciocínio, admitindo-se o processo como quase estático, a expressão local que corresponde ao balanço termodinâmico (Primeira Lei da Termodinâmica), DYM \& SHAMES (1973), é:

$\mathrm{d} \varepsilon=\mathrm{d}^{\prime} q+\mathrm{d}^{\prime} w$,

onde $\varepsilon$ é a energia interna (função de estado) por unidade de volume; $q$ é a quantidade de calor trocada com o exterior (positiva, quando o sólido recebe calor), por unidade de volume; e $w$ é o trabalho, por unidade de volume, realizado sobre o sistema (positivo, portanto, quando ações externas realizam trabalho sobre o corpo). $\mathrm{Na}$ verdade, essa última parcela corresponde ao trabalho interno, ou energia de deformação, armazenado no sólido, em consequiência das ações a ele aplicadas. À semelhança do que foi apresentado no Capítulo 1, as parcelas d' $q$ e d'w são diferenciais inexatas, porque nem calor nem trabalho são funções de estado, mas funções do caminho seguido pelo processo de aquecimento e de deformação, em cada ponto. No entanto sua soma, tal como revela a eq.(3.4), tem de ser uma diferencial exata.

Admitindo-se a existência de um vazio inicial no sólido, a partir do qual uma fissura poderá evoluir, imagina-se aqui, diferentemente de Griffith, que somente com 
a quebra das ligações materiais é que a fissura poderá avançar, havendo, em consequiência, uma dissipação de energia associada à superfície adicionada ao orifício inicial, quando do avanço irreversível da fissura ${ }^{2}$. A idéia original de Griffith, como demonstra a citação apresentada no início deste capítulo, não era que essa fosse uma energia dissipada, mas que teria o caráter de energia potencial.

A consideração da irreversibilidade do processo de fissuração é a novidade introduzida com a presente análise que, auxiliada pelo recurso à Termodinâmica, traz consigo também uma nova interpretação de $\gamma$, de Griffith. Esse parâmetro passa a ter, na nova formulação, um caráter absolutamente distinto do anterior. Trata-se agora de algo bem palpável, isto é, $\gamma$ passa a ser interpretado como energia dissipada na superfície de avanço da fissura. E esse parâmetro mede o limite da capacidade do material de se acomodar à dissipação localizada de energia, antes de se desintegrar. É evidente que uma parcela dessa energia dissipada localmente, no entorno da extremidade da fissura que cresce, poderá estar relacionada a outros fenômenos, associados a volume, tal como a plasticidade, por exemplo. Essa questão será retomada adiante, após a apresentação do instrumental teórico adequado para bem colocá-la.

A energia dissipada quando o eixo maior do furo achatado sofre um acréscimo irreversível $\mathrm{d} a$, vale, portanto, $-4 \gamma \mathrm{d} a$, tendo sinal negativo porque corresponde a um trabalho realizado pelo sistema, na superfície de avanço da fissura. Integrando-se a eq.(3.4) no volume $V$ do sólido fissurado, entre os dois estados considerados, adicionando-se agora o calor dissipado na superfície de área $4 \gamma \mathrm{d} a$, surgida com o avanço da fissura, tem-se:

$$
\int_{\mathrm{V}} \mathrm{d} \varepsilon \mathrm{d} V=\int_{\mathrm{V}} \mathrm{d}^{\prime} w \mathrm{~d} V+\int_{\mathrm{V}} \mathrm{d}^{\prime} q \mathrm{~d} V-4 \gamma \mathrm{d} a
$$

A perspectiva da construção de uma teoria que leve em conta a irreversibilidade do processo de fissuração exige a consideração da entropia $S$,

\footnotetext{
${ }^{2}$ É evidente que o orifício simulador da fissura pode aumentar elasticamente sua superfície interna, sendo essa operação reversível. Mas a parcela da energia relacionada com isso já está incluída na energia associada a volume, no sólido.
} 
através da qual é estabelecida uma relação entre a variação da quantidade de calor trocada com o exterior (de um estado do corpo para o outro) e a temperatura absoluta de equilíbrio $T$. Se não houvesse a formação de fissura no interior do sólido, então d' $q$ seria igual a $T \mathrm{~d} S$ Mas, admitindo-se que haja o crescimento de uma fissura no interior do sólido, como consta da eq. (3.5), acresce-se a d' $q$ a parcela correspondente à dissipação de energia associada ao avanço da fissura. Portanto, após a integração no sólido, tem-se:

$$
\int_{d \mathrm{~V}}\left(\mathrm{~d}^{\prime} q\right) \mathrm{dV}-4 \gamma \mathrm{d} a=\int_{\mathrm{V}}(T \mathrm{~d} S) \mathrm{d} V
$$

De modo semelhante ao que foi feito no Capítulo 1, introduz-se a grandeza $\psi=\varepsilon-T S$, energia livre de Helmholtz, onde $\psi$ é uma função de estado que, quando o processo é irreversível, corresponde à máxima quantidade de energia disponível para transformação em trabalho, LEWIS \& RANDALL (1961). Diferenciando-se essa grandeza, resulta:

$\mathrm{d} \psi=\mathrm{d} \varepsilon-T d S-S d T$.

Usando-se o valor de de, dessa última expressão, na eq. (3.5) e também a integral de $T \mathrm{~d} S$ da eq.(3.6), substituindo-os na eq.(3.5), rearrumando-a posteriormente, vem:

$$
\int_{\mathrm{V}}(\mathrm{d} \psi) d V=\int_{\mathrm{V}}\left(\mathrm{d}^{\prime} w\right) d V+4 \gamma \mathrm{d} a-\int_{\mathrm{V}}(S \mathrm{~d} T) \mathrm{d} V
$$

A primeira parcela do segundo membro da eq.(3.8) corresponde à variação do trabalho interno (energia de deformação) entre os dois estados, antes e depois do crescimento irreversível do furo elíptico. O valor desse incremento, integrado no sólido, será aqui representado por $\mathrm{d} E_{\mathrm{d}}$, diferencial da energia de deformação no sólido. Admitindo-se que o processo seja isotérmico, na medida em que supõe-se que esteja sendo realizado no meio ambiente, então, na expressão anterior, $d T=0$, e o balanço termodinâmico, expresso pela eq.(3.8), conduz a: 
$\int_{d \mathrm{~V}} d \psi \mathrm{d} V=\mathrm{d} E_{d}+4 \gamma \mathrm{d} a$

onde o primeiro membro corresponde à variação da energia livre de todo o sólido. Reorganizando-se a eq.(3.9), fica:

$-d E_{d}=4 \gamma d a+\left(-\int_{d V} d \psi d V\right)$.

Passa-se agora à interpretação do fenômeno à luz da Segunda Lei da Termodinâmica, usando-se a equivalência dessa Lei como seguinte resultado, relacionado ao conceito de energia livre de Helmholtz: Para ocorrer a iniciação espontânea de um fenômeno, fato que caracteriza sua irreversibilidade, é necessário que haja um decréscimo na energia livre $\psi$, decréscimo que deverá ser o mínimo possível, LEWIS \& RANDALL (1961). Isso significa que a segunda parcela do segundo membro da eq.(3.10) deve ser positiva, na hipótese aqui admitida, de haver um avanço da fissura. Logo, isso é suficiente para que a seguinte inequação seja válida:

$-\mathrm{d} E_{\mathrm{d}}>4 \gamma \mathrm{d} a$.

Essa expressão, que guarda certa identidade com a obtida por Griffith, eq. (3.2), resulta, portanto, da interpretação termodinâmica da fratura. Evidentemente, a desigualdade (3.11) não cogita de quão grande deve ser o valor da segunda parcela do segundo membro da eq. (3.10), podendo estar aí uma fonte importante de imprecisão do critério de Griffith. E observe-se que ela depende das características constitutivas do material.

A eq.(3.11) revela um resultado que, embora dentro do espírito da teoria de Griffith, tem uma importante distinção em relação ao que consta da expressão de seu critério original: $O$ primeiro membro da eq.(3.11) não é o valor absoluto da variação da energia potencial total (dU), como afirmou Griffith $^{3}$,

\footnotetext{
${ }^{3}$ Convém mencionar que, embora a fundamentação teórica do critério de Griffith, tal como está em GRIFFITH (1920,1924), seja baseada no conceito de energia potencial total, o que ele usa mesmo nos cálculos é a expressão da energia de deformação. E convém frisar que isto não exime sua interpretação
} 
mas o valor simétrico da variação da energia de deformação $\mathrm{d} E_{d}$, entre dois estados infinitesimalmente próximos, um antes e outro após o avanço da fissura. Como o segundo membro dessa desigualdade é, por definição, positivo, e a energia de deformação é uma forma positiva definida, isso quer dizer que há um decréscimo da energia de deformação entre os estados anterior e posterior ao avanço da fissura.

Fazendo-se um paralelo com a energy release rate, $G$, definida como a derivada da energia potencial elástica em relação ao parâmetro de fratura, define-se agora a derivada da energia de deformação em relação ao parâmetro de fratura, $G_{\mathrm{t}}=d E_{\mathrm{d}} / d a$, uma grandeza que mede algo como a sensibilidade da energia de deformação do sólido, em relação ao parâmetro de fissuração $a$. Para que seja possível a aplicação prática do critério dado pela expressão (3.11), será necessário determinar-se experimentalmente uma grandeza, de natureza termodinâmica, análoga a $\gamma$, uma espécie de valor limite de dissipação energética, por unidade de área da fissura, a partir do qual a fissura tende a crescer. Consta do Capítulo 6, a discussão a respeito da possibilidade de determinação experimental de tal grandeza.

A introdução do critério termodinâmico representado pela eq. (3.11) é a parte essencial da contribuição trazida pelo presente trabalho que, no entanto, não teria sido concebida se o critério de Griffith não existisse. Por esse motivo, o critério da eq. (3.11) será aqui denominado de critério termodinâmico de Griffith. A introdução do parâmetro termodinâmico, $G_{\mathrm{t}}$, no estudo da fratura traz, naturalmente, um questionamento sobre algumas concepções tidas como bem consolidadas na Mecânica da Fratura, a exemplo dos fatores de intensidade de tensões e da integral $J$. Por definição, essas grandezas estão relacionadas com $G$, que, por sua vez, está associada à extensão do princípio da mínima energia potencial à Mecânica da Fratura. A utilização de tal Princípio, como revela a citação do início deste capítulo, foi feita impropriamente por Griffith, porque ele não pode ser aplicado quando o processo de deformação é marcado pela presença de dissipação de energia, tal como ocorre no caso em que o fenômeno da fratura está presente.

da crítica que aqui se apresenta, porque a variação da energia de deformação que aparece na eq. (3.11), relaciona-se com uma quantidade de energia dissipada, algo que Griffith não considera em sua teoria. 
Sem que se esteja fazendo qualquer juízo de valor a respeito da extensa e significativa gama de trabalhos realizados com o auxílio das teorias anteriores, decorre da interpretação termodinâmica do fenômeno da fratura, que os fatores de intensidade de tensões, parâmetros de larga utilização tecnológica, perdem a razão de ser, simplesmente porque a utilização de modos simples de fratura, baseados na elasticidade linear, são um contra-senso dentro de uma teoria que associa crescimento de fissura a dissipação energética. Nesse sentido, embora tenha um significativo papel histórico, a Mecânica da Fratura Elástica Linear deixa de fazer sentido, frente à formulação termodinamicamente consistente.

A opção aqui adotada, da construção de uma Mecânica da Fratura fundada em um modelo termodinamicamente consistente, terá de enfrentar dificuldades, naturalmente, ao nível dos modelos matemáticos, para que a nova idéia possa ser levada à prática. Nesse plano, muito do esforço anteriormente desenvolvido, principalmente por Griffith, Irwin e Rice, poderá ser aproveitado. As possibilidades metodológicas ensejadas pela idéia da integral $J$, por exemplo, serão examinadas no Capítulo 4. Lá, com o auxílio da Análise de Sensibilidade à mudança de forma, uma técnica adaptada, do campo da Otimização Estrutural para o estudo da fratura, será utilizada para calcular a derivada material da energia de deformação, em relação ao parâmetro de fratura, trazendo desdobramentos importantes na construção de métodos aproximados de cálculo.

$\mathrm{Na}$ sequiência, ainda dentro do mesmo espírito, será buscada uma generalização do critério termodinâmico aqui obtido, eq. (3.11), com o auxílio de resultados dos Capítulos 1 e 2, com destaque para a utilização da idéia de densidade de energia superficial termodinâmica de fratura.

\subsection{A dinâmica da propagação de uma fissura e o critério de Griffith}

No processo de propagação da fissura, mesmo que o sólido esteja submetido a um carregamento estático, o próprio movimento da fissura gera a necessidade da inclusão no balanço, de uma parcela de energia cinética, algo que, como se viu, não 
foi cogitado por Griffith, na formulação de seu critério. A análise que a seguir se desenvolve, busca considerar também o aspecto dinâmico do processo, em uma formulação ainda não completamente geral, mas adequada à fixação de conceitos importantes para a generalização a ser realizada na seção seguinte.

Seguindo-se os mesmos passos da seção anterior, usados na interpretação termodinâmica que conduziu ao critério termodinâmico de Griffith, ainda considerando, somente para simplificar, o problema plano $^{4}$, vai-se substituir a energia superficial específica, $\gamma$, parâmetro do material obtido no caso de um processo quase estático, por outra, $\gamma_{\mathrm{d}}$, capaz de incorporar o aspecto dinâmico da propagação da fissura, denominada densidade dinâmica de energia superficial. Isso corresponde a um primeiro passo, no sentido da completa generalização do parâmetro $\gamma$, a ser feita adiante. A grandeza $\gamma_{\mathrm{d}}$ é como se fosse a anterior energia superficial específica, $\gamma$, acrescida de uma componente cinética, relacionada com o avanço da fissura. Nessa versão, para fazer-se o balanço energético local, basta que se tome a eq.(3.4) e adicione a seu primeiro membro uma parcela $\mathrm{d} \kappa$, correspondente à energia cinética. Essa parcela dará conta dos efeitos inerciais, ao nível local, no volume do sólido. Assim sendo:

$$
\mathrm{d} \varepsilon+\mathrm{d} \kappa=\mathrm{d}^{\prime} q+\mathrm{d}^{\prime} w .
$$

Procedendo-se de maneira análoga ao caso anterior, obtém-se, então, a versão global da eq.(3.12), válida para o volume total do corpo:

$$
\int_{\mathrm{V}} \mathrm{d} \varepsilon \mathrm{d} V+\int_{\mathrm{V}} \mathrm{d} \kappa \mathrm{d} V=\int_{\mathrm{V}} \mathrm{d}^{\prime} w \mathrm{~d} V+\int_{\mathrm{V}} \mathrm{d}^{\prime} q \mathrm{~d} V-4 \gamma_{d} \mathrm{~d} a
$$

Refazendo-se, a partir da eq. (3.13), uma seqüência similar à realizada no desenvolvimento que levou a eq. (3.5) à eq. (3.11), chega-se a:

$$
-\mathrm{d} E_{\mathrm{d}}+\int_{V} \mathrm{~d} \kappa \mathrm{dV}>4 \gamma_{d} \mathrm{~d} a
$$

\footnotetext{
${ }^{4}$ Embora o raciocínio esteja sendo desenvolvido para um problema plano, a extensão para os problemas tridimensionais pode ser feita sem dificuldade.
} 
expressão que representa a versão do critério termodinâmico de Griffith em que o aspecto dinâmico do processo é considerado.

Comparada com a eq.(3.11), a eq.(3.14) revela que a influência dinâmica sobre o processo de fissuração faz-se, no primeiro membro dessa última, pela presença de uma integral que representa a energia cinética do volume do sólido, e no segundo membro, através de $\gamma_{d}$, uma grandeza influenciada também pela energia cinética dos pontos da superfície de avanço da fissura.

\subsection{Critério termodinamicamente consistente de fratura}

O objetivo desta seção é a análise da possibilidade de um critério de fratura, o mais geral possível, capaz, de prever, tanto o início da fratura quanto o caminho a ser seguido por uma fissura, após iniciado seu processo de crescimento. A base para a construção do critério geral é o balanço de energia no sólido fraturado, que deve levar em conta, por um lado o que ocorre no volume, e por outro, o fenômeno desenvolvido na superfície de avanço da fissura. Tudo se comporta como se houvesse um limite máximo de dissipação energética capaz de ser acomodado pelo material. Acima desse limite, medido com o auxílio da densidade termodinâmica superficial de energia, $\gamma^{*}$, na sua forma mais geral, dada pela eq. (2.83), a resposta do material poderia ser na forma de um processo orientado segundo determinada direção, que poderia levar ao avanço de uma fissura. Convém observar que a análise será formalmente realizada em uma parte do sólido contendo inicialmente um só vazio preexistente. Partindo-se do pressuposto, bastante factível, de que o número de fissuras desenvolvidas no sólido seja finito, sempre será possível isolar-se uma subregião em cujo interior só haja uma fissura. Isso não impede, entretanto, que após o início do processo, outra fissura venha a penetrar no domínio da região em estudo.

Outra questão importante, no contexto do presente estudo, diz respeito à consideração de outras causas de dissipação, que não as relacionadas imediatamente com a fratura. A pergunta chave seria: É possível isolar-se, no modelo, as causas de dissipação associadas à plasticidade e ao dano, da causa da fratura? A resposta, em primeira instância, seria a de que esse não parece ser um problema da formulação 
termodinamicamente consistente mas, pelo contrário, uma solução, na medida em que passa a existir agora, a possibilidade concreta de um modelo capaz de integrar os três fenômenos, compreendendo a plasticidade, o dano e a fratura como se fossem graus, em uma escala crescente, no rumo da perda da capacidade resistente do sólido.

No caso geral, agora tratado, não mais pode ser utilizada a interpretação baseada na energia livre de Helmholtz, porque ela só pode substituir a Segunda Lei da Termodinâmica quando o regime é isotérmico. O ponto de partida terá de ser, portanto, a equação de balanço global de entropia (2.67), obtida em termos da taxa de produção de entropia $\xi$, tal como definida pela eq. (2.73), na Seção 2.3. Assim, chega-se ao Princípio da Irreversibilidade, ou Desigualdade de Clausius-Duhem), no qual já se acha incorporada a Primeira lei da Termodinâmica:

$$
\int_{P_{t}} \rho \xi \mathrm{dv}=\int_{P_{t}} \rho\left(\dot{\eta}-\frac{r}{T}\right) \mathrm{dv}+\int_{s_{f}(t)} \frac{\mathbf{q} \cdot \mathbf{n}}{T} \mathrm{ds}+\int_{\partial P_{t}} \frac{\mathbf{q} \cdot \mathbf{n}}{T} \mathrm{ds} \geq 0
$$

sendo que $\xi$, é dada pela equação abaixo:

$\xi=\frac{\Lambda}{\rho T}-\frac{1}{\rho T^{2}} \mathbf{q} \cdot \operatorname{grad} T \geq 0$

onde

$\Lambda=\rho \dot{\eta} T+\mathbf{T}: \mathbf{D}-\rho \dot{\varepsilon}$.

$\Lambda$ é a de dissipação de energia por unidade de volume. A eq. (3.15) é, portanto, a expressão do critério geral de fratura, válido para o caso geral, inclusive em caso de regimes não isotérmicos. No caso do regime isotérmico, como já se viu, as eq. (3.11) e (3.14) são expressões mais simples que a (3.15), por valerem-se da metodologia que deu origem ao critério original de Griffith. Naqueles casos, exatamente por conta de o regime ser isotérmico, a Segunda Lei da Termodinâmica pode ser aplicada com o auxílio da afirmação equivalente, de que à ocorrência espontânea de um fenômeno associa-se uma diminuição da energia livre do sistema, energia livre que é a máxima parcela da energia interna capaz de ser transformada em trabalho. No caso do critério 
geral, da eq. (3.15), no entanto, usaram-se, diretamente, as equações dos balanços de energia e de entropia, apresentados no Capítulo 2. É evidente que sua aparência foge completamente da forma mais simples, obtida para o caso isotérmico. Convém observar que é a condição isotérmica que prevalece, na maioria dos fenômenos que ocorrem no meio ambiente, por conta de ser ele um reservatório térmico (v. Capítulo 1). A aparência simples, no caso dos critérios válidos para o caso isotérmico, deve-se, sem sombra de dúvida, à importante contribuição metodológica de Griffith.

Subjacente a esses critérios, pode-se pesquisar também a direção preferencial segundo a qual a fissura irá avançar. A orientação de tal avanço será fornecida, a partir do seguinte raciocínio: Se, ao crescimento da fissura está associada a diminuição da energia livre, sendo essa diminuição a menor possível, a direção (ou direções?) a ser seguida pela fissura, deve ser aquela que corresponda ao mínimo decréscimo dessa grandeza. Isso será aproveitado na elaboração do programa automático ELCFRAT (v. Anexo 5).

Por oportuno, vale recordar que, no caso em que a deformação do sólido ocorre sem a presença de fissura no meio, sendo o processo, por hipótese, reversível e isotérmico, tal como o analisado no final do Capítulo 1, a energia livre corresponde à parcela (e não à máxima parcela) da energia interna que pode ser transformada em trabalho. Nesse caso, e só nesse caso, como revela a eq. (1.14), a energia livre equivale à energia de deformação armazenada no sólido (ou o trabalho realizado pelas forças e momentos aplicados sobre ele).

Observe-se que as expressões (3.11), (3.14) e (3.15), que representam critérios de fratura, em diversos graus de generalidade, são condições suficientes, mas não necessárias, para o avanço da fissura. Isso porque outros fenômenos espontâneos, ocorridos no curso dos processos de deformação dos materiais, rumo á ruptura, podem-se constituir em causa de dissipação sem que, necessariamente, uma fissura se apresente.

Até o presente capítulo, a ênfase foi colocada no aperfeiçoamento do modelo físico do fenômeno da fratura, buscando-se tratar o problema a partir da constatação 
da irreversibilidade do processo de fissuração. Os critérios de iniciação de fissura utilizados até agora na Mecânica da Fratura, a rigor, não incluem a consideração da irreversibilidade. A decisão de tomar-se esse partido, traz como conseqüência a exigência de modelos matemáticos e esquemas numéricos que permitam a obtenção aproximada de resultados úteis à resolução dos inúmeros problemas tecnológicos identificados no crescente campo de aplicação da Mecânica da Fratura. Sem a intenção de esgotar o conjunto de possibilidades abertas com a formulação termodinamicamente consistente da fratura, a busca de soluções aproximadas, a ser encetada a partir do próximo capítulo, estará baseada na utilização de um recurso recente, advindo de uma adaptação à Mecânica da Fratura, da Análise de Sensibilidade à variação de forma, uma técnica própria da Otimização Estrutural. Essa ferramenta, já utilizada com sucesso no cálculo da integral $J$, via Método dos Elementos Finitos, adiante será adaptada para o cálculo da variação da energia de deformação, considerada como o parâmetro decorrente da análise termodinâmica da fratura, obtida com o auxílio do Método dos Elementos de Contorno. 


\section{CAPÍTULO 4}

\section{A ANÁLISE DE SENSIBILIDADE APLICADA NA OBTENÇÃO DA DERIVADA MATERIAL DA ENERGIA DE DEFORMAÇÃO}

No Capítulo 3 chegou-se ao critério termodinâmico geral de fratura, representado pela desigualdade (3.15). A consistência termodinâmica faz com que, em tese, esse critério seja capaz de dar conta do problema da fratura em um sólido deformável qualquer, sujeito às ações mais gerais, incluindo as de caráter térmico e dinâmico. Neste capítulo, no entanto, o critério de fratura será particularizado para o caso das eq. (3.10), ou mesmo (3.14), que correspondem a situações em que o processo é isotérmico.

A aplicação da Análise de Sensibilidade à Mecânica da Fratura, como se verá, é útil para resolver o problema do cálculo da energy release rate, ou integral $J$, de uma maneira mais geral que a tradicional, gerada a partir da definição original de RICE (1968). Aqui, será aproveitada a metodologia da Análise de Sensibilidade, para o cálculo do parâmetro termodinâmico de fratura, $G_{\mathrm{t}}$, identificado com a variação da energia de deformação, quando varia o parâmetro geométrico da fissura.

Antes, porém, será feito um ligeiro apanhado sobre a integral $J$, de Rice. O paralelo entre a metodologia de interesse do presente trabalho e a do cálculo da integral $J$, seguirá por todo o desenvolvimento deste trabalho, tanto que o mesmo programa automático, via Método dos Elementos de Contorno, será utilizado para o cálculo aproximado da integral $J$, e do parâmetro $G_{\mathrm{t}}$ (v. Capítulo 5). Ressalte-se que a formulação aqui obtida é absolutamente geral, valendo para o caso de problemas tridimensionais, e podendo ser estendida para problemas dinâmicos. No entanto, o 
cálculo automático será realizado para o caso particular do problema bidimensional, quase-estático e em regime isotérmico. O que será mostrado, servirá mais para a fixação de conceitos relacionados com a nova proposta, do que para explorar todas as suas potencialidades.

\subsection{A integral $J$ de Rice}

Para o estudo da fratura em problemas da elasticidade plana, RICE (1968) introduziu uma integral independente do caminho, conhecida como integral $J$. Nesse mesmo trabalho, mostrou também que a ela está associada a grandeza que Irwin denominou energy release rate, $G$, correspondente ao caso de uma chapa, com cargas situadas no plano médio, contendo uma fissura. Para criar a noção de integral $J$, Rice afirma ter se inspirado no tensor momentum-energia, definido por ESHELBY (1956) “como um ente matemático capaz de caracterizar as forças generalizadas nas discordâncias e nos defeitos pontuais em campos elásticos" (RICE, 1968, p.379). A integral $J$ seria, segundo seu criador, a componente estática desse tensor.

No trabalho de Rice, a integral $J$ é definida para o caso plano, através da seguinte expressão:

$J=\int_{\Gamma}\left(\phi d x_{2}-\mathbf{t} \cdot \frac{\partial \mathbf{u}}{\partial x_{1}} d \Gamma\right)$

onde

$\phi=\phi(\varepsilon)=\int_{0}^{\varepsilon} T_{i j} d \varepsilon_{\mathrm{ij}}$

é a densidade de energia de deformação. Na integral da eq. (4.1), $\Gamma$ é uma curva arbitrária e regular, que se desenvolve em torno da extremidade da fissura. Percorrida a curva no sentido anti-horário, a região interna fica sempre à esquerda do observador, sendo o vetor normal unitário, em qualquer ponto de $\Gamma$, orientado para fora. Ao vetor deslocamento u está associado o tensor de deformação infinitesimal $\varepsilon=\left[\varepsilon_{i j}\right]$. O vetor de tensão de Cauchy é notado por $\mathbf{t}$ (traction), e $\mathrm{d} \Gamma$ é o comprimento do elemento de arco do caminho $\Gamma$. 
Havendo uma fissura no interior da região contornada por $\Gamma$, a integral $J$ capta um campo local associado ao estado tensional da extremidade da fissura. Caso contrário, não havendo fissura no interior da região, a integral $J$ se anula.

A principal vantagem do uso da integral $J$ está em sua propriedade de independência do caminho. Isso permite a escolha de curvas $\Gamma$ distantes da zona perturbada, de tal forma que os campos envolvidos no cálculo da integral $J$ possam ser determinados com melhor precisão, porque aí o material, caracterizado através de uma função densidade de energia, tem um comportamento mais suave, i. e., menos influenciado pelos efeitos da alta concentração das tensões na vizinhança da extremidade da fissura. A rigor, a integral $J$ só pode ser calculada se o caminho de integração for constituído de pontos nos quais seja possível definir-se uma função densidade de energia de deformação.

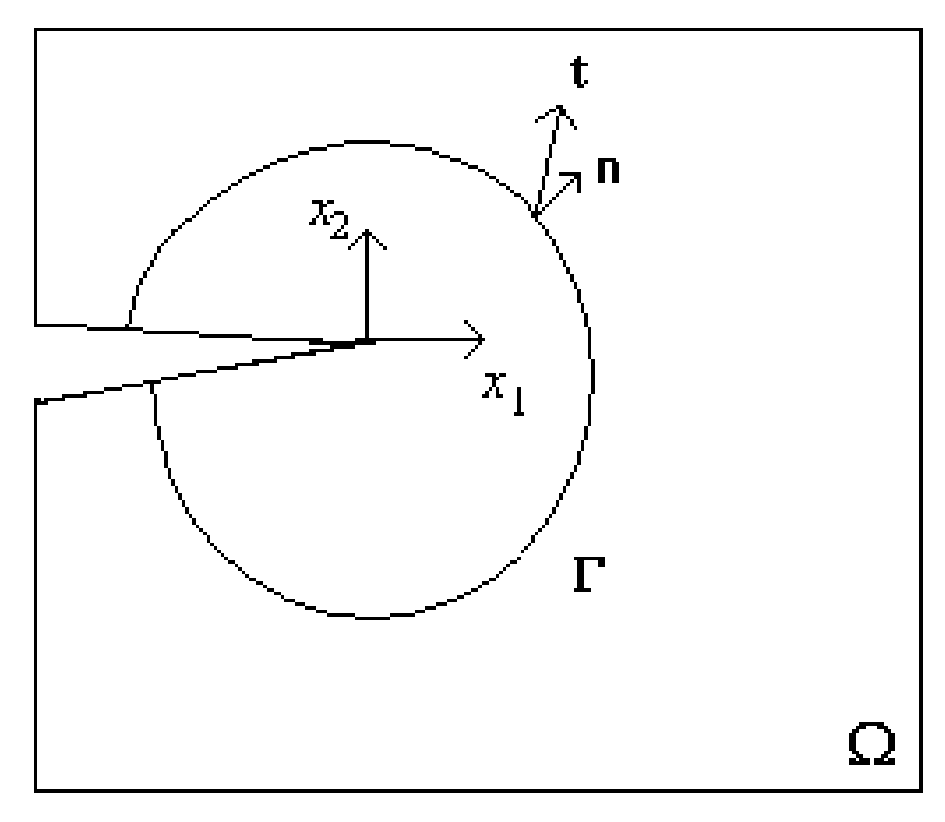

FIGURA 4- FISSURA RETA CRESCENDO NA DIREÇÃO $x_{1}$

As hipóteses admitidas por Rice, para a obtenção da integral $J$, segundo CUNHA et al.(1995), podem ser assim sintetizadas:

1. O material é hiperelástico, ou seja, é caracterizado por uma função densidade de energia, $\phi$, que é um potencial a partir do qual podem ser obtidas as componentes do tensor de tensão, isto é: 


$$
T_{i j}=\frac{\partial \phi}{\partial \varepsilon_{i j}}
$$

2. Não existem deformações iniciais, nem cargas no domínio, havendo somente cargas aplicadas no contorno, e as bordas da fissura estão livres de tensões;

3. A fissura inicial é reta e se propaga na mesma direção;

4. A base de referência $\left(\mathbf{e}_{1}, \mathbf{e}_{2}\right)$ é ortogonal e $\mathbf{e}_{1}$ coincide com a direção da fissura, como está indicado na Figura 4.1.

Restringindo-se ao problema bidimensional, levando-se em conta, na eq. (4.1), as relações:

$$
\mathrm{d} x_{2}=\mathbf{n} . \mathbf{e}_{1} \mathrm{~d} \Gamma, \quad \mathbf{t}=\mathrm{Tn} \quad \mathrm{e} \quad \partial \mathrm{u} / \partial \mathrm{x}_{1}=(\nabla u) \mathbf{e}_{1},
$$

e usando-se a definição de tensor transposto, então:

$$
J=\int_{\Gamma}\left[\phi \mathbf{n} . \mathbf{e}_{1}-\mathbf{T n} \cdot(\nabla u) \mathbf{e}_{1}\right] d \Gamma=\mathbf{e}_{1} \cdot \int_{\Gamma}\left[\phi \mathbf{I}-\nabla \mathbf{u}^{T} \mathbf{T}\right] \mathbf{n} d \Gamma=\mathbf{e}_{1} \cdot \int_{\Gamma} \Sigma \mathbf{n} d \Gamma
$$

onde $\Sigma=\phi \mathbf{I}-\nabla \mathbf{u}^{\mathrm{T}} \mathbf{T}$ é conhecido como o tensor momentum-energia de Eshelby.

A energy release rate $G$, apresentada no Capítulo 3, é definida como o valor simétrico da variação da energia potencial elástica do sólido, por unidade de área do avanço de uma fissura. Interpretada por Irwin como uma força (por unidade de área), associada ao crescimento da fissura, $G$ tem sido calculada para cada um dos três modelos clássicos da Mecânica da Fratura: de abertura, de cisalhamento e de rasgamento. A comparação entre esses valores de $G$ (obtidos através de métodos exatos, ou de métodos aproximados) com seus valores críticos, por sua vez relacionados aos fatores de intensidade de tensão críticos, formam o quadro de referência tradicional utilizado na aferição da integridade estrutural dos sólidos e estruturas, fundamentada na Mecânica da Fratura.

A interpretação termodinâmica do fenômeno da fratura evidencia, no entanto, a necessidade da introdução de uma nova grandeza que, diferentemente da tradicional $G$, esteja associada à dissipação de energia ocorrida com a quebra de ligações 
materiais que provoca o avanço da fissura. Como adiante se justificará, essa nova grandeza deve ser calculada a partir da variação da energia de deformação, e não da variação da energia potencial elástica, como supõe-se que Griffith tenha indicado, para a obtenção de G.

Nesse particular, convém esclarecer que, em seu trabalho pioneiro de 1920, embora tenha definido uma grandeza, por ele denominada energia potencial total, como a soma da energia potencial elástica com a energia superficial desenvolvida nas faces da fissura, Griffith produz uma certa confusão, ao usar, de fato, a energia de deformação, e não a energia potencial elástica, nos cálculos para a obtenção de seu conhecido critério. Ver GRIFFITH, 1920, p. 169, eqs. (4.7) a (4.10). Ressalte-se ainda que, no seu trabalho de 1924, Griffith continua a defender o uso da energia potencial elástica, como base para a construção de seu conhecido critério. A razão desse segundo trabalho, aliás, é quase que só para apresentar a expressão corrigida do primeiro membro da inequação que representa o critério (somente um coeficiente de Poisson é eliminado da fórmula original, nessa correção). Aí, Griffith assegura que o erro cometido no primeiro trabalho deveu-se somente a um equívoco que cometera em uma passagem matemática. Embora não seja mostrado o desenvolvimento matemático responsável pela correção, é certo ${ }^{1}$ que ele tenha continuado a referir-se, de fato, à energia de deformação, e não à energia potencial elástica, embora sempre afirmando o contrário!.

O fato de não se ter apercebido desse equívoco, de 1920 até agora, parece ser explicável somente por achar-se que a sugestão de Griffith estaria de acordo com a extensão natural de um princípio de uso bastante generalizado na Mecânica dos Materiais, a saber o Princípio da mínima energia potencial elástica (chamado, por

\footnotetext{
${ }^{1}$ A certeza baseia-se num fato ainda pouco conhecido da história da Mecânica da Fratura: Trata-se do surgimento do trabalho "Zur Bruchtheorie von A. Griffith", de 1923, cujo autor, K. Wolf, o enviou ao criador da Mecânica da Fratura, sugerindo a correção, que foi feita no trabalho de 1924, embora sem a referência explicita de Griffith.
} 
Griffith, de Princípio da mínima energia potencial total). Como pode ser verificado através da leitura cuidadosa de seus dois citados trabalhos, Griffith não definiu de maneira muito precisa, a natureza da energia associada ao avanço da fissura, acreditando que não seria problemático tomá-la como se fosse uma parcela com caráter de energia potencial. Não atentou, porém, para o fato de que, para a fissura crescer, teria de ocorrer uma dissipação de energia, que não pode, evidentemente, ser enquadrada como energia potencial, no sentido estrito da expressão ${ }^{2}$. Isso só seria possível se ocorresse a reversibilidade da fissura, fazendo com que pudesse voltar a sua situação original, cessado o carregamento. Imagine-se, por exemplo, que existissem molas lineares ligando pontos opostos, nas duas faces de uma fissura inicial, antes de ela começar a crescer. Se as molas, por hipótese os únicos elementos responsáveis pelo controle da abertura da fissura, pudessem manter-se íntegras e elásticas, de modo que, ao serem retiradas as ações sobre o sólido, ele voltasse a seu estado inicial, então, essa parcela de energia poderia ser considerada como potencial, totalmente recuperável, portanto. Mas, se pelo menos algumas molas se rompessem, para assim ficar caracterizado o avanço do processo de fissuração, não mais seria possível desprezar-se a parcela de energia dissipada, evidentemente não recuperável e, portanto, não associável a um potencial.

Como fica bastante bem evidenciado em TAROCO (1996), o conceito de integral $J$ está diretamente relacionado com a idéia de Griffith, de estender o Princípio da Energia Potencial Elástica para o estudo da fratura. E nos trabalhos clássicos de KNOWLES \& STERNBERG (1972) e GURTIN (1979), fica evidente a necessidade de que o caminho de integração usado para o cálculo de $J$, esteja totalmente inserido em uma região hiperelástica. Além disso, esses últimos trabalhos associam a idéia de ESHELBY (1956), base para a concepção da integral $J$ de Rice, ao Teorema de Noether, segundo o qual pode-se partir da propriedade da invariância, em relação a determinados parâmetros, de funcionais associados a princípios variacionais, para a obtenção de algumas leis de conservação da Mecânica, tais como a da conservação de energia e da quantidade de movimento linear, NOETHER

\footnotetext{
${ }^{2}$ Diz-se no sentido estrito, porque hoje utiliza-se a expressão potencial simplesmente para representar alguma grandeza cuja derivada serve para definir uma outra. No sentido original, dado por George
} 
$(1918)^{3}$ apud LANCZOS (1986). Com o auxílio desse raciocínio fica resolvida, também, a questão da legitimidade do uso da integral $J$ quando se leva em conta a acomodação plástica ocorrida na vizinhança da extremidade de uma fissura: para todos os efeitos, $J$ e $G$ sempre coincidem, e têm sua legitimidade garantida, desde que o caminho de integração sobre o qual seu cálculo seja feito, esteja imerso em uma região hiperelástica do sólido, da qual exclui-se, naturalmente, a vizinhança plastificada em torno da extremidade da fissura.

É difícil a obtenção de soluções fechadas, tanto para o cálculo de $G$ (a partir da energia potencial elástica), quanto para o aqui denominado parâmetro termodinâmico de fratura, $G_{\mathrm{t}}$ (a partir da energia de deformação). Essa dificuldade vem sendo superada, no entanto, a partir do cálculo indireto de $G$, auxiliado por uma técnica recente, baseada na aplicação à Mecânica da Fratura, da Análise de Sensibilidade á variação de forma, originária da área de Otimização Estrutural. Tal técnica vale-se da analogia existente entre o problema da fratura e um outro, no contexto da otimização estrutural, no qual é estudado o efeito particular da variação da forma do domínio do sólido, e de seu contorno, em relação a um determinado parâmetro real. Utilizando-se, no essencial, o desenvolvimento matemático contido em TAROCO (1996), para o cálculo de $G$, passa-se à apresentação dessa técnica, visando a obtenção de uma medida da sensibilidade da energia de deformação em relação a um parâmetro do domínio. Tal parâmetro, como à frente se verá, é concebido de uma maneira que, com o auxílio de sua variação, pode-se simular o avanço da fissura.

\subsection{Derivada material da energia de deformação}

O desenvolvimento que se segue, baseia-se na análise de sensibilidade á variação de forma, cujos fundamentos são apresentados no Anexo C. A base para as operações matemáticas que se seguem, encontra-se também nos Anexos A e B.

Green, e aqui adotado, só tem sentido falar-se em potencial no caso de sistemas conservativos.

${ }^{3}$ NOETHER, E.(1918). Invariante Variationsprobleme. Goett Nachr. p.235-257 apud LANCZOS,

C.(1986). The Variational Principles of Mechanics. $4^{\mathrm{a}}$ ed. New York. Dover Publications, p.384. 
Para cada forma do corpo, associada ao domínio parametrizado $\Omega_{\tau}$, expressa-se a energia de deformação, $E_{\mathrm{d} \tau}$, como:

$E_{d \tau}=\int_{\Omega} \phi_{\tau} \mathrm{d} \Omega_{\tau}$

onde $\phi_{\tau}$ é a energia de deformação específica associada ao domínio $\Omega_{\tau}$.

Para obter-se a taxa de variação da energia de deformação armazenada no sólido, quando o domínio sofre modificação, é necessário derivar ambos os membros da eq.(4.4) em relação ao parâmetro $\tau$. Após, calcula-se o valor da derivada quando o valor desse parâmetro é zero, o que fornece a medida da tendência de evolução da energia de deformação do sólido, na configuração considerada. A derivação em relação ao parâmetro $\tau$ guarda analogia com a derivação material no tempo, usada no balanço termomecânico, da Mecânica do Contínuo. Os Anexos A e B contêm os resultados da Análise Tensorial, úteis ao desenvolvimento matemático que se segue.

A derivada $\dot{E}_{d}$, da energia de deformação em relação a $\tau$, em $\tau=0$, é uma grandeza associada ao sólido real, ou melhor, à configuração atualizada do sólido real, e mede a sensibilidade dessa configuração, em relação à variação de forma do domínio. $\dot{E}_{d}$ pode ser obtida da mesma forma como se calcula a derivada material no tempo, da Mecânica do Contínuo. Assim:

$\dot{E}_{d}=\left.\frac{\mathrm{d} E_{d \tau}}{\mathrm{d} \tau}\right|_{\tau=0}=\int_{\Omega}(\dot{\phi}+\phi \operatorname{div} \mathbf{v}) \mathrm{d} \Omega$

Ainda conforme o Anexo B:

$\dot{\phi}=\phi^{\prime}+\nabla \phi . \mathbf{v}$.

Considerando-se a simetria de $\mathbf{T}$ e usando da comutatividade entre operações lineares, tem-se: 
$\phi^{\prime}=\frac{\mathrm{d} \phi}{\mathrm{d}\left(\nabla \mathbf{u}^{\mathrm{s}}\right)}: \nabla \mathbf{u}^{\prime} \mathrm{S}=\mathrm{T}: \nabla \mathbf{u}^{\prime \mathrm{S}}=\mathbf{T}: \nabla \mathbf{u}^{\prime}$

Então a eq. (4.5) fica:

$\dot{E}_{d}=\int_{\Omega}\left(\mathbf{T}: \nabla \mathbf{u}^{\prime}+\nabla \phi \cdot \mathbf{v}+\phi \operatorname{div} \mathbf{v}\right) \mathrm{d} \Omega$.

Mas, de acordo com o resultados expressos pelas eqs. (A.89b) e (A.89d):

$\mathbf{T}: \nabla \mathbf{u}^{\prime}=\operatorname{div}\left(\mathbf{T} \mathbf{u}^{\prime}\right)-\mathbf{u}^{\prime} \cdot \operatorname{div} \mathbf{T}$

e

$\nabla \phi \cdot \mathbf{v}+\phi \operatorname{div} \mathbf{v}=\operatorname{div}(\phi \mathbf{v})$

cuja substituição na eq. (4.8) conduz a:

$\dot{E}_{d}=\int_{\Omega}\left[\operatorname{div}\left(\mathbf{T} \mathbf{u}^{\prime}\right)-\mathbf{u}^{\prime} . \operatorname{div} \mathbf{T}+\operatorname{div}(\phi \mathbf{v})\right] \mathrm{d} \Omega$.

Aplicando-se o teorema de Gauss (da divergência) à primeira e à terceira parcelas da integral do segundo membro da eq. (4.11), vem:

$\dot{E}_{d}=\int_{\partial \Omega}\left[\mathbf{T} \mathbf{u}^{\prime} \cdot \mathbf{n}+\phi \mathbf{v} \cdot \mathbf{n}\right] \mathrm{d} \partial \Omega-\int_{\Omega} \mathbf{u}^{\prime} \cdot \operatorname{div} \mathbf{T} \mathrm{d} \Omega$.

Adotando-se o vetor das forças de corpo como identicamente nulo, e levando-se em conta o equilíbrio do sólido, então $\operatorname{div} \mathbf{T}=\mathbf{0}$, e a eq. (4.12) fica:

$\dot{E}_{d}=\int_{\partial \Omega}\left[\mathbf{T} \mathbf{u}^{\prime} \cdot \mathbf{n}+\phi \mathbf{v} \cdot \mathbf{n}\right] \mathrm{d} \partial \Omega$.

Em virtude da simetria de $\mathbf{T}$, e considerando-se as definições de tensor transposto e de tensor identidade (Anexo A), tem-se, finalmente:

$\dot{E}_{d}=\int_{\partial \Omega}\left[\mathbf{T n} \cdot \mathbf{u}^{\prime}+(\phi \mathbf{I}) \mathbf{n} \cdot \mathbf{v}\right] \mathrm{d} \partial \Omega$. 
Essa expressão fornece, pois, a derivada material no parâmetro $\tau$, em $\tau=0$, da energia de deformação armazenada no sólido. Os campos $\mathbf{T}, \phi$ e $\mathbf{u}^{\prime}$, aí presentes, estão associados ao estado inicial, i. e., ao sólido não perturbado pela variação de forma $(\tau=0)$. $\mathbf{T}$ e $\phi$ correspondem, portanto, à configuração do sólido associada a $\tau=0$. Quanto ao campo $\mathbf{u}^{\prime}$, verifica-se que adquire uma forma especial, relacionada com à estratégia utilizada para a simulação do avanço da fissura, com auxílio da Análise da Sensibilidade, tema que será tratado a seguir.

\subsection{A simulação do avanço da fissura, via Análise de Sensibilidade}

Conforme ilustrado através das Figuras 5 e 6, o avanço da fissura será simulado com auxílio de uma translação dos pontos do sólido e de sua fronteira, de modo que, para todos os pontos de $\Gamma, \mathbf{v}=\mathbf{- e}$ e, para todos os pontos de $\Gamma_{\mathrm{T}}, \mathbf{v}=\mathbf{0}$, tal como se a fissura estivesse parada, e a fronteira $\Gamma$ estivesse em movimento, dirigindo-se para ela em sentido inverso ao da propagação.

Assim, pode-se provar (v. Anexo C) que, $\mathbf{u}^{\prime}=\mathbf{0}$, tanto em $\Gamma$, como em $\Gamma_{\mathrm{T}}$. A exigência sobre $\mathbf{v}$, relembrando, é que seja um campo definido em $\Omega$, capaz de simular a perturbação causada no sólido por uma fissura, não necessariamente reta, de comprimento característico inicial igual a $a_{0}$, partindo do contorno $\partial \Omega$, e evoluindo segundo a orientação dada pelo vetor unitário e, Figura 5.

Como antes já foi dito, a extensão $\Gamma_{\mathrm{T}}$, do contorno da parte $P$, é tomada tão próximo à extremidade da fissura, quanto seja necessário para o isolamento de uma região $\Omega_{\mathrm{o}}$, a ela solidária, de forma a garantir que $P$ esteja, completamente, em uma região hiperelástica. Os limites dessa região são implicitamente estabelecidos em função da extensão da zona de acomodação plástica, típica da vizinhança da extremidade da fissura. Isso corresponde a uma simulação bastante razoável do movimento da fissura, cuja orientação é dada pelo vetor unitário e que, como se verá no Capítulo 5, será considerado de orientação inicialmente variável, cuja definição será dada em função da condição de mínima variação da energia livre. Para completar-se o contorno fechado da parte $P$, passa-se a analisar como seria a 
descrição adequada para o campo v, nas partes planas do contorno de $P$, i. e, em $\Gamma^{+}$e em $\Gamma^{-}$, e assim completar-se o modelo.

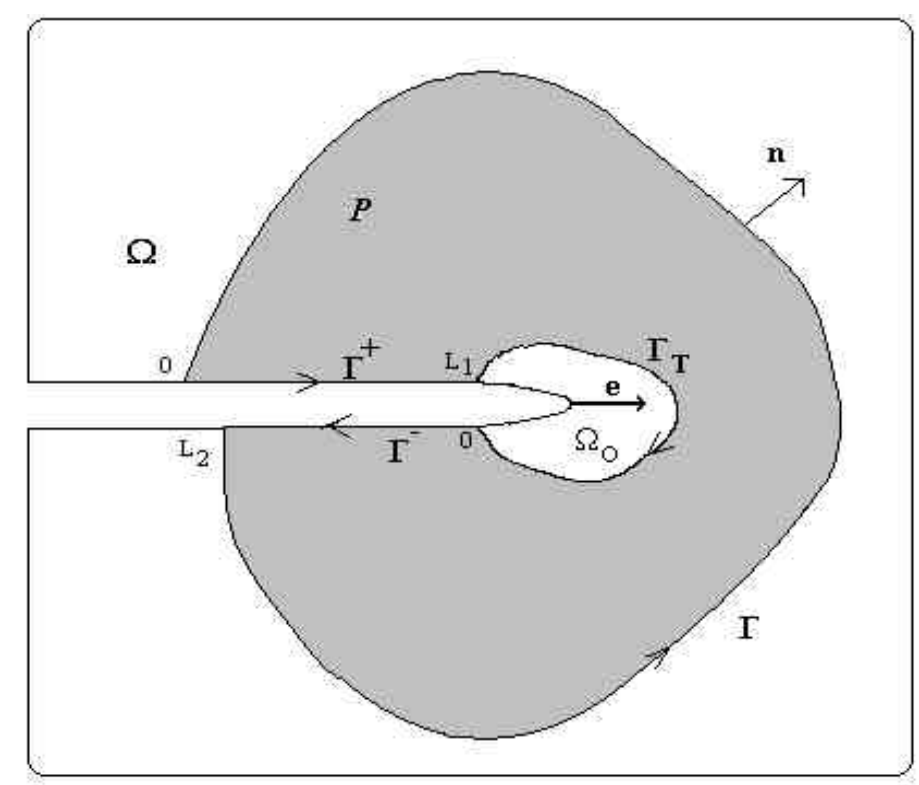

\section{FIGURA 5 - A DELIMITAÇÃO DA PARTE $P$ E O AVANÇO DA FISSURA}

Admite-se, por necessidade, que as tractions nas faces da fissura devem ser nulas, isto é, $\mathbf{T n}=\mathbf{0}$, em $\Gamma^{+}$e $\Gamma^{-}$. Por conta do compromisso de manutenção da continuidade geométrica, será aqui adotado um campo de translações $\mathbf{v}$, variável segundo uma lei linear, em $\Gamma^{+}$e $\Gamma^{-}$, de tal modo que seu valor seja nulo nas intercessões de $\Gamma^{+}$e $\Gamma^{-}$com $\Gamma_{\mathrm{T}}$, e igual a -e, nas intercessões $\Gamma$.

De acordo com o esquema acima exposto, Figura 5, o desdobramento da eq.(4.14) no contorno de $P$ fornece: 


$$
\begin{aligned}
\left(\dot{E}_{d}\right)_{P}= & \int_{\partial \mathrm{P}}\left[\mathbf{T n} . \mathbf{u}^{\prime}+(\phi \mathbf{I}) \mathbf{n} . \mathbf{v}\right] \mathrm{d} \partial \Omega=\int_{\Gamma}[\mathbf{T n} .(\mathbf{0})+(\phi \mathbf{I}) \mathbf{n} .(-\mathbf{e})] \mathrm{d} \Gamma+ \\
& \int^{L_{1}}\left[\mathbf{T n} . \mathbf{u}^{\prime}+(\phi \mathbf{I}) \mathbf{n} .\left(\frac{s-L_{1}}{L_{1}}\right) \mathbf{e}\right] \mathrm{d} \Gamma+\int_{\Gamma_{\mathrm{T}}}[\mathbf{T n} . \mathbf{0}+(\phi \mathbf{I}) \mathbf{n} . \mathbf{0}] \mathrm{d} \Gamma+ \\
& \quad \int^{L}\left[\mathbf{T n} . \mathbf{u}^{\prime}+(\phi \mathbf{I}) \mathbf{n} .\left(\frac{-s}{L_{2}} \mathbf{e}\right] \mathrm{d} \Gamma .\right.
\end{aligned}
$$

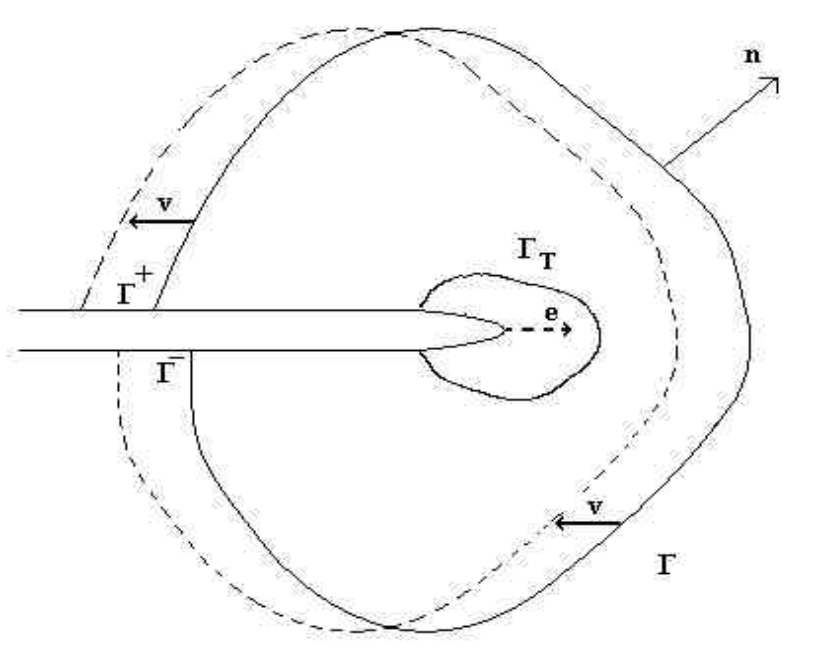

\section{FIGURA 6- SIMULAÇÃO DO AVANÇO DA FISSURA}

Observe-se que, na segunda e na quarta integrais do segundo membro da última equação, em virtude de $\mathbf{v}$ não ser um campo de translações constantes, nessas partes da fronteira de $P$, a derivada espacial $\mathbf{u}^{\prime}$ não foi substituída por $\mathbf{0}$, embora isso seja verdade nos limites das integrações. Daí a exigência de que sejam nulas as tractions em $\Gamma^{+}$e $\Gamma^{-}$, para que as parcelas (desconhecidas), envolvendo $\mathbf{u}^{\prime}$, desapareçam dessas integrais. Assim, a eq.(4.15) reduz-se a:

$$
\left(\dot{E}_{\mathrm{d}}\right)_{P}=\int_{\Gamma}(-\phi \mathbf{I}) \mathbf{n} . \mathbf{e d} \Gamma+b_{1} \int_{0}^{L_{1}}\left(\frac{s_{1}-L_{1}}{L_{1}} \phi\right) \mathrm{d} s-b_{2} \int_{0}^{L_{2}}\left(\frac{s_{2}}{L_{2}} \phi\right) \mathrm{d} s
$$

onde

$$
b_{1}=\text { n.e, constante em } \Gamma^{+} \text {, }
$$


$b_{2}=$ n.e, constante em $\Gamma^{-}$.

Como se observa na eq. (4.16), as duas últimas integrais do segundo membro são realizadas nos trechos planos da superfície do entalhe. Vê-se, portanto, que os valores de $b_{1}$ e $b_{2}$ serão nulos quando o avanço da fissura for na direção do vetor unitário e, que é normal ao vetor unitário n nessas superfícies. No caso da integral $J$, por definição, exige-se que o vetor e tenha sempre a direção paralela às faces do entalhe (supondo que o ângulo entre elas seja bem próximo de zero). No entanto, no caso de $G_{\mathrm{t}}$, isso, necessariamente, não ocorre, embora se possa admitir, com boa aproximação, no caso de entalhes de faces retas, que a contribuição das integrais nelas realizadas tende a se anular. No caso em que isso ocorre, a eq. (4.16) fica:

$$
\left(\dot{E}_{\mathrm{d}}\right)_{P}=\int_{\Gamma}(-\phi \mathbf{I}) \mathbf{n d} \Gamma . \mathbf{e} .
$$

Referida a uma parte $P$ do sólido contendo uma fissura, o valor simétrico da derivada material da energia de deformação, $\left(\dot{E}_{\mathrm{d}}\right){ }_{P}$, será doravante denominado parâmetro termodinâmico de fratura, sendo notado por $G_{\mathrm{t}}$.

Com base na estrutura da eq. (4.18), o programa automático também calculará a integral $J$, dada pela eq. (4.3), que pode ser obtida, segundo TAROCO (1996), como a derivada material da energia potencial elástica em relação ao parâmetro $\tau$, quando $\tau=0$. Para isso, basta a troca do tensor $(\phi I)$ da eq. (4.18), pelo tensor momentum-energia, $\Sigma$, da eq. (4.3).

Desprezadas as forças de corpo, e sob um regime quase estático e isotérmico, a eq.(4.16) é aplicável a qualquer parte $P$ do sólido que contenha uma fissura. Convém lembrar, também, que a eq. (4.18) foi deduzida com o intuito de permitir a análise do fenômeno desenvolvido na parte $P$ do domínio $\Omega$, partindo-se do que ocorre nos pontos do caminho regular $\Gamma$ que a delimita. Fica-se, portanto, com a liberdade de estendê-la, de modo a incluir pontos cada vez mais distantes da extremidade da fissura (alterando-se, por consequiência, o contorno $\Gamma$ ). 
E o que dizer sobre a fronteira $\Gamma_{\mathrm{T}}$, da Figura 5? Como se viu, na simulação do avanço da fissura via Análise de Sensibilidade, a translação dos pontos dessa fronteira é tomada como nula. Isto simula uma espécie de adesão dos pontos da região próxima da extremidade da fissura, ao provável movimento da mesma. Passase a usar, a propósito, a expressão zona de processo, tomada de empréstimo a HILLERBORG (1991), para caracterizar essa região plastificada, vizinha da extremidade da fissura. A delimitação estabelecida para $\Gamma_{\mathrm{T}}$, deve ser, portanto, aquela que seja capaz de assegurar, implicitamente, a vigência da condição hiperelástica em todos os pontos da parte $P \subset \Omega$, lembrando-se que ela é delimitada por $\Gamma, \Gamma_{\mathrm{T}}$, e também pelas faces da fissura, $\Gamma^{+}$e $\Gamma^{-}$, como na Figura 5.

Do ponto de vista da organização do programa automático para o cálculo de $J$ e de $G_{\mathrm{t}}$, o risco só estaria em escolher-se um caminho de integração $\Gamma$, de tal forma que algum de seus pontos estivessem fora da condição de hiperelasticidade. Assim, é necessário que se pesquise os limites da zona de processo da fissura. Obviamente, essa preocupação só tem sentido no caso em que, no programa automático, estiver incluído um modelo de elastoplasticidade, capaz de considerar a hipótese de acomodação plástica na vizinhança da extremidade da fissura.

\subsection{Discussão sobre o significado e a obtenção dos parâmetros $J$ e $G_{t}$}

A eq. (4.18) mostra que o parâmetro $G_{\mathrm{t}}$ está associado ao tensor $\phi \mathbf{I}$, que guarda certa semelhança formal com o tensor momentum-energia $\Sigma=\phi \mathbf{I}-(\nabla \mathbf{u})^{\mathrm{T}} \mathbf{T}$, TAROCO (1996). A partir do tensor $\Sigma$, a integral $J$ pode ser obtida mediante uma variante da equação (4.18), a eq. (4.3), como há pouco foi explicado. A integral $J$ coincide com a energy release rate $G$, quando o material é hiperelástico em toda a parte $P$. Válida esta última hipótese, sabe-se que a integral $J$ possui a propriedade de independência do caminho. Mas, essa propriedade só se verifica porque o vetor unitário e está orientado em uma direção paralela às faces do entalhe a partir do qual a fissura se desenvolve, como revela a eq. (4.3). Com maior grau de precisão e generalidade, isso é mostrado no trabalho de GURTIN (1969). 
Vale destacar a importante distinção entre os tensores $\phi \mathbf{I}$ e $\Sigma$, refletida nos respectivos parâmetros, $G_{\mathrm{t}}$ e $G$ (ou $J$ ), gerados a partir deles, como as respectivas projeções dos fluxos definidos na fronteira de $P$, sobre o vetor e. $\mathrm{O}$ que resulta, em geral, é que são calculados como integrais no contorno de uma parte arbitrária do sólido circundando a fissura (Figura 5). O tensor $\phi \mathbf{I}$, por um lado, surge em decorrência da interpretação termodinâmica do fenômeno da fratura, portanto, com base em um modelo que considera a dissipação de energia em $\Omega_{0}$, vizinhança da extremidade da fissura, quando esta sofrer um avanço. Tal tensor, como se viu, é calculado como a variação da energia de deformação da parte $P$, em relação ao parâmetro geométrico da fissura. Já o tensor $\Sigma$, não está associado à dissipação de energia, porque é obtido como a variação da energia potencial elástica do sólido, em relação ao mesmo parâmetro geométrico da fissura. Do ponto de vista prático, nisso se resume a diferença entre a abordagem com base na integral $J$, e a que aqui se desenvolve, baseada no parâmetro $G_{\mathrm{t}}$.

Em razão do extenso uso tecnológico de $J$ como parâmetro de fratura, e da introdução de $G_{\mathrm{t}}$ como uma alternativa, associada à formulação termodinamicamente consistente, cabe uma discussão comparativa. A propriedade de independência do caminho, de $J$, é atraente e importante, no entanto, convém observar que a obtenção dessa grandeza a partir de uma integral realizada sobre uma variedade bidimensional (ou superfície interna) do sólido, baseia-se no pressuposto de que a fissura avança segundo alguma direção que, necessariamente guarda relação com às faces da fissura prévia (essa relação é de paralelismo, no caso de uma fissura original de faces planas, por exemplo). A possibilidade da aplicação de um critério de integridade do sólido baseado nesse parâmetro, dependerá, naturalmente, da obtenção experimental de algum valor crítico, $J_{c}$, por exemplo, que deverá ser conseguido mediante um ensaio que seja capaz de reproduzir as mesmas características de crescimento da fissura, exigidas pela definição da integral $J$. Assim sendo, a rigor, a utilização dos dados experimentais só teria sentido, na avaliação da integridade, se a situação na qual a hipótese de crescimento da fissura, no sólido real, obedecesse estritamente à da 
integral $J$, isto é, que a fissura real precisaria crescer segundo uma direção paralela às faces da mesma.

Reconhece-se, evidentemente, a importância de $J$ que, se bem utilizada, pode ser um eficiente sensor da presença, ou ausência, de uma fissura em uma região fechada: no caso de o caminho de integração não circundar qualquer extremidade de fissura, seu valor é zero; caso contrário, é diferente de zero. Mas, do ponto de vista físico, a propriedade de independência do caminho não acrescenta à integral $J$, qualquer qualidade especial como, à primeira vista, parece fazê-lo. A propriedade da independência de caminho é, pois, simplesmente uma propriedade decorrente da concepção atribuída a Griffith, de que o Princípio da mínima energia potencial elástica pode ser estendido ao estudo da fratura. De outro modo, mais pelo lado estritamente matemático, aduzido pela interpretação advinda da Análise de Sensibilidade, no caso de uma fissura reta, a integral $J$ pode ser definida como a projeção (na direção original da fissura), do vetor fluxo do tensor de Eshelby, tomado sobre o caminho de integração. O certo é que, a invariância da integral $J$ não pode ser interpretada como se isso fosse uma propriedade do sólido, ou do material, como às vezes transparece, em aplicações simplificadas da Mecânica da Fratura, particularmente quando se trabalha com uma expressão assintótica, que relaciona integral $J$ com fator de intensidade de tensão. É claro que a base sobre a qual Rice a concebeu, o trabalho de ESHELBY (1956), por sua vez baseado no Teorema de Noether (1918), da Mecânica, deu à integral $J$ um suporte matemático sofisticado, embora isso não se possa afirmar, no que respeita ao suporte físico, porque assim só o seria, se fosse possível, de fato, a extensão do Princípio da mínima energia potencial elástica para o estudo da fratura, como queria Griffith (e também Irwin, que concebeu a idéia de força, a chamada força de Irwin, que seria a responsável pelo movimento da fissura). Isso quer dizer que Griffith, Irwin e Rice compõem a mesma vertente na história da Mecânica da Fratura, isto é, aquela que propõe a extensão do Princípio da mínima energia potencial elástica à Mecânica da Fratura. Ademais, conforme mostra TAROCO (1966), a integral $J$, sempre calculada sobre um caminho em cujos pontos o material tenha um comportamento hiperelástico, equivale à energy release rate $G$, de Irwin, e pode ser obtida com o auxílio da 
Análise de Sensibilidade, para o caso mais geral, tridimensional, como a derivada material da energia potencial elástica (energia de deformação menos o somatório dos produtos das ações externas pelos respectivos deslocamentos generalizados), em relação ao parâmetro $\tau$, em $\tau=0$.

Com todo respeito à relevante às contribuições anteriores, particularmente às dos três importantes pioneiros, Griffith, Irwin e Rice, referências básicas para a maior parte do que se produziu no campo dos estudos da fratura, o presente trabalho propõe-se a elaborar os desdobramentos advindos da substituição do Princípio da mínima energia potencial elástica, pela consideração da Primeira e da Segunda Leis da Termodinâmica, na análise do fenômeno da fratura.

A concepção da qual emerge o parâmetro $G_{\mathrm{t}}$ aqui obtido, que seria uma alternativa à integral $J$, tem sua legitimidade respaldada na idéia de um modelo físico do problema que inclui, como necessidade, a consideração do caráter dissipativo do processo de qualquer avanço de uma fissura. Inerente a essa concepção, a determinação de $G_{\mathrm{t}}$ estaria acoplada à obtenção da direção do avanço da fissura (ou do processo de dissipação), não precisando-se estabelecer a priori, portanto, como é feito na definição da integral $J$, a direção do avanço, como condição para a independência dessa grandeza, em relação ao caminho de integração.

Uma conseqüência prática desse fato, no caso da adoção da metodologia baseada no valor crítico, $\gamma_{\mathrm{E}}$, do parâmetro $G_{\mathrm{t}}$, seria, por exemplo, a de que não mais seria necessário exigir-se (como se exige na determinação de $J_{\text {ic }}$ e na construção de uma curva $J-R$ ), que um corpo de prova para um ensaio de fratura tivesse de conter uma pré-fissura de fadiga, sob um carregamento rigorosamente simétrico, para garantir um avanço da fissura sempre paralelo às suas faces originais.

Conquanto o resultado teórico, até aqui, seja geral, organizado para o caso de problemas tridimensionais, daqui em diante a análise será particularizada para o problema de uma chapa finita, em regime isotérmico e quase estático, contendo uma fissura iniciando-se no contorno. Será a oportunidade de se retomar o paralelo com a teoria original de Griffith, cujo desenvolvimento foi discutido no Capítulo 3, agora 
com base no resultado sintetizado através da eq.(4.18), útil inclusive ao propósito da determinação da direção preferencial de propagação da fissura.

Dentro dessa linha, organiza-se um programa automático (ELCFRAT), com o intuito de demonstrar as possibilidades de aplicação da presente proposta. $\mathrm{Na}$ verdade, a fronteira $\Gamma_{\mathrm{T}}$ (Figura 5), resulta, implicitamente, da exigência de que $P$ seja completamente hiperelástica. Enquanto isso, no interior de $\Omega_{0}$ o processo de deformação é complexo, sendo necessário adotar-se um modelo elastoplástico, para os pontos dessa região. Esta exigência não é cumprida pelo citado programa automático ELCFRAT. Mais adiante, resultados são apresentados com o auxílio de um programa mais completo (modelo elastoplástico, elemento de contorno isoparamétrico quadrático, para problemas planos), adaptado para o caso aqui estudado, que foi cedido gentilmente pelo Prof. Humberto Coda, do Departamento de Engenharia de Estruturas da USP/São Carlos.

A experimentação numérica aqui desenvolvida, com a utilização do Programa ELCFRAT (Anexo E), organiza-se com base no que consta do Capítulo 5. Faz uso de um modelo de elemento de contorno reto, isoparamétrico, cujo aumento da eficiência numérica foi conseguido com auxílio de uma técnica de sub-elementação, também desenvolvida no presente trabalho. O programa ELCFRAT realiza, tanto o cálculo de $J$, quanto o de $G_{\mathrm{t}}$, em regime elástico. Corresponde, portanto, a um programa que só cumpre o propósito de mostrar a simplicidade do processo de determinação dessas duas grandezas, utilizando-se o BEM.

A comprovação da independência do caminho da integral $J$ é fácil de ser demonstrada, porque, para a escolha de caminhos de integração, utiliza-se a vocação natural do BEM para o cálculo de integrais sobre variedades. Para a avaliação prática da integridade dos sólidos, com o uso do critério termodinâmico apresentado no Capítulo 3 e sintetizado na eq. (3.10), seria necessária a determinação experimental de $\gamma_{\mathrm{E}}$. No entanto, a experimentação numérica auxiliada pelo programa ELCFRAT, revela que é possível avançar-se um pouco, mesmo sem o conhecimento 
experimental do parâmetro crítico: um processo iterativo incluído no programa, permite que se chegue, para cada problema particular, a um valor de $G_{\mathrm{t}}$ que, se ultrapassado, levará à instabilidade da fissura. O assunto será explorado no capítulo 7, no qual são apresentados exemplos numéricos a respeito.

Convém repetir que a determinação, tanto de $G($ ou $J)$, quanto de $G_{\mathrm{t}}$, com o auxílio da na Análise de Sensibilidade, exige a validade da hipótese de que o material seja hiperelástico na parte $P$ do sólido em análise. Já a sub-região $\Omega_{\mathrm{O}}$, considerada solidária à extremidade da fissura, enquanto esta se movimenta, não precisa ter seus limites conhecidos a priori, para efeito de aplicação da Análise de Sensibilidade. Esta observação serve para mostrar como a metodologia baseada na Análise de Sensibilidade soluciona uma questão que é muito freqüente na literatura, a respeito da utilização da integral $J$ (e $G_{\mathrm{t}}$, por extensão) em problemas elastoplásticos. A rigor, $J$ e $G_{\mathrm{t}}$ só podem ser calculados em uma região hiperelástica. Por seu turno, a zona de processo da fissura, $\Omega_{0}$, não hiperelástica por definição, sempre situa-se, estrategicamente, fora da parte $P$. Um programa automático que incorpore modelos elastoplásticos faz-se necessário, portanto, para que se delimite os pontos dessa região, balizando assim o caminho de integração, que deve estar todo contido no exterior de $\Omega_{\mathrm{o}}$

\subsection{Particularização de $G_{t}$ para o caso de uma chapa de espessura constante contendo uma fissura iniciando-se no contorno}

O sentido do que se segue, é traçar um paralelo entre a metodologia aqui proposta, e o critério de iniciação de fratura de Griffith, propondo-se o exemplo de uma chapa de espessura constante, como tal representada por uma região plana, $\Omega$, correspondente ao plano médio, e com um carregamento contido nesse plano.

Admite-se que a chapa esteja em equilíbrio com um campo externo de cargas $\overline{\mathbf{t}}$, aplicado em uma parte, $\Gamma_{\mathrm{t}}$, da fronteira de $\Omega$; e submetida a restrições de deslocamento na parte complementar, $\Gamma_{\mathrm{u}}$, sendo que, nas faces da fissura, $\overline{\mathbf{t}}$ é nulo. Nessa chapa, que pode ser finita, supõe-se a presença de um entalhe retangular, de comprimento de $a$, e pequena abertura, iniciando-se no contorno (Figura 5). Como a 
chapa tem espessura unitária, essa fissura possui, conseqüentemente, uma área aproximadamente igual a $2 a$.

Desde já, convém esclarecer que o parâmetro $\gamma$, de Griffith, tem um significado distinto do de $\gamma_{\mathrm{E}}$, aqui introduzido, que corresponde ao valor crítico do parâmetro termodinâmico $G_{\mathrm{t}}$. Enquanto $\gamma_{\mathrm{E}}$ está associado à variação da energia livre de Helmholtz, ocorrida enquanto a fissura avança, $\gamma$ estaria associado a uma suposta parcela da energia potencial elástica, que somada com a clássica energia potencial elástica do corpo, permitiria a obtenção da energia potencial total, de Griffith.

O critério utilizado é semelhante ao da eq. (3.11), só que, nesse caso, pelo fato de a fissura iniciar-se no contorno, o segundo membro sofrerá uma ligeira alteração, já que a área da fissura é $2 \mathrm{~d} a$, ao invés de $4 \mathrm{~d} a$. Assim:

$$
-\mathrm{d} E_{\mathrm{d}}>2 \gamma_{\mathrm{E}} \mathrm{d} a
$$

ou, de acordo com a eq.(4.18) :

$$
\left(-E_{d}\right)_{\Omega}=G_{\mathrm{t}}=\left[\int_{\partial \Omega}(\phi \mathbf{I}) \mathbf{n} . \mathbf{e} \mathrm{d} \partial \Omega\right]>2 \gamma_{E}
$$

Esta seria, portanto, a expressão do critério termodinâmico, para o caso de uma chapa, em regime isotérmico e quase estático, sendo que a fissura se inicia a partir do contorno da chapa.

Antecipando-se ao que vai ser feito nos Capítulos 6 e 7, imagine-se que $\gamma_{E}$, o valor crítico de $G_{t}$, tenha sido obtido experimentalmente. A interpretação mais adequada seria: se a variação da energia de deformação, entre um estado imediatamente anterior ao início do avanço da fissura, e outro, imediatamente posterior, for tal que o critério da eq. (4.20) se verifique, então a fissura sofrerá um avanço inicial. Para saber se ela continuará avançando, será necessário, do ponto de vista da análise numérica do problema, uma atualização do domínio e, do ponto de vista da física do problema, a adoção de um critério semelhante ao representado pela eq. (3.14), porque seria necessário adotar-se uma formulação capaz de levar em conta 
o movimento, cabendo, assim, o uso de um parâmetro dinâmico, $\gamma_{\mathrm{Ed}}$, ao invés de $\gamma_{\mathrm{E}}$ que é adequado somente para o caso quase estático. 


\section{CAPÍTULO 5}

\section{A INTEGRAL J E O PARÂMETRO TERMODINÂMICO DE FRATURA OBTIDOS COM O AUXÍLIO DO MÉTODO DOS ELEMENTOS DE CONTORNO}

Conforme visto no Capítulo 4, se o material de uma parte $P$, de um sólido fissurado, é hiperelástico, isto é, quando está definida, em todos os pontos dessa parte, uma função densidade de energia, então é possível calcular-se uma integral de superfície (ou de linha, em problemas bidimensionais) que, no caso de uma fissura formada por faces planas (ou segmentos de reta), é independente do caminho. Tratase da integral $J$, originalmente concebida por Rice, para o caso bidimensional, que também pode ser obtida, de maneira generalizada, com o auxílio da Análise de Sensibilidade. Nesse caso, é interpretada como sendo a projeção, em direção paralela à fissura, do fluxo do tensor momentum-energia, sobre um caminho arbitrário que circunda a extremidade da fissura. Na Análise de Sensibilidade, a obtenção da integral $J$ faz-se a partir da derivação material da energia potencial elástica, em relação a um parâmetro ligado à simulação de alteração geométrica do domínio. Como resultado da associação desse parâmetro com o parâmetro geométrico da fissura, resulta que a integral $J$ é equivalente à energy release rate $G$, TAROCO (1966).

Para a obtenção do parâmetro $G_{t}$, eq. (4.20), tudo é feito de forma semelhante, bastando que se substitua a variação da energia potencial elástica, pela variação da energia de deformação em relação ao parâmetro geométrico da fissura. 
Neste capítulo, utiliza-se o $B E M$ para calcular, com o auxílio da Análise de Sensibilidade, a grandeza $G_{\mathrm{t}}$ dada pela eq.(4.20), do Capítulo 4. Verifica-se que, diferentemente da integral $J$, o parâmetro $G_{\mathrm{t}}$ não é dado por uma integral independente do caminho. Sua importância decorre, entretanto, do fato de ter emergido da interpretação termodinâmica do fenômeno da fratura, isto é, de uma formulação que guarda consistência com as leis em relação às quais os fenômenos naturais guardam obediência.

Feita a particularização para o caso de problemas bidimensionais, os resultados aproximados que, à frente serão obtidos, com o auxílio dos desenvolvimentos elaborados no presente capítulo, visam, exclusivamente, demonstrar a possibilidade prática das conclusões teóricas decorrentes do conjunto da investigação levada a efeito nos capítulos anteriores. Vale observar que o critério de fratura aqui adotado, na forma da eq. (4.19), ainda não pode ser plenamente verificado, porquanto não foi determinado experimentalmente o parâmetro termodinâmico crítico de fratura, $\gamma_{\mathrm{E}}$. Esse parâmetro poderá ser obtido mediante um método, cujo esboço é apresentado no Capítulo 6.

Optou-se por calcular também a integral $J$, em primeiro lugar para facilitar o balisamento do programa, na medida em que ela é um parâmetro bem conhecido, com muita presença na literatura. E em segundo lugar, mais especificamente para a finalidade de comparação de desempenho entre o programa aqui elaborado, que utiliza o $B E M$, e outros que usam também a Análise de Sensibilidade, embora apliquem o MEF, tais como TAROCO et al. (1994), CUNHA et al. (1995) e TAROCO \& FEIJÓO (1997).

Convém observar que há uma ligeira distinção entre a metodologia para o tratamento do problema da fratura, aqui proposta, e as metodologias anteriores, em particular a da integral $J$, em que é proposto o desenvolvimento paralelo de dois procedimentos: um, o analítico, realizado sobre o modelo de uma estrutura real, normalmente auxiliado por um método aproximado, que calcula algum parâmetro de fratura e o outro, experimental, que fornece um valor crítico do parâmetro de fratura. A comparação entre os dois valores, é a base do critério de integridade. 
No caso da presente proposta, diferentemente, o parâmetro crítico experimental, $\gamma_{\mathrm{E}}$, deve ser um dado inicial, para ser utilizado na análise de fratura da estrutura real. Daí, o programa automático é organizado para responder se a tendência da fissura é o avanço, ou a estabilização. E se avança, em que direção se orienta.

Embora não conste da presente proposta a realização de experimentos em laboratório, apresenta-se, no Capítulo 6, uma proposta sobre a forma como o experimento deve ser realizado, para que a metodologia possa ter sentido. Uma primeira exigência é que o esquema montado para o cálculo computacional aproximado de $G_{\mathrm{t}}$, também seja aproveitado, para a localização dos pontos em que as componentes de deformação devem ser medidas, com o auxílio de extensômetros elétricos de resistência, do tipo roseta, no caso particular de uma chapa de espessura constante, em estado plano. A colocação dos extensômetros elétricos de resistência (strain gages) deve ser feita, portanto, em pontos de integração do método de GaussLegendre, definidos pela experimentação numérica. Mais detalhes sobre a proposta de determinação experimental de $\gamma_{\mathrm{E}}$, são apresentados no Capítulo 6.

Na seqüência, desenvolvem-se os algoritmos para a construção do programa automático (ELCFRAT), que calcula, sobre um caminho de integração elíptico arbitrário, os valores de $J$ e de $G_{\mathrm{t}}$.

\subsection{Esquema teórico para a determinação aproximada de $G_{\mathrm{t}}$ no EPD}

Obtém-se, a seguir, para o caso do estado plano de deformação, a integral da eq.(4.20), que fornece o valor de $G_{\mathrm{t}}$, a partir de uma fissura inicial orientada segundo o vetor unitário e, consideradas nulas as forças de corpo (para caso do estado plano de tensão, basta que se forneça ao programa automático, o valor $v /(1+v)$ no lugar do coeficiente de Poisson, v). 
$G_{\mathrm{t}}=\left[\int_{\Gamma}(\phi \mathbf{I}) \mathbf{n d} \Gamma\right] . \mathbf{e}$,

considerando-se orientado para fora, da parte considerada do sólido, o vetor normal unitário n, em cada ponto do contorno percorrido no sentido anti-horário:

$$
\mathbf{n}=\left\{\begin{array}{c}
\mathrm{d} x_{2} / \mathrm{d} \Gamma \\
-\mathrm{d} x_{1} / \mathrm{d} \Gamma
\end{array}\right\}
$$

A integral do segundo membro da eq. (4.20) será:

$$
\begin{aligned}
& \int_{\Gamma}(\phi \mathbf{I}) \mathbf{n} d \Gamma=\int_{\Gamma}\left[\begin{array}{cc}
\phi & 0 \\
0 & \phi
\end{array}\right]\left\{\begin{array}{c}
d x_{2} / d \Gamma \\
-d x_{1} / d \Gamma
\end{array}\right\} d \Gamma= \\
& =\int_{\Gamma}\left\{\begin{array}{c}
\phi d x_{2} \\
-\phi d x_{1}
\end{array}\right\} .
\end{aligned}
$$

O contorno regular $\Gamma$, que pode ser arbitrário, será aqui adotado na forma de uma elipse de eixo maior $2 a$ (na direção $x_{2}$ ) e eixo menor $2 b$ (na direção $x_{1}$ ), cujo centro é o ponto $O$ (Figura 7). Assim sendo:

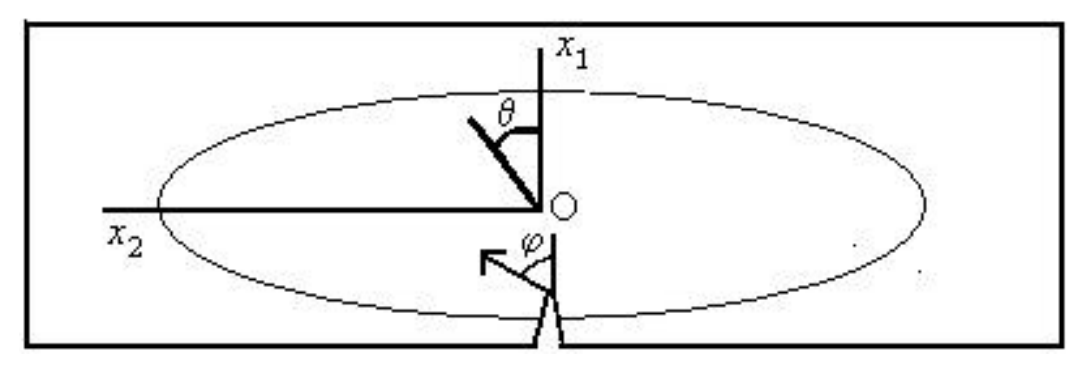

FIGURA 7- CONVENÇÕES DE EIXOS E DE ÂNGULOS

$$
x_{1}=b \cos \theta\left[k^{2} \operatorname{sen}^{2} \theta+\cos ^{2} \theta\right]^{-1 / 2} \quad \text { e } \quad x_{2}=a \operatorname{sen} \theta\left[\operatorname{sen}^{2} \theta+k^{-2} \cos ^{2} \theta\right]^{-1 / 2},
$$

onde $k=b / a$. Daí:

$$
\mathrm{d} x_{1}=-k^{2} b \operatorname{sen} \theta\left(k^{2} \operatorname{sen}^{2} \theta+\cos ^{2} \theta\right)^{-3 / 2} \mathrm{~d} \theta
$$


e $\quad \mathrm{d} x_{2}=k^{-2} a \cos \theta\left(\operatorname{sen}^{2} \theta+k^{-2} \cos ^{2} \theta\right)^{-3 / 2} \mathrm{~d} \theta$

Considerando $h$ a espessura constante da chapa, então a eq. (5.2) fica:

$$
\int_{\Gamma}[\phi \mathbf{I}] \mathbf{n} \mathrm{d} \Gamma=\int_{\theta_{1}}^{\theta_{2}}\left\{\begin{array}{l}
\phi k^{-2} a \cos \theta\left(\operatorname{sen}^{2} \theta+k^{-2} \cos ^{2} \theta\right)^{-3 / 2} \\
\phi k^{2} b \operatorname{sen} \theta\left(k^{2} \operatorname{sen}^{2} \theta+\cos ^{2} \theta\right)^{-3 / 2}
\end{array}\right\} h \mathrm{~d} \theta
$$

onde $\phi$ é a densidade de energia, para a elasticidade linear $(\phi=1 / 2 \mathbf{T} . \mathbf{E})$, sendo $\mathbf{T}$ o tensor de tensões de Cauchy, e $\mathbf{E}$ o tensor de deformações infinitesimais, nos pontos do caminho de integração $\Gamma$, onde vale a linearidade, na medida em que é escolhido à distância de extremidades de fissuras .

Visando a aplicação do esquema de integração de Gauss-Legendre, será realizada a mudança da variável $\theta$, para a variável $\zeta$ de forma a que os limites de integração sejam -1 e +1 . Assim:

$\theta=p \zeta+q \rightarrow d \theta=p d \zeta$

Fazendo com que, para $\theta=\theta_{1}, \zeta=-1$ e, para $\theta=\theta_{2}, \zeta=+1$, então:

$p=\frac{\theta_{2}-\theta_{1}}{2} \quad$ e $q=\frac{\theta_{1}+\theta_{2}}{2}$.

Por conta de uma opção de programação, a função densidade de energia de deformação $\phi$ será colocada em termos das componentes do tensor T. Assim, no caso do EPD:

$$
\begin{aligned}
& \mathbf{T}=\left[\begin{array}{ll}
T_{11} & T_{12} \\
T_{12} & T_{22}
\end{array}\right] \quad \text { e } \quad \mathbf{E}=\left[\begin{array}{ll}
\varepsilon_{11} & \varepsilon_{12} \\
\varepsilon_{12} & \varepsilon_{22}
\end{array}\right], \\
& \varepsilon_{11}=\frac{1}{2 \mu}\left[(1-v) T_{11}-v T_{22}\right], \quad \varepsilon_{12}=\frac{1}{2 \mu} T_{12}, \\
& T_{11}=\frac{2 \mu}{1-2 v}\left[(1-v) \varepsilon_{11}-v \varepsilon_{22}\right], \quad T_{12}=2 \mu \varepsilon_{12} \quad e \quad \varepsilon_{22}=\frac{1}{2 \mu}\left[(1-v) T_{22}-v T_{11}\right), \\
&
\end{aligned}
$$

onde $\mu$ é o módulo de elasticidade transversal. 
Obtém-se, então, o valor de $\phi$ :

$$
\begin{aligned}
& \phi=\frac{1}{2} \mathbf{T} . \mathbf{E}=\frac{1}{2} \operatorname{tr}(\mathbf{T E})=\frac{1}{2}\left(T_{11} \varepsilon_{11}+2 T_{12} \varepsilon_{12}+T_{22} \varepsilon_{22}\right)= \\
& =\frac{1}{4 \mu}\left[(1-v)\left({T_{11}}^{2}+T_{22}{ }^{2}\right)+2 T_{12}{ }^{2}-2 v T_{11} T_{22}\right] .
\end{aligned}
$$

É conveniente obter-se $\phi$ também em termos das deformações, para o EPD. Assim:

$$
\phi=\frac{\mu}{(1-2 v)}\left[(1-v)\left(\varepsilon_{11}^{2}+\varepsilon_{22}^{2}\right)+2(1-2 v) \varepsilon_{12}^{2}+2 v \varepsilon_{11} \varepsilon_{12}\right]
$$

Com o valor de $\phi$ dado pela eq. (5.6), pode-se agora calcular o valor de $G_{\mathrm{t}}$, segundo a eq. (4.20), admitindo-se que o vetor unitário arbitrário e seja dado por $\mathbf{e}=\{\cos \varphi$, sen $\varphi\}$, onde $\varphi$ é o ângulo entre ele e o eixo dos $x_{1}$ (Figura 7). Assim, temse:

$$
G_{\mathrm{t}}=\left[\int_{\Gamma}(\phi \mathbf{I}) \mathbf{n d} \Gamma\right] \cdot \mathbf{e}=\left(C_{1}, D_{1}\right) \cdot(\cos \varphi, \operatorname{sen} \varphi)=C_{1} \cos \varphi+D_{1} \operatorname{sen} \varphi
$$

onde, de acordo com a eq. (5.4):

$$
\begin{gathered}
C_{1}=\frac{h\left(\theta_{2}-\theta_{1}\right)}{2} \int_{-1}^{+1}\left[\phi a k^{-2} \cos \theta\left(\operatorname{sen}^{2} \theta+k^{-2} \cos ^{2} \theta\right)^{-3 / 2}\right] d \zeta \\
\text { e } D_{1}=\frac{h\left(\theta_{2}-\theta_{1}\right)}{2} \int_{-1}^{+1}\left[\phi b k^{2} \operatorname{sen} \theta\left(k^{2} \operatorname{sen}^{2} \theta+\cos ^{2} \theta\right)^{-3 / 2}\right] d \zeta,
\end{gathered}
$$

onde $\mathrm{d} \zeta=p \mathrm{~d} \theta$. 


\subsection{Obtenção da direção segundo a qual a fissura avançará}

A partir da eq. (5.8), pode-se determinar o ângulo $\varphi$ (Figura 7), que dá a direção segundo a qual a fissura avançará, no caso em que se dê a sua deflagração. Trata-se de determinar o ângulo para o qual $G_{\mathrm{t}}$ atinge o seu valor crítico, $\gamma_{\mathrm{E}}$, isto é, para o qual a eq. (5.8) fica:

$C_{1} \cos \varphi+D_{1} \operatorname{sen} \varphi \equiv \gamma_{\mathrm{E}}$,

$\mathrm{O}$ parâmetro termodinâmico crítico, $\gamma_{\mathrm{E}}$, deve ser medido experimentalmente, no exato instante da deflagração irreversível do processo de fissuração. Evidentemente, enquanto o processo for reversível, a energia de deformação, representada por $\gamma_{E}$, será recuperada quando do descarregamento. No entanto, a componente da fissura que estiver associada a fenômeno irreversível, tal como, por exemplo, em decorrência de plastificação, deverá se refletir na medida experimental de $\gamma_{\mathrm{E}}$, isto é, o calor dissipado no processo irreversível deverá ser automaticamente subtraído da medida experimental de $\gamma_{\mathrm{E}}$. O modelo teórico, por seu turno, tem que ser capaz de representar, o mais fielmente possível, o que ocorre na experimentação e nos sólidos reais. Para isso, tem-se que escolher, adequadamente, tanto o modelo elastoplático, quanto os parâmetros adequados a sua capacidade de representar um dado material. A metodologia aqui proposta tem o objetivo de permitir a calibração de tais parâmetros, de forma a bem caracterizar a acomodação plástica que ocorre na vizinhança da extremidade de uma fissura. Os detalhes da experimento proposto para fornecer o valor de $\gamma_{\mathrm{E}}$, bem como a metodologia para a calibração de parâmetros do modelo elastoplástico, estão no Capítulo 6.

Elevando-se ambos os membros da eq. (5.10) ao quadrado, e efetuando-se as operações cabíveis, resulta:

$\left(C_{1}^{2}+D_{1}^{2}\right) \operatorname{sen}^{2} \varphi-2 \gamma_{\mathrm{E}} D_{1} \operatorname{sen} \varphi+\gamma_{\mathrm{E}}^{2}-C_{1}^{2}=0$

cuja solução é: 
$\operatorname{sen} \varphi=\frac{\gamma_{E} D_{1} \pm C_{1} \sqrt{C_{1}^{2}+D_{1}^{2}-\gamma_{E}{ }^{2}}}{C_{1}^{2}+D_{1}^{2}}$

A depender do sinal da expressão sob o radical, na eq. (5.12), a solução para a eq. (5.11) poderá dar:

a) dois valores reais, no caso em que $C_{1}{ }^{2}+{D_{1}}^{2}>{\gamma_{E}}^{2}$, dados pela expressão (5.12);

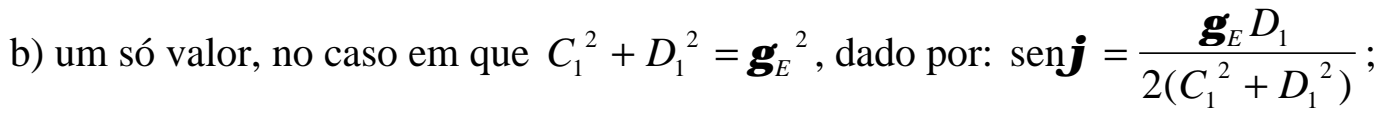

c) nenhum valor real, se $C_{1}^{2}+D_{1}^{2}<\gamma_{E}^{2}$.

Evidentemente, ocorre a situação em que alguma das raízes é estranha à eq. (5.10), devido às operações sobre elas realizadas, antes de se chegar à eq. (5.11). No entanto, isto é facilmente perceptível ao ser feita análise dos resultados, na medida em que se faça o confronto entre o valor resultante da substituição das raízes na expressão (5.10) e o valor limite de $G_{\mathrm{t}}$.

Convém observar que, diferentemente da integral $J$ cujo processo de obtenção será analisado a seguir, a interpretação das hipóteses a), b) e c), revelam um resultado novo, decorrente da premissa de que é possível determinar-se o parâmetro experimental $\gamma_{\mathrm{E}}$. Como se sabe, a determinação da integral $J$ baseia-se na hipótese segundo a qual o avanço da fissura deve ser simulado em uma direção paralela às faces da fissura, sendo por essa razão que ela é independente do caminho. Já no caso do parâmetro $G_{\mathrm{t}}$ isso não ocorre, porque ele é calculado para uma determinada parte $P$, do sólido, o que significa que não é independente do caminho. Assim, não se faz qualquer exigência a respeito da direção para onde a fissura, a priori, deva-se dirigir, contrariamente ao caso da integral $J$. Evidentemente, a direção do processo de avanço da fissura é definida fisicamente e, segundo a Termodinâmica, a direção de seu avanço deverá ser aquela para a qual a variação da energia livre de Helmholtz seja mínima. Em suma, é isso que está por trás da eq. (5.11). Sendo assim, suas raízes, que revelam o sentido do avanço da fissura, fornecem um resultado termodinamicamente consistente. 


\subsection{Obtenção aproximada da energy release rate $G$ (integral ل) no EPD}

Para o cálculo aproximado de $G$, basta que se mude o núcleo da integral do primeiro membro da eq. (5.2): Ao invés de T- $\phi \mathbf{I}$, ele será agora constituído pelo tensor momentum-energia de Eshelby, calculado com base na consideração de que o Princípio da Mínima Energia Potencial, pode ser estendido para a Mecânica da Fratura, TAROCO (1996). Nessa última referência, o tensor momentum-energia de Eshelby é calculado mediante um desenvolvimento semelhante ao anterior. Aqui, com vistas à programação computacional, basta que se obtenham os valores $C$ e $D$, a partir das expressões análogas às eqs.(5.9a) e (5.9b), onde a única novidade reside na introdução, no programa, do gradiente do deslocamento, $\nabla \mathbf{u}$, por suas componentes cartesianas $u_{i, j}$. Assim:

$$
G=\left[\int_{\Gamma}\left(\phi \mathbf{I}-(\nabla \mathbf{u})^{\mathrm{T}} \mathbf{T}+\right) \mathbf{n d} \Gamma\right] \cdot \mathbf{e}=(C, D) \cdot(\cos \varphi, \operatorname{sen} \varphi)=C \cos \varphi+D \operatorname{sen} \varphi
$$

na qual:

$C=\frac{\left(\theta_{2}-\theta_{1}\right) h}{2}\left[\begin{array}{l}\int^{+1}\left(\phi-u_{1,1} T_{11}-u_{2,1} T_{12}\right) a k^{-2} \cos \theta\left(\operatorname{sen}^{2} \theta+k^{-2} \cos ^{2} \theta\right)^{-3 / 2} d \zeta \\ -1 \\ +\int_{-1}^{+1}\left(-u_{1,1} T_{12}-u_{2,1} T_{22}\right) b k^{2} \operatorname{sen} \theta\left(k^{2} \operatorname{sen}^{2} \theta+\cos ^{2} \theta\right)^{-3 / 2} d \zeta\end{array}\right]$

$\mathrm{e}$

$$
D=\frac{\left(\theta_{2}-\theta_{1}\right) h}{2}\left[\begin{array}{l}
\int_{1,2}^{+1}\left(-u_{11} T_{2,2} T_{12}\right) a k^{-2} \cos \theta\left(\operatorname{sen}^{2} \theta+k^{-2} \cos ^{2} \theta\right)^{-3 / 2} d \zeta- \\
-1 \\
+\int_{-1}^{+1}\left(\phi-u_{1,2} T_{12}-u_{2,2} T_{22}\right) b k^{2} \operatorname{sen} \theta\left(k^{2} \operatorname{sen}^{2} \theta+\cos ^{2} \theta\right)^{-3 / 2} d \zeta
\end{array}\right]
$$

Mostra-se, a seguir, o esquema baseado no no $B E M$, através do qual serão obtidos, nos pontos de um caminho elíptico, com a origem e os eixos arbitrariamente fixados, o gradiente do vetor deslocamento e o tensor de tensão, permitindo o cálculo 
aproximado das integrais das eqs. (5.9) e (5.14), mediante a aplicação do esquema de integração de Gauss-Legendre.

O ponto de partida é a expressão que fornece as componentes do vetor deslocamento nos pontos do interior do domínio $\Omega$, em função dos valores das componentes, em cada ponto do contorno $\partial \Omega$, do vetor deslocamento e do vetor de Cauchy (traction), no caso do problema elástico bidimensional, (v. Anexo D):

$u_{i}(P)=-\int_{\partial \Omega} p_{i j}^{*}(P, S) u_{j}(S) d \Gamma+\int_{\partial \Omega} u_{i j}^{*}(P, S) p_{j}(S) d \Gamma$,

onde $P$ indica um ponto genérico no interior do domínio $\Omega$, e $S$, um ponto também genérico, porém no contorno $\partial \Omega$ desse domínio. Daí, as derivadas parciais das componentes do vetor deslocamento são dadas por:

$u_{i, k}(P)=\int_{\partial \Omega} u_{i j, k}^{*}(P, S) p_{j}(S) d \Gamma-\int_{\partial \Omega} p_{i j, k}^{*}(P, S) u_{j}(S) d \Gamma$

Observe-se que a derivação parcial, no índice $k$, por ser aplicada ao ponto $P$, do interior do domínio, não afeta as variáveis dependentes de $S$, ponto do contorno. Assim sendo, desde que seja assegurada a exigência de continuidade das funções, a derivação transfere-se para os integrandos, no segundo membro da eq. (5.16), indo afetar somente as soluções fundamentais, $u_{\mathrm{ij}}^{*}$ e $p^{*}{ }_{\mathrm{ij}}$, que dependem da variável $P$. As derivadas parciais das soluções fundamentais $u^{*}{ }_{\mathrm{ij}}$ e $p^{*}{ }_{\mathrm{ij}}$, em relação a $x_{\mathrm{k}}$, obtidas no Anexo D, são:

$$
\begin{aligned}
& u_{i j, k}^{*}(P, S)=\frac{1}{8 \pi E(1-v) r}\left\{r_{, k}\left[(3-4 v) \delta_{i j}+2 r_{, i} r_{, j}\right]-r_{, i} \delta_{j k}-r_{, j} \delta_{i k}\right\} \quad \text { e } \\
& p_{i j, k}^{*}(P, S)=\frac{-1}{4 \pi(1-v) r^{2}}\left\{2 r_{, n}\left[(2 v-1) \delta_{i j} r_{, k}-4 r_{, i} r_{, j} r_{, k}+r_{, i} \delta_{j k}+r_{, j} \delta_{i k}\right]+\right. \\
& \left.+(1-2 v)\left[n_{j}\left(\delta_{i k}-2 r_{, i} r_{, k}\right)+2 n_{i} r_{, j} r_{, k}-n_{i} \delta_{j k}-n_{k} \delta_{i j}\right]-2 r_{, i} r_{, j} n_{k}\right\},
\end{aligned}
$$


onde $\quad r_{, n}=r_{, l} n_{l}, \mathrm{e} i, j, k, l=1,2$.

Com o auxílio das eqs. (5.17 a, b), obtém-se, através da substituição na eq. (5.16), as componentes do tensor de tensão $\mathbf{T}$ e do tensor gradiente dos deslocamentos $\nabla \mathbf{u}$, para os pontos do caminho elíptico de integração.

Tendo em vista as aplicações que serão apresentadas, a título de exemplo, com auxílio do Programa ELCFRAT, aqui desenvolvido, convém utilizar-se as expressões que dão as componentes desses tensores em função das derivadas das componentes do tensor deslocamento em um sistema cartesiano ortogonal:

$$
\begin{aligned}
& (\nabla \mathbf{u})_{i j}=u_{i, j} \\
& T_{i j}=\frac{E}{2(1+v)}\left[\frac{2 v}{1-2 v} \delta_{i j} u_{m, m}+u_{i, j}+u_{j, i}\right],
\end{aligned}
$$

onde $i, j$ e $m$ assumem os valores 1 e 2 . 


\section{CAPÍTULO 6}

\section{ASPECTOS EXPERIMENTAIS E NORMATIVOS SOBRE PARÂMETROS DE FRATURA}

A determinação experimental de parâmetros de fratura serve à análise de estruturas (ou de seus componentes) submetidas a ações (mecânicas, térmicas, etc), auxiliando no projeto, visando garantir a integridade dos componentes e a estabilidade da estrutura durante a vida útil da construção. Além disso, serve também à manutenção, ou recuperação dessas estruturas, com o objetivo do prolongamento de sua vida segura útil. Para isso, a Mecânica da Fratura formula critérios através dos quais, parâmetros resultantes da análise, em geral obtidos com o auxílio dos métodos numéricos aplicados à Mecânica dos Materiais, são comparados a seus respectivos valores críticos, determinados experimentalmente.

Seguindo-se o desenvolvimento histórico da Mecânica da Fratura, a partir de Griffith, no início da década de 1920, o primeiro parâmetro desse tipo que se buscou determinar em laboratório, foi a energia superficial específica de fratura, que aparece em seu conhecido critério de de iniciação de fratura, e que seria, para ele, uma característica do material. Mais tarde, verificou-se que isso não era verdade e, devido à limitação da aplicabilidade do critério de Griffith, válido somente para casos de materiais quase que perfeitamente frágeis, o parâmetro deixou de ser determinado.

A interpretação do fenômeno da fratura, advinda da contribuição de Irwin, no final da década de 1940, ensejou uma nova concepção sobre a determinação experimental de parâmetros de fratura. A noção de fator de intensidade de tensão, decorrente da análise da singularidade de tensões em problemas bidimensionais, 
levou Irwin a propor a determinação experimental de valores críticos de três fatores de intensidade de tensão, o que daria a base para Mecânica da Fratura Elástica Linear.

A determinação dos valores críticos dos fatores de intensidade de tensão traria um grande desenvolvimento dos métodos experimentais, particularmente na caracterização de materiais metálicos, permitindo a realização de ensaios de grande porte, já que a necessidade de se garantir a realização dos ensaios no estado plano de deformação, exigiria o rompimento de chapas com grande espessura. Tabelas de fatores de intensidade de tensão, para as mais diversas configurações de pré-fissuras, em variados casos de condições ambientais (altas ou baixas temperaturas, presença de hidrogênio, radiação, agentes corrosivos, etc), passaram a ser preparadas, no intuito de prover os projetistas e os engenheiros de manutenção, de instrumentos capazes de auxiliá-los na avaliação da integridade de estruturas e de seus componentes.

A ênfase na produção de novos materiais e a competitividade internacional baseada na exigência de qualidade, características da crescente corrida tecnológica mundial, principalmente após a Segunda Grande Guerra, fizeram com que se estendesse bastante o campo de aplicação da Mecânica da Fratura, levando-a naturalmente, a gerar diversas sub-especializações, nos campos de estudo das rochas, das cerâmicas, dos polímeros, do concreto, do gelo, dos compósitos em geral e da madeira, além de ter-se de sofisticar ainda mais, nos casos das aplicações mais tradicionais, como às indústrias da construção metálica, ferroviária, naval e offshore, aeronáutica, nuclear e espacial.

Em razão do objetivo do presente trabalho relacionar-se com uma proposta teórica, que visa o aperfeiçoamento da contribuição da Mecânica dos Materiais (mais particularmente da Mecânica do Contínuo), à Mecânica da Fratura, será dada aqui, especial atenção à experimentação relacionada com a integral $J$. O intuito não é propriamente o de fornecer-se um exaustivo conjunto de técnicas de ensaios, e muito menos o de induzir-se a que os resultados teóricos apresentados nos capítulos anteriores servem exclusivamente para os aços. O objetivo é somente o de organizarse o cenário para a apresentação, em caráter inicial, de uma proposta de ensaio de 
laboratório que permita a determinação do valor crítico do parâmetro termodinâmico de fratura (e também da integral $J$ ). Optou-se, pois, pela descrição sumária dos procedimentos de ensaio de laboratório normalizados pela ASTM (American Society for Testing and Materials), aplicados aos materiais metálicos, cujo uso é mais freqüente em nosso país. Para a organização do resumo que se segue, foi de muita valia, tanto o volume de informações, quanto o conteúdo de caráter didático de DeAQUINO et al.(1998)

Diversos organismos internacionais vêm elaborando procedimentos normalizados de ensaios, visando medir a tenacidade à fratura (fracture toughness, ou simplesmente toughness) dos materiais . Entre eles, destacam-se a DIN (Deutsche Industrie Normen), da Alemanha, a BSI (Britsh Standards Institute), do Reino Unido, e a $A S T M$, dos EUA. A maior parte dos países industrializados possui suas próprias entidades normativas, mas a ISO (International Standard Organization), vem realizando esforços no sentido de criar um padrão internacional de normalização técnica.

\subsection{Ensaios para as medidas da integral $J$ e do $C T O D$}

O primeiro ensaio proposto para a obtenção da integral $J$, foi normalizado através da $E 813$, da $A S T M$. A metodologia baseaia-se na utilização de uma curva relacionando $J$ com a variação do parâmetro geométrico da trinca, $\Delta a$ (valor estimado do avanço da fissura, como é definido nessa norma), a fim de determinar um ponto através do qual fosse possível caracterizar a tenacidade à fratura. Este ponto, denominado $J_{\text {Ic }}$, é definido como o valor de $J$ correspondente ao ponto próximo à iniciação do processo de rasgamento dúctil, responsável pelo processo de crescimento da trinca, característico do caso da fratura dúctil.

Em 1987, a ASTM elaborou seu segundo procedimento de ensaio para a determinação da integral $J$, a $E$ 1152. A Figura 8 mostra a curva denominada $J-R$, ou curva de resistência, que representa a variação de $J$ em relação à variação $\Delta a$, a partir de um comprimento inicial de trinca, $a_{0}$. Essa curva expressa a propriedade básica da tenacidade à fratura, em regime elastoplástico. $\mathrm{O}$ desenvolvimento do procedimento 
de ensaio foi de tal forma aperfeiçoado, que passou a bastar um único corpo de prova para a determinação de $J$. Exigências de tamanho são especificadas, de modo a garantir a manutenção das condições geométricas capazes de assegurar o small scale yelding, ou escoamento de pequena escala, que corresponde à localização do fenômeno da plastificação, de forma a resguardar a independência do resultado, em relação a variações de tamanho e de geometria.

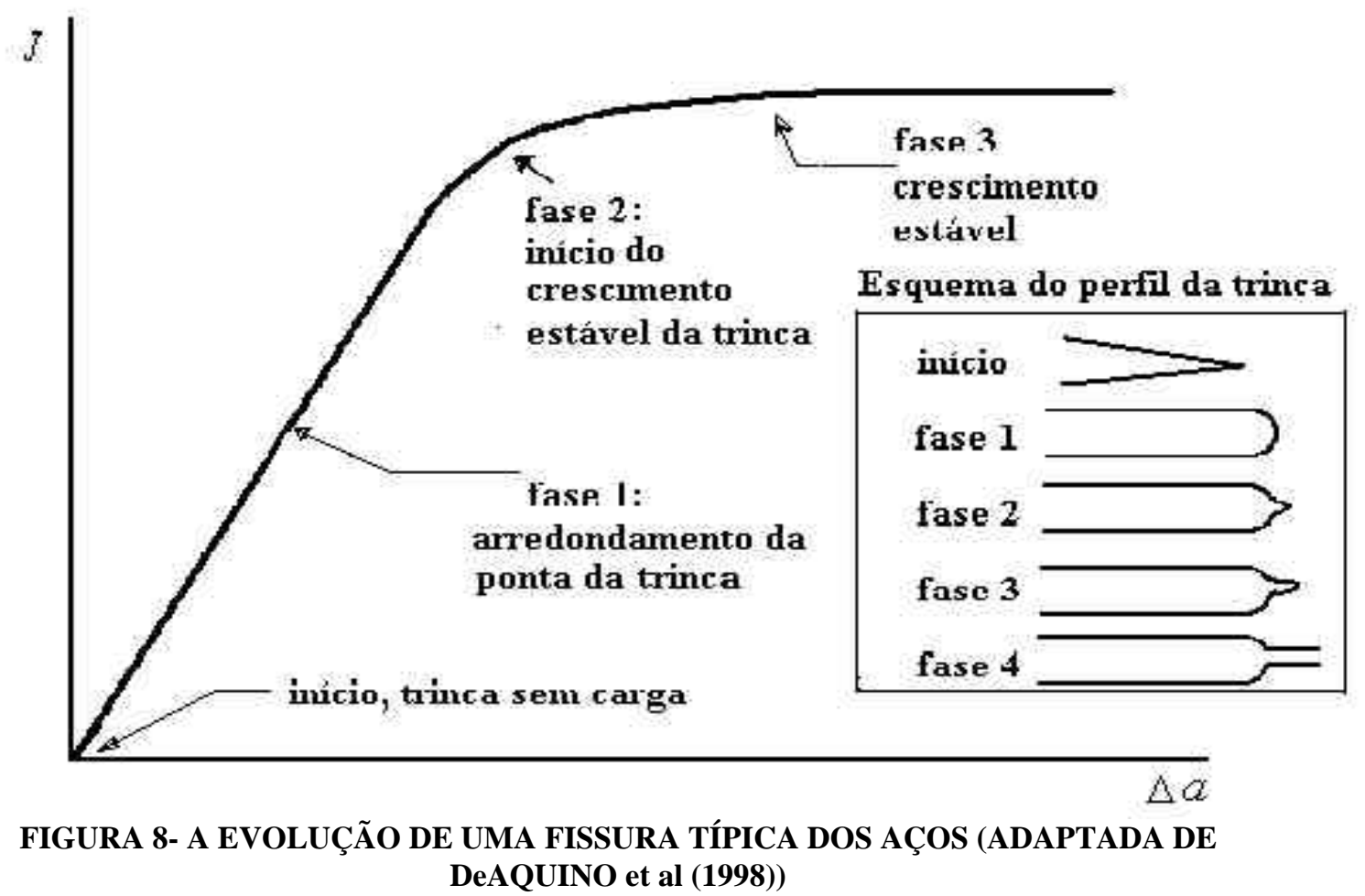

Os ensaios de fratura visando a obtenção de $J$ correspondem à metodologia predominante na determinação da tenacidade à fratura, particularmente nos casos em que o comportamento do material extrapola o limite elástico linear. Nos EUA e em muitas outras partes do mundo, incluindo o Brasil, a preferência é por ensaios desse tipo. No Reino Unido, entretanto, predomina o uso do ensaio de tenacidade baseado no CTOD (crack tip opening displacement).

Esse procedimento de ensaio foi primeiramente normalizado pela $B S I$, em 1979. No entanto, a ASTM, pressionada por algumas indústrias dos EUA, principalmente as de soldagem, padronizou ensaios baseados no CTOD, publicados em 1989, como a norma $E 1290$. 


\subsection{Outros ensaios tradicionais}

Os ensaios anteriormente descritos são realizados sob carregamentos lentos, aplicados em forma quase estática. A aplicação de um carregamento dinâmico pode influenciar bastante o comportamento dos materiais à fratura. A norma $E$ 399, da ASTM, possui um anexo que trata do ensaio dinâmico para a determinação do $K_{\text {Id }}$, a tenacidade dinâmica, medida em um estado plano de tensão. Note-se que, até agora, ainda não existe qualquer norma estabelecida para a obtenção de $J$ em regime dinâmico, mas somente para o fator de intensidade de tensão dinâmico, $K_{\mathrm{Id}}$.

A capacidade de interrupção do crescimento de uma trinca, para um dado material, também é quantificada através de um parâmetro característico da tenacidade. $\mathrm{O}$ ensaio que fornece a tenacidade de parada de trinca (crack arrest) é normalizado através da $E$ 1221, de 1988.

Embora ainda não divulgada, está sendo desenvolvida pela ASTM uma metodologia específica para o tratamento de problemas relacionados às soldas, tais como: localização da trinca, processo de pré-trincamento no corpo de prova, tensões residuais, etc. Nesse método, de acordo com os estudos já realizados, a tendência é para que os ensaios e a análise dos resultados sejam baseados em normas já existentes.

\subsection{Os procedimentos normativos mais recentes de ensaios}

Os comitês técnicos da ASTM trabalham sob a exigência de que as normas sejam reavaliadas de cinco em cinco anos. O Comitê E08, dessa entidade, responsável pelas áreas de fadiga e de fratura, passou a adotar a tendência mundial de unificação dos procedimentos de ensaios para a obtenção da tenacidade à fratura. Dentre tais procedimentos, destacam-se:

a) A norma combinada de $J$ 


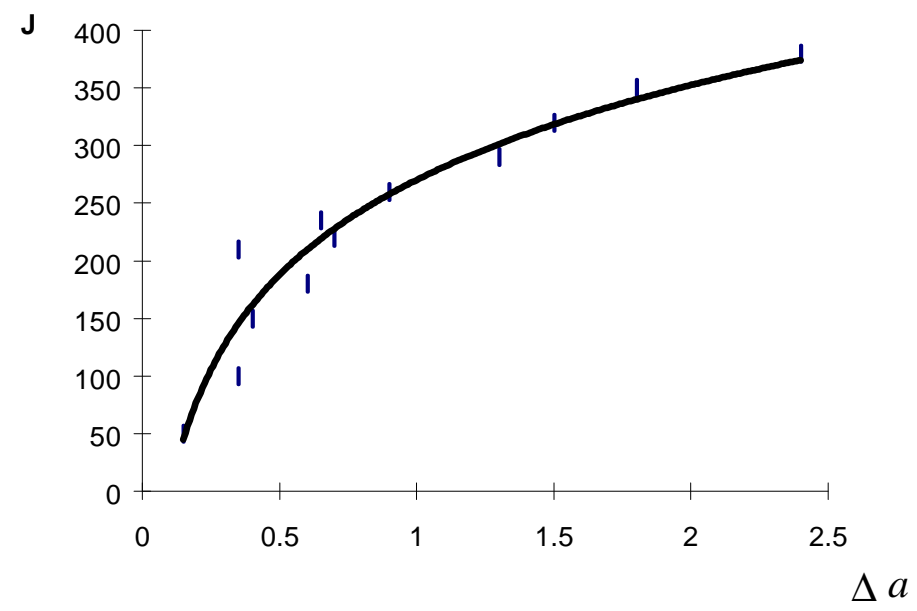

FIGURA 9- AJUSTE DE INICIALIZAÇÃO DE $\Delta a$ (ADAPTADA DE DeAQUINO et al (1998))

Trata-se da norma $E$ 1737, aprovada em 1996, que inclui os procedimentos de ensaios para a obtenção da curva $J-R$, e do valor de $J_{\text {Ic }}$, além de estabelecer regras para a caracterização de uma tenacidade à fratura associada a um ensaio de $J$ terminado por uma fratura instável, ou frágil $\left(J_{\mathfrak{c}}\right.$, ou $J$ de clivagem). Uma outra novidade, trazida pela $E$ 1737, é a da inicialização dos dados, para a definição do tamanho da trinca inicial, na curva $J-R$. Através dessa determinação, evitam-se erros na obtenção de $J_{\text {Ic }}$, a partir de um ajuste linear dos pontos da curva $\mathrm{J} \times \Delta a$, conforme mostra a Figura 9.

b) A norma unificada de tenacidade à fratura

Desenvolvida para incorporar praticamente todas as metodologias de ensaios de obtenção da tenacidade à fratura, a E 1820, publicada pela ASTM, em 1997, objetiva medir, através de um único procedimento, os valores de $K, J$ e $C T O D$. Isso porque as metodologias para a determinação desses parâmetros utilizam, essencialmente, os mesmos corpos-de-prova e os mesmos procedimentos. Dessa forma, a norma unificada produz resultados de tenacidade, em termos de $K_{\text {Ic }}$, sempre que o ensaio revela um comportamento do material próximo ao elástico linear; no caso da ocorrência predominante de um comportamento elasto-plástico, os valores da tenacidade são baseados em $J$ ou no $C T O D$.

c) A norma de fratura para a transição dúctil-frágil 
Aprovada em 1997, a norma ASTM que centra-se na metodologia para a obtenção de valores médios, e limites de confiança, para a tenacidade à fratura, na região de transição dúctil-frágil em aços, é a E 1921. Essa é a linha mais recente, no desenvolvimento de procedimentos e metodologias normalizadas de ensaios de fratura. A caracterização da tenacidade na transição dúctil frágil, tem grande utilidade prática, em particular na indústria de vasos de pressão e nuclear.

\subsection{Sugestão de experimentação para a determinação do parâmetro termodinâmico crítico $\gamma_{E}$}

Como consequiência da proposta teórica, sugerem-se aqui as linhas gerais de um método experimental para a determinação do valor crítico, $\gamma_{\mathrm{E}}$, do parâmetro termodinâmico de fratura. Evidentemente, entende-se que não é o caso de entrar-se em minúcias, pois somente a experimentação real poderá dar conta de detalhes importantes, para a eliminação completa de toda dubiedade, exigência fundamental para a padronização de um método de ensaio. Pretende-se, pois, que esses elementos iniciais sirvam de base para um projeto de trabalho experimental que, caso se confirme a utilidade da proposta teórica sugerida, seja capaz de produzir um verdadeiro método de ensaio para a determinação precisa de $\gamma_{\mathrm{E}}$. $\mathrm{O}$ parâmetro $\gamma_{\mathrm{E}}(\mathrm{F})$, cuja concepção é apresentada no Capítulo 4, fornece, experimentalmente, a medida da sensibilidade da energia de deformação de $P$, em relação à variação de um parâmetro geométrico da fissura (entalhe).

Considerações gerais . Denomina-se parte $P$, uma região da chapa a ser ensaiada, limitada externamente por um segmento de superfície cilíndrica de base elíptica. Portanto, $P$ é um segmento de cilindro oco, cuja altura é a espessura da chapa, que contorna a aresta vertical de um dos entalhes. A modelagem teórica simplificada do problema, como um estado bidimensional de elasticidade, permite que a chapa seja representada por seu plano médio. Assim, a região $P$, quase sempre será referenciada como tendo uma fronteira elíptica (v. Figura 5, no Capítulo 4), ao invés de uma superfície cilíndrica. A utilidade de $\gamma_{E}(F)$ é calibrar modelos elastoplásticos termodinamicamente consistentes, isto é, modelos nos quais seja considerada a dissipação de energia na vizinhança da extremidade de uma fissura que 
avança. A obtenção desse parâmetro, que não possui a propriedade da independência do caminho, refere-se a uma determinada parte da chapa, delimitada por um dado caminho elíptico. $\gamma_{\mathrm{E}}(\mathrm{F})$ depende, portanto, da parte, $P$, escolhida no sólido. Logo, não é uma propriedade do material.

Objetivo do ensaio. Determinar o parâmetro termodinâmico crítico de fratura $\gamma_{\mathrm{E}}(F)$, associado a uma parte arbitrária, $P$, de uma chapa de espessura, $B(L)$, constante.

Preparação do corpo de prova. Devem ser feitos, previamente, na chapa, dois entalhes angulares iguais, e simétricos (Figura 10) em relação ao eixo longitudinal da peça, devendo ser realizados os procedimentos capazes de assegurar a máxima atenuação possível das tensões residuais surgidas em decorrência do processo de entalhamento. Extensômetros elétricos de resistência (strain gages), tipo roseta, devem ser colados em ambas as faces da chapa, em pontos previamente determinados dos segmentos de elipses iguais que delimitam a região $P$. A fixação dos pontos de colagem das rosetas decorre de um experimento numérico feito previamente, com um modelo idêntico ao da chapa utilizada como corpo de prova

Quanto à espessura da chapa, sabe-se que uma chapa fina, submetida a carregamentos e a restrições de deslocamentos especiais, orientados segundo direções contidas em seu plano médio, reproduzem o que se convenciona chamar, na Elasticidade Bidimensional, de estado plano de tensão (EPT). Na verdade, é uma situação que não guarda consistência com as equações de compatibilidade da Elasticidade, embora tenha grande utilidade, enquanto aproximação, quanto menor seja a espessura da chapa. A outra possibilidade de problema plano é o estado plano de deformação (EPD), em que um sólido, também com com um carregamento especial do mesmo tipo, pode ser estudado em uma seção plana, representativo do que ocorre a certa distância de seus apoios laterais. O EPD é um estado elasticamente compatível, mas não adianta aumentar-se a espessura de uma chapa, em um ensaio de laboratório, na ilusão de que o EPD venha a ser atingido, porque isso levaria à necessidade de chapas tão espessas que os equipamentos de laboratório teriam de ser extremamente potentes e, mesmo assim, o resultado ainda seria aproximado, porque 
só seria exato se a espessura fosse infinita. Do ponto de vista do cálculo automático, o mesmo programa pode resolver problemas no EPD e no EPT, bastando, para isso, no caso de um sólido isótropo, por exemplo, que se mude um único valor no arquivo de dados, alterando o valor coeficiente de Poisson. Desse modo, a espessura da chapa, no ensaio, deve ser a menor possível, levando-se em conta, para isso, principalmente a questão da boa fixação das garras do equipamento, para produzir a restrição de deslocamentos controlada, nas extremidades do corpo de prova.

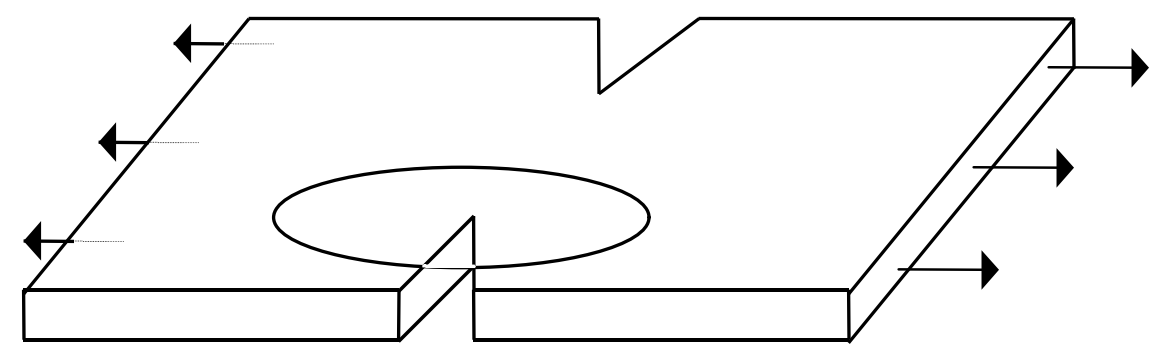

FIGURA 10- ESBOÇO DA CHAPA A SER ENSAIADA PARA A OBTENÇÃO DE $\gamma_{E}(F)$

As demais dimensões, no plano da chapa, devem ser tais que deixem o espaço adequado para a boa colagem das rosetas de strain gages, e garantam um razoável afastamento das extremidades ligadas à máquina, para diminuir a perturbação devida a inevitáveis efeitos localizados, decorrentes da fixação do corpo de prova.

Descrição do ensaio. Na direção do eixo longitudinal da peça, devem ser aplicadas, em ambas as extremidades, uma restrição positiva de deslocamento, constante em todos os pontos de ambas as seções transversais acionadas pelo equipamento de carga. O processo de deformação deve ser o mais lento possível, de forma a assegurar o regime quase estático e isotérmico.

As medidas das três componentes planas de deformação, sobre os predeterminados pontos dos caminhos elípticos iguais, desenhados sobre as faces da chapa, deverão ser tomadas pelos extensômetros, em intervalos regulares, durante o período de realização do ensaio. Os resultados deverão ser as respectivas médias dessas medidas em cada par de pontos opostos, nas faces, ligados pela mesma perpendicular, no sentido da espessura. O esquema de aquisição de dados deverá alimentar um equipamento capaz de realizar as médias, para cada uma das três 
componentes planas de deformação medidas. Essas médias, entre os respectivos valores, tomados nas duas faces, deverão, por sua vez, alimentar um sistema capaz de realizar a integral sobre o caminho elíptico, em tempo real, fornecendo o valor de $G_{\mathrm{t}}$ (F), em intervalos de tempo regulares. A informação sobre o instante de iniciação do processo de fratura, que deverá ser obtida opticamente, no momento em que a medida $G_{\mathrm{t}}$ fornecerá o valor crítico $\gamma_{\mathrm{E}}(\mathrm{F})$, deverá ser registrada, dentro da cronologia do ensaio. A saída dos resultados também poderá ser na forma gráfica, fornecendo algo semelhante a uma curva de $G_{\mathrm{t}} \mathrm{x}$ tempo.

Sobre a metodologia. A experimentação numérica, complementar à de laboratório, centra-se na obtenção aproximada de dois resultados importantes: o primeiro, anterior à experimentação de laboratório, refere-se ao fornecimento das coordenadas dos pontos do Método de Gauss, para a integração numérica aproximada, nos quais deverão ser coladas as rosetas de strain gages no corpo de prova. O segundo resultado diz respeito ao cálculo do valor limite do parâmetro $G_{\mathrm{t}}(F)$, com o auxílio do BEM, ou do MEF, que deverá ser feito para o mesmo caminho elíptico usado na experiência de laboratório. Em particular, o programa automático ELCFRAT (v. Anexo E), realiza, via BEM, em sua sub-rotina INTEGJ, o processo numérico iterativo que conduz ao valor limite de $G_{\mathrm{t}}(F)$. Uma parte desse esquema, que realiza o processo de integração numérica, pelo esquema de GaussLegendre, deverá ser adaptada ao equipamento de integração acoplado ao equipamento de aquisição dos dados no laboratório.

Obtido o valor de a partir do ensaio de laboratório, deve-se realizar uma nova experimentação numérica, usando-se o ELCFRAT, em que o dado GAMMA, que poderia ser fornecido como um valor positivo arbitrário, será fornecido agora como o valor medido, $\gamma_{\mathrm{E}}(\mathrm{F})$. Como mostra o Anexo $\mathrm{E}$, a saída do programa inclui a direção da fissura e o valor limite de $G_{\mathrm{t}}(\mathrm{F})$. Caso esse último valor for diferente do $\gamma_{\mathrm{E}}(\mathrm{F})$

medido, podem-se aventar, por exemplo, algumas hipóteses, não necessariamente exclusivas: 
1. O experimento foi mal realizado, por conta da falta de cuidados com a colagem dos extensômetros ou com a fixação do verdadeiro ponto, a partir do qual o processo de crescimento da fissura se iniciou, etc.

2. A velocidade do ensaio foi maior do que aquela capaz de assegurar o caráter de regime quase estático e isotérmico do processo.

3. Os valores do módulo de elasticidade transversal e do coeficiente de Poisson, fornecidos ao ELCFRAT, não correspondem aos do verdadeiro material do corpo de prova.

4. A dissipação de energia na vizinhança da extremidade do entalhe alterou, de tal maneira, os valores das deformações, nos pontos do circuito elíptico, mesmo ele estando imerso em uma região hiperelástica, que o modelo elástico, do ELCFRAT, foi incapaz de simular uma razoável aproximação. Evidentemente, só a experimentação poderá levar ao aperfeiçoamento da idéia de se caracterizar um material, à fratura, a partir do parâmetro termodinâmico aqui proposto. A intenção é mostrar que a proposta teórica apresentada tem a possibilidade de ser posta à prova., na prática.

Por último, convém registrar que FAUCHER (1994), partindo de uma série de contribuições anteriores por ele sistematizadas, propôs a medida experimental de $J$ crítico com auxílio de um ensaio de tração. Sua justificativa está baseada numa referência a HANCOCK, et al. (1993) ${ }^{1}$ apud FAUCHER (1994), segundo o qual, a curva $J-R$ pode alterar-se significativamente, em razão do tipo de carregamento aplicado, não valendo, segundo ele, a crença de que os ensaios do tipo ASTM forneçam uma medida standard, capaz de caracterizar plenamente o comportamento

à fratura, seja da peça, seja do material.. Embora o sentido da presente proposta não seja o mesmo da de Faucher, vale registrar que a idéia da realização de ensaios de

\footnotetext{
${ }^{1}$ HANCOCK, J. W. , REUTER, W. G., PARKS, D. M. .(1993). Constraint and toughness parametrized by T. In : Constraint Effects in Fracture, ASTM STP 1171, E. M. Hackett, R.-H Schwalbe and R. H. Dodds, Eds., American Society for Testing Materials, Philadelphia, 1993, p. 21-40 apud FAUCHER (1994), B. Crack Lenght and $J$-integral expressions for specimens loaded in tansion. Journal of Testing and Evaluation, v.22, n.1, p.30-35.
} 
tração, visando a obtenção de parâmetros de fratura, não se origina no presente trabalho. 


\section{CAPÍTULO 7}

\section{EXEMPLOS DE APLICAÇÃO}

Os cálculos referentes aos sete primeiros exemplos aqui apresentados, são feitos com auxílio do programa automático ELCFRAT, aqui desenvolvido, cujos detalhes encontram-se no Anexo E.

Os dois primeiros exemplos são, de fato, dois casos de carregamento para uma mesma haste, constituída de material (elástico linear), (Figuras 11 e 12), contendo um entalhe em forma de ângulo agudo. Antes das considerações sobre fratura, mostra-se, com o auxílio das Figuras 14 e 15, o resultado do experimento numérico no qual se ressalta a tendência à singularidade e à tridimensionalidade do estado de tensão, na vizinhança da extremidade da fissura. O Exemplo 1 corresponde a um caso de tração simples. Já no Exemplo 2, a haste é submetida somente a uma força tangencial distribuída na extremidade livre. É de se esperar que, quanto mais as dimensões da peça, no plano, tendam para valores infinitos, e o ângulo entre as faces do entalhe se aproxime de zero, a singularidade da tensão vá-se tornando próxima de $1 / \sqrt{ } r$, tal como o previsto pela Teoria da Elasticidade. Nessa situação, de acordo com IRWIN (1957), podem-se obter os fatores de intensidade de tensão, $K_{\mathrm{I}}$ e $K_{\mathrm{II}}$, a partir da consideração de que eles nada mais são do que os coeficientes das respectivas parcelas singulares, nas expressões das tensões, em casos como os dos Exemplos 1 e 2. 
EXEMPLO 1- HASTE SUBMETIDA À TRAÇÃO SIMPLES (FIGURA 11) e EXEMPLO 2. HASTE SUBMETIDA A FORÇA TANGENCIAL NA EXTREMIDADE LIVRE (FIGURA 12)

\section{DADOS:}

NÚMERO DE NÓS DO CONTORNO $=51$

NÚMERO DE PONTOS INTERNOS $=48$

NÚMERO DE PARES DE NÓS DUPLOS $=13$

NÚMERO DE ELEMENTOS DE COTORNO $=38$

CARGA DISTRIBUÍDA NA EXTREMIDADE LIVRE $=.2000000 \mathrm{E}+09 \mathrm{~Pa}$

MÓDULO DE ELASTICIDADE TRANSVERSAL $=.8000000 \mathrm{E}+11 \mathrm{~Pa}$

COEFICIENTE DE POISSON $=.2000000 \mathrm{E}+00$

ESPESSURA DA CHAPA $=0.3000000 \mathrm{E}-2$

VALOR INICIAL DO PARÂMETRO TERMODINÂMICO CRÍTICO GAMMA $=.5000000 \mathrm{E}+05$

TOLERÂNCIA DE GAMA $\mathrm{e}=.3000000 \mathrm{E}-03$

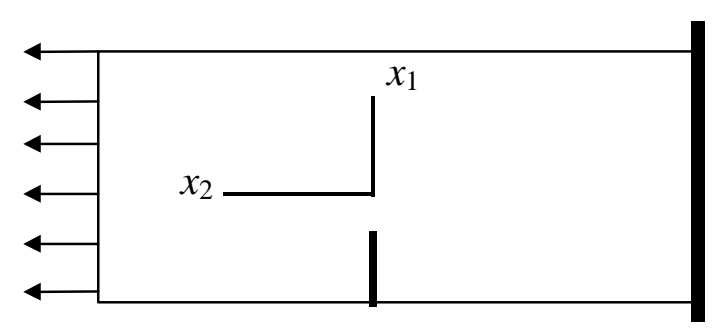

FIGURA 11- EXEMPLO 1

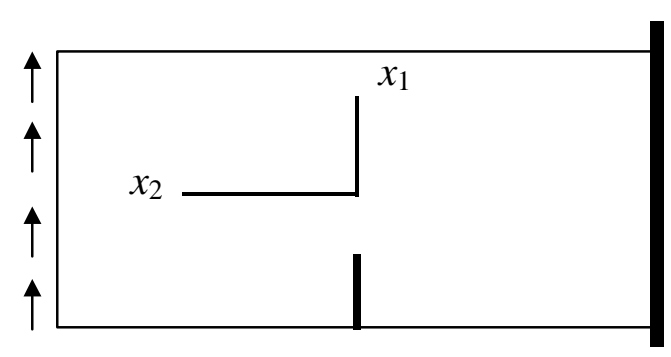

FIGURA 12- EXEMPLO 2

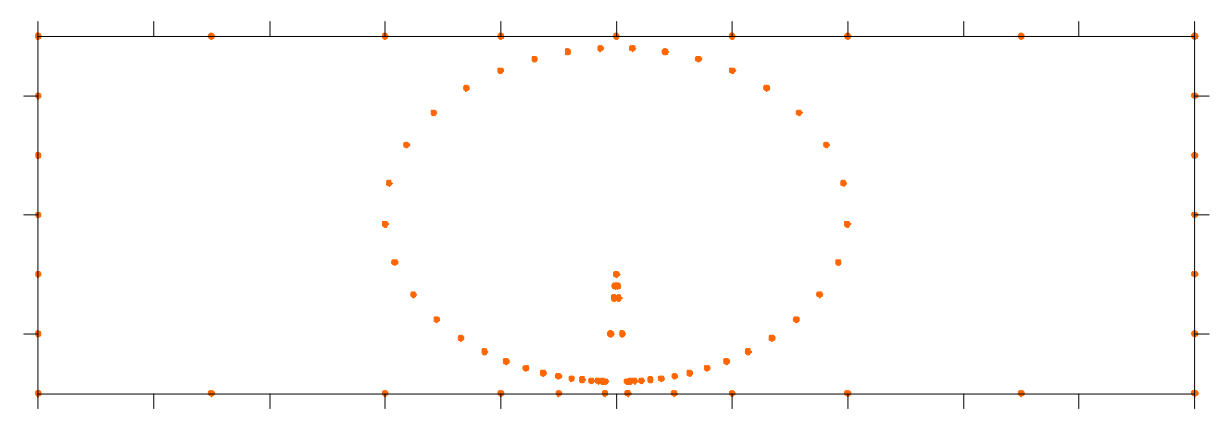

FIGURA 13- HASTE DOS EXEMPLOS 1 E 2, INDICANDO OS PONTOS DE INTEGRAÇÃO DO CONTORNO ELÍPTICO E OS NÓS DO CONTORNO

Observações: i) A unidade de comprimento adotada para as medidas indicadas na Figura 15 é o metro; ii) diferentemente do que é feito nos textos sobre fratura, a unidade a seguir considerada para a integral $J$ é Joule/metro, ou Newton, em razão de incluir-se no cálculo, por conveniência, a multiplicação pela medida da espessura da chapa (constante), o que é excluído da definição clássica de RICE (1968). Essa opção tem o intuito de fazer com que seja uma só a unidade de medida da integral $J$ e do 
parâmetro termodinâmico $G_{\mathrm{t}}$, da forma como são definidos para o caso de sólidos tridimensionais (v. Capítulo 5).

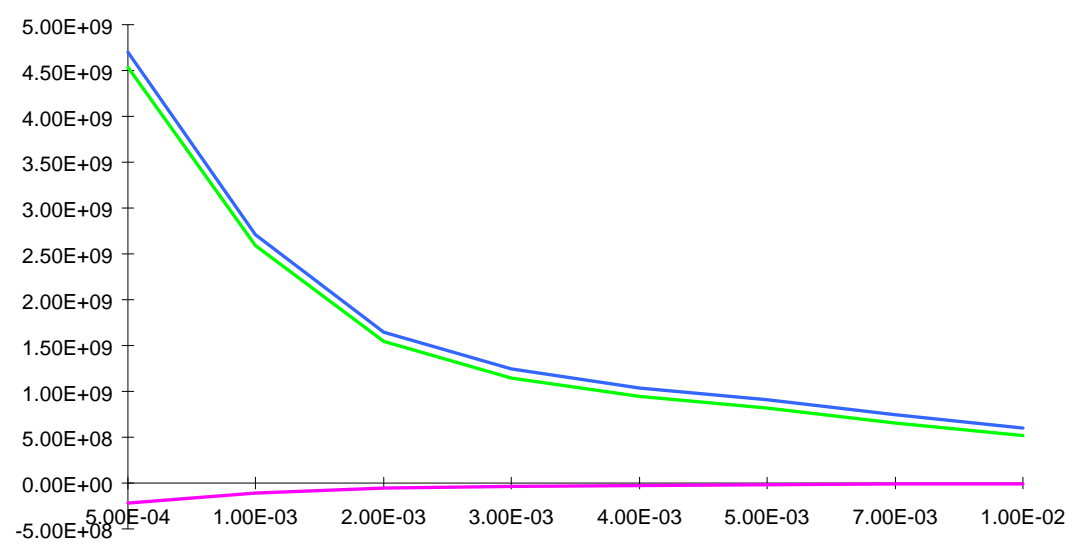

FIGURA 14- COMPONENTES $\sigma_{22}, \sigma_{11}$ E $\tau_{12}$, COMO FUNÇÃO DE $r$, NO EXEMPLO 1

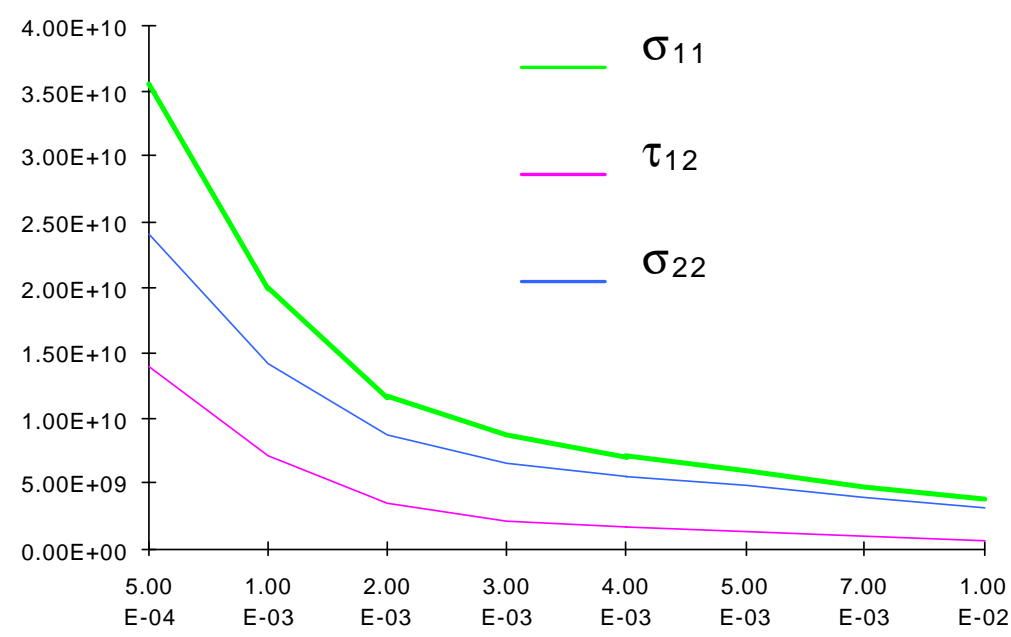

FIGURA 15- COMPONENTES $\sigma_{11}, \sigma_{22}$ E $\tau_{12}$ COMO FUNÇÃO DE $\boldsymbol{r}$, NO EXEMPLO 2

A seguir, apresentam-se os valores da integral $J$, calculados para o caso dos Exs. 1, e 2, respectivamente, para diversos valores da medida do semi-eixo maior (a), conformando os caminhos elípticos sobre os quais é calculada aquela grandeza. De acordo com a Tabela 1, verifica-se a propriedade da independência do caminho, da integral $J$, com boa aproximação. 
TABELA 1-VALORES DA INTEGRAL $\boldsymbol{J}$, CALCULADA PELO BEM (ELCFRAT), PARA O CASO DE UMA HASTE COM ENTALHE EM ÂNGULO $\left(\theta=11,42^{\circ}\right.$; abertura inferior = $\left.2 \times 10^{-2} \mathrm{~m}\right)$

\begin{tabular}{|c|c|c|}
\hline $\begin{array}{c}\text { Valor de } a \\
\mathrm{~m}\end{array}$ & $\begin{array}{c}\text { Exemplo 1 } \\
\mathrm{J} / \mathrm{m}\end{array}$ & $\begin{array}{c}\text { Exemplo 2 } \\
\mathrm{J} / \mathrm{m}\end{array}$ \\
\hline 0,250 & 629,749 & 21774,2 \\
\hline 0,300 & 630,183 & 21809,2 \\
\hline 0,400 & 630,640 & 21872,5 \\
\hline 0,450 & 630,457 & 21980,4 \\
\hline 0,490 & 630,156 & 22253,8 \\
\hline
\end{tabular}

A Tabela 2, na seqüência, dá uma idéia a respeito da influência do tipo do entalhe sobre a integral $J$. Para os mesmos Exemplos 1 e 2, obtém-se, agora, o resultado quando o entalhe tem a forma retangular. Na comparação ente as Tabelas 1 e 2 , é curioso observar que, mesmo para uma abertura muito pequena $\left(2 \times 10^{-4} \mathrm{~m}\right)$, do entalhe retangular, o fato de de a fissura ter um trecho horizontal reto, em seu final, e não um ponto, faz com que o valor da integral $J$, tanto no Exemplo 1, quanto no Exemplo 2, sofra uma alteração significativa, segundo uma razão próxima de $4: 1$.

TABELA 2-VALORES DA INTEGRAL $\boldsymbol{J}$, CALCULADA PELO BEM (ELCFRAT), QUANDO, NOS EXEMPLOS $1 \mathrm{E} 2$, O ENTALHE É RETANGULAR (abertura $=10^{-4} \mathrm{~m}$, comprimento $=10^{-1} \mathrm{~m}$ )

\begin{tabular}{|c|c|c|}
\hline Valor de $a$ & Ex 1: Tração simples: & Ex 2: Força tangencial \\
\hline 0,250 & 144,982 & 5698,08 \\
\hline 0,300 & 144,976 & 5695,27 \\
\hline 0,400 & 144,954 & 5681,16 \\
\hline 0.450 & 144,931 & 5664,14 \\
\hline 0.490 & 144,903 & 5643,33 \\
\hline
\end{tabular}

O Exemplo 3, ilustrado pela Figura 16, é útil para uma comparação com o resultado obtido para a integral $J$, por CUNHA et al.(1991), através do Método dos Elementos Finitos. Trata-se de uma peça plana, de espessura constante, com uma fissura reta, central, cuja simetria permite que a análise seja realizada na quarta parte da chapa, de acordo com a Figura 16. Na resolução via BEM, toma-se metade do 
caminho, isto é uma semi-elipse de pontos de Gauss-Legendre, em torno de uma das extremidades da fissura.

EXEMPLO 3: HASTE TRACIONADA, CONTENDO UMA FISSURA INTERNA

DADOS:

NÚMERO DE NÓS DO CONTORNO $=44$

NÚMERO DE PONTOS INTERNOS $=48$

NÚMERO DE PARES DE NÓS DUPLOS

NÚMERO DE ELEMENTOS DE CONTORNO= 39

CARGA DE TRAÇÃO, DISTRIBUÍDA NA EXTREMIDADE LIVRE $=.1000000 \mathrm{E}+09 \mathrm{~Pa}$

MÓDULO DE ELASTICIDADE TRANSVERSAL $=.8080000 \mathrm{E}+11$

COEFICIENTE DE POISSON $=.2300000 \mathrm{E}+00$

ESPESSURA DA CHAPA $=0.1000000 \mathrm{E}-2$

VALOR INICIAL DO PARÂMETRO TERMODINÂMICO CRÍTICO GAMMA $=.5000000 \mathrm{E}+05$

TOLERÂNCIA DE GAMA e $=.3000000 \mathrm{E}-03$

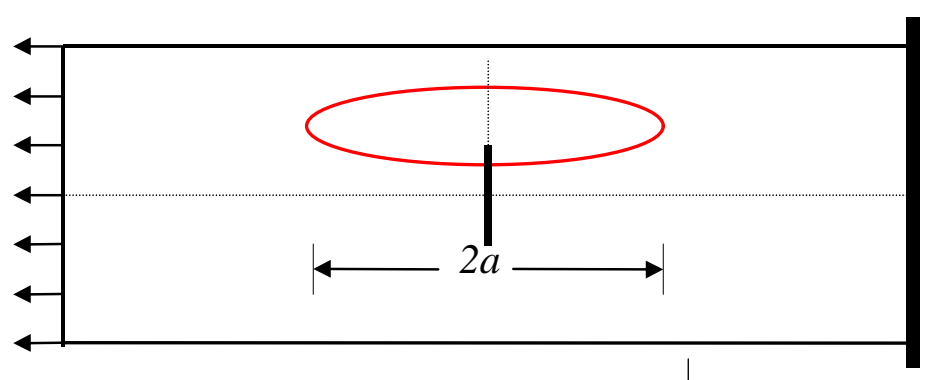

FIGURA 16- EXEMPLO 3: PEÇA COM FISSURA CENTRAL

Na Figura 17 estão indicados os nós dos elementos de contorno e os pontos de integração situados na semi-elipse da parte superior esquerda da Figura 16. Sendo assim, o valor real da integral $J$, referente a uma extremidade da fissura, deverá ser igual a duas vezes o valor calculado pelo ELCFRAT (os valores colocados na terceira coluna da Tabela 3, já estão duplicados). Observe-se que, com esse programa, só será possível o cálculo da integral $J$, no caso de fissura interna (Figura 16), quando o carregamento for simétrico em relação a um eixo, tal como a linha pontilhada longitudinal daquela figura. Assim, ao ser subdividida a peça, com base na simetria, para efeito de cálculo, o seja de tal forma a simular-se uma fissura iniciando-se no contorno. No caso, o contorno será aquela linha pontilhada longitudinal da Figura 16.

A seguir, na Tabela 3, apresentam-se os resultados referentes ao Exemplo 3, comparando-os com os obtidos para a integral $J$, por CUNHA et al. (1991), que utilizaram uma malha refinada de elementos finitos para efetuar a análise do equilíbrio, realizando o cálculo da integral $J$ em pós-processamento, com base no 
recurso ao tensor momentum- energia de Eshelby. Três caminhos de integração foram utilizados no estudo.

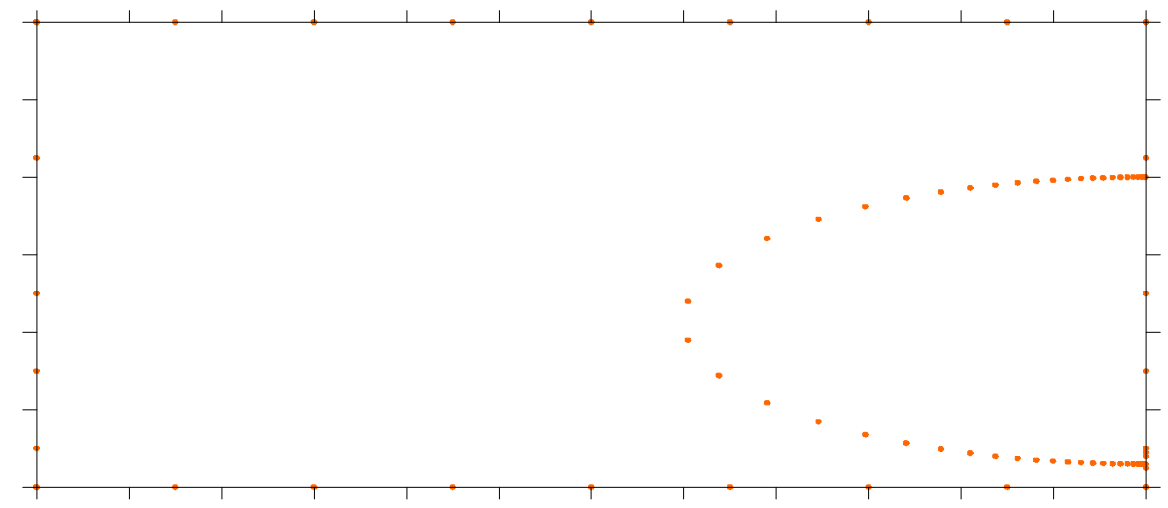

FIGURA 17- EXEMPLO 3: SEMI-ELIPSE, METADE DO CAMINHO DA INTEGRAL $\boldsymbol{J}$, EM TORNO DE UMA DAS EXTREMIDADES DA FISSURA

A malha II, como lá é referida, é obtida por um processo adaptativo, ou seja, é uma malha que permite uma melhor representação das tensões próximo à trinca. São considerados elementos triangulares de 3 nós, e depois, elementos triangulares de 6 nós. Consta, ainda, daquele trabalho, a referência a um valor de $K_{\mathrm{I}}$, calculado para o mesmo problema, tomado de OWEN \& FAWKES (1983), que seria $K_{\mathrm{I}}=560$ (unidade: ?), o que, pela expressão $J=K_{\mathrm{I}}^{2} / \mathrm{E}$, no caso do Exemplo 3, daria o valor de $J=1,4933$. No entanto, não fica claro, com a consulta à fonte acima indicada, porque esse valor de $K_{\mathrm{I}}$ pode ser tomado como o verdadeiro. Os resultados, para o cálculo da integral $J$, com base no programa ELCFRAT, que aparecem na última coluna da Tabela 3, são obtidos para três caminhos elípticos distintos, e revelam, com uma bastante razoável aproximação, a propriedade da independência do caminho de $J$. Porém, se comparados com os valores apresentados por CUNHA et al. (1995), eles diferem entre si, em torno de $3 \%$ até $9 \%$. Como há pouco foi dito, o valor de $J=1,4933$, tomado no referido trabalho, como base para avaliação da eficiência, por ser obtido a partir de $K_{\mathrm{I}}$, fator de intensidade de tensão do modo de abertura, não pode ser tomado como a expressão mais próxima da verdade. Assim, pode-se considerar que a Tabela 3 revela uma razoável aproximação entre os resultados baseados no BEM e no MEF, para a integral $J$. Quanto a questão do sistema de 
unidades, embora não haja referência ao que foi utilizado por CUNHA et al. (1995), e nem mesmo seja explicitada a unidade de medida de $K_{\mathrm{I}}$, o recurso foi admitir-se que o exemplo apresentado deveria estar algo próximo de um que foi incluído em CIMINI JUNIOR et. al (1991), no qual a unidade de força adotado é o Newton, e a unidade de comprimento é o milímetro.

TABELA 3- COMPARAÇÃo DO CÁLCULO DE $J$ (J/m) PELO MEF E PELO BEM

\begin{tabular}{|c|c|c|c|}
\hline & $\begin{array}{c}\text { CUNHA et al (1995) } \\
\text { MEF } \\
\text { linear }\end{array}$ & $\begin{array}{c}\text { CUNHA et al (1995) } \\
\text { MEF } \\
\text { quadrático }\end{array}$ & $\begin{array}{c}\text { Presente trabalho } \\
\text { BEM } \\
\text { linear }\end{array}$ \\
\hline Caminho 1 & 1,4520 & 1,4120 & - \\
\hline Caminho 2 & 1,4074 & 1,4934 & - \\
\hline Caminho 3 & 1,4618 & 1,4990 & - \\
\hline Elipse 1 $(a=0,10 \mathrm{~m})$ & - & - & 1,53851 \\
\hline Elipse 2 $(a=0,16 \mathrm{~m})$ & - & - & 1,53912 \\
\hline Elipse 3 $(a=0,18 \mathrm{~m})$ & - & - & \\
\hline
\end{tabular}

Assim sendo, os valores constantes em CUNHA et al. (1995), devem ser $K_{\mathrm{I}}=560 \mathrm{~N} / \mathrm{mm}^{3 / 2}, E=210000 \mathrm{~N} / \mathrm{mm}^{2}$. E o valor da integral $J$, segundo ele retirada de OWEN \& FAWKES (1983), e calculada através da expressão $J=K_{\mathrm{I}}^{2} / E$, deve ter o valor $1,4933 \mathrm{Nmm} / \mathrm{mm}^{2}$. Com base nessa hipótese, adotou-se uma espessura de 1 mm para a chapa, a fim de serem compatibilizados os resultados constantes das colunas 2 e 3 da Tabela 3.

No intuito de explicar-se a metodologia baseada no parâmetro termodinâmico de fratura, serão apresentados, a seguir, dois Exemplos, o 4 e o 5, com base nos mesmos dados geométricos dos Exemplos 1 e 2, respectivamente. No entanto, ao invés de uma carga uniforme aplicada em uma das extremidades da haste, têm-se agora deslocamentos uniformes prescritos, em ambas as extremidades. No caso do Exemplo 4, o valor dos deslocamentos prescritos, aplicados no sentido do aumento do comprimento da peça, é igual a $10^{-3} \mathrm{~m}$. Na Tabela 4 são apresentados os resultados referentes a esse exemplo, ficando evidenciado que, diferentemente da integral $J$, não vale a propriedade de independência do caminho no caso do parâmetro termodinâmico $G_{\mathrm{t}}$. Observe-se que é bastante razoável a previsão para a orientação do possível avanço da fissura, indicada pelos ângulos das duas últimas colunas da 
Tabela 4: a simetria dos deslocamentos prescritos sugere que o ângulo da fissura com o eixo $x_{1}$ seja zero, e nessa tabela verifica-se que dão sempre algo em torno do décimo de grau.

Neste ponto, vale descrever em linhas gerais o procedimento para a realização dos experimentos numéricos cujos resultados estão sendo apresentados. Inicialmente, fornece-se como dado ao programa ELCFRAT, um valor positivo arbitrário para o parâmetro $\gamma_{\mathrm{E}}$ e, também, uma valor de tolerância, para o cálculo iterativo do valor limite de $G_{\mathrm{t}}$. A convergência para um só valor do limite de $G_{\mathrm{t}}$, revela-se bastante boa. Além disso, conforme revela a teoria (Capítulo 5), existem as possibilidades de uma, duas, ou nenhuma solução para a direção de avanço da fissura, como solução para o problema. Isto significa dizer que, para dado um carregamento, e para dadas restrições de deslocamento no contorno, o sólido pode assumir uma dessas três opções. O que resulta mais freqüente é haver, ao final do processo iterativo, duas soluções para o ângulo da direção (em relação a $x_{1}$ ) prevista para avanço da fissura. As duas soluções, no entanto, vão sempre tendendo para um só valor, indicando que só há mesmo duas hipóteses em jogo: ou uma única solução, no caso em que a fissura avança; ou nenhuma solução, caso em que a fissura fica estável.

TABELA 4- VALORES DE $J, G_{\mathrm{t}}$ E A DIREÇÃO DE PROPAGAÇÃO DA FISSURA: EXEMPLO .4

\begin{tabular}{|c|c|c|c|c|}
\hline $\begin{array}{c}\text { Valor de } a \\
\mathrm{~m}\end{array}$ & \multicolumn{2}{|c|}{$\begin{array}{c}\text { Caso de deslocamento constante } \\
\text { prescrito nas extremidades da haste } \\
(\mathrm{J} / \mathrm{m})\end{array}$} & \multicolumn{2}{c|}{$\begin{array}{c}\text { Angulo da direção de propagação } \\
\text { da fissura com o eixo } x_{1}(\mathrm{em} \\
\text { graus })\end{array}$} \\
\hline & $J$ & $G_{\mathrm{t}}$ & $\alpha_{1}$ & $\alpha_{2}$ \\
\hline 0,200 & 1056,285 & 241,3896 & 0,1435836 & $-0,1435836$ \\
\hline 0,280 & 1056,589 & 365,0595 & 0,08337552 & $-0,08337552$ \\
\hline 0,345 & 1056,516 & 473,57781 & 0,08698883 & $-0,08698883$ \\
\hline 0,472 & 1058,628 & 703,0787 & 0,01428787 & $-0,01428787$ \\
\hline 0,495 & 1057,548 & 744,8425 & 0,05833340 & $-0,05833340$ \\
\hline
\end{tabular}

O método iterativo aqui utilizado revela, portanto, para cada caminho de integração elíptico adotado, o mínimo valor do parâmetro crítico, $G_{\mathrm{t}}$, para o qual a fissura tende a crescer. 
No Exemplo 5, a seguir, a prescrição é de um deslocamentos constante, $10^{-2}$ m, na direção tangencial, em todos os nós da face extrema esquerda, na Figura 12, ficando a outra com deslocamento nulo na mesma direção. Note-se que há uma tendência clara de convergência para um valor do ângulo de avanço da fissura em torno de $16,8^{\circ}$, sentido horário, em relação ao eixo $x_{1}$ (Tabela 5).

TABELA 5- VALORES DE $J G_{\mathrm{t}}$ E DA DIREÇÃO DE AVANÇO DA FISSURA: EXEMPLO 5

\begin{tabular}{|c|c|c|c|c|}
\hline $\begin{array}{c}\text { Valor de } a \\
(\mathrm{~m})\end{array}$ & \multicolumn{2}{|c|}{$\begin{array}{c}\text { Caso de deslocamento constante } \\
\text { prescrito nas extremidades da } \\
\text { haste }(\mathrm{J} / \mathrm{m})\end{array}$} & $\begin{array}{c}\text { Ângulo da direção de propagação } \\
\text { da fissura com o eixo } x_{1} \\
(\mathrm{grau})\end{array}$ \\
\hline & $I$ & $G$ & $\alpha$ & N. \\
\hline 0,200 & 687,9999 & 356,3301 & $-10,24077$ & $-10,25972$ \\
\hline 0,280 & 689,42519 & 438,4738 & $-11,65751$ & $-11,70861$ \\
\hline 0,345 & 690,8777 & 486,9242 & $-13,73409$ & $-13,77354$ \\
\hline 0,405 & 692,3343 & 522,0943 & $-15,27493$ & $-15,32919$ \\
\hline 0,472 & 689,7161 & 548,6402 & $-16,37041$ & $-16,43787$ \\
\hline 0,495 & 680,7566 & 550,9933 & $-16,72136$ & $-16,76072$ \\
\hline 0,499 & 678,3267 & 550,9299 & $-16,80196$ & $-16,83412$ \\
\hline
\end{tabular}

Evidentemente, $G_{\mathrm{t}}$ é um parâmetro que depende do tamanho da parte $P$ contornada pelo correspondente caminho elíptico. Isso faz com que a concepção de $G_{\mathrm{t}}$, seja a do que se denomina, na Termodinâmica, de uma grandeza extensiva. Assim, quanto maior for a extensão da parte $P$, mais aumenta a possibilidade do valor de $G_{\mathrm{t}}$ representar o que ocorre, na realidade, com o sólido inteiro.

Os valores da integral $J$, como se vê na segunda coluna da Tabela 5, mantêmse razoavelmente próximos de uma constante, como o previsto pela teoria, fazendo jus ao significado de grandeza intensiva, da Termodinâmica, semelhante à temperatura, por exemplo, cujo valor não depende da extensão do corpo.

Com o intuito de evidenciar-se a distinção entre duas as filosofias, uma, a que utiliza $J$, e outra, a que propõe a utilização alternativa de $G_{t}$, convém lembrar-se, inicialmente, que as colunas 2 e 3 das Tabela 4 e 5, apresentam resultados obtidos 
pelo ELCFRAT, calculados, portanto, no regime elástico. Daí, está implícito que, retirado o carregamento, tudo voltará à situação inicial, isto significando que esse programa não detectou, por não ser capaz de fazê-lo, qualquer avanço irreversível da fissura. Os valores de $G_{\mathrm{t}}$ aqui calculados, são, portanto, valores limites dessa grandeza, para um certo circuito elíptico, e para um dado caso de carregamento e de restrições de deslocamento no contorno da chapa. Isto significa que, se um experimento for realizado em laboratório, com um corpo de prova em tudo igual à chapa da experimentação numérica, então, no instante em que iniciar-se a fratura, o valor de $\gamma_{E}$, medido no mesmo circuito elíptico, terá correspondência com o respectivo valor limite de $G_{\mathrm{t}}$. Entenda-se por valor crítico, $\gamma_{\mathrm{E}}$, o menor valor do parâmetro termodinâmico de fratura, para um dado caminho de integração, medido em laboratório quando o entalhe começa a crescer de forma irreversível. Ora, se o material fosse, de fato, elástico linear, com os valores de $\mu$ e de $v$ corretos, e a experimentação fosse feita com rigor absoluto, o valor de $\gamma_{\mathrm{E}}$ e o valor limite de $G_{\mathrm{t}}$ tenderiam a ser iguais. Mas, se a hipótese aqui aventada, é de que a acomodação plástica, presente na vizinhança da extremidade do entalhe, deve envolver dissipação de energia, é certo que o estado de deformação, induzido por esse motivo, nos pontos do caminho usado para o cálculo de $G_{\mathrm{t}}$, irá levar a que ocorra uma diferença entre os valores dos dois parâmetros. Com base nesse raciocínio, a experimentação numérica aliada à experimentação de laboratório permitirá, portanto, a calibração de parâmetros constitutivos do material afetado pelo processo de fratura.

A metodologia de estudo da fratura baseada na integral $J$, está fundamentada na determinação experimental de valores críticos ( $J_{\text {ic }}$, por exemplo) dessa grandeza, que deverão servir de referência para critérios de integridade baseados na comparação com $J$, correspondente ao modelo teórico de um sólido em análise. O valor $J$ será determinado teoricamente, em função do carregamento e das restrições de deslocamento às quais a peça estiver submetida. A partir de uma argumentação fundamentada na propriedade da independência do caminho, costuma-se imaginar que a concepção da integral $J$ seja capaz de respaldar uma generalização próxima à de atribuir ao valor crítico de $J$ algo como uma propriedade do material. Isto é 
questionável, bastando que se relembre a razão pela qual a integral $J$ possui a propriedade de independência do caminho: conforme o apresentado no Capítulo 4.

Por outro lado, no caso da análise baseada em $G_{t}$, vale observar-se que, no referente às propriedades do material, a experimentação numérica só está informada dos valores de $\mu$ e de $v$, no pressuposto de que o sólido tenha um comportamento elástico. Em razão de que a realidade se afasta, naturalmente, dessa condição ideal, é de se esperar portanto, que seja pouco provável a coincidência entre o valor crítico, $\gamma_{\mathrm{E}}$, obtido experimentalmente, e o valor limite de $G_{\mathrm{t}}$ obtido numericamente. Assim sendo, o confronto entre esses dois valores, baseado na utilização da experimentação numérica associada à experimentação de laboratório, nos termos em que aqui se coloca, constitui-se em uma metodologia para a calibração de parâmetros de modelos elastoplásticos, desde que, naturalmente, seja usado um programa automático capaz de simular hipóteses de relações constitutivas elastoplásticas do material, na vizinhança da extremidade da fissura.

Imagina-se que essa calibração de parâmetros elastoplásticos poderá ser feita, utilizando-se qualquer parte do corpo que contenha a extremidade da fissura, desde que se assegure estar o caminho de integração, para os cálculos de $\gamma_{E}$, por um lado, e do valor limite de $G_{t}$, por outro, dentro de uma mesma região hiperelástica dessa parte. Válido esse pressuposto, podem-se fazer simulações, associando a experimentação numérica com a de laboratório, tanto para uma vizinhança próxima à fissura, quanto para outras mais distantes.

A apresentação do Exemplo 6, a seguir, cuja forma de carregamento está indicada na Figura 18, servirá para suscitar uma discussão a respeito da influência da mudança da escala geométrica e da escala do carregamento sobre os valores de $J$ e $G_{\text {t }}$ De um caso para o outro, todo o carregamento é alterado, linearmente, com o auxílio de um parâmetro.

De maneira independente, a geometria completa (inclusive o entalhe) pode também ser alterada, com o auxílio de outro parâmetro. A espessura, no entanto, não sofre a influência da escala geométrica, mantendo-se constante, e igual a $0,003 \mathrm{~m}$. A Tabela 6 evidencia a propriedade comum, de $J$ e de $G_{\mathrm{t}}$, de variarem com o quadrado 
do parâmetro do carregamento. Por outro lado, percebe-se que não parece haver qualquer fator de escala associando a variação de ambas as grandezas, com a mudança da escala geométrica da chapa.

EXEMPLO 6: HASTE COM GEOMETRIA PARAMETRIZADA, SUBMETIDA A CARREGAMENTO MISTO, TAMBÉM PARAMETRIZADO

NÚMERO DE NÓS DO CONTORNO $=54$

NÚMERO DE PONTOS INTERNOS $=48$

NÚMERO DE PARES DE NÓS DUPLOS $=16$

NÚMERO DE ELEMENTOS $=38$

FATOR DE ESC.GEOMÉTRICO HORIZONTAL $=.1000000 \mathrm{E}+01$

FATOR DE ESC. GEOMÉTRICO VERTICAL $=.1000000 \mathrm{E}+01$

MÓDULO DE ELASTICIDADE TRANSVERSAL $=.8000000 \mathrm{E}+11$

COEFICIENTE DE POISSON $=.2000000 \mathrm{E}+00$

ESPESSURA DA CHAPA $=0.3000000 \mathrm{E}-2$

VALOR INICIAL DO PARÂMETRO TERMODINÂMICO CRÍTICO $=.5000000 \mathrm{E}+05$

TOLERÂNCIA DE GAMA e $=.3000000 \mathrm{E}-03$

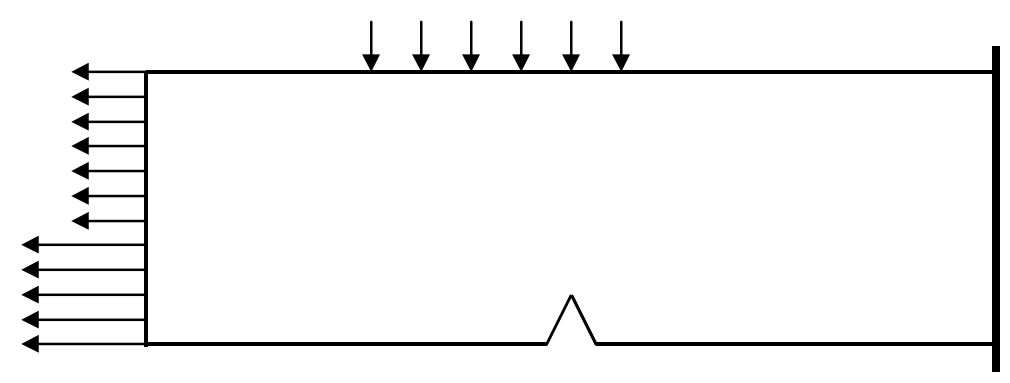

FIGURA 18- CHAPA COM GEOMETRIA E CARREGAMENTO PARAMETRIZADOS

TABELA 6- ESTUDO DA VARIAÇÃO DE $J$ E $G_{t}$, COM AS ESCALAS GEOMÉTRICA E DE CARREGAMENTO

\begin{tabular}{|c|c|c|c|c|c|c|}
\hline \multirow{2}{*}{$\begin{array}{c}\text { Valor de } a \\
\mathrm{~m}\end{array}$} & $\begin{array}{c}\text { Fator de } \\
\text { escala }\end{array}$ & \multirow{2}{*}{$\begin{array}{c}\text { Fator } \\
\text { de escala do }\end{array}$} & \multicolumn{5}{|c|}{ Exemplo 6: carregamento misto } \\
\cline { 4 - 7 } & geométrico & carregamento & $J(\mathrm{~J} / \mathrm{m})$ & $J / J_{\text {linha } 1}$ & $G_{\mathrm{t}}(\mathrm{J} / \mathrm{m})$ & $G_{\mathrm{t}} / G_{\mathrm{t} \text { linha1 }}$ \\
\hline 0,495 & 1 & 1 & 588,3567 & 1 & 859,9191 & 1 \\
\hline 0,990 & 2 & 1 & 1358,960 & 2,304 & 1489,789 & 1,732 \\
\hline 1,485 & 3 & 1 & 546,9216 & 0,930 & 149,7957 & 0,174 \\
\hline 1,980 & 4 & 1 & 1042,105 & 1,771 & 5799,524 & 6,774 \\
\hline 0,495 & 1 & 1.5 & 1323,803 & 2,250 & 1934,818 & 2.250 \\
\hline 0,495 & 1 & 2 & 2353,427 & 4,000 & 3439,677 & 4,000 \\
\hline 0,495 & 1 & 2,5 & 3677,230 & 6,250 & 5374,495 & 6,250 \\
\hline 0,495 & 1 & 3 & 5295,211 & 9,000 & 7739,272 & 9,000 \\
\hline 0,990 & 2 & 3 & 12230,64 & 20,788 & 13408,11 & 15,592 \\
\hline
\end{tabular}


Convém observar que, quando da utilização do BEM, deve-se colocar nós duplos nos pontos de transição brusca de carregamento, tais como os que aparecem nesse exemplo.

EXEMPLO 7: CHAPA CONTENDO DUAS FISSURAS INICIANDO-SE NO CONTORNO DADOS:

NÚMERO DE NÓS DO CONTORNO = 68

NÚMERO DE PONTOS INTERNOS $=48$

NÚMERO DE PARES DE NÓS DUPLOS $=23$

NÚMERO DE ELEMENTOS $=45$

FATOR DE ESC.GEOMÉTRICO HORIZONTAL $=.1000000 \mathrm{E}+01$

FATOR DE ESC. GEOMÉTRICO VERTICAL $=.1000000 \mathrm{E}+01$

MÓDULO DE ELASTICIDADE TRANSVERSAL $=.8000000 \mathrm{E}+11$

COEFICIENTE DE POISSON $=.2000000 \mathrm{E}+00$

ESPESSURA DA CHAPA $=0.3000000 \mathrm{E}-2$

VALOR INICIAL DO PARÂMETRO TERMODINÂMICO CRÍTICO $=.5000000 \mathrm{E}+05$

TOLERÂNCIA DE GAMA $\mathrm{e}=.3000000 \mathrm{E}-03$

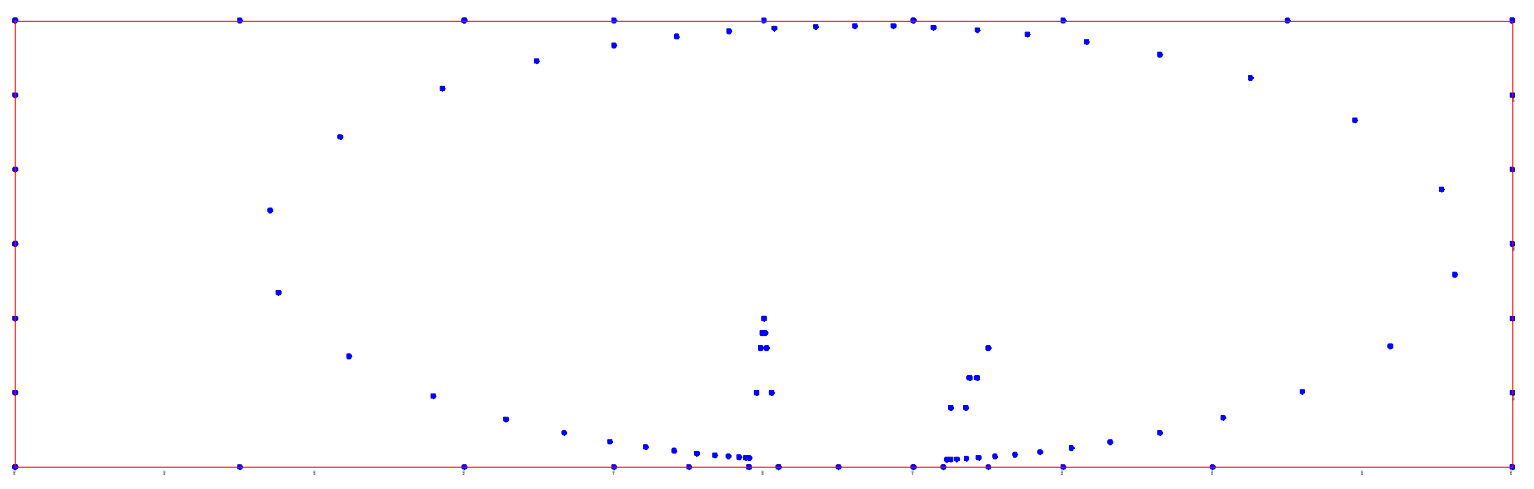

FIGURA 19- CASO DE DUAS FISSURAS: DISCRETIZAÇÃO PELO BEM E CIRCUITO ELÍPTICO INTERNO

O Exemplo 7 corresponde ao caso de uma chapa contendo duas fissuras, conforme a Figura 19, que mostra a distribuição dos nós dos elementos de contorno e dos pontos do método de Gauss-Legendre sobre o caminho elíptico usado para o cálculo de $J$ e $G_{\text {t. }}$ O carregamento, nesse caso, é do mesmo tipo do utilizado no 
exemplo anterior, tal como está na Figura 18, só que agora não parametrizado. Vê-se, pela Tabela 7, que a precisão do cálculo de $J$ é menor do que nos casos anteriores.

Quanto a $G_{\mathrm{t}}$, verifica-se que cresce quando o circuito elíptico se amplia, confirmando o seu caráter de grandeza extensiva. Observe-se que, também nesse caso, o programa ELCFRAT faz a previsão do ângulo segundo o qual a fissura tenderia a seguir, caso houvesse o avanço. Mas, no caso, há duas fissuras, de modo que a interpretação do resultado tem de ser dada em função do instrumento analítico que está por trás dessa determinação. No caso, tal instrumento é a Análise de Sensibilidade e como tal, o que prevê é a indicação de uma tendência média, relacionada com a direção do avanço do processo termodinâmico associado ao conjunto das duas fissuras.

TABELA 7- VALORES DE $J$ E DE $G_{T}$, NO CASO DE UMA CHAPA CONTENDO DUAS FISSURAS

\begin{tabular}{|c|c|c|}
\hline Valor de $a(\mathrm{~m})$ & $J(\mathrm{~J} / \mathrm{m})$ & $G_{\mathrm{t}}(\mathrm{J} / \mathrm{m})$ \\
\hline 0,30 & 533,0004 & 915,9679 \\
\hline 0,35 & 554,2414 & 760,5400 \\
\hline 0,38 & 560,3449 & 853,3931 \\
\hline 0,40 & 559,8806 & 915,9679 \\
\hline 0,43 & 550,7285 & 1010,146 \\
\hline
\end{tabular}

O Exemplo 8, a seguir, ilustra como se pode aproveitar os resultados de outro programa automático, seja baseado no BEM e/ou no MEF, para calcular-se o valor limite de $G_{\text {t }}$. Exige-se, obviamente, que o cálculo das tensões tenha boa precisão, deslocando-se a questão, assim, do âmbito do estudo da fratura, para o âmbito da eficiência numérica do método aproximado.

No presente caso, utiliza-se um programa automático de elementos de contorno com mais recursos que o ELCFRAT. Trata-se de um programa organizado pelo Prof. Humberto Coda, da EESC-USP, que faz uso de elementos isoparamétricos quadráticos, estando apto a resolver problemas bidimensionais, estáticos ou dinâmicos, podendo trabalhar com os modelos elastoplásticos de Tresca, von Mises, Mohr ou Drucker-Prager. 
Do ponto de vista da metodologia aqui adotada, a importância da utilização de um programa com essas características está, em primeiro lugar, na possibilidade de delimitar-se a zona de processo da fissura, isto é, o bulbo de plasticidade em torno da extremidade. Em segundo lugar, serve também para de selecionar uma região hiperelástica, para assim balizar o caminho de integração sobre o qual será calculado o valor limite de $G_{\mathrm{t}}$, atendendo à exigência da teoria.

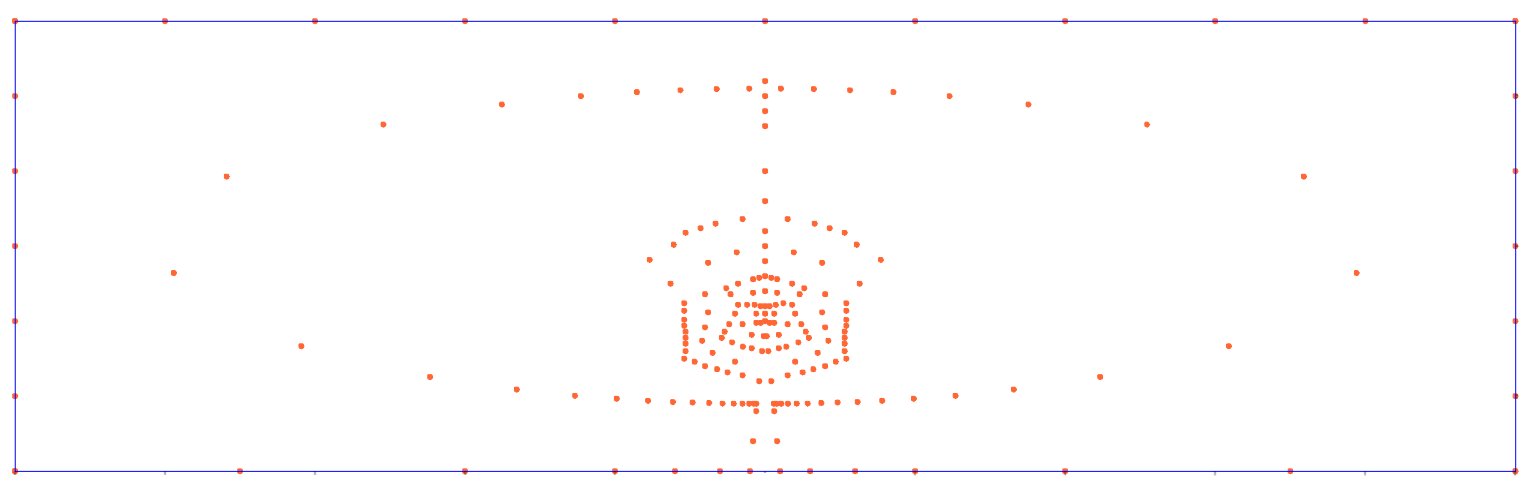

FIGURA 20- CONTORNO ELÍPTICO E CÉLULAS INTERNAS EM TORNO DA EXTREMIDADE DA FISSURA

Para isso, faz-se uso do recurso da colocação de células internas em torno da extremidade da fissura, tais como aquelas cujos pontos limítrofes estão mostrados na Figura 20. A colocação dessas células é obrigatória quando o BEM é usado, porque depende delas a possibilidade de serem incluídos os efeitos de plasticidade, na forma de tensões residuais, na seqüência do processo incremental-iterativo utilizado na análise elastoplástica. Evidentemente, é necessário certa sensibilidade para a escolha adequada dessas células.

Por outro lado, o uso do recurso às células internas serve para que se delimite o bulbo de plasticidade formado em torno da extremidade da fissura, no pressuposto de que o efeito de acomodação plástica seja algo localizado e dependente, somente da presença dessa fissura.

No exemplo em análise, utiliza-se o critério de von Mises, em que a constante de hardening é tomada como nula, o que quer dizer, elastoplasticidade perfeita. 
EXEMPLO 8 DESLOCAMENTO PRESCRITO NAS EXTREMIDADES:

$\delta \quad=.05 \mathrm{~mm}$. VON MISES, $\mathrm{h}=0$.

DADOS:

NÚMERO DE INCREMENTOS DE CARGA $=5$

MÓDULO DE ELASTICIDADE TRANSVERSAL $=.8000000 \mathrm{E}+11$

COEFICIENTE DE POISSON $=.2000000 \mathrm{E}+00$

ESPESSURA CONSTANTE DA CHAPA $=.003000000 \mathrm{E}+00$

TENSÃO LIMITE DE PLASTICIDADE $=.2500000 \mathrm{E}+09$

PARÂMETRO TERMODINÂMICO CRÍTICO $=.5000000 \mathrm{E}+04$

TOLERÂNCIA DE GAMA $\mathrm{e}=.3000000 \mathrm{E}-03$

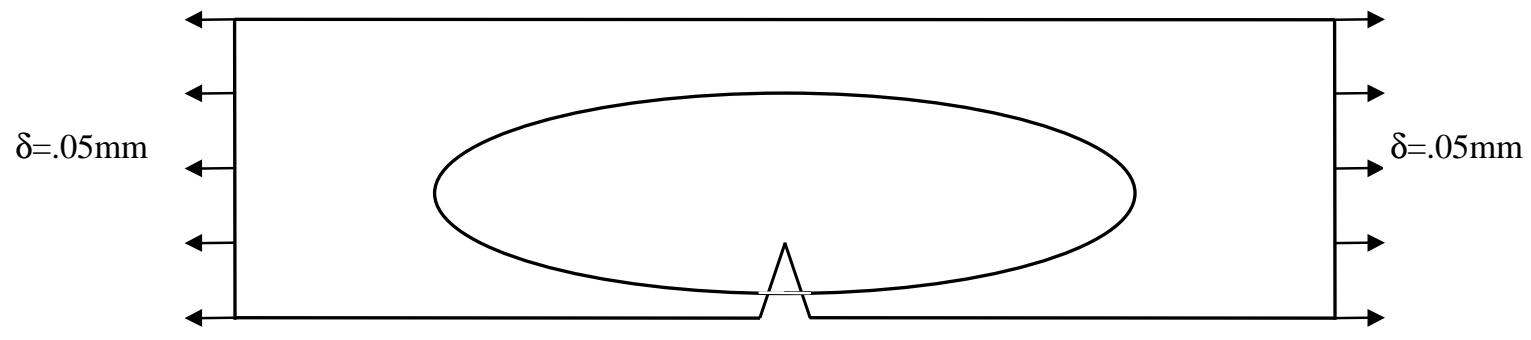

FIGURA 21 - CHAPA COM DESLOCAMENTOS PRESCRITOS NAS EXTREMIDADES

Para a finalidade de inserir, como dados do problema de fratura, as tensões saídas da análise elastoplástica, elaborou-se um programa automático, PLASTFRAT, incluído no disquete que acompanha a tese, que fornece, para um determinado circuito elíptico, a cada incremento de carga, o valor limite de $G_{\mathrm{t}}$. Como ilustração, apresenta-se, a seguir, a entrada de dados do PLASTFRAT, evidenciando-se que pode ser facilmente adaptada para ler qualquer outra saída de tensões, ressaltando-se ainda que, em virtude de a subrotina que calcula a densidade de energia de deformação ter sido feita para casos bidimensionais, o uso do PLASTFRAT fica restrito a esses casos. No entanto, para problemas mais gerais, de placas, cascas, ou tridimensionais, basta que se incluam as devidas parcelas do expressão da energia de deformação, além, evidentemente, do caminho de integração, que pode ser uma linha (no plano, ou no espaço), ou uma superfície, no caso tridimensional. O que vale a pena comentar, é que a utilização da metodologia do BEM facilita bastante a 
utilização de caminhos de integração parametrizados, tal como é feito no ELCFRAT e no PLASTFRAT, em que a opção foi por caminhos de forma elíptica.

TABELA 8 - VALORES DE $G_{\mathrm{T}}$ EM UM CASO DE ELASTOPLASTICIDADE PERFEITA

\begin{tabular}{|c|c|c|}
\hline $\begin{array}{c}\text { Incremento de } \\
\text { deslocamento }\end{array}$ & Comportamento & $G_{\mathrm{t}}(\mathrm{J} / \mathrm{m})$ \\
\hline 1 & elástico & 0,5494554 \\
\hline 2 & elastoplástico & 0,025578 \\
\hline 3 & elastoplástico & 0,415873 \\
\hline 4 & elastoplástico & 0,949044 \\
\hline 5 & elastoplástico & $-0,131202$ \\
\hline
\end{tabular}

Os resultados acima referem-se a um circuito elíptico com centro no centro geométrico da chapa, sendo o eixo maior igual a $0,3 \mathrm{~m}$ e eixo menor igual $0,21 \mathrm{~m}$.. Como bem se observa na Tabela 8 , os números da terceira coluna carecem de uma interpretação cuidadosa, por conta de que não seria de se esperar um valor negativo para $G_{\text {t. }}$ No entanto, convém lembrar que as integrações levadas a efeito numericamente, dentro da metodologia do BEM, são muito sensíveis, havendo de se verificar se o esquema de sub-elementação está sendo adequado à precisão exigida pelo método, para o valor das componentes de tensão.

Para concluir, apresenta-se, a seguir, o esquema de entrada de dados do programa PLASTFRAT, no caso de elastoplasticidade perfeita, o caso do Exemplo 8:

a) Dados gerais do problema, lidos em formato livre: NP, NIP, NIC, GE, ,XNU, TE, TENPLAS, GAMMA, TOL.

. NP é o número de incrementos de carga

. NIP é o número de pontos internos, onde tensão e deslocamento são calculados. Tem de ser igual ao numero de pontos de Gauss usados na sub-rotina INTEGJ. No caso, está fixado em 48.

. NIC é o número de pontos internos, os isolados mais os dos contornos das células.

. GE é o módulo de elasticidade transversal. 
. XNU será o coeficiente de Poisson, $v$, se o estado plano for de deformação. Se o problema é de estado plano de tensão, entrar com $\mathrm{XNU}=\mathrm{v} /(1+\mathrm{v})$

. TE é a espessura da chapa.

. TENPLAS é a tensão limite de plasticidade.

. GAMMA é um número real positivo qualquer.

. TOL é a tolerância, para o processo iterativo que busca o valor limite de $G_{\text {t. }}$ Pode ser dado como um número muito pequeno (abaixo de $10^{-3}$, por exemplo)

b) Dados do circuito elíptico de integração, lidos em formato livre: X0, Y0, CX1, CY1, CX2, CY2, ELIPSY

. X0,Y0 são as coordenadas do centro da elipse.

- CX1,CY1 são as coordenadas do primeiro ponto do circuito de integração, e CX2,CY2, o mesmo, para o último ponto do circuito(sentido de percurso antihorário).

. ELIPSY é a medida do semi-eixo maior da elipse, no eixo $x_{2}$.

c) Leitura das componentes de tensões vindas de outro programa: Convém observar que a leitura desses dados deve-se restringir somente aos pontos internos (os do esquema de Gauss-Legendre) situados sobre o contorno elíptico. Seu número é dado por NIP. 


\section{CONCLUSÕES}

A iniciativa da aproximação entre a Mecânica da Fratura, a Termodinâmica, a Mecânica do Contínuo, a Análise de Sensibilidade e o Método dos Elementos de Contorno, organizada no presente trabalho, contribuiu para o refinamento dos instrumentos teóricos e numéricos de análise, com um objetivo bem delineado: atacar o problema da fratura, a partir da busca de uma alternativa à hipótese introduzida por Griffith, segundo a qual seria legítima a aplicação do Princípio da mínima energia potencial elástica à interpretação de um fenômeno essencialmente dissipativo, como o da fratura. Quando se imagina que além de Grifith, Irwin e Rice também desenvolveram suas importantes concepções a partir da idéia de energy release rate (derivada da energia potencial elástica em relação a um parâmetro geométrico da fissura), percebe-se que o presente trabalho contribui com novos elementos para a discussão sobre os fundamentos do tema em estudo.

Embora a idéia de uma teoria termodinamicamente consistente da fratura não seja original, alguns resultados aqui apresentados o são. Dentre eles, destaca-se a obtenção da equação geral do balanço termomecânico local, nos pontos da superfície de avanço de uma fissura, eq. (2.20), no Capítulo 2, resultado que decorreu, por sinal, da idéia de utilizar-se, diretamente, a definição da integral de Riemann para a obtenção de derivadas materiais no tempo, apresentada no Anexo B. A aplicação da função energia livre de Helmholtz, para chegar-se a um critério de iniciação de fratura, seguindo um caminho semelhante ao de Griffith, no caso quase estático e isotérmico, também parece ser uma contribuição original. A maneira de utilização do BEM, tanto no cálculo da integral $J$, quanto no cálculo de $G_{\mathrm{t}}$, bem como a dedução da expressão válida para o contorno, via Análise de Sensibilidade, para o cálculo desse último parâmetro, também são contribuições trazidas pelo presente trabalho. Além disso, a proposta, apresentada no Capítulo 6, para a determinação de 
experimental do valor crítico de $G_{\mathrm{t}}$, com o auxílio de extensômetros elétricos de resistência (strain gages), é também uma contribuição, cujo desenvolvimento posterior pode levar à elaboração de um procedimento normalizado com essa finalidade.

Acredita-se que o principal objetivo da pesquisa foi atingido, com a determinação do parâmetro $G_{\mathrm{t}}$ adequado à aplicação prática da interpretação termodinamicamente consistente do fenômeno da fratura, no caso isotérmico e quase estático. Partindo da hipótese de que o fenômeno da fratura obedece à Primeira e à Segunda Leis da Termodinâmica, a pesquisa do parâmetro $G_{\mathrm{t}}$ foi auxiliada pela adoção formal dos paradigmas de Griffith (critério de iniciação de fratura) e de Rice (integral $J$ ), embora a negação da essência conceitual de ambos esteja implícita, em razão da opção do trabalho pela busca de uma interpretação termodinâmica, com base na consideração de que o avanço da fissura é um fenômeno irreversível.

A percepção de que a energia livre de Helmholtz poderia ser utilizada, no caso particular do regime isotérmico, para aperfeiçoar o estudo da iniciação e do avanço de uma fissura, ao estilo da análise de Griffith, forneceu uma saída importante para o desenvolvimento do trabalho. Daí surgiram, tanto o parâmetro termodinâmico $G_{\mathrm{t}}$, útil à construção de um novo critério de iniciação, ou continuidade, do avanço da fissura, quanto uma nova forma de prever-se a direção desse avanço .

Embora o recurso à Mecânica do Contínuo tenha sido fundamental para o embasamento das conclusões práticas que emergiram ao final, é certo que só os problemas em regime quase estático e isotérmico foram satisfatoriamente abordados, restando ainda os problemas dinâmicos e os não isotérmicos. No caso dos problemas dinâmicos, a base está bem construída, bastando que se elabore melhor a questão do experimento capaz de fornecer o valor crítico do $G_{\mathrm{t}}$ dinâmico. No caso dos problemas não isotérmicos, no entanto, em razão de não ser possível, nesses casos, o recurso à energia livre de Helmholtz para a interpretação do avanço da fissura, a metodologia a ser desenvolvida, tende a ser bastante distinta da utilizada no caso isotérmico. Mas, certamente, a base foi construída. Acredita-se, assim, que o 
fundamento teórico está seguramente colocado e que a investigação de parâmetros experimentais capazes de permitir o estudo termodinamicamente consistente da fratura, também no caso não isotérmico, fica como proposta para a continuidade da pesquisa.

A utilização do Método dos Elementos de Contorno como ferramenta numérica para a obtenção da integral $J$ e do parâmetro $G_{\mathrm{t}}$, a partir de um método baseado na Análise de Sensibilidade, revela-se bastante promissora como uma alternativa simples para uso prático, na medida em que a obtenção de $G_{\mathrm{t}}$ (ou também da integral $J$ ) é praticamente um trabalho de pós-processamento, desde que sejam fornecidas as informações, sobre a distribuição de tensões e dos gradientes de deslocamento, advindas de programas automáticos que não precisam ser, necessariamente, especializados em Mecânica da Fratura, nem em Elementos de Contorno. Espera-se que, com isso, os problemas tridimensionais de fratura, ou de placas e cascas, possam ser resolvidos com muito maior facilidade, em razão de que o método desenvolvido, para percorrer-se o caminho de integração (elíptico, no caso do programa automático aqui apresentado), pode ser facilmente adaptado para outros tipos de caminho, inclusive sobre superfícies, no caso problemas tridimensionais.

A possibilidade de aperfeiçoamento do método de obtenção, em laboratório, do valor crítico, $\gamma_{\mathrm{E}}$, esboçado no Capítulo 6, pode levar, naturalmente, a um procedimento normativo inovador, tanto para esse caso, quanto também para o caso de $J_{\text {ic. }}$. Além disso, aquela proposta abre a perspectiva de uma experimentação bastante adequada a finalidades de pesquisa de parâmetros de modelos elastoplásticos, válida também para casos fora da Mecânica da Fratura.

A rigor, a síntese do resultado deste trabalho encaminha-se para o reforço da idéia de unificação dos procedimentos de análise, nos níveis teórico, numérico e de experimentação em laboratório, visando ao aperfeiçoamento da caracterização da integridade dos sólidos, sem a necessidade de distinções qualitativas relevantes, e dignas de tratamentos especializados, entre todos fenômenos de caráter dissipativo desenvolvido nos sólidos, tenham eles o nome de microfissuração, dano, plasticidade, ou fratura. Espera-se que a concepção do parâmetro $G_{\mathrm{t}}$, dependente do 
caminho, mas com uma fundamentação física segura, possa ser útil à calibração de parâmetros característicos de modelos elastoplásticos, podendo assim, servir à idéia unificadora do estudo dos problemas de integridade das estruturas e seus componentes. 


\section{ANEXO A}

\section{ELEMENTOS DE ÁLGEBRA E DE ANÁLISE TENSORIAL ${ }^{1}$}

\section{A. 1 Tensores}

Seja $E$ o espaço euclidiano pontual tridimensional. Os elementos desse espaço são denominados pontos. A expressão vetor será adotada para os elementos do espaço vetorial associado, $V$. A diferença entre dois pontos quaisquer, $x$ e $y$ de $E$, define um vetor $\mathbf{v}$, tal que:

$\mathbf{v}=x-y \quad \mathrm{e} \quad-\mathbf{v}=y-x$.

A soma de um ponto e um vetor define um ponto:

$x=y+\mathbf{v}$.

A soma de dois pontos não possui significado.

Escolhida uma base ortonormal $\left\{\mathbf{e}_{\mathrm{i}}\right\}$ em $V$, a origem $o$ de $E$ e essa base formam um sistema de referência, ou referencial de $E$. Daí, todo ponto de $E$ pode ser escrito como

$x=(x-o)+o$,

sendo suas coordenadas relativas a $\left\{\mathbf{e}_{i}\right\}$, definidas por:

$x^{\mathrm{i}}=(x-o) \cdot \mathbf{e}_{\mathrm{i}}$,

${ }^{1}$ O presente Anexo valeu-se, basicamente, da síntese encontrada em FEIJÓO (1978). 
na qual é usado o ponto para indicar o produto interno (ou escalar) de dois vetores. A definição de produto interno de um vetor qualquer u por si mesmo, leva, de uma forma natural, ao conceito de norma de um vetor:

$$
\|\mathbf{u}\|=\sqrt{\mathbf{u} \cdot \mathbf{u}}
$$

Tensor. Chama-se tensor a qualquer transformação linear $\mathbf{T}: V \rightarrow V$, sendo $V$ o espaço vetorial associado ao espaço euclidiano pontual $E$. Isto significa que $T$ associa a cada vetor $\mathbf{v} \in V$ um único vetor $\mathbf{u} \in V$ :

$\mathbf{u}=\mathbf{T} \mathbf{v}$

Entende-se por transformação linear a aplicação que possui as seguintes propriedades:

$\mathbf{T}(\mathbf{u}+\mathbf{v})=\mathbf{T u}+\mathbf{T} \mathbf{v}, \quad \forall \mathbf{u}, \mathbf{v} \in V$,

$\mathbf{T}(\alpha \mathbf{u})=\alpha \mathbf{T u} \quad \forall \alpha \in \mathrm{IR}, \forall \mathbf{u} \in V$.

O conjunto de todos os tensores $\mathbf{T}, \mathbf{T}: V \rightarrow V$, é denominado $\operatorname{Lin}$. Se em $\operatorname{Lin}$ definimos a adição de dois tensores por:

$\left(\mathbf{T}_{1}+\mathbf{T}_{2}\right) \mathbf{u}=\mathbf{T}_{1} \mathbf{u}+\mathbf{T}_{2} \mathbf{u}, \quad \forall \mathbf{u} \in V$

e a multiplicação por escalar:

$(\alpha \mathbf{T}) \mathbf{u}=\alpha \mathbf{T} \mathbf{u} \quad \forall \mathbf{T} \in \operatorname{Lin}, \forall \alpha \in \mathrm{IR}, \forall \mathbf{u} \in V$,

então Lin, munido dessas duas operações é um espaço vetorial. Neste espaço existe um tensor nulo, representado por $\mathbf{0}$, tal que:

$\mathbf{0} \mathbf{u}=\mathbf{0}, \forall \mathbf{u} \in V$.

Observe-se que o símbolo 0 também está sendo usado para representar o vetor nulo de $V$. O tensor identidade, designado por I, é tal que:

$\mathbf{I} \mathbf{u}=\mathbf{u}, \forall \mathbf{u} \in V$. 
O produto de dois tensores, $\mathbf{T}$ e $\mathbf{S}$, indicada por $\mathbf{T S}$, é definida como a composição de ambas aplicações, isto é:

$\mathbf{T} \mathbf{S}=\mathrm{T}$ o $\mathbf{S}$, onde

( T S $) \mathrm{u}=\mathbf{T}(\mathbf{S} \mathbf{u})$.

Verifica-se que o produto de tensores possui as seguintes propriedades:

Associativa:

$\mathbf{T}(\mathbf{S D})=(\mathbf{T S}) \mathbf{D}$,

distributiva, em relação à adição de dois tensores:

$\mathbf{T}(\mathbf{S}+\mathbf{D})=\mathbf{T S}+\mathbf{T D}$,

$(\mathbf{S}+\mathbf{D}) \mathbf{T}=\mathbf{S T}+\mathbf{D T}$,

distributiva, em relação à adição escalar:

$(a+b) \mathbf{T}=a \mathbf{T}+b \mathbf{T} \quad \forall a, b \in \mathrm{IR}$,

$\mathrm{I} \mathrm{T}=\mathrm{T} \mathrm{I}=\mathrm{T}$.

Quando TS=ST diz-se que $\mathbf{T}$ e $\mathbf{S}$ comutam, embora esta não seja uma propriedade válida no conjunto de todas as aplicações lineares de $V$ em $V$.

A definição de produto de tensores permite que se fale de potências de um tensor. Assim:

$\mathbf{T}^{0}=\mathbf{I}, \mathbf{T}^{1}=\mathbf{T}, \mathbf{T}^{1}=\mathbf{T} \mathbf{T}$, etc.

A associatividade do produto permite que se tenha:

$\mathbf{T}^{\mathrm{m}+\mathrm{n}}=\mathbf{T}^{\mathrm{m}} \mathbf{T}^{\mathrm{n}}=\mathbf{T}^{\mathrm{n}} \mathbf{T}^{\mathrm{m}}$

Associando-se os conceitos anteriores, define-se polinômio de um tensor $\mathbf{T}$ como sendo:

$$
\mathrm{f}(\mathbf{T})=a_{0} \mathbf{I}+a_{1} \mathbf{T}^{\mathbf{1}}+\ldots a_{i} \mathbf{T}^{\mathrm{i}}+\ldots a_{n} \mathbf{T}^{\mathbf{n}}, \quad a_{i} \in \mathrm{IR}
$$


é uma função tensorial de argumento tensorial que pode ser associada a um polinômio de grau $n$, com coeficientes $a_{0}, a_{1}, \ldots a_{\mathrm{n}}$.

Tensor transposto. $\mathrm{O}$ tensor transposto de um tensor arbitrário $\mathbf{T}$ é o único tensor, $\mathbf{T}^{\mathrm{T}}$, com a propriedade:

$\mathbf{T u} \cdot \mathbf{v}=\mathbf{u} \cdot \mathbf{T}^{\mathrm{T}} \mathbf{v}, \forall \mathbf{u}, \mathbf{v} \in: V$.

Daí resulta que:

$(\mathbf{S}+\mathbf{T})^{\mathrm{T}} \mathbf{u} \cdot \mathbf{v}=\mathbf{u} \cdot(\mathbf{S}+\mathbf{T}) \mathbf{v}=\mathbf{u} \cdot \mathbf{S} \mathbf{v}+\mathbf{u} \cdot \mathbf{T} \mathbf{v}=\mathbf{S}^{\mathrm{t}} \mathbf{u} \cdot \mathbf{v}+\mathbf{T}^{\mathrm{T}} \mathbf{v}=\left(\mathbf{S}^{\mathrm{T}}+\mathbf{T}^{\mathrm{T}}\right) \mathbf{u} \cdot \mathbf{v}$

e $\quad(\alpha \mathbf{S})^{\mathrm{T}} \mathbf{u} \cdot \mathbf{v}=\mathrm{u} \cdot(\alpha \mathbf{S}) \mathbf{v}=\alpha \mathbf{u} \cdot \mathbf{S v}=\alpha \mathbf{S}^{\mathrm{T}} \mathbf{u} \cdot \mathbf{v}, \quad \forall \alpha \in \mathrm{IR}$,

o que assegura ser a transposição, uma operação linear que associa cada tensor de Lin a seu transposto, também em Lin.

O transposto do produto de dois tensores é definido como:

$(\mathbf{S T})^{\mathrm{T}}=\mathbf{T}^{\mathrm{T}} \mathbf{S}^{\mathrm{T}}$.

De fato:

$(\mathbf{S T})^{\mathrm{T}} \mathbf{u} \cdot \mathbf{v}=\mathbf{u} \cdot(\mathbf{S T}) \mathbf{v}=\mathbf{u} \cdot \mathbf{S}(\mathbf{T v})=\mathbf{S}^{\mathrm{t}} \mathbf{u} \cdot \mathbf{T} \mathbf{v}=\left(\mathbf{T}^{\mathrm{T}} \mathbf{S}^{\mathrm{T}}\right) \mathbf{u} \cdot \mathbf{v}$

Da mesma maneira, pode-se mostrar que:

$\left(\mathbf{S}^{\mathrm{T}}\right)^{\mathrm{T}}=\mathbf{S}$.

Diz-se que um tensor é simétrico se:

$\mathbf{S}=\mathbf{S}^{\mathrm{T}}$

e anti-simétrico se:

$\mathbf{S}=-\mathbf{S}^{\mathrm{T}}$

Todo tensor admite uma decomposição única:

$\mathbf{S}=\operatorname{sym} \mathbf{S}+$ skw $\mathbf{S}$. 
Assim sendo:

$\operatorname{sym} \mathbf{S}=\left(\mathbf{S}+\mathbf{S}^{\mathrm{T}}\right) / 2, \quad$ parte simétrica de $\mathbf{S}$,

skw $\mathbf{S}=\left(\mathbf{S}-\mathbf{S}^{\mathrm{T}}\right) / 2, \quad$ parte anti-simétrica de $\mathbf{S}$

Por ser a transposição uma aplicação linear de Lin em Lin, segue-se que:

(1) Toda combinação linear de tensores simétricos é um tensor simétrico, e

(2) toda combinação linear de tensores anti-simétricos é um tensor anti-simétrico.

Assim, o conjunto de todos os tensores simétricos, que será denominado Sym, e o dos tensores anti-simétricos, que será denominado $S k w$, são dois subespaços de Lin. Convém observar que o produto de dois tensores simétricos (respectivamente, anti-simétricos) não é necessariamente um tensor anti-simétrico (respectivamente, anti-simétrico).

Outros resultados dignos de nota são os seguintes:

(1) Seja $\mathbf{E} \in S y m$ e $\mathbf{W} \in S k w$, tensores arbitrários, logo:

$\mathbf{u} . \mathbf{W} \mathbf{u}=\mathbf{0}, \forall \mathbf{u} \in V$.

Para demonstrar, basta a que se use as definições de tensor transposto, eq. (A.17), e de tensor anti-simétrico, eq. (A.22), para um vetor u arbitrário:

$\mathbf{u} \cdot \mathbf{W} \mathbf{u}=\mathbf{W}^{\mathrm{T}} \mathbf{u} \cdot \mathbf{u}=-\mathbf{W} \mathbf{u} \cdot \mathbf{u} \Rightarrow 2(\mathbf{u} \cdot \mathbf{W} \mathbf{u})=0$.

(2) Seja $\mathbf{S}=\mathbf{E}+\mathbf{W}$, logo:

$\mathbf{u} . \mathbf{S} \mathbf{u}=\mathbf{u} . \mathbf{E} \mathbf{u} \forall \mathbf{u} \in V$,

uma conseqüência direta de (1).

Produto tensorial. O produto tensorial de dois vetores $\mathbf{u}, \mathbf{v} \in V$, representado por $\mathbf{u} \otimes \mathbf{v}$, é um tensor que a cada vetor $\mathbf{w} \in V$, associa um vetor paralelo a $\mathbf{u}$, dado por $\mathbf{u}(\mathbf{v . w})$, isto é:

$(\mathbf{u} \otimes \mathbf{v}) \mathbf{w}=\mathbf{u}(\mathbf{v} \cdot \mathbf{w}), \quad \forall \mathbf{w} \in V$ 
Observe-se que $\mathbf{u} \otimes \mathbf{v}: V \rightarrow V$ é uma aplicação linear e, portanto, é um tensor. Com base na definição de produto tensorial, verifica-se que:

(1) $(\mathbf{u} \otimes \mathbf{v})^{\mathrm{T}}=(\mathbf{v} \otimes \mathbf{u})$.

Demonstração:

Sejam $\mathbf{d}, \mathbf{w} \in V$ vetores arbitrários. Utilizando-se propriedades anteriores, tem-se:

$(\mathbf{u} \otimes \mathbf{v})^{\mathrm{T}} \mathbf{d} \cdot \mathbf{w}=\mathbf{d} \cdot(\mathbf{u} \otimes \mathbf{v}) \mathbf{w}=\mathbf{d} \cdot \mathbf{u}(\mathbf{v} \cdot \mathbf{w})=(\mathbf{v} \cdot \mathbf{w})(\mathbf{u} \cdot \mathbf{d})=(\mathbf{v})(\mathbf{u} \cdot \mathbf{d}) \cdot \mathbf{w}=$ $=(\mathbf{v} \otimes \mathbf{u}) \mathbf{d} \cdot \mathbf{w}$.

(2) $(\mathbf{u} \otimes \mathbf{v})(\mathbf{c} \otimes \mathbf{d})=(\mathbf{v . c}) \mathbf{u} \otimes \mathbf{d}$.

Demonstração:

Seja $\mathbf{w} \in V$, logo:

$[(\mathbf{u} \otimes \mathbf{v})(\mathbf{c} \otimes \mathbf{d})] \mathbf{w}=(\mathbf{u} \otimes \mathbf{v}) \mathbf{c}(\mathbf{d} \cdot \mathbf{w})=\mathbf{u}(\mathbf{v} \cdot \mathbf{c})(\mathbf{d} \cdot \mathbf{w})=(\mathbf{v} \cdot \mathbf{c}) \mathbf{u}(\mathbf{d} \cdot \mathbf{w})=$ $=(\mathbf{v} \cdot \mathbf{c})(\mathbf{u} \otimes \mathbf{d}) \mathbf{w}$.

(3) Seja $\left\{\mathbf{e}_{\mathbf{i}}\right\}$ uma base ortonormal de $V$, isto é, $\mathbf{e}_{\mathrm{i}} \cdot \mathbf{e}_{\mathrm{j}}=\delta_{\mathrm{ij}}$, delta de Kronecker, então:

$I=\mathbf{e}_{1} \otimes \mathbf{e}_{1}+\mathbf{e}_{2} \otimes \mathbf{e}_{2}+\mathbf{e}_{3} \otimes \mathbf{e}_{3}=\delta_{\mathrm{ij}} \mathbf{e}_{\mathrm{i}} \cdot \mathbf{e}_{\mathrm{j}}$.

(A.31)

Demonstração: Basta provar que $\delta_{\mathrm{ij}}\left(\mathbf{e}_{\mathrm{i}} \otimes \mathbf{e}_{\mathrm{j}}\right) \mathbf{v}=\mathbf{v}$. De fato, se $\mathbf{v}=v_{\mathrm{i}} \mathbf{e}_{\mathrm{i}}$, tem-se:

$\delta_{\mathrm{kj}}\left(\mathbf{e}_{\mathrm{k}} \otimes \mathbf{e}_{\mathrm{j}}\right) \mathbf{v}=\delta_{\mathrm{ij}} v_{\mathrm{r}}\left(\mathbf{e}_{\mathrm{k}} \otimes \mathbf{e}_{\mathrm{j}}\right) \mathbf{e}_{\mathrm{r}}=\delta_{\mathrm{kj}} v_{\mathrm{r}} \mathbf{e}_{\mathrm{k}}\left(\mathbf{e}_{\mathrm{j}} \cdot \mathbf{e}_{\mathrm{r}}\right) \mathbf{v}=\delta_{\mathrm{kj}} v_{\mathrm{r}} \mathbf{e}_{\mathrm{k}} \delta_{\mathrm{jr}}=v_{\mathrm{j}} \mathbf{e}_{\mathrm{j}}=\mathbf{v}$

Produto anti-simétrico. Dados $\mathbf{u}, \mathbf{v} \in V$ arbitrários, o tensor anti-simétrico $\mathbf{u} \otimes \mathbf{v}-\mathbf{v} \otimes \mathbf{u}$ será representado por $\mathbf{u} \wedge \mathbf{v}$, denominado produto anti-simétrico, ou produto externo.

Componentes de um tensor. Até aqui o trabalho com tensores limitou-se a estudálos com o auxílio das definições e regras de composição. Da mesma forma como os vetores, em $V$, são independentes da base escolhida para representá-los os tensores, em Lin, também são entidades independentes de qualquer base desse conjunto. No 
entanto, escolhida uma determinada base, pode-se determinar as componentes do tensor nessa base de Lin.

Considere-se em $V$ uma base $\left\{\mathbf{e}_{\mathbf{i}}\right\}$, não necessariamente ortogonal, chamando de $g_{\mathrm{ij}}$ os escalares provenientes do produto interno $\mathbf{e}_{\mathrm{i}} \cdot \mathbf{e}_{\mathrm{j}}$, isto é:

$\mathbf{e}_{\mathrm{i}} \cdot \mathbf{e}_{\mathrm{j}}=g_{\mathrm{ij}} \cdot$

Em razão de $\left\{\mathbf{e}_{\mathbf{i}}\right\}$ ser uma base, segue-se que o determinante da matriz $\left[g_{\mathrm{ij}}\right]$ é diferente de zero. Existe, portanto a matriz inversa, denominada $\left[g^{\mathrm{ij}}\right]$. Logo:

$g^{\mathrm{ij}} g_{\mathrm{jk}}=\delta_{\mathrm{k}}^{\mathrm{i}}$.

Resulta da eq. (A.32) que $\left[g_{\mathrm{ij}}\right]$ é uma matriz simétrica. Por outro lado, dada uma base $\left\{\mathbf{e}_{\mathbf{i}}\right\}$ pode-se definir outra base, $\left\{\mathbf{e}^{\mathrm{i}}\right\}$, denominada base dual de $\left\{\mathbf{e}_{\mathrm{i}}\right\}$, que fica determinada, de modo único, através da condição:

$\mathbf{e}^{\mathrm{i}}=g^{\mathrm{ij}} \mathbf{e}_{\mathrm{j}} \quad, \quad \mathbf{e}_{\mathrm{i}}=g_{\mathrm{ij}} \mathbf{e}^{\mathrm{j}}$.

De (A.32), (A.33) e (A.34), resulta que:

$\mathbf{e}^{\mathrm{i}} \cdot \mathbf{e}_{\mathrm{j}}=\delta^{\mathrm{i}}{ }_{\mathrm{j}} \quad, \quad \mathbf{e}^{\mathrm{i}} \cdot \mathbf{e}^{\mathrm{j}}=g^{\mathrm{ij}}$.

Com i, j=1,3, demonstra-se que são bases de Lin os seguintes conjuntos de tensores:

$\left\{\mathbf{e}_{\mathbf{i}} \otimes \mathbf{e}_{j}\right\}, \quad\left\{\mathbf{e}_{\mathrm{i}} \otimes \mathbf{e}^{\mathrm{j}}\right\}, \quad\left\{\mathbf{e}^{\mathrm{i}} \otimes \mathbf{e}^{\mathrm{j}}\right\}, \quad$ e $\quad\left\{\mathbf{e}^{\mathrm{i}} \otimes \mathbf{e}_{\mathrm{j}}\right\}$.

Dessa maneira, a representação de um tensor pode possuir as seguintes representações possíveis, em função de suas componentes nessas bases:

$\mathbf{T}=T_{\mathrm{ij}} \mathbf{e}^{\mathrm{i}} \otimes \mathbf{e}^{\mathrm{j}}=T^{\mathrm{ij}} \mathbf{e}_{\mathrm{i}} \otimes \mathbf{e}_{\mathrm{j}}=T_{\mathrm{j}}^{\mathrm{i}} \mathbf{e}_{\mathrm{i}} \otimes \mathbf{e}^{\mathrm{j}}=T_{\mathrm{i}}^{\mathrm{j}} \mathbf{e}^{\mathrm{i}} \otimes \mathbf{e}_{\mathrm{j}}$.

As relações entre as diversas componentes são deduzidas a partir da definição de produto tensorial e das eqs. (A.32) a (A.35). Por exemplo:

$T_{\mathrm{ij}} \mathbf{e}^{\mathrm{i}} \otimes \mathbf{e}^{\mathrm{j}}=T_{\mathrm{ij}} \mathbf{e}^{\mathrm{i}} \otimes \mathbf{e}^{\mathrm{j}}\left(g^{\mathrm{ik}} \mathbf{e}_{\mathrm{k}} \otimes \mathbf{e}^{\mathrm{j}}\right)=T_{\mathrm{ij}} g^{\mathrm{ik}} \mathbf{e}_{\mathrm{k}} \otimes \mathbf{e}^{\mathrm{j}}=T^{\mathrm{k}} \mathrm{e}_{\mathrm{k}} \otimes \mathbf{e}^{\mathrm{j}}$, daí 
$T_{\mathrm{j}}^{\mathrm{k}}=T_{\mathrm{ij}} g^{\mathrm{ik}}$

Em particular $T^{\mathrm{ij}}$ e $T_{\mathrm{ij}}$ recebem o nome, respectivamente, de componentes contravariantes e covariantes de $\mathbf{T}$, enquanto que $T_{\mathrm{j}}^{\mathrm{i}}$ e $T_{\mathrm{i}}^{\mathrm{j}}$ são denominadas componentes mistas. A notação (A.37) permite que se reconheça facilmente, dado um vetor $\mathbf{v}$, em que base está representado o vetor $\mathbf{T v}$, quando $\mathbf{T}$, por exemplo, está expresso como $\mathbf{T}=T_{\mathrm{ij}} \mathbf{e}^{\mathrm{i}} \otimes \mathbf{e}^{\mathrm{j}}$. De fato, em razão da definição de produto tensorial resulta que, $\mathbf{T v}$ está representado por suas componentes relativas à base $\left\{\mathbf{e}^{\mathrm{k}}\right\}$. Com efeito, suponha-se $\mathbf{v}=v^{\mathrm{k}} \mathbf{e}_{\mathrm{k}}$. Então:

$\mathbf{u}=\mathbf{T} \mathbf{v}=T_{\mathrm{ij}}\left(\mathbf{e}^{\mathrm{i}} \otimes \mathbf{e}^{\mathrm{j}}\right) v_{\mathrm{k}} \mathbf{e}_{\mathrm{k}}=T_{\mathrm{ij}} v^{\mathrm{k}}\left(\mathbf{e}^{\mathrm{i}} \otimes \mathbf{e}^{\mathrm{j}}\right) \mathbf{e}_{\mathrm{k}}=T_{\mathrm{ij}} v^{\mathrm{k}} \mathbf{e}^{\mathrm{i}} \delta_{\mathrm{k}}^{\mathrm{j}}=T_{\mathrm{ij}} v^{\mathrm{j}} \mathbf{e}^{\mathrm{i}}$ ou, $\mathbf{u}=v_{\mathrm{i}} \mathbf{e}^{\mathrm{i}}, v_{\mathrm{i}}=T_{\mathrm{ij}} v^{\mathrm{j}}$

A partir das definições anteriores, pode-se expressar a multiplicação de tensores e a transposta, em termos de suas componentes:

a) Multiplicação de tensores:

$\mathbf{B}=\mathbf{T S}=T_{\mathrm{ij}}\left(\mathbf{e}^{\mathrm{i}} \otimes \mathbf{e}^{\mathrm{j}}\right) S_{\mathrm{m}}^{\mathrm{k}}\left(\mathbf{e}_{\mathrm{k}} \otimes \mathbf{e}^{\mathrm{m}}\right)=T_{\mathrm{ij}} S_{1}^{\mathrm{k}}\left(\mathbf{e}^{\mathrm{i}} \otimes \mathbf{e}^{\mathrm{m}}\right) \delta_{\mathrm{k}}^{\mathrm{j}}=T_{\mathrm{ik}} S_{\mathrm{m}}^{\mathrm{k}}\left(\mathbf{e}^{\mathrm{i}} \otimes \mathbf{e}^{\mathrm{m}}\right)$.

Por sua vez:

$\mathbf{B}=B_{\mathrm{im}} \mathbf{e}^{\mathrm{i}} \otimes \mathbf{e}^{\mathrm{m}} \Rightarrow B_{\mathrm{im}}=T_{\mathrm{ik}} S_{\mathrm{m}}^{\mathrm{k}}$.

b) Transposto de um tensor:

$\mathbf{T}=T_{\mathrm{ij}}\left(\mathbf{e}^{\mathrm{i}} \otimes \mathbf{e}^{\mathrm{j}}\right) \Rightarrow \mathbf{T}^{\mathrm{T}}=T_{\mathrm{ij}}\left(\mathbf{e}^{\mathrm{i}} \otimes \mathbf{e}^{\mathrm{j}}\right)^{\mathrm{T}}=T_{\mathrm{ij}}\left(\mathbf{e}^{\mathrm{j}} \otimes \mathbf{e}^{\mathrm{i}}\right)$.

Por outro lado:

$\mathbf{T}^{\mathrm{T}}=T_{\mathrm{ji}}^{\mathrm{T}}\left(\mathbf{e}^{\mathrm{j}} \otimes \mathbf{e}^{\mathrm{i}}\right), \log \mathrm{o} T_{\mathrm{ij}}=T_{\mathrm{ji}}^{\mathrm{t}}$

Se a base $\left\{\mathbf{e}^{\mathrm{i}}\right\}$ for ortonormal, a posição dos índices é indiferente. Nesse caso as componentes do tensor são chamadas de componentes cartesianas. 
Traço de um tensor. Define-se como traço de um tensor $\mathbf{T} \in \operatorname{Lin}$, a aplicação que associa ao tensor um escalar, representado por tr $\mathbf{T}$, e que satisfaz a:

$\operatorname{tr}(\mathbf{u} \otimes \mathbf{v})=\mathbf{u} \cdot \mathbf{v}$

Decorre da definição de traço de um tensor:

(1) A aplicação tr $\mathbf{T}$ é linear, já que o produto interno o é.

(2) A expressão do tr T, em função das componentes, é a seguinte:

$\operatorname{tr} \mathbf{T}=T_{\mathrm{ij}} \operatorname{tr}\left(\mathbf{e}^{\mathrm{i}} \otimes \mathbf{e}^{\mathrm{j}}\right)=T_{\mathrm{ij}} g^{\mathrm{ij}}=T_{\mathrm{i}}^{\mathrm{i}}=T_{\mathrm{i}}^{\mathrm{i}}=T^{\mathrm{ij}} g_{\mathrm{ij}}$, o que significa que tr $\mathbf{T}$ está bem definido.

(3) Seja $\mathbf{u} \otimes \mathbf{v}$ um tensor arbitrário $\mathbf{S}$, logo:

$\operatorname{tr} \mathbf{S}=\operatorname{tr} \mathbf{S}^{\mathrm{T}}$

Com efeito, $\operatorname{tr} \mathbf{T}=\operatorname{tr}(\mathbf{u} \otimes \mathbf{v})=\mathbf{u} . \mathbf{v}=\mathbf{u} . \mathbf{v}=\operatorname{tr} \mathbf{S}^{\mathrm{T}}$.

(4) Se S e T são dois tensores arbitrários de Lin, então:

$$
\operatorname{tr}(\mathbf{S T})=\operatorname{tr}(\mathbf{T S})
$$

De fato, da eq. (A.30), tem-se:

$\operatorname{tr}[(\mathbf{u} \otimes \mathbf{v})(\mathbf{c} \otimes \mathbf{d})]=\operatorname{tr}[(\mathbf{v . c}) \mathbf{u} \otimes \mathbf{d}]=(\mathbf{v . c})(\mathbf{u . d})=\operatorname{tr}[(\mathbf{d} . \mathbf{u}) \mathbf{c} \otimes \mathbf{v}]=$

$=\operatorname{tr}[(\mathbf{c} \otimes \mathbf{d})(\mathbf{u} \otimes \mathbf{v})]$.

E de (A.31) tem-se:

(5) $\operatorname{tr}(\mathbf{I})=\operatorname{tr}\left(\delta_{\mathrm{ij}} \mathbf{e}_{\mathrm{i}} \cdot \mathbf{e}_{\mathrm{j}}\right)=\delta_{\mathrm{ij}} \delta_{\mathrm{ij}}=3$.

Produto interno em Lin. Define-se o produto interno (produto escalar) de dois tensores $\mathbf{S}$ e $\mathbf{T}$, simbolizado por $\mathbf{S}: \mathbf{T}$, o escalar definido por:

$\mathbf{S}: \mathbf{T}=\operatorname{tr}\left(\mathbf{S}^{\mathrm{T}} \mathbf{T}\right)$

Mostra-se, agora, que essa definição satisfaz as propriedades de produto interno: 
(1) Simetria: $\mathbf{S}: \mathbf{T}=\mathbf{T}: \mathbf{S}$; de fato, $\mathbf{S} . \mathbf{T}=\operatorname{tr}\left(\mathbf{S}^{\mathrm{T}} \mathbf{T}\right)=\operatorname{tr}\left(\mathbf{S}^{\mathrm{T}} \mathrm{T}\right)^{\mathrm{T}}=\operatorname{tr}\left(\mathbf{T}^{\mathrm{T}} \mathbf{S}\right)=\mathbf{T}: \mathbf{S}$.

(2) $\mathbf{S}: \mathbf{S} \geq 0, \forall \mathbf{S}$, sendo que ocorre o valor nulo se e somente se $\mathbf{S}=\mathbf{0}$. De fato, em função das componentes cartesianas de $\mathbf{S}$, tem-se:

$\mathbf{S}: \mathbf{S}=\operatorname{tr}\left[S_{\mathrm{ij}}\left(\mathbf{e}_{\mathrm{j}} \otimes \mathbf{e}_{\mathrm{i}}\right) S_{\mathrm{km}}\left(\mathbf{e}_{\mathrm{k}} \otimes \mathbf{e}_{\mathrm{m}}\right)\right]=S_{\mathrm{ij}} S_{\mathrm{km}} \delta_{\mathrm{ik}} \delta_{\mathrm{jm}}=S_{\mathrm{ij}} S_{\mathrm{ij}}=\sum_{\mathrm{i}, \mathrm{j}}\left(S_{i \mathrm{j}}\right)^{2} \geq 0$

E daí, se $\mathbf{S}: \mathbf{S}=0$, então $S_{\mathrm{ik}}=0$, para todo i,k, $\operatorname{logo} \mathbf{S}=\mathbf{0}$, sendo a recíproca imediata.

A introdução do produto interno induz, de forma natural, o conceito de norma de um tensor, representada por $\|$.$\| . Logo:$

$\|\mathbf{S}\|=\sqrt{\operatorname{tr}\left(\mathbf{S}^{\mathrm{T}} \mathbf{S}\right)}, \forall \mathbf{S} \in \operatorname{Lin}$

Algumas propriedades do produto interno:

(1) $\operatorname{tr}(\mathbf{S})=\operatorname{tr}(\mathbf{I S})=\operatorname{tr}(\mathbf{S I})=\mathbf{I}: \mathbf{S}=\mathbf{S}: \mathbf{I}$.

(2) $\mathbf{R}:(\mathbf{S T})=\left(\mathbf{S}^{\mathrm{T}} \mathbf{R}\right): \mathbf{T}$.

De fato, $\mathbf{R}: .(\mathbf{S T})=\operatorname{tr}\left(\mathbf{R}^{\mathrm{T}} \mathbf{S T}\right)=\operatorname{tr}\left(\mathbf{T}^{\mathrm{T}} \mathbf{S}^{\mathbf{T}} \mathbf{R}\right)=\mathbf{T}: \mathbf{S}^{\mathbf{T}} \mathbf{R}=\mathbf{S}^{\mathbf{T}} \mathbf{R}: \mathbf{T}$

(3) $\mathbf{u} \cdot \mathrm{Sv}=\mathrm{S} \cdot(\mathbf{u} \otimes \mathbf{v})$.

De fato, $\mathbf{S} \cdot(\mathbf{u} \otimes \mathbf{v})=\operatorname{tr}\left[S^{\mathbf{T}}(\mathbf{u} \otimes \mathbf{v})\right]=\operatorname{tr}\left[S^{\mathbf{T}} \mathbf{u} \otimes \mathbf{v}\right]=S^{\mathrm{t}} \mathbf{u} \cdot \mathbf{v}=\mathbf{u} \cdot \mathbf{S v}$,

onde se fez uso da identidade $\mathbf{S}^{\mathbf{T}}(\mathbf{u} \otimes \mathbf{v})=\left(\mathbf{S}^{\mathbf{T}} \mathbf{u}\right) \otimes \mathbf{v}$, que é verdadeira, pois:

$S^{T}(u \otimes v) w=S^{T}[(u \otimes v) w]=S^{T} u(v \cdot w)=\left(S^{T} u^{T} \otimes v\right) w$.

(4) Se $\mathbf{S} \in$ Sym, então:

$\mathbf{S}: \mathbf{T}=\mathbf{S}: \mathbf{T}^{\mathrm{T}}=\mathbf{S} .(1 / 2)\left(\mathbf{T}+\mathbf{T}^{\mathrm{T}}\right)=\mathbf{S}: \operatorname{sym} \mathbf{T}, \forall \mathbf{T} \in \operatorname{Lin}$.

De fato:

$\mathbf{S}: \mathbf{T}=\operatorname{tr}\left(\mathbf{S}^{\mathrm{T}} \mathbf{T}\right)=\operatorname{tr}\left(\mathbf{T}^{\mathrm{T}} \mathbf{S}\right)=\operatorname{tr}\left(\mathbf{S} \mathbf{T}^{\mathrm{T}}\right)=\mathbf{S}: \mathbf{T}^{\mathrm{T}}$ 
(5) Se $\mathbf{W} \in S k w$, então:

$\mathbf{W}: \mathbf{T}=\mathbf{W}^{\mathrm{T}}: \mathbf{T}^{\mathrm{T}}=-\mathbf{W}: \mathbf{T}^{\mathrm{T}}=\mathbf{W}(1 / 2)\left(\mathbf{T}-\mathbf{T}^{\mathrm{T}}\right)=\mathbf{W}:$ skw $\mathbf{T}, \forall \mathbf{T} \in \operatorname{Lin}$.

(6) Se $\mathbf{S} \in S y m$ e $\mathbf{W} \in S k w$, então:

$\mathbf{S}: \mathbf{W}=0$

conseqüência da propriedade (4), ou da (5).

(7) $\operatorname{Se} \mathbf{T}: \mathbf{S}=\mathbf{0} \quad \forall \mathbf{S}$, então $\mathbf{T}=\mathbf{0}$.

(8) Se T : S = $\mathbf{0} \quad \forall \mathbf{S} \in S y m$, então $\mathbf{T} \in S k w$.

(9) Se T : $\mathbf{S}=\mathbf{0} \quad \forall \mathbf{T} \in S k w$, então $\mathbf{S} \in S y m$.

Determinante de um tensor. Define-se como determinante de um tensor $\mathbf{S}$, $\operatorname{det} \mathbf{S}$, o determinante da matriz [S], associada a $\mathbf{S}$ a partir da escolha de uma base, isto é:

$\operatorname{det} \mathbf{S}=\operatorname{det}[\mathrm{S}]$.

Pode-se demonstrar que esta função é bem definida, no sentido de que, a cada tensor $\mathbf{S}$ corresponde um único det $\mathbf{S}$, isto significando que o determinante independe da representação de $\mathbf{S}$. Pode-se mostrar, também, que esta função é não linear.

$\mathbf{S}$ é inversível se existe um tensor, chamado tensor inverso de $\mathbf{S}, \mathbf{S}^{-1}$, tal que:

$\mathbf{S S}^{-1}=\mathbf{S}^{-1} \mathbf{S}=\mathbf{I}$.

Partindo-se da definição de determinante de um tensor, pode-se mostrar que $\mathbf{S}$ é inversível se e somente se $\operatorname{det} \mathbf{S} \neq 0$.

Valem as seguintes identidades:

(1) $\operatorname{det}(\mathbf{S T})=(\operatorname{det} \mathbf{S})(\operatorname{det} \mathbf{T})$,

(2) $\operatorname{det} \mathbf{S}^{\mathrm{T}}=\operatorname{det} \mathbf{S}$. 
As demonstrações dessas duas identidades dependem de alguns resultados encadeados de Álgebra Linear que não estão contemplados neste apêndice. Pode-se encontrá-la em FEIJÓO (1978).

(3) $\operatorname{det} \mathbf{S}^{-1}=(\operatorname{det} \mathbf{S})^{-1}$.

\section{Demonstração:}

Basta considerar que $\mathbf{I}=\mathbf{S S} \mathbf{S}^{-1}$, pela propriedade $(1), \operatorname{det}\left(\mathbf{S S}^{-1}\right)=\operatorname{det} \mathbf{I}=1=\operatorname{det} \mathbf{S}$ $\operatorname{det} \mathbf{S}^{-1}$.

Desse último resultado, decorre que:

(4) $(\mathbf{S T})^{-1}=\mathbf{T}^{-1} \mathbf{S}^{-1}$

(5) $\left(\mathbf{S}^{-1}\right)^{\mathrm{T}}=\left(\mathbf{S}^{\mathrm{T}}\right)^{-1}$,

o que justifica a notação $\mathbf{S}^{-\mathrm{T}}=\left(\mathbf{S}^{-1}\right)^{\mathrm{T}}$.

Diz-se que um tensor $\mathbf{Q}$ é ortogonal se preserva o produto interno, quando aplicado a um vetor de $V$ isto é:

$\mathbf{u} . \mathbf{v}=\mathbf{Q u} \cdot \mathbf{Q v}$.

A condição necessária e suficiente para que um tensor $\mathbf{Q}$, seja ortogonal é:

$\mathbf{Q} \mathbf{Q}^{\mathrm{T}}=\mathbf{Q}^{\mathrm{T}} \mathbf{Q}=\mathbf{I}$,

o que equivale a:

$\mathbf{Q}^{\mathrm{T}}=\mathbf{Q}^{-1}$

Demonstração: Suponha-se que $\mathbf{Q}$ preserva o produto interno, logo, da definição de tensor transposto:

$\mathbf{u} \cdot \mathbf{v}=\mathbf{Q u} \cdot \mathbf{Q v}=\mathbf{Q}^{\mathrm{T}} \mathbf{Q} \mathbf{u} \cdot \mathbf{v}$ e, portanto:

$\mathbf{Q}^{\mathrm{T}} \mathbf{Q}=\mathbf{Q} \mathbf{Q}^{\mathrm{T}}=\mathbf{I} \Rightarrow \mathbf{Q}^{\mathrm{T}}=\mathbf{Q}^{-1}$ 
A recíproca, prova-se a partir de (A.62), mostrando-se que, se isso for verdade, então o produto interno é preservado e, portanto, $\mathbf{Q}$ é ortogonal:

$\mathbf{Q}^{\mathrm{T}} \mathbf{Q} \mathbf{u} \cdot \mathbf{v}=\mathbf{I} \mathbf{u} \cdot \mathbf{v}=\mathbf{u} \cdot \mathbf{v}=\mathbf{Q u} \mathbf{Q} \mathbf{v}$.

Dado $\mathbf{Q} \in$ Orth, o conjunto de todos os tensores ortogonais, então:

$\operatorname{det} \mathbf{Q}= \pm 1$, .

que se prova mediante consideração das eqs. (A.51),(A.52) e (A.62).

Se $\mathbf{Q} \in$ Orth e det $\mathbf{Q}=1$, diz-se que o tensor $\mathbf{Q}$ é uma rotação. $\mathrm{O}$ conjunto de todas as rotações é representado pela notação $\operatorname{Orth}^{+}$

Um tensor é positivo definido se a seguinte condição é verificada:

$\mathbf{u} . \mathbf{S u}>0$, para todo $\mathbf{u} \neq \mathbf{0}$.

\section{A.2 Diferenciação}

Sejam $U$ e $V$ dois espaços vetoriais normados e seja $f: U \rightarrow V$, definida em uma vizinhança do zero de $U$. Diz-se que $f(\mathbf{u})$ aproxima-se de zero mais rapidamente que $\mathbf{u}$, ou que é de ordem $\mathbf{u}$, se a seguinte condição é verificada:

$$
\lim _{\substack{\mathbf{u} \| \rightarrow 0 \\ \mathbf{u} \neq \mathbf{0}}} \frac{\|f(\mathbf{u})\|}{\|\mathbf{u}\|}=0 .
$$

Se $f(\mathbf{u})$ satisfizer a essa condição, diz-se que:

$f(\mathbf{u})=\mathrm{o}(\mathbf{u}), \quad$ para $\mathbf{u} \rightarrow 0$ ou, simplesmente:

$f(\mathbf{u})=\mathrm{o}(\mathbf{u})$.

Da mesma maneira, dadas duas funções $f$ e $g$, diz-se que:

$f(\mathbf{u})=g(\mathbf{u})+\mathrm{o}(\mathbf{u})$

se se verifica a condição $\quad f(\mathbf{u})-g(\mathbf{u})=\mathrm{o}(\mathbf{u})$. 
Observe-se que essa última definição tem sentido mesmo se $f$ e $g$ assumem cvalores em $E$ (espaço euclidiano pontual). De fato, segundo se viu, $(f-g)$ assume valores em um espaço vetorial associado a $E$.

Seja $g$ uma função a valores escalares, vetores, tensores, ou até mesmo pontos. Suponha-se que seu domínio, $D(g)$, seja um intervalo aberto de IR. A derivada de $g$ em $t, \dot{g}(t)$, caso exista, é definida por:

$$
\dot{g}(t)=\frac{\mathrm{d}}{\mathrm{d} t} g(t)=\lim _{\alpha \rightarrow 0} \frac{1}{\alpha}[g(t+\alpha)-g(t)] .
$$

Verifica-se, partir de (A.68), que, se $g$ é uma função que toma valores em $E$, então sua derivada é um vetor. Da mesma maneira, a derivada de uma função de valor vetorial é um vetor, para uma função de valor vetorial, é um tensor.

Diz-se que $g$ é regular se $\dot{g}(t)$ existe, para cada $t \in D(g)$ e se $g(t)$ é contínua em $D(g)$.

Da definição (A.68), segue-se que:

$g(t+\alpha)=g(t)+\alpha \dot{g}(t)+o(\alpha)$, para $\alpha \rightarrow 0$

A parcela $\alpha \dot{g}(t)$, em particular, é linear em $\alpha$, logo:

$g(t+\alpha)-g(t)$

é igual a um termo linear em $\alpha$ mais um termo da ordem de $\alpha$.

Para tratar-se com derivadas em espaços de dimensão maior que 1, a definição de derivada estará fundamentada no resultado anterior, do qual derivam as seguintes definições: 
(1) A derivada de uma função $g$ é uma aplicação linear que se aproxima de $g(t+\alpha)$ $g(t)$ para valores pequenos de $\alpha$.

(2) Sejam $U$ e $W$ dois espaços vetoriais normados de dimensão finita, sendo $C$ um subconjunto aberto de $U$. Então $g: D \rightarrow W$ é diferenciável em $\mathbf{x}$, se existe uma transformação linear:

$\mathrm{D} g(\mathbf{x}): U \rightarrow W$,

tal que

$g(\mathbf{x}+\mathbf{u})=g(\mathbf{x})+\mathrm{D} g(\mathbf{x})[\mathbf{u}]+\mathrm{o}(\mathbf{u}), \quad$ para $\|\mathbf{u}\| \rightarrow 0$

A seguir, mostra-se que, se $\mathrm{D} g(x)$ existe, então é única. De fato, de (A.71):

$g(\mathbf{x}+\mathbf{u})-g(\mathbf{x})-\operatorname{D} g(\mathbf{x})[\mathbf{u}]=\mathrm{o}(\mathbf{u}), \log \mathrm{O}:$

$\mathrm{D} g(\mathbf{x})[\mathbf{u}]=\lim _{\substack{\alpha \rightarrow 0 \\ \alpha \in I R}} \frac{1}{\alpha}[g(\mathbf{x}+\alpha \mathbf{u})-g(\mathbf{x})]=\left.\frac{\mathrm{d}}{\mathrm{d} \alpha} g(\mathbf{x}+\alpha \mathbf{u})\right|_{\alpha=0}$.

Seguindo-se as definições, $\mathrm{D} g(\mathbf{x})$ é a derivada de $g$ em $\mathbf{x}$. Como duas normas em espaços vetoriais finitos são equivalentes, então $\mathrm{D} g(\mathbf{x})$ é independente das normas adotadas em $U$ e $W$.

Um caso particular importante é aquele em que $D(g) \subset \mathrm{IR}$, para o qual, aplicando-se (A.69) e (A.71) resulta:

$\mathrm{D} g(t)[\alpha]=\alpha \dot{g}(t)$, para todo $\alpha \in \mathrm{IR}$

A seguir serão apresentados alguns exemplos, que correspondem a casos de interesse do presente trabalho:

EXEMPLO 1. Seja a aplicação $\phi: V \rightarrow I R$, definida pela lei $\phi(\mathbf{v})=\mathbf{v} \cdot \mathbf{v}$. Tem-se:

$\phi(\mathbf{v}+\mathbf{u})=(\mathbf{v}+\mathbf{u}) \cdot(\mathbf{v}+\mathbf{u})=\mathbf{v} \cdot \mathbf{v}+2 \mathbf{v} \cdot \mathbf{u}+\mathbf{u} \cdot \mathbf{u}=\phi(\mathbf{v})+2 \mathbf{v} \cdot \mathbf{u}+\mathbf{u} \cdot \mathbf{u}=\phi(\mathbf{v})+2 \mathbf{v}$ $. \mathbf{u}+\mathrm{o}(\mathbf{u})$. 
Daí, $\operatorname{D\phi }(\mathbf{v})[\mathbf{u}]=2 \mathbf{v} \cdot \mathbf{u}$.

EXEMPLO 2. Seja a aplicação $G$ : $\operatorname{Lin} \rightarrow \operatorname{Lin}$, definida por $G(\mathbf{A})=\mathbf{A}^{3}, \forall \mathbf{A} \in \operatorname{Lin}$.

Tem-se, então, que:

$G(\mathbf{A}+\mathbf{U})=(\mathbf{A}+\mathbf{U})^{3}=\mathbf{A}^{3}+\mathbf{A}^{2} \mathbf{U}+\mathbf{A} \mathbf{U} \mathbf{A}+\mathbf{U} \mathbf{A}^{2}+o(\mathbf{U})$,

Portanto, $\mathrm{D} G(\mathbf{A})[\mathbf{U}]=\mathbf{A}^{2} \mathbf{U}+\mathbf{A} \mathbf{U} \mathbf{A}+\mathbf{U ~ A}^{2}$.

EXEMPLO 3. Seja a transformação linear $\mathbf{L}: U \rightarrow V$ (observe-se que $\mathbf{L}$ é um tensor). Então:

$\mathbf{L}(\mathbf{v}+\mathbf{u})=\mathbf{L}(\mathbf{v})+\mathbf{L}(\mathbf{u}), \log 0:$

$\mathrm{DL}(\mathbf{v})[\mathbf{u}]=\mathbf{L} \mathbf{u}$, , o que mostra ser a derivada em $\mathbf{v}$ igual ao próprio tensor, isto é:

$\operatorname{DL}(\mathbf{v})=\mathbf{L}$.

EXEMPLO 4. Seja $\phi:$ Lin $\rightarrow$ IR, definida através da seguinte lei:

$\phi(\mathbf{A})=\mathbf{A}: \mathbf{A} \operatorname{tr} \mathbf{A},$. Logo, $\forall \mathrm{U} \in \operatorname{Lin}$, tem-se:

$\phi(\mathbf{A}+\mathbf{U})=\operatorname{tr}(\mathbf{A}+\mathbf{U})(\mathbf{A}+\mathbf{U}) \cdot(\mathbf{A}+\mathbf{U})=[\operatorname{tr}(\mathbf{A})+\operatorname{tr}(\mathbf{U})][\mathbf{A}: \mathbf{A}+2 \mathbf{A}: \mathbf{U}+\mathbf{U}: \mathbf{U}]=$

$=\mathbf{A}: \mathbf{A} \operatorname{tr} \mathbf{A}+2 \mathbf{A}: \mathbf{U} \operatorname{tr}(\mathbf{A})+\mathbf{A}: \mathbf{A} \operatorname{tr}(\mathbf{U})+o(\mathbf{U})$

Portanto, daí decorre que:

$\mathrm{D} \phi(\mathbf{A})[\mathbf{U}]=2 \mathbf{A}: \mathbf{U} \operatorname{tr}(\mathbf{A})+\mathbf{A}: \mathbf{A} \operatorname{tr}(\mathbf{U})$.

EXEMPLO 5. Seja $\phi: V \rightarrow V$, definida por:

$\phi(\mathbf{v})=(\mathbf{a} \cdot \mathbf{v}) \mathbf{v}$, para todo $\mathbf{v} \in V$, sendo a um vetor fixo de $V$. Logo:

$\phi(\mathbf{v}+\mathbf{u})=[\mathbf{a} \cdot(\mathbf{v}+\mathbf{u})](\mathbf{v}+\mathbf{u})=(\mathbf{a} \cdot \mathbf{v}) \mathbf{v}+(\mathbf{a} \cdot \mathbf{u}) \mathbf{v}+(\mathbf{a} \cdot \mathbf{v}) \mathbf{u}+(\mathbf{a} \cdot \mathbf{u}) \mathbf{u}=$

$=\phi(\mathbf{v})+[(\mathbf{a} \cdot \mathbf{u}) \mathbf{v}+(\mathbf{a} \cdot \mathbf{v}) \mathbf{u}]+\mathrm{o}(\mathbf{u})$.

Daí, a diferencial de $\phi$, calculada em $\mathbf{v}$, para um incremento $\mathbf{u}$, é dada por: 
$\operatorname{D\phi }(\mathbf{v})[\mathbf{u}]=(\mathbf{a} \cdot \mathbf{u}) \mathbf{v}+(\mathbf{a} \cdot \mathbf{v}) \mathbf{u}$.

EXEMPLO 5 (diferencial de um determinante): Seja $\phi$ uma função, definida no conjunto de todos os tensores inversíveis $\mathbf{A}$, tal que:

$\phi(\mathbf{A})=\operatorname{det}(\mathbf{A})$.

Aqui será usado um resultado da Álgebra de Matrizes, aplicado também aos tensores, emr consequiência da definição de determinante de um tensor, segundo o qual:

$\operatorname{det}(\mathbf{S}-\alpha \mathbf{I})=-\alpha^{3}+I_{1}(\mathbf{S}) \alpha^{2}-I_{2}(\mathbf{S}) \alpha+I_{3}(\mathbf{S})$

onde $I_{1}, I_{2}$ e $I_{3}$ são invariantes em relação à base de $V$, segundo a qual $\mathbf{S}$ é representado. Seus valores são:

$I_{1}(\mathbf{S})=\operatorname{tr}(\mathbf{S})$

$I_{2}(\mathbf{S})=(1 / 2)\left[(\operatorname{tr} \mathbf{S})^{2}-\operatorname{tr}\left(\mathbf{S}^{2}\right)\right]$,

$I_{3}(\mathbf{S})=\operatorname{det} \mathbf{S}$.

Fazendo $\alpha=-1$, na eq. (A.73), tem-se:

$\operatorname{det}(\mathbf{I}+\mathbf{A})=1+\operatorname{tr} \mathbf{A}+\mathrm{o}(\mathbf{A})$

para $\|\mathbf{A}\| \rightarrow 0$. Logo, se $\mathbf{A}$ é inversível e $\mathbf{U} \in \operatorname{Lin}$, é arbitrário, então:

$\operatorname{det}(\mathrm{A}+\mathbf{U})=\operatorname{det}\left[\left(\mathrm{I}+\mathbf{U} \mathbf{A}^{-1}\right) \mathbf{A}\right]=\operatorname{det}\left(\mathrm{I}+\mathbf{U A}^{-1}\right) \operatorname{det} \mathbf{A}=(\operatorname{det} \mathbf{A})\left[1+\operatorname{tr}\left(\mathbf{U A}^{-1}\right)+\mathrm{o}(\mathbf{U})\right]=$

$=\operatorname{det} \mathbf{A}+(\operatorname{det} \mathbf{A}) \operatorname{tr}\left(\mathbf{U A}^{-1}\right)+o(\mathbf{U})$, para $\|\mathbf{U}\| \rightarrow 0$.

Como a aplicação $f: \mathbf{U} \rightarrow(\operatorname{det} \mathbf{A}) \operatorname{tr}\left(\mathbf{U A}^{-1}\right)$ é linear, por ser linear a operação traço, então:

$\operatorname{D\phi }(\mathbf{A})[\mathbf{U}]=(\operatorname{det} \mathbf{A}) \operatorname{tr}\left(\mathbf{U A}^{-1}\right)$, para todo $\mathbf{U} \in \operatorname{Lin}$.

\section{REGRA DO PRODUTO.}


No desenvolvimento da Mecânica do Contínuo costumam aparecer operações com uma estrutura comum de produto, que merecem ser vistas segundo uma regra unificadora. Dentre elas destacam-se:

(1) produto de um escalar por um vetor: $\operatorname{prod}(\alpha, \mathbf{v})$,

(2) produto interno, ou escalar, entre dois vetores: $\operatorname{prod}(\mathbf{u}, \mathbf{v})$,

(3) produto interno de dois tensores: $\operatorname{prod}(\mathbf{U}, \mathbf{V})=\mathbf{U}: \mathbf{V}$,

(4) produto tensorial entre dois vetores: $\operatorname{prod}(\mathbf{u}, \mathbf{v})=\mathbf{u} \otimes \mathbf{v}$,

(5) aplicação de um tensor $\mathbf{S}$ sobre um vetor $\mathbf{v}: \operatorname{prod}(\mathbf{S}, \mathbf{v})=\mathbf{S} \mathbf{v}$, etc.

O objetivo, aqui, é estabelecer uma regra geral para calcular a derivada do produto de duas funções. Para isso, observe-se que as operações-produto, definidas de (1) a (5) têm uma propriedade comum: São todas bilineares. Generalizando, considere-se a seguinte operação produto:

prod: $F \times G \rightarrow W$,

onde $F, G$ e $W$ são espaços normados de dimensão finita, e prod é uma aplicação bilinear. Deste modo, o produto, $\mathrm{h}(x)=\operatorname{prod}(f(x), g(x))$, para todo $x \in D$. Suponha-se que o domínio comum, $D$, das funções $f$ e $g$, seja um subconjunto aberto de um espaço normado de dimensão finita $U$, ou do espaço euclidiano pontual $E$, associado ao espaço vetorial $V$.

LEMA. Regra do produto. Sejam $f$ e $g$ duas funções diferenciáveis em $x \in D$. Logo o produto $h=\operatorname{prod}(f, g)$ é diferenciável em $x$, e:

$\mathrm{D} h(x)[u]=\operatorname{prod}(f(x), \mathrm{D} g(x)[u])+\operatorname{prod}(\mathrm{D} f(x)[\mathrm{u}], g(x))$,

para todo $u \in U$.

Demonstração: 
Como os espaços $F, G, W$ e $U$ são de dimensão finita, a aplicação bilinear prod é limitada, e as aplicações lineares $\mathrm{D} f(x)$ e $\mathrm{D} g(x)$ são finitas. Logo, para todo $a \in F$, $b \in G$, e $u \in U$, existem escalares $k_{0}, k_{1}$ e $k_{2}$, tais que:

$\|\operatorname{prod}(a, b)\| \leq k_{0}\|a\|\|b\|$,

$\|D f(x)[u]\| \leq k_{1}\|u\| \quad \mathrm{e}$

$\|D g(x)[u]\| \leq k_{2}\|u\|$.

Por outro lado:

$f(x+u)=f(x)+\mathrm{D} f(x)[u]+\mathrm{o}(u)$,

$g(x+u)=g(x)+\mathrm{D} g(x)[u]+\mathrm{o}(u)$.

Usando agora a bilinearidade da operação prod, conjuntamente com as propriedades listadas anteriormente, resulta:

$h(x+u)=\operatorname{prod}(f(x+u), g(x+u))=$

$=\operatorname{prod}(f(x), g(x))+\{\operatorname{prod}(f(x), \mathrm{D} g(x)[u])+\operatorname{prod}(\mathrm{D} f(x)[u], g(x))\}+o(u)$.

Como se vê, a primeira parcela do segundo membro é a função $h$ calculada em $x$, e o termo entre chaves é uma função linear de $u$. Logo, a expressão anterior demonstra a eq. (A.75).

No caso particular em que $f$ é uma função constante, a eq. (A.75) reduz-se a :

$\mathrm{D} h(x)[u]=\operatorname{prod}(f(x), \mathrm{D} g(x)[u])$.

Em uma situação mais particular ainda, quando o conjunto $D$ é um intervalo aberto de IR, tem-se que (A.76) reduz-se a:

$\dot{h}(t)=\operatorname{prod}(f(t), \dot{g}(t))+\operatorname{prod}(\dot{f}(t), g(t))$,

onde se substitui $x$ por $t, u$ por $\alpha$, e $\mathrm{D} f(x)$ por $\dot{f}(t)$, onde se faz uso da bilinearidade de prod. Observe-se que a ausência de $\alpha$ na eq. (A.77), faz com que $\dot{h}(t)$ caracterizese como uma derivada e não como uma diferencial. 
A utilização da regra do produto permite que se chegue aos seguintes resultados:

$$
\begin{aligned}
& (\phi \mathbf{v})^{\cdot}=\dot{\phi} \mathbf{v}+\dot{\phi} \mathbf{v}, \\
& (\mathbf{v} \cdot \mathbf{w})^{\cdot}=\mathbf{v} \cdot \dot{\mathbf{w}}+\dot{\mathbf{v}} \cdot \mathbf{w}, \\
& (\mathbf{T S})^{\cdot}=\mathbf{T} \dot{\mathbf{S}}+\dot{\mathbf{T S} S} \\
& (\mathbf{T} \cdot \mathbf{S})^{\cdot}=\mathbf{T} \cdot \dot{\mathbf{S}}+\dot{\mathbf{T}} \cdot \mathbf{S} \\
& (\mathbf{S v})^{\cdot}=\mathbf{T} \dot{\mathbf{v}}+\dot{\mathbf{S}} \mathbf{v} .
\end{aligned}
$$

\section{REGRA DA CADEIA}

Considere-se $U, F$ e $G$ espaços normados de dimensão finita (ou espaços euclidianos pontuais). Sejam $C$ e $D$ subconjuntos abertos de $G$ e $U$, respectivamente, e sejam :

$f: C \rightarrow F \quad$ e $\quad g: D \rightarrow G$, onde $R(g) \subset C$.

Regra da cadeia: Seja $g$ diferenciável em $x$, e $f$ diferenciável em $y=g(x)$. Logo, a composição $h=f_{\text {o }} g$ é diferenciável em $x$. E

$\mathrm{D} h(x)=\mathrm{D} f(y) \circ \mathrm{D} g(x)$,

expressão que corresponde a uma simplificação de:

$\mathrm{D} h(x)[u]=\mathrm{D} f(g(x))\{\mathrm{D} g(x)[u]\}$, para todo $u \in U$.

Em particular, se $U=\mathrm{IR}$, então $g$ será uma função de variável real. Escrevendo-se $t$ em lugar de $x, \dot{g}(t)$ em lugar de $\mathrm{D} g(x)$, e $\alpha$ em lugar de $u$, tem-se a derivada definida por:

$\mathrm{D} f(g(t))=\mathrm{D} f(g(t))[\dot{g}(t)]$. 
PROPOSIÇÃO: Seja $\mathbf{S}$ uma função de valor tensorial definida em um intervalo aberto $D$ de IR. Então:

$\left(\mathbf{S}^{\mathrm{T}}\right)^{\cdot}=(\dot{\mathbf{S}})^{\mathrm{T}} \equiv \dot{\mathbf{S}}^{\mathrm{T}}$

e se $\mathbf{S}$ é inversível em todo $x \in D$, então:

$$
(\operatorname{det} \mathbf{S})^{\cdot}=(\operatorname{det} \mathbf{S}) \operatorname{tr}\left(\dot{\mathbf{S}} \mathbf{S}^{-1}\right)
$$

Demonstração: Inicialmente, define-se a operação transposição, como sendo

$(\text {. })^{\mathrm{T}}:$ Lin $\rightarrow$ Lin, que está definida por:

$(.)^{\mathrm{T}}(\mathbf{A})=\mathbf{A}^{\mathrm{T}}, \forall \mathbf{A} \in \operatorname{Lin}$, que é uma operação linear (v. definição de tensor transposto). Portanto, os operadores transposição e derivação, por serem lineares, podem comutar, isto é:

$\left(\mathbf{S}^{\mathrm{T}}\right)^{\cdot}=\left[(\bullet)^{\mathrm{T}}(\mathbf{S})\right]^{\cdot}=(\bullet)^{\mathrm{T}}(\dot{\mathbf{S}})=(\dot{\mathbf{S}})^{\mathrm{T}}$,

com o qual se demonstra (A.81). O resultado (A.82) é uma conseqüência direta de (A.74) e (A.80).

\section{A.3 Gradiente e divergência}

Pelo teorema da representação das formas lineares, seja $\phi: V \rightarrow$ IR linear, então existe um único vetor a, tal que:

$\phi(\mathbf{v})=\mathbf{a} \cdot \mathbf{v}, \forall \mathbf{v} \in V$.

Campo escalar: Seja $\phi$ um campo escalar regular, definido em um conjunto aberto $R \subset V$. Portanto, para cada $\mathbf{x} \in R, \mathrm{D} \phi(\mathbf{x})$ é uma aplicação de $V$ em IR. Pelo teorema da representação das formas lineares, existe um único vetor, $\nabla \phi(\mathbf{x})$, chamado gradiente de em $\mathbf{x}$, tal que:

$\mathrm{D} \phi(\mathbf{x})[\mathbf{u}]=\nabla \phi(\mathbf{x}) \cdot \mathbf{u}$, 
de maneira que a eq. (A.71) torna-se:

$\phi(\mathbf{x}+\mathbf{u})=\phi \mathbf{x})+\nabla \phi(\mathbf{x}) \cdot \mathbf{u}+o(\mathbf{u})$.

CAMPO VETORIAL E CAMPO PONTUAL. De maneira semelhante à anterior, seja $\phi$ um campo vetorial (ou pontual) regular, definido em $R \subset V$, então, para cada $\mathbf{x} \in R$, $\operatorname{Dv}(\mathbf{x})$ é uma transformação linear de $V$ em $V$, sendo portanto é um tensor. Neste caso, $\nabla \mathbf{v}(\mathbf{x})$, chamado gradiente de $\mathbf{v}$ em $\mathbf{x}$, será usado para representar $\operatorname{Dv}(\mathbf{x})$, isto é:

$\mathrm{D} \mathbf{v}(\mathbf{x})[\mathbf{u}]=\nabla \mathbf{v}(\mathbf{x}) \mathbf{u}$

Considere-se agora um campo vetorial regular $\mathbf{v}$, definido em $R$. O campo escalar:

$\operatorname{div} \mathbf{v}=\operatorname{tr}(\nabla \mathbf{v})$

é denominado divergência de $\mathbf{v}$.

Com o operador definido pela eq. (A.87), pode-se introduzir o conceito de divergência de um tensor, a ser representado por div $\mathbf{S}$. Com efeito, div $\mathbf{S}$ é o único vetor com a seguinte propriedade:

$(\operatorname{div} \mathbf{S}) \cdot \mathbf{a}=\operatorname{div}\left(\mathbf{S}^{\mathrm{T}} \mathbf{a}\right)$

para um vetor a arbitrário.

PROPOSIÇÃO. Sejam $\phi$, v, w e $\mathbf{S}$ campos regulares, sendo $\phi$ escalar, $\mathbf{v}$ e w vetoriais e $\mathbf{S}$ tensorial, então valem as seguintes identidades:

$\nabla(\phi \mathbf{v})=\phi \nabla \mathbf{v}+\mathbf{v} \otimes(\nabla \phi)$,

$\operatorname{div}(\phi \mathbf{v})=\phi \operatorname{div} \mathbf{v}+(\nabla \phi) \cdot \mathbf{v}$,

$\nabla(\mathbf{v} \cdot \mathbf{w})=(\nabla \mathbf{w})^{\mathrm{T}} \mathbf{v}+(\nabla \mathbf{v})^{\mathrm{T}} \mathbf{w}$, 
$\operatorname{div}(\mathbf{v} \otimes \mathbf{w})=\mathbf{v} \operatorname{div} \mathbf{w}+(\nabla \mathbf{v}) \mathbf{w}$,

$\operatorname{div}\left(\mathbf{S}^{\mathrm{T}} \mathbf{v}\right)=\mathbf{S}: \nabla \mathbf{v}+\mathbf{v} \cdot \operatorname{div} \mathbf{S} \mathbf{e}$

$\operatorname{div}(\phi \mathbf{S})=\phi \operatorname{div} \mathbf{S}+\mathbf{S}: \nabla \phi$

Demonstração: Seja $\mathbf{h}=\phi \mathbf{v}$. Logo, da regra do produto, eq. (A.75), e das eqs. (A.85) e (A.86), tem-se:

$\nabla \mathbf{h}(\mathbf{x}) \mathbf{u}=\phi(\mathbf{x}) \nabla \mathbf{v}(\mathbf{x}) \mathbf{u}+(\nabla \phi(\mathbf{x}) \cdot \mathbf{u}) \quad \mathbf{v}(\mathbf{x}), \log 0:$

$\{\nabla(\phi \mathbf{v})\}[\mathbf{u}]=\{\phi(\mathbf{x}) \nabla \mathbf{v}(\mathbf{x})+(\mathbf{v}(\mathbf{x}) \otimes \nabla \phi(\mathbf{x})\}[\mathbf{u}]$,

o que prova a eq. (A.89) $)_{1}$.

Da definição (A.87), tomando-se o traço de (A.89) ${ }_{1}$, tem-se:

$\operatorname{div}(\phi \mathbf{v})=\operatorname{tr} \nabla(\phi \mathbf{v})=\operatorname{tr}(\phi \nabla \mathbf{v}+\mathbf{v} \otimes \nabla \phi)=\phi \operatorname{div} \mathbf{v}+\operatorname{tr}(\mathbf{v} \otimes \nabla \phi)$

Relembrando a eq. (A.39), tem-se:

$\operatorname{div}(\phi \mathbf{v})=\phi \operatorname{div} \mathbf{v}+\operatorname{tr}(\mathbf{v} \otimes \nabla \phi)$

que prova $(\mathrm{A} .89)_{2}$.

Seja agora $h=\mathbf{v} \cdot \mathbf{w}$, então, da eq. (A.75) resulta:

$\nabla \mathbf{h}(\mathbf{x}) \cdot \mathbf{u}=\mathbf{v}(\mathbf{x}) \cdot(\nabla \mathbf{w}(\mathbf{x}) \mathbf{u})+\left(\nabla \mathbf{v}(\mathbf{x}) \mathbf{u} \cdot \mathbf{w}(\mathbf{x})=\left(\nabla \mathbf{w}(\mathbf{x})^{\mathrm{T}} \mathbf{v}(\mathbf{x})+(\nabla \mathbf{v}(\mathbf{x}))^{\mathrm{T}} \mathbf{w}(\mathbf{x})\right.\right.$, que corresponde à prova de $(\mathrm{A} .89)_{3}$.

Observe-se que, se em (A.89) ${ }_{3}$ faz-se $\mathbf{w}=\mathbf{v}$, então:

$\nabla(\mathbf{v} \cdot \mathbf{v})=\nabla\left(\mathbf{v}^{2}\right)=2(\nabla \mathbf{v})^{\mathrm{T}} \mathbf{v}$

Para provar-se (A.89) ${ }_{4}$, basta que se considere a definição (A.88), segundo a qual:

$\operatorname{div}(\mathbf{v} \otimes \mathbf{w}) \cdot \mathbf{a}=\operatorname{div}[(\mathbf{w} \otimes \mathbf{v}) \mathbf{a}]=\operatorname{div}[(\mathbf{w}(\mathbf{v} \cdot \mathbf{a})]=(\mathbf{v} \cdot \mathbf{a}) \operatorname{div} \mathbf{w}+\mathbf{w} \cdot \nabla(\mathbf{v} \cdot \mathbf{a})=$ (v.a) $\operatorname{div} \mathbf{w}+\mathbf{w} \cdot(\nabla \mathbf{v})^{\mathrm{T}} \cdot \mathbf{a}$,

onde se fez uso do fato de que a não depende de $\mathbf{x}$. Logo: 
$\operatorname{div}(\mathbf{v} \otimes \mathbf{w}) . \mathbf{a}=[\operatorname{div}(\mathbf{w v})+(\nabla \mathbf{v}) \mathbf{w}] . \mathbf{a}$, que implica em $(\text { A.89 })_{4}$

Para provar (A.89)5, parte-se do seguinte: Seja v um campo vetorial regular, logo:

$\mathbf{v}(\mathbf{x}+\mathbf{u})=\mathbf{v}(\mathbf{x})+\nabla \mathbf{v}(\mathbf{x}) \mathbf{u}+\mathbf{o}(\mathbf{u})$

Seja $\mathbf{A}$ um tensor arbitrário independente de $\mathbf{x}$, logo:

$\nabla(\mathbf{A v})=\mathbf{A} \nabla \mathbf{v}$

para todo tensor A e todo campo vetorial regular v. Tomando o traço de (A.91) e considerando as definições (A.87) e (A.43), tem-se:

$\operatorname{div}(\mathbf{A v})=\operatorname{tr} \nabla(\mathbf{A v})=\operatorname{tr}(\mathbf{A} \nabla \mathbf{v})=\mathbf{A}^{\mathrm{T}} \cdot \nabla \mathbf{v}$

Pode-se, agora, provar (A.89) 5 . De fato, da definição (A.87):

$\operatorname{div}\left(\mathbf{S}^{\mathrm{T}} \mathbf{v}\right)=\operatorname{tr} \nabla\left(\mathbf{S}^{\mathrm{T}} \mathbf{v}\right)$

Pela regra do produto, $\nabla\left(\mathbf{S}^{\mathrm{T}} \mathbf{v}\right)[\mathrm{x}]$ é a soma dos termos: o gradiente, mantendo $\mathbf{S}$ constante com o valor $\mathbf{S}_{0}=\mathbf{S}(\mathbf{x})$, mais o gradiente mantendo $\mathbf{v}$ constante com o valor $\mathbf{v}_{0}=\mathbf{v}(\mathbf{x})$, isto é:

$\nabla\left(\mathbf{S}^{\mathrm{T}} \mathbf{v}\right)[\mathrm{x}]=\nabla\left(\mathbf{S}_{0}^{\mathrm{T}} \mathbf{v}\right)[\mathrm{x}]+\nabla\left(\mathbf{S}^{\mathrm{T}} \mathbf{v}_{0}\right)[\mathrm{x}]$. Logo:

$\operatorname{div}\left(\mathbf{S}^{\mathrm{T}} \mathbf{v}\right)[\mathrm{x}]=\operatorname{tr}\left\{\nabla\left(\mathbf{S}_{0}^{\mathrm{T}} \mathbf{v}\right)[\mathrm{x}]+\nabla\left(\mathbf{S}^{\mathrm{T}} \mathbf{v}_{0}\right)[\mathrm{x}]\right\}=\operatorname{div}\left(\mathbf{S}_{0}^{\mathrm{T}} \mathbf{v}\right)[\mathrm{x}]+\operatorname{div}\left(\mathbf{S}^{\mathrm{T}} \mathbf{v}_{0}\right)[\mathrm{x}]$

Da eq. (A.92), $\operatorname{com} \mathbf{A}=\mathbf{S}_{0}^{\mathrm{T}}$, tem-se:

$\operatorname{div}\left(\mathbf{S}^{\mathrm{T}} \mathbf{v}\right)[\mathrm{x}]=\mathbf{S}(\mathbf{x}) . \nabla \mathbf{v}(\mathbf{x})+\operatorname{div}\left(\mathbf{S}^{\mathrm{T}} \mathbf{v}_{0}\right)[\mathrm{x}]$. A aplicação da eq. (A.88), faz com que a última expressão resulte em:

$\operatorname{div}\left(\mathbf{S}^{\mathrm{T}} \mathbf{v}\right)[\mathrm{x}]=\mathbf{S}(\mathbf{x}) \cdot \nabla \mathbf{v}(\mathbf{x})+\mathrm{v}(\mathrm{x}) \cdot(\operatorname{div} \mathbf{S})$,

resultando demonstrada a identidade $(\mathrm{A} .89)_{5}$.

A demonstração de (A.89) ${ }_{6}$ faz-se de maneira semelhante. Assim: 
$\operatorname{div}(\phi \mathbf{S})[\mathbf{x}]=\operatorname{div}\left(\phi_{0} \mathbf{S}\right)[\mathbf{x}]+\operatorname{div}\left(\phi \mathbf{S}_{0}\right)[\mathbf{x}]$

Da definição de divergência de um tensor, pela eq. (A.88), resulta:

$\operatorname{div}\left(\phi_{0} \mathbf{S}\right)=\phi_{0} \operatorname{div} \mathbf{S}$,

e para um vetor qualquer $\mathbf{a}$, independente de $\mathbf{x}$, tem-se:

a $\cdot \operatorname{div}\left(\phi \mathbf{S}_{0}\right)=\phi_{0} \operatorname{div}\left(\phi \mathbf{S}_{0}^{\mathrm{T}} \mathbf{a}\right)$. Considerando agora, $\mathbf{v}=\mathbf{S}_{0}^{\mathrm{T}} \mathbf{a}$ na identidade (A.89) $)_{2}$, tem-se:

$\mathbf{a} \cdot \operatorname{div}\left(\phi \mathbf{S}_{0}\right)=\phi \operatorname{div}\left(\mathbf{S}_{0}^{\mathrm{T}} \mathbf{a}\right)+\mathbf{S}_{0}^{\mathrm{T}} \mathbf{a} \cdot \nabla \phi=\mathbf{a} \cdot \mathbf{S}_{0} \nabla \phi$, e então:

$\operatorname{div}\left(\phi \mathbf{S}_{0}\right)=\mathbf{S}_{0} \nabla \phi$

Finalmente, introduzindo as eqs. (A.94) e (A.95) na eq. (A.93), chega-se à eq. (A.89) $)_{6}$

$\operatorname{div}(\phi \mathbf{S})[\mathbf{x}]=\phi(\mathbf{x}) \operatorname{div} \mathbf{S}(\mathbf{x})+\mathbf{S}(\mathbf{x}) \nabla \phi(\mathbf{x})$.

\section{Teorema da Divergência (Gauss)}

A seguir, apresenta-se a terminologia essencial para o enunciado, sem demonstração, desse teorema, que tem grande aplicação em todas as áreas científicas.

Seja X um espaço métrico. Para as seguintes definições, todos os pontos referidos são pertencentes a $\mathrm{X}$, assim como todos os subconjuntos estão contidos em $\mathrm{X}$.

1. A vizinhança de um ponto $p$ é um subconjunto $N_{\rho}(p)$, formada por todos os pontos $q$, para os quais $d(p, q)<\rho$. A distância $\rho$ é chamada de raio de $N_{\rho}(p)$.

2. $\Omega$ O ponto $p$ é um ponto limite de um conjunto $E$, se toda vizinhança de $p$ contém ao menos um ponto $q \neq p$, com $Q \in E$.

3. Diz-se que um conjunto $E$ é fechado, se todo ponto limite de $E$ é um ponto de $E$.

4. Um ponto $p$ é um ponto interior de $E$, se existe uma vizinhança $N(p)$, tal que $N \subset E$.

5. Um conjunto $E$ é aberto, se todo ponto de $E$ é um ponto interior. 
6. Diz-se que $E$ é limitado se existe um número real $M$, e um ponto $q \in X$.

7. Se $E$ ' for designado como o conjunto de todos os pontos limites de $E$, em $X$, então a cobertura de $E$ é o conjunto $\bar{E}=E \cup E^{\prime}$.

8. Dois conjuntos são ditos separados se as interseções $A \cap \bar{B}$ e $\bar{A} \cap B$ são vazias.

9. Um conjunto $E$ é conexo se e somwnte si não é a união de dois conjuntos separados não vazios.

10. Uma região aberta é um conjunto conexo aberto, em $E$. A cobertura de uma região aberta é uma região fechada.

Diz-se que uma região é regular, se é uma região fechada, com contornos seccionalmente regulares. Entende-se por contornos seccionalmente regulares a união de um número finito de superfícies fechadas regulares, que não se interceptam, sendo que, em cada uma dessas superfícies o vetor normal à mesma está definidos em todos os pontos.

\section{Teorema da Divergência :}

Seja $\Omega$ uma região regular, limitada, e seja $\Upsilon$ um campo regular (vetorial, ou tensorial de segunda ordem), para o qual faça sentido (no segundo membro) a operação (.) sobre o vetor normal unitário n. Então: $\int_{\Omega}(\Upsilon . \nabla) d v=\int_{\partial \Omega}(\Upsilon \cdot \mathbf{n}) \mathrm{d} s$, onde a notação $\Upsilon$. $\nabla$ é o mesmo que div $\Upsilon$.

Enuncia-se a seguir, outro importante resultado, o

\section{Teorema da Localização:}

Seja $\phi$ um campo escalar, ou vetorial, contínuo e definido em conjunto aberto $\Omega$ de $E$. Então, dado um $x \in \Omega$ arbitrário, tem-se:

$\phi(x)=\lim _{\rho \rightarrow 0} \frac{1}{\operatorname{vol}\left(N_{\rho}(x)\right.} \int_{N_{\rho}(x)} \phi \mathrm{d} V$.

Por sua vez, se $\int_{\Omega} \phi \mathrm{d} V=0$, para todo $\bar{\Omega} \subset \Omega$, então: $\phi=0$. 


\section{ANEXO B}

\section{DERIVAÇÕES MATERIAIS NO TEMPO}

Admitindo-se que $\Phi(\mathbf{x}, t)$ e $\Phi^{*}(\mathbf{x}, t)$ sejam campos, aplicados à configuração atualizada, com valores escalares ou vetoriais, e tenham propriedades compatíveis com as operações abaixo realizadas, então:

$\frac{D}{D t} \int_{P_{t}} \Phi(\mathbf{x}, t) d v=\lim _{\Delta t \rightarrow 0} \frac{\Delta\left(\int_{P_{t}} \Phi(\mathbf{x}, t) d v\right)}{\Delta t}$.

Mas,

$\Delta\left(\int_{P_{t}} \Phi(\mathbf{x}, t) d v\right)=\left.\int_{P_{t+\Delta t}} \Phi(\mathbf{x}(\mathbf{X}, t+\Delta t), t+\Delta t) d v\right|_{t+\Delta t}-\left.\int_{P_{t}} \Phi(\mathbf{x}(\mathbf{X}, t), t) d v\right|_{t}$

Desenvolvendo $\Phi(\mathbf{x}(\mathbf{X}, t+\Delta t), t+\Delta t)$ em série,

$$
\Phi(\mathbf{x}(\mathrm{X}, t+\Delta t), t+\Delta t)=\Phi(\mathbf{x}(\mathbf{X}, t), t)+\left[(\operatorname{grad} \Phi) \mathbf{v}+\partial \Phi /\left.\partial t\right|_{\mathrm{t}}\right] \Delta \mathrm{t}+\mathrm{O}(\Delta t)
$$

onde $\operatorname{grad} \Phi$ é o gradiente de $\Phi$ em relação a $\mathbf{x} ; o(\Delta t)$ representa a soma das parcelas de ordens superiores a $\Delta t \mathrm{e}$

$$
\mathbf{v}=(\mathrm{D} / \mathrm{D} t)(\mathbf{x}(\mathbf{X}, t))
$$

Por outro lado:

$$
\left.d v\right|_{t}=\left.(\operatorname{det} F)\right|_{t} d V \quad \text { e }\left.\quad d v\right|_{t+\Delta t}=\left.(\operatorname{det} F)\right|_{t+\Delta t} d V \text {, }
$$


onde $\mathrm{d} V$ é o elemento de volume em $P_{0}$. As eqs. (B.5) mostram as relações entre volumes de elementos infinitesimais, em $P_{\mathrm{t}}$ e $P_{\mathrm{t}+\mathrm{dt}}$, respectivamente, com o volume de um elemento infinitesimal em $\left.P_{0} \cdot \operatorname{det} F\right|_{\mathrm{t}}$ e $\left.\operatorname{det} F\right|_{\mathrm{t}+\Delta \mathrm{t}}$ são os determinantes jacobianos de $F$, gradiente de $\Phi$ em relação a $\mathbf{X}$, nos respectivos instantes. O desenvolvimento em série, para $\left.\operatorname{det} F\right|_{\mathrm{t}+\Delta t}$, dá:

$$
\left.(\operatorname{det} F)\right|_{t+\Delta t}=\left.(\operatorname{det} F)\right|_{t}+\left.\left(\frac{D(\operatorname{det} F)}{D t}\right)\right|_{t} \Delta t+O(\Delta t) \text {. }
$$

Mas,

$$
\left.\left(\frac{D(\operatorname{det} F)}{D t}\right)\right|_{t}=\left.\left[(\operatorname{det} F) \operatorname{tr}\left(\dot{F} F^{-1}\right)\right]\right|_{t}
$$

onde $\dot{F}=(\mathrm{D} / \mathrm{D} t) F$. Substituindo-se a eq. (B.7) na eq. (B.6) e após, levando esta à segunda eq.(B.5), tem-se:

$$
\left.d v\right|_{t+\Delta t}=\left.\left\{(\operatorname{det} F)+(\operatorname{det} F) \operatorname{tr}\left(\dot{F} F^{-1}\right)(\Delta t+o(\Delta t))\right\}\right|_{t} d V
$$

Substituindo-se a eq.(B.8) na eq.(B.2), e levando-a, depois, à eq.(B.1), então:

$$
\begin{aligned}
& \frac{D}{D t} \int_{p_{t}} \Phi(x, t) d v=\lim _{\Delta t \rightarrow 0} \frac{1}{\Delta t}\left\{\int_{P_{o}}[\Phi(x(t+\Delta t), t+\Delta t)] .[\operatorname{det} F+\right. \\
& \left.\left.\cdot \quad+(\operatorname{det} F) \operatorname{tr}\left(\dot{F} F^{-1}\right)\right]_{t} d V-\left.\int_{P_{o}} \Phi(x(X, t), t)(\operatorname{det} F)\right|_{t} d V\right\} .
\end{aligned}
$$

Considerando-se a eq.(B.3), reunindo-se em $o(\Delta t)$ as parcelas de ordem $(\Delta t)^{2} \mathrm{em}$ diante, e calculando-se o limite, então a eq.(B.9) fica:

$$
\frac{D}{D t} \int_{P_{t}} \Phi d v=\int_{P_{o}}[\operatorname{grad} \Phi) \mathbf{v}+\frac{\partial \Phi}{\partial t}+\Phi \operatorname{tr}\left(\dot{F} F^{-1}\right](\operatorname{det} F) d V
$$

onde $\Phi=\Phi(\mathbf{x}(\mathbf{X}, t), t)$. A substituição da primeira das eqs.(B.5). na eq.(B.10) permite que a integração volte para a configuração atualizada, isto é: 
$\frac{D}{D t} \int_{P_{t}} \Phi \mathrm{d} v=\int_{P t}\left[(\operatorname{grad} \Phi) \mathbf{v}+\frac{\partial \Phi}{\partial t}+\Phi \operatorname{tr}\left(\dot{F} F^{-1}\right)\right] \mathrm{d} v$.

Levando em conta que $\dot{F} F^{-1}=\operatorname{grad} \mathbf{v}, \quad \operatorname{tr}\left(\dot{F} F^{-1}\right)=\operatorname{divv} \quad$ e $(\operatorname{grad} \Phi) \mathbf{v}+\partial \Phi / \partial t=(\mathrm{D} / \mathrm{D} t) \Phi$, tem-se:

$\frac{D}{D t} \int_{P_{t}} \Phi d v=\int_{P_{t}}\left[\frac{D \Phi}{D t}+\Phi d i v \mathbf{v}\right] d v$

Na seqüência, será calculada a derivada material no tempo da segunda parcela dessa equação. O procedimento é bastante semelhante ao anterior, no entanto é necessário atentar que a aplicação, nesse caso, deve levar pontos de $S_{\mathrm{f}}(t)$ a $S_{\mathrm{f}}(t)$. Assim:

$\frac{D}{D t} \int_{s_{f}(t)} \Phi^{*}(\mathbf{x}, t) d s=\lim _{\Delta t \rightarrow 0} \frac{\Delta\left(\int_{s_{f}(t)} \Phi^{*}(\mathbf{x}, t) d s\right)}{\Delta t}$

onde $\Phi^{*}(\mathbf{x}, t)$, definida em $s_{\mathrm{f}}(t)$, é um campo (vetorial ou escalar), com propriedades de continuidade e derivabilidade compatíveis com as operações realizadas; e ds é o elemento de área em $s_{\mathrm{f}}(t)$. Assim:

$$
\Delta\left(\int_{s_{f}(t)} \Phi^{*}(\mathbf{x}, t) d s\right)=\left.\int_{s_{f}(t+\Delta t)} \Phi^{*}(\mathbf{x}(\mathbf{X}, t+\Delta t), t+\Delta t) d s\right|_{t+\Delta t}-\left.\int_{s_{f}(t)} \Phi^{*}(\mathbf{x}(\mathbf{X}, t), t) d s\right|_{t} .
$$

Desenvolvendo $\Phi^{*}(\mathbf{x}(\mathbf{X}, t+\Delta t), t+\Delta t)$ em série, tem-se:

$$
\begin{aligned}
& \Phi^{*}(\mathbf{x}(\mathbf{X}, t+\Delta t), t+\Delta t)= \\
& =\Phi^{*}(\mathbf{x}(\mathbf{X}, t), t)+\left[\left(\operatorname{grad} \Phi^{*}\right)+\partial \Phi^{*} / \partial t\right] \|_{t} \Delta t+\mathrm{o}(\Delta t)
\end{aligned}
$$

onde $\operatorname{grad} \Phi^{*}$ é o gradiente da função $\Phi^{*}$ em relação a $\mathbf{x}$. Por outro lado:

$$
\left.d s\right|_{t+\Delta t}=\left.\left(\operatorname{det} F^{*}\right)\right|_{t+\Delta t} d S \quad \text { e }\left.\quad d s\right|_{t}=\left.\left(\operatorname{det} F^{*}\right)\right|_{t} d S
$$

onde $\mathrm{d} S$ é o elemento de área de $S_{\mathrm{f}}(\mathrm{t})$. As eqs. (B.16) mostram as relações entre áreas de elementos infinitesimais, na configuração atualizada e na configuração de 
referência, nos instantes $t+\Delta t$ e $t$, respectivamente. Os determinantes jacobianos de superfície, do gradiente $F^{*}$, nos instantes $t$ e $t+\Delta t$, são, respectivamente, $\left.\operatorname{det} F^{*}\right|_{\mathrm{t}} \mathrm{e}$ $\left.\operatorname{det} F^{*}\right|_{\mathrm{t}+\Delta \mathrm{t}}$. Considerando-se que o desenvolvimento em série, para $\left.\operatorname{det} F^{*}\right|_{\mathrm{t}+\Delta \mathrm{t}}$, é análogo ao da eq. (B.6), então a eq. (B.14) fica:

$$
\begin{gathered}
\frac{D}{D t} \int_{s_{f}(t)} \Phi^{*}(\mathbf{x}, t) d s=\lim _{\Delta t \rightarrow 0} \frac{1}{\Delta t}\left\{\int_{s_{f}(t+\Delta t)}\left[\Phi^{*}(\mathbf{x}(t+\Delta t), t+\Delta t)\right]\right. \\
\left.\cdot\left[\operatorname{det}\left(F^{*}\right)+\operatorname{det}\left(F^{*}\right) \operatorname{tr}\left[\dot{F}^{*}\left(F^{*}\right)^{-1}\right]\right]_{t} d s-\left.\int_{s_{f}(t)} \Phi^{*}(\mathbf{x}(\mathbf{X}, t), t)\left(\operatorname{det} F^{*}\right)\right|_{t} d s\right\} .
\end{gathered}
$$

Considerando-se a eq.(B.15), reunindo-se em $o(\Delta t)$ as parcelas de ordem $(\Delta t)^{2}$ em diante, e calculando o limite, a eq.(B.17) fica:

$$
\frac{D}{D t} \int_{s_{f}} \Phi^{*} d s=\int_{S_{f}}\left\{\left(\operatorname{grad} \Phi^{*}\right) \mathbf{v}+\frac{\partial \Phi^{*}}{\partial t}+\Phi^{*} \operatorname{tr}\left[\dot{F}^{*}\left(F^{*}\right)^{-1}\right]\right\}\left(\operatorname{det} F^{*}\right) d S
$$

onde $\Phi^{*}=\Phi^{*}(\mathbf{x}(\mathbf{X}, t), t)$. Na equação acima, a omissão do lugar e do instante onde as variáveis estão sendo calculadas, implica que tudo se refere a $\mathbf{x}(\mathbf{X}, t)$ e $t$. A substituição da segunda eq.(B.16) na eq.(B.18) permite que a integração volte para a configuração atualizada . Assim:

$$
\frac{D}{D t} \int_{s_{f}} \Phi^{*} d s=\int_{s_{f}}\left\{\left(\operatorname{gradF}^{*}\right) \mathbf{v}+\frac{\partial \Phi^{*}}{\partial t}+\Phi^{*} \operatorname{tr}\left[\dot{F}^{*}\left(F^{*}\right)^{-1}\right]\right\} d s
$$

Como $\quad \dot{F}^{*}\left(F^{*}\right)^{-1}=\operatorname{grad}(\mathbf{v}), \quad \operatorname{tr}\left[\dot{F}^{*}\left(F^{*}\right)^{-1}=\operatorname{div} \mathbf{v}\right.$ e $\left(\operatorname{grad} \Phi^{*}\right) \mathbf{v}+\partial \Phi^{*} / \partial t=(\mathrm{D} / \mathrm{D} t) \Phi^{*}$, tem-se, finalmente:

$$
\frac{D}{D t} \int_{s_{f}} \Phi^{*} d s=\int_{s_{f}}\left[\frac{D \Phi^{*}}{D t}+\Phi^{*} d i v \mathbf{v}\right] d s
$$




\section{ANEXO C \\ ANÁLISE DE SENSIBILIDADE À MUDANÇA DE FORMA DO DOMÍNIO}

De uma maneira um tanto quanto sumária, pretende-se analisar o que ocorre quando um sólido sujeito a determinado estado de tensões, decorrente da aplicação de ações externas e de deslocamentos prescritos no contorno, sofre uma mudança de forma ocasionada por uma transformação dependente de um parâmetro. O material será considerado homogêneo. E hiperelástico, porquanto supõe-se a existência de uma função densidade de energia de deformação, $\phi$, função escalar de variável tensorial, assim definida:

$\phi: S y m \mapsto R ; \mathbf{T}=\frac{\mathrm{d} \phi}{\mathrm{d} \mathbf{E}}=\phi_{, \mathbf{E}}$,

onde Sym é o espaço dos tensores simétricos de segunda ordem (transformações lineares do $\mathrm{R}^{3}$ em si mesmo), e $\phi, \mathbf{E}$ é a derivada de $\phi$ em relação ao tensor $\mathbf{E}=\nabla \mathbf{u}^{\mathrm{s}}$, parte simétrica do gradiente material dos deslocamentos. Essa derivada é simplesmente um tensor, tal que, no lugar de cada componente de E, tem-se a derivada parcial da função $\phi$, em relação à respectiva componente deste tensor.

Apresenta-se, a seguir, o conceito de mudança de forma, sendo estudado o comportamento de funções definidas na representação do sólido, no $\mathrm{R}^{3}$, quando sua forma é modificada, TAROCO (1996).

\section{C.1 Conceitos básicos}

Inicialmente, o sólido é identificado com um domínio $\Omega \subset \mathrm{R}^{3}$, limitado pelo contorno $\partial \Omega \subset \mathrm{R}^{2}$. No contorno há dois subconjuntos de pontos, em geral disjuntos, 
um, no qual há tractions prescritas $\left(\partial \Omega_{\mathrm{t}}\right)$, e outro, no qual há deslocamentos prescritos $\left(\partial \Omega_{\mathrm{u}}\right)$. A mudança de forma é descrita com o auxílio de um parâmetro adimensional, $\tau$, e de um campo vetorial $\mathbf{v}=\mathbf{v}(\mathbf{x})$, considerado conhecido a priori, que define a transformação de $\Omega$ em um domínio modificado $\Omega_{\tau}$, como sendo:

$$
\mathbf{x}_{\tau}=\mathbf{x}_{\tau}(\mathbf{x})=\mathbf{x}+\tau \mathbf{v}(\mathbf{x})
$$

expressão na qual o subscrito $\tau$ lembra a dependência em relação a esse parâmetro. Admite-se que a regularidade do campo $\mathbf{v}(\mathbf{x})$ seja tal que sua aplicação não altere a regularidade geométrica da configuração do sólido e de seu contorno.

O domínio modificado, $\Omega_{\tau}$, pode ser entendido como uma pequena perturbação do domínio inicial $\Omega$, e a transformação de $\Omega$ em $\Omega_{\tau}$ como sendo uma função do ponto $\mathbf{x}$ e do parâmetro $\tau$, de maneira que:

$$
\Omega \mapsto \Omega_{\tau} \quad ; \quad \partial \Omega \mapsto \partial \Omega_{\tau} \quad ; \quad \mathbf{x} \mapsto \mathbf{x}_{\tau}
$$

A mudança de forma é simulada, portanto, com o auxílio de uma família de transformações parametrizadas através de $\tau$, conforme mostra a Figura 22. Pode-se fazer uma analogia entre a mudança de forma e o movimento de um corpo: Para diferentes valores do parâmetro $\tau$, o domínio $\Omega_{\tau}$ é o equivalente da trajetória, na Mecânica do Contínuo, sendo que agora o parâmetro $\tau$ faz as vezes do tempo $t$, GURTIN $^{1}$ e MALVERN ${ }^{2}$. Nesse sentido, $\Omega_{\tau}$ pode ser visto como o lugar ocupado por $\Omega$, no tempo $\tau$. Quando $\tau=0$, o domínio $\Omega_{\tau}$ reduz-se ao domínio inicial $\Omega_{0}$, que, a rigor, poderia ser qualquer configuração atualizada do movimento (Mecânica do Contínuo). Aqui, escolhe-se uma configuração de referência (não necessariamente a configuração de referência do movimento), denominada $\Omega$, por simplicidade, porque não está em questão o tempo verdadeiro $t$, do movimento real, e sim o parâmetro $\tau$. Daí:

\footnotetext{
${ }^{1}$ GURTIN, N. E. (1981) An introduction to continuum mechanics, Mathematics in Science and Engineering, Academic Press, New York apud TAROCO (1996).

${ }^{2}$ MALVERN, L.E. (1969) Introduction to the Mechanics of a continuous medium, Prentice Hall apud. TAROCO (1996)..
} 
$\Omega_{\tau}=\left\{\mathbf{x}_{\tau} ; \mathbf{x}_{\tau}=\mathbf{x}+\tau \mathbf{v}(\mathbf{x}), \mathbf{x} \in \Omega, \tau \in \mathrm{R}\right\}$

Desde que, para cada $\tau$, a mudança de forma é uma transformação biunívoca de $\Omega$ em $\Omega_{\tau}$, existe a transformação inversa:

$\Omega_{\tau} \rightarrow \Omega \quad \partial \Omega_{\tau} \rightarrow \partial \Omega \quad \mathbf{x}_{\tau} \rightarrow \mathbf{x}$

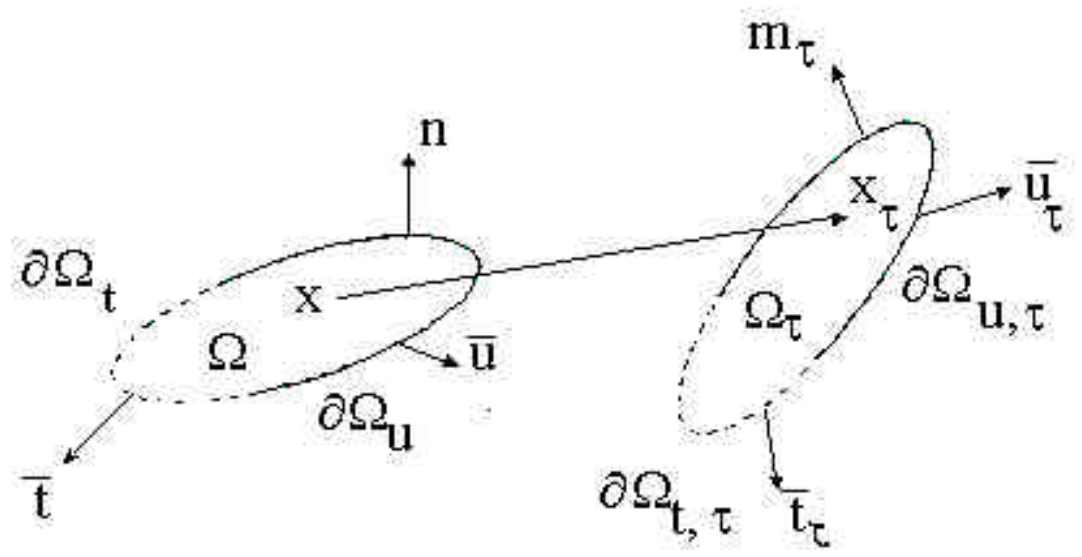

FIGURA 22 - VARIAÇÃO DE FORMA DO DOMÍNIO E DE SEU CONTORNO

Assim, qualquer campo (escalar, vetorial ou tensorial) associado à mudança de forma pode ser expresso tanto por uma função definida em $\Omega$, quanto por outra definida em $\Omega_{\tau}$. Continuando com a analogia entre a mudança de forma e o movimento, da Mecânica do Contínuo, essas duas transformações serão chamadas de descrição material e descrição espacial, respectivamente. No caso de um deslocamento $\mathbf{u}$, por exemplo, pode-se escrever, respectivamente:

$\mathbf{u}=\mathbf{u}(\mathbf{x}, \tau)$

$\mathbf{x} \in \Omega ; \tau \in \mathrm{R}$

$$
\text { e }
$$

$$
\mathbf{u}_{\tau}=\mathbf{u}_{\tau}\left(\mathbf{x}_{\tau}, \tau\right)
$$$$
\mathbf{x}_{\tau} \in \Omega_{\tau}, \tau \in \mathrm{R}
$$

Introduz-se, a seguir, o conceito de gradiente da mudança de forma, ainda dentro da analogia proposta:

$\mathbf{F}=\nabla[\mathbf{x}+\tau \mathbf{v}(\mathbf{x})]=\mathbf{I}+\tau \nabla \mathbf{v}$, 
onde $(\nabla)$ é o gradiente material, uma operação definida no domínio inicial $\Omega$. Da mesma forma, (div) é a divergência material definida no mesmo domínio. De maneira similar, $(\mathrm{Grad})$ e (Div), definidos em $\Omega_{\tau}$, correspondem ao gradiente e à divergência espacial, respectivamente.

Para a Análise de Sensibilidade à mudança de forma, será introduzido, como na Mecânica do Contínuo, um conceito semelhante ao de derivada de campos espaciais. Por exemplo, no caso do campo de deslocamentos $\mathbf{u}_{\tau}$, a derivada espacial no parâmetro $\tau$, em $\tau=0$, é dada por:

$$
\mathbf{u}^{\prime}=\left.\frac{\partial}{\partial \tau} \mathbf{u}_{\tau}\left(\mathbf{x}_{\tau}, \tau\right)\right|_{\tau=0}
$$

Além disso, define-se a derivada material de $\mathbf{u}$ em relação a $\tau$, na direção de $\mathbf{v}$, em $\mathbf{x}$, como sendo:

$$
\dot{\mathbf{u}}=\frac{\partial}{\partial \tau} \mathbf{u}_{\tau}\left(\left.\left(\mathbf{x}_{\tau}\left(\mathbf{x}_{\tau}, \tau\right), \tau\right)\right|_{\tau=0}=\left.\left[\frac{\partial}{\partial \tau} \mathbf{u}_{\tau}+\operatorname{div} \mathbf{u}_{\tau} \frac{\partial \mathbf{x}_{\tau}}{\partial \tau}\right]\right|_{\tau=0}=\mathbf{u}^{\prime}+\left.\mathbf{v} \operatorname{div} \mathbf{u}_{\tau}\right|_{\tau=0}\right.
$$

\section{C.2 Cálculo de $u^{\prime}$ no caso em que v é arbitrado como uma translação dos pontos do contorno}

Em decorrência da análise de sensibilidade, aparece no desenvolvimento, em algumas integrais no contorno, a grandeza $\mathbf{u}^{\prime}$, que é a derivada espacial do vetor deslocamento, tal como se define na eq. (C.5). Para simular o movimento das fissura, imagina-se que um ponto genérico $\mathbf{x}$, do sólido, sofre uma transformação dada pela transformação da eq. (C.2), da qual decorre que:

$\mathbf{x}=\mathbf{x}_{\tau}-\tau \mathbf{v}(\mathbf{x})$

Imaginando que, da expressão (C.7), seja possível explicitar-se o valor de x, com o auxílio de uma função vetorial $f$, tem-se:

$\mathbf{x}=\boldsymbol{f}\left(\mathbf{x}_{\tau}, \tau\right)$ 
O objetivo, agora, é obter-se a expressão de $\mathbf{u}_{\tau}$, em função de $\mathbf{x}_{\tau}$ e $\tau$, que é a transformação sofrida pelo vetor deslocamento, $\mathbf{u}=\mathbf{x}-\mathbf{X}$. Assim:

$\mathbf{u} \rightarrow \mathbf{u}_{\tau}=\mathbf{x}_{\tau}-\mathbf{X}$

onde $\mathbf{X}$ é a representação de referência do ponto $\mathbf{x}$. Daí:

$\mathbf{u}_{\tau}=\mathbf{x}+\tau \mathbf{v}(\mathbf{x})-\mathbf{X}$

onde $\mathbf{v}(\mathbf{x})$ é um vetor qualquer. Substituindo $\mathbf{x}$ da eq. (C.8) na equação (C.10), temse:

$\mathbf{u}_{\tau}=f\left(\mathbf{x}_{\tau}, \tau\right)+\tau \mathbf{v}\left(f\left(\mathbf{x}_{\tau}, \tau\right)\right)-\mathbf{X}$

e então, pela definição da derivada material $\mathbf{u}^{\prime}$, dada pela eq. (C.5), tem-se, para um $\mathbf{X}$ fixo, que:

$\mathbf{u}^{\prime}=\left.\frac{\partial}{\partial \tau} \mathbf{u}_{\tau}\left(\mathbf{x}_{\tau}, \tau, \mathbf{X}\right)\right|_{\tau=0}=\left.\frac{\partial}{\partial \tau} \boldsymbol{f}\left(\boldsymbol{x}_{\tau}, \tau\right)\right|_{\tau=0}+\left.\mathbf{v}\left(\boldsymbol{f}\left(\boldsymbol{x}_{\tau}, \tau\right)\right)\right|_{\tau=0}$

No caso particular, de interesse do problema da fratura, simula-se o movimento da fissura na direção do vetor unitário e, através de um movimento, em sentido contrário, da parte $\Gamma$ da fronteira, isto é, $v=-e$. Por outro lado, em $\Gamma_{\mathrm{T}}$, imagina-se que $\mathbf{v}=\mathbf{0}$.. Então, as eqs. (C.7) e (C.8) levam a:

$\boldsymbol{f}\left(\mathbf{x}_{\tau}, \tau\right)=\mathbf{x}_{\tau}+\tau \mathbf{e}$, em $\Gamma$, e a $\boldsymbol{f}\left(\mathbf{x}_{\tau}, \tau\right)=\mathbf{x}_{\tau}$, em $\Gamma_{\mathrm{T}}$

Daí, chega-se, finalmente, com auxílio da eq. (C.12), que:

$\mathbf{u}^{\prime}=\mathbf{e}-\mathbf{e}=\mathbf{0}, \mathrm{em} \Gamma$

e $\mathbf{u}^{\prime}=\mathbf{0}+\mathbf{0}=\mathbf{0}$, também em $\Gamma_{\mathrm{T}}$. 


\section{ANEXO D \\ MÉTODO DOS ELEMENTOS DE CONTORNO APLICADO A PROBLEMAS BIDIMENSIONAIS DE ELASTICIDADE}

O Método dos Elementos de Contorno aplicado a problemas bidimensionais da elasticidade é uma extensão do caso do potencial plano, para a qual obtém-se a resposta na forma da solução de uma equação diferencial, nas componentes do vetor deslocamento, após a aplicação de uma carga tipo distribuição $\delta$-Dirac, na direção de um dos eixos coordenados do plano, em um ponto genérico do domínio.

Obtém-se, inicialmente, a partir das exigências de equilíbrio e de compatibilidade da elasticidade, as expressões das componentes do deslocamento, em pontos do interior do domínio, em função dos valores prescritos no contorno, em termos de componentes de deslocamento e de tractions. Depois, estende-se esse resultado para pontos do próprio contorno, chegando-se, finalmente, às equações integrais que permitirão a aplicação do método aproximado, cuja solução final resultará da resolução de um sistema de equações algébricas, cujas incógnitas são as componentes de deslocamento e as tractions no contorno.

No caso da Mecânica da Fratura, necessita-se das componentes do tensor de tensões e das componentes do tensor gradiente do deslocamento, em pontos do interior do domínio plano, o que deverá ser fornecido, de forma aproximada, a partir da utilização de um programa automático, no qual é utilizado um elemento de contorno reto, com funções de interpolação lineares. 
Mostra-se, a seguir, o esquema baseado no Método dos Elementos de Contorno, através do qual serão obtidos, nos pontos de um contorno elíptico com eixos arbitrariamente fixados, o tensor gradiente do deslocamento, e o tensor de tensão.

A equação integral que fornece as duas componentes cartesianas do vetor deslocamento em pontos do domínio é, BREBBIA \& DOMINGUEZ (1989):

$u_{i}(P)=-\int_{\partial \Omega} p_{i j}^{*}(P, S) u_{j}(S) \mathrm{d} S+\int_{\partial \Omega} u_{i j}^{*}(P, S) p_{j}(S) \mathrm{d} S$

onde $P$ indica um ponto genérico no interior do domínio $\Omega$, e $S$, um ponto também genérico, porém situado no contorno, $\Gamma$, desse domínio. As soluções fundamentais $u_{\mathrm{ij}}^{*}$ e $p_{\mathrm{ij}}^{*}$, que aparecem nas integrais do segundo membro da eq. (D.1) são, respectivamente, respostas à aplicação de distribuições $\delta$-Dirac, associadas à direção $j$. Essas funções, válidas para o caso bidimensional, são dadas através das expressões, (v. BREBBIA \& DOMINGUEZ (1989)):

$u_{i j}^{*}(P, S)=\frac{1}{8 \pi G(1-v)}\left[(4 v-3) \delta_{i j} \ln r+r_{, i} r_{j}\right]$
$p_{i j}^{*}(P, S)=\frac{-1}{4 \pi(1-v) r}\left\{\left[(1-2 v) \delta_{i j}+2 r_{, i} r_{, j}\right] r_{, n}+(1-2 v)\left[n_{i} r_{, j}-n_{j} r_{, i}\right]\right\}$.

Para que se obtenham as componentes cartesianas do tensor gradiente do deslocamento e do tensor de tensão, é necessário a derivação da eq. (D.1) em relação a $x_{\mathrm{k}}$. Assim:

$u_{i, k}(P)=\int_{\partial \Omega} u_{i j, k}^{*}(P, S) p_{j}(S) d s-\int_{\partial \Omega} p_{i j, k}^{*}(P, S) u_{j}(S) d s$.

Observe-se que, por ser a derivação parcial em relação à variável $x_{\mathrm{k}}$, relativa ao ponto $P$, do interior do domínio, isso não afeta as variáveis dependentes de $S$, ponto do contorno. Assim sendo, desde que seja assegurada a continuidade das funções integrandas, passa-se a derivação para o interior das integrais do segundo membro da eq. (D.4). Vê-se, portanto, que a derivação somente afeta as soluções fundamentais, 
$u_{\mathrm{ij}}^{*}$ e $p_{\mathrm{ij}}^{*}$, que dependem do ponto interior $P$. Em resumo, somente as derivadas parciais das soluções fundamentais $u_{\mathrm{ij}}^{*}$ e $p_{\mathrm{ij}}^{*}$, em relação à variável $x_{\mathrm{k}}$, são calculadas, entendendo-se que o seu sinal deve ser invertido, para que se mantenha a convenção tradicional de $r,{ }_{i}$ como sendo a derivada do raio em relação à variável relacionada com o ponto do contorno. Efetuando as derivações, resulta que:

$u_{i j, k}^{*}(P, S)=\frac{1}{8 \pi \mu(1-v) r}\left\{r_{, k}\left[(3-4 v) \delta_{i j}+2 r_{, i} r_{j}\right]-r_{, i} \delta_{j k}-r_{, j} \delta_{i k}\right\}$

e

$p_{i j, k}^{*}(P, S)=\frac{-1}{4 \pi(1-v) r^{2}}\left\{2 r_{, n}\left[(2 v-1) \delta_{i j} r_{, k}-4 r_{, i} r_{, j} r_{, k}+r_{, i} \delta_{j k}+r_{, j} \delta_{i k}\right]+\right.$

$\left.+(1-2 v)\left[n_{j}\left(\delta_{i k}-2 r_{, i} r_{, k}\right)+2 n_{i} r_{, j} r_{, k}-n_{i} \delta_{j k}-n_{k} \delta_{i j}\right]-2 r_{, i} r_{, j} n_{k}\right\}$,

onde $\mu$ é o módulo de elasticidade transversal e $r_{, n}=r_{, l} n_{l}$, e $i, j, k, l=1,2$. Substituindo-se as eqs. (D.5) e (D.6) na eq. (D.4) obtêm-se as derivadas das componentes do vetor deslocamento, com as quais pode-se compor o tensor gradiente do vetor deslocamento:

$$
(\nabla \mathbf{u})_{i j}=u_{i, j}
$$

Obtido este tensor, pode-se formular a expressão da densidade de energia, $\phi$, da qual derivam-se as componentes do tensor de tensão:

$$
T_{i j}=\frac{E}{2(1+v)}\left[\frac{2 v}{1-2 v} \delta_{i j} u_{m, m}+u_{i, j}+u_{j, i}\right],
$$

Com as componentes do tensor gradiente dos deslocamentos $\nabla \mathbf{u}$ e do tensor de tensão T nos pontos do caminho elíptico de integração, pode-se determinar, tal como é feito no Capítulo. 5, realizar o cálculo de $G \mathbf{e} G^{*}$.

\section{D.1 A técnica da sub-elementação}

No intuito de melhorar a precisão dos resultados, já que as integrações, no Método dos Elementos de Contorno envolvem funções portadoras de singularidades, 
que são muito sensíveis à distância do ponto de colocação, utiliza-se uma eficiente técnica que consiste na possível subdivisão de um dado elemento reto, em subelementos, a decisão ficando por conta da distância do ponto de colocação em relação ao elemento. Em seqüência, realiza-se a integração numérica, no domínio do sub-elemento, com auxílio do Método de Gauss-Legendre, usando-se, no caso do ELCFRAT, o mesmo número de pontos de integração que o utilizado nos elementos que não precisaram de sub-elementação.

Para isso, usam-se duas opções, segundo o seguinte esquema: na primeira, imagine-se um elemento $P_{1} P_{2}$, e o ponto de colocação $P_{0}$, cujas posições relativas estão indicadas na Figura. $23 a$. Um ponto genérico do segmento $P_{1} P_{2}$ pode, então, ser dado através da seguinte expressão:

$P=P_{1}+\alpha \vec{t}$, onde $0 \leq \alpha \leq L$, sendo $L$ o comprimento do elemento, e $\vec{t}=\left(\frac{x_{2}-x_{1}}{L}, \frac{y_{2}-y_{1}}{L}\right)$, o vetor unitário da direção $P_{1} P_{2}$.

Para a formular-se um critério de subdivisão, o elemento $P_{1} P_{2}$, a seguinte condição será estabelecida, no primeiro caso, em termos de distâncias:

$d\left(P_{1}, P\right)=d\left(P_{0}, P\right)$

Como

$d\left(P_{1}, P\right)=\sqrt{\left(x-x_{1}\right)^{2}+\left(y-y_{1}\right)^{2}}$ e $d\left(P_{0}, P\right)=\sqrt{\left(x-x_{0}\right)^{2}+\left(y-y_{0}\right)^{2}}$,

então, fazendo a substituição na eq. (D.9), chega-se à definição do valor do parâmetro localizador $\alpha$ :

$\alpha=-\frac{L}{2}\left[\frac{\left(x_{1}-x_{0}\right)^{2}+\left(y_{1}-y_{0}\right)^{2}}{\left(x_{2}-x_{1}\right)\left(x_{1}-x_{0}\right)+\left(y_{2}-y_{1}\right)\left(y_{1}-y_{0}\right)}\right]$.

Pelo observado na Figura $23 a$, se $0<\alpha \leq L$, então o ponto $P(x, y)$ definirá o sub-elemento $P_{1} P$. No entanto, se $\alpha \leq 0$ ou $\alpha>L$, então um segundo critério deverá ser utilizado. 

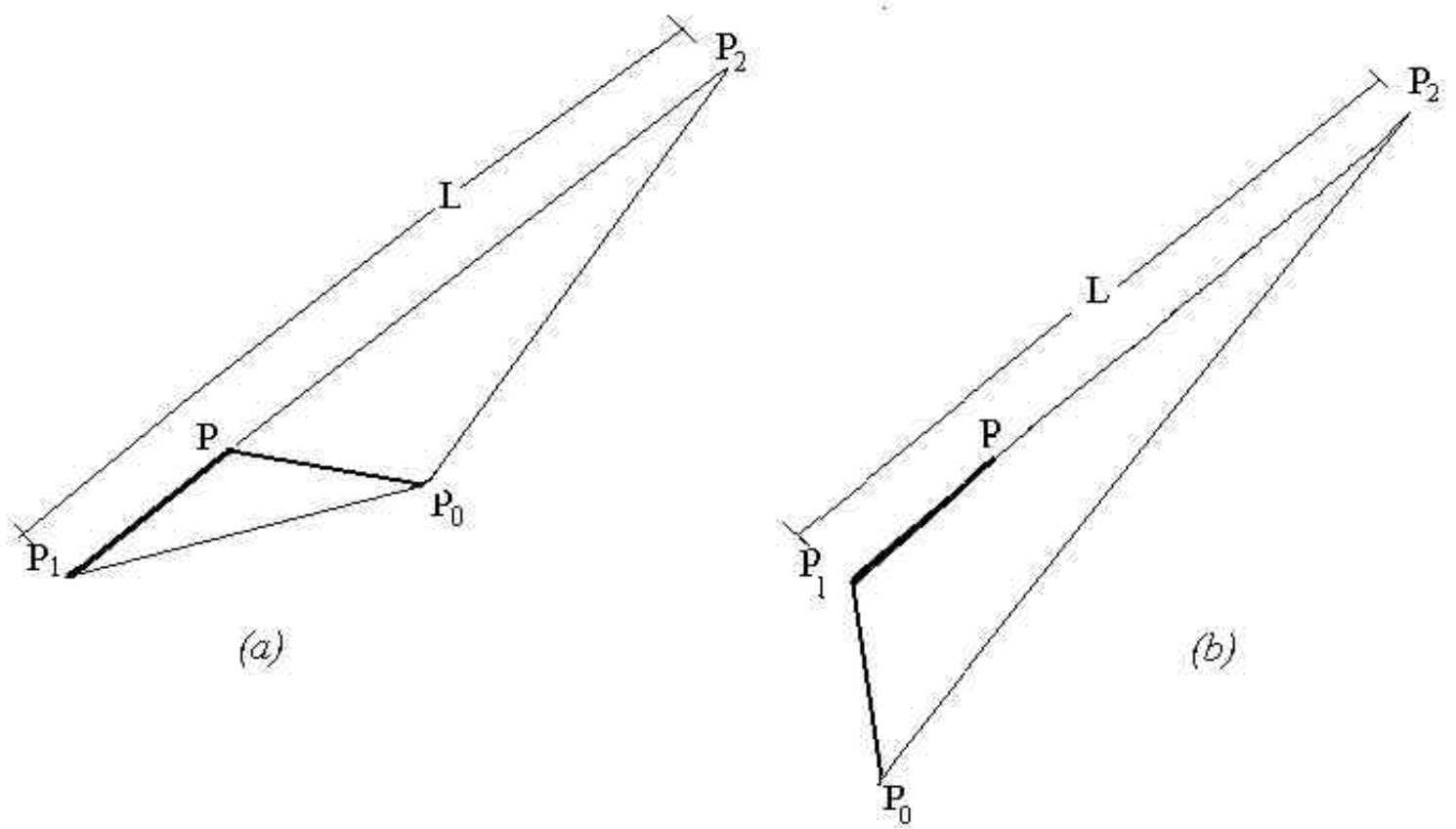

FIGURA 23-POSIÇÕES RELATIVAS DO PONTO DE COLOCAÇÃO EM RELAÇÃO AO ELEMENTO RETILÍNEO

A Figura $23 b$ ilustra o segundo critério, para a definição do sub-elemento, caracterizada pela seguinte condição:

$d\left(P, P_{1}\right)=d\left(P, P_{0}\right)$

onde o ponto genérico $P$, do segmento $P_{1} P_{2}$ agora é dado através da seguinte expressão:

$P=P_{1}+\beta \vec{t}$, sendo $0 \leq \beta \leq L$, e $\vec{t}=\left(\frac{x_{2}-x_{1}}{L}, \frac{y_{2}-y_{1}}{L}\right)$, o vetor unitário da direção $P_{1} P_{2}$. As distâncias de $P$ a $P_{1}$ e de $P$ a $P_{0}$ são dadas, respectivamente, por:

$d\left(P, P_{1}\right)=\sqrt{\left(x-x_{1}\right)^{2}+\left(y-y_{1}\right)^{2}}$ e $d\left(P, P_{0}\right)=\sqrt{\left(x-x_{0}\right)^{2}+\left(y-y_{0}\right)^{2}}$.

A aplicação da condição (D.11) conduz ao seguinte valor de $\beta$ :

$\beta=\sqrt{\left(x_{1}-x_{0}\right)^{2}+\left(y_{1}-y_{0}\right)^{2}}$. 
Fica evidente que o valor de $\beta$ é sempre positivo, devendo no entanto obedecer a condição $0<\beta \leq L$.

Em síntese, deverá ser seguido o seguinte roteiro, para o teste e a aplicação do processo de divisão do elemento de contorno em sub-elementos:

1) Calcula-se $\alpha$ e $\beta$, correspondentes ao ponto de colocação $P_{0}$, usando-se as expressões (D.10) e (D.12), respectivamente;

2) Caso $\alpha$ atenda à condição $0<\alpha \leq L$, obtém-se o sub-elemento $P_{1} P$, onde $P=\left(x_{1}+\alpha\left[x_{2}-x_{1}\right] ; y_{1}+\alpha\left[\mathrm{y}_{2}-y_{1}\right]\right)$;

3) Se a condição anterior não for verificada, testa-se, nessa ordem, a segunda: $\beta \leq L$. Caso esta seja atendida, então $P=\left(x_{1}+\beta\left(x_{2}-x_{1}\right) ; y_{1}+\beta\left(\mathrm{y}_{2}-y_{1}\right)\right)$

4) Se ambas as condições não forem atendidas, não é necessária aplicação da técnica para o par $\left(P_{0}, P_{1} P_{2}\right)$;

5) Se couber a aplicação da técnica a um par $\left(P_{0}, P_{1} P_{2}\right)$; a continuidade de sua utilização será testada, podendo os dois critério irem se alternando, até esgotar-se o processo, para esse par, passando-se, então ao seguinte, e assim sucessivamente.

\section{D.1.1 A integração numérica no sub-elemento}

Imagine-se uma função $f(s)$, integrável, definida no elemento reto $A B$, cujas extremidades sejam dadas através dos valores $s_{a} \quad e \quad s_{b}$ do parâmetro $s$, respectivamente. Para sua integração numérica, num elemento de contorno, através do Método de Gauss-Legendre, por exemplo, deve-se realizar uma mudança da variável $s$ (comprimento de arco) para variável adimensional $\xi$, de maneira que esta assuma os valores -1 e +1 , respectivamente, nas extremidades $A$ e $B$ desse elemento. Para que tal condição seja obedecida, admitindo-se que $s=a \xi+b$, tem-se:

$$
a=\frac{s_{b}-s_{a}}{2} \quad, \quad b=\frac{s_{b}+s_{a}}{2} \quad e \quad \mathrm{~d} s=a \mathrm{~d} \xi .
$$


Para realizar-se a integração em um sub-elemento contido nesse elemento reto, de extremidades $i$ e $j$, por seu turno, é necessário mudar-se da variável $\xi$ para a variável $\eta$, de forma a que a integral, nessa nova variável, seja realizada entre $\eta=-1$ e $\eta=+1$, porque o esquema de integração aproximado será o mesmo, com base no Método de Gauss-Legendre. Assim:

$\xi=p \eta+q$, onde

$p=\frac{\xi_{j}-\xi_{i}}{2} \quad, \quad q=\frac{\xi_{j}+\xi_{i}}{2} \quad$ e $\mathrm{d} \xi=p \mathrm{~d} \eta$

O caso do elemento reto, por exemplo, com uma função de interpolação linear, está ilustrado na Figura 24:

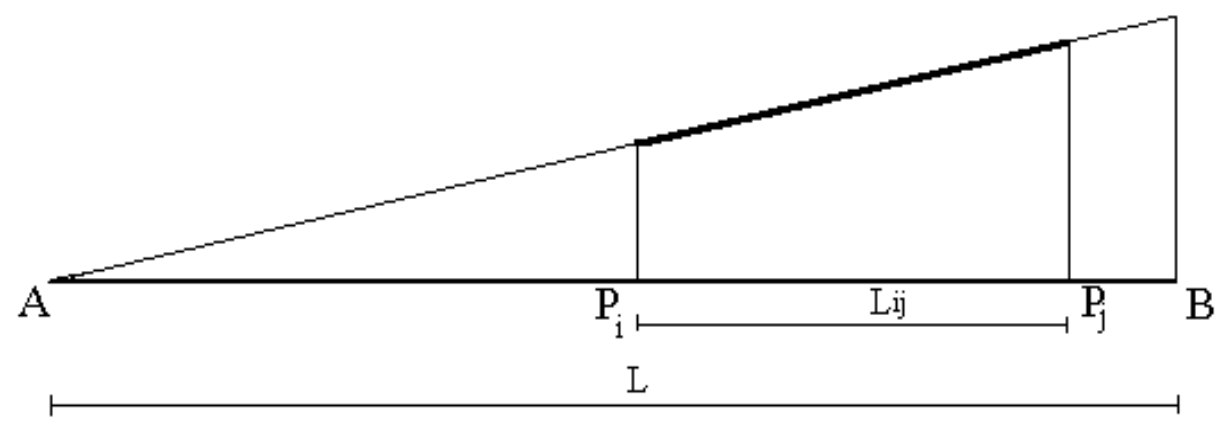

FIGURA 24- SUB-ELEMENTO DE UM ELEMENTO DE CONTORNO RETILÍNEO

Pode-se concluir, também, usando-se as expressões de $s=s(\xi)$ e $\xi=\xi(\eta)$, que:

$a=\frac{s_{j}-s_{i}}{\xi_{j}-\xi_{i}} \quad$ e $\quad b=s_{i}-\xi_{i} \frac{s_{j}-s_{i}}{\xi_{j}-\xi_{i}}$.

Considerando-se as eqs.(D.13) e (D.14), a integral da função $f(s)$ será:

$$
\int_{s_{i}}^{s_{j}} f(s) d s=a \int_{\xi_{i}}^{\xi_{j}} f(s(\xi)) d \xi=a p \int_{\eta=-1}^{\eta=+1} f(s(\xi(\eta))) d \eta=a p \int_{-1}^{+1} g(\eta) d \xi,
$$

onde $g(\eta)=f(s(\xi(\eta)))$. Mas, de acordo com as equações (D.14) e (D.15):

$a p=s_{j}-s_{i}=L_{i j}$, 
onde $L_{\mathrm{ij}}$, tal como indica a Figura 24, é o comprimento do sub-elemento considerado. Conclui-se também, a partir da manipulação dessas duas equações, que:

$p=\frac{L_{i j}}{L} \quad e \quad q=\frac{L_{i j}+2\left(s_{i}-b\right)}{L}, \quad$ onde $L$ é o comprimento total do elemento $A B$, e $b$ é dado pela eq. (D.13).

Embora no presente caso, a opção tenha sido por uma função de interpolação linear, observe-se que o esquema é válido, desde que o elemento seja reto, quaisquer que sejam as funções de interpolação, pois em nenhum momento se cogitou de particularizar a função $f=f(s)$.

No caso do Programa ELCFRAT, a técnica de sub-elementos foi usada, tanto para as integrações visando à montagem do sistema de equações algébricas do Método dos Elementos de Contorno, quanto para o cálculo das componentes do tensor gradiente do deslocamento. Além disso, também foi usada para calcular os tensores tensão e de deformação nos pontos internos da chapa, produzindo uma sensível melhoria na aproximação. No caso desse programa automático, a função $f(s)$ foi tomada como linear, tal como ilustra a Figura 24, mas a utilização de funções de interpolação nãolineares, em elementos não retilíneos, pode ser desenvolvida sem dificuldade, usando-se a técnica de sub-elementação aqui apresentada. 


\section{ANEXO E}

\section{PROGRAMA ELCFRAT: CÁLCULO DA INTEGRAL $\boldsymbol{J}$ E DO PARÂMETRO TERMODINÂMICO DE FRATURA \\ $\left(G_{t}\right)^{1}$}

Desenvolvido com a finalidade de ilustrar a possibilidade de utilização prática do critério termodinâmico de fratura, formulado teoricamente no Capítulo 4 , o programa automático ELCFRAT, escrito em linguagem FORTRAN, para utilização em microcomputador, (Powerstation, versão 4), aplica-se a casos de problemas de estados planos. A idéia que presidiu sua concepção, foi a de testar procedimentos de cálculo baseados na Análise de Sensibilidade, tanto aquele que permite a obtenção da integral $J$, a partir do tensor momentum-energia, de Eshelby, quanto o que calcula $G_{\mathrm{t}}$, a partir do tensor ao qual se chegou, no presente trabalho. Embora aqui obtidos para o caso tridimensional, ambos os tensores são particularizados para problemas bidimensionais, no caso do ELCFRAT.

O programa ELCFRAT utiliza o Método dos Elementos de Contorno (BEM) como ferramenta de cálculo numérico. A eficiência do programa, em termos da precisão dos resultados, foi sendo gradativamente melhorada, tirando-se proveito, para isso, da propriedade de independência do caminho, da integral $J$, da seguinte forma: variando-se o número de pontos de integração de Gauss-Legendre, ia-se realizando o cálculo da integral $J$, para distintos caminhos, sendo a medida da melhoria da eficiência dada pelos resultados, cada vez mais próximos, entre si, quando as alternativas de uso de vários caminhos elípticos, ia sendo utilizada. Parouse em número de pontos de Gauss igual a quarenta e oito, para a integração no

\footnotetext{
${ }^{1}$ A listagem-fonte do programa ELCFRAT, bem como o arquivo de dados, e a saída dos resultados referente a esses dados, gravados em um disquete, são parte integrante desta tese.
} 
circuito elíptico. Além desse número, não foi percebido qualquer aumento significativo na precisão, isto após verificar-se um aumento bastante significativo na eficiência do cálculo de $J$, após a utilização da técnica de sub-elementação (v. Anexo D), no caso do elemento de contorno utilizado (retilíneo, isoparamétrico, e com funções de interpolação lineares).

Em síntese, como ainda não foi verificado, na literatura, qualquer registro de metodologia utilizando o parâmetro $G_{\mathrm{t}} \mathrm{e}$, ao verificar-se, através da experimentação numérica, que ele não possui a propriedade de independência do caminho, a maneira de aperfeiçoar o seu cálculo, foi buscada, indiretamente, através da melhoria da eficiência do cálculo de $J$.

Ao final, ficou-se com uma ferramenta capaz, tanto de calcular bem a integral $J$, quanto de aplicar a metodologia aqui desenvolvida, utilizando-se da vocação natural do BEM, que é permitir a simplificação na realização de cálculos em variedades (no presente caso, a realização de integrais sobre caminhos de forma elíptica, situados no interior da chapa).

O ELCFRAT pode ser entendido como um programa contendo dois subprogramas: o primeiro, para o cálculo do tensor de tensão, do tensor de deformação e do tensor gradiente do vetor deslocamento, em um problema bidimensional contendo uma, ou mais trincas no domínio; e o segundo, um pós-processador desses valores, para o cálculo da integral $J$ e para a aplicação do critério termodinâmico de fratura, baseado no parâmetro $G_{\mathrm{t}}$. Nesse sentido, a inovação aqui apresentada reside, basicamente, no segundo sub-programa, cuja generalização, para o caso tridimensional, por exemplo, não é difícil. Assim, desde que o tensor tensão, o tensor gradiente de deslocamento e o tensor deformação sejam fornecidos, até mesmo por um programa automático não especializado em fratura, qualquer que seja o sólido, o segundo sub-programa do ELCFRAT, basicamente a subrotina INTEGJ, se encarregará do cálculo de $J$ e de $G_{\text {t }}$. 


\section{E.1 Descrição do programa automático e entrada de dados}

\section{E.1.1 Subrotinas do ELCFRAT}

LEDAD - Lê ou gera dados de entrada, imprimindo-os após. É chamada pelo programa principal.

CALCGH : Monta as matrizes G e H, formando, na sequiência, o sistema

A $x==f$. Chama as sub-rotinas EXATIN e INTNUM, e é chamada pelo programa principal.

INTNUM - Calcula as matrizes locais AG e AH, quando o ponto de colocação é um nó de contorno situado fora do elemento, ou um ponto interno. As integrações são feitas de forma aproximada, através do método de Gauss-Legendre. Ë chamada por CALCGH e TDDOM..

EXATIN - Calcula as matrizes locais AG e AH, quando o ponto de colocação está situado no elemento de integração. As integrais são exatas. É chamada por CALCGH.

SOLVE - Resolve o sistema de equações, pelo método de eliminação de Gauss. É chamada pelo programa principal.

SDMAT - Calcula as componentes das matrizes auxiliares, que irão permitir a obtenção do vetor deslocamento, do tensor gradiente do deslocamento, do tensor deformação e do tensor tensão, nos pontos do interior do domínio. É chamada por TDDOM.

TDDOM - Calcula, e fornece como saída, os resultados, em termos de componentes do vetor deslocamento e do tensor de tensão, em pontos do interior do domínio. É chamada pelo programa principal.

INTEGJ - É a sub-rotina que contém a inovação essencial trazida pelo presente trabalho. Calcula e imprime o valor da integral $J$ sobre caminhos elípticos. Calcula, também para qualquer caminho elíptico, o parâmetro $\mathrm{G}_{\mathrm{t}}$, e aplica o critério termodinamicamente consistente de fratura, na forma de um processo iterativo. Esse 
processo inicia-se com o fornecimento de um valor positivo arbitrário, para o parâmetro GAMMA, e um valor tão pequeno quanto seja permitido pelos limites da programação, para a TOLERÂNCIA, fornecendo, como saída, o resultado do teste e a direção tendente a ser tomada pelo possível avanço da fissura. Esta subrotina é chamada pelo programa principal.

\section{E.1.2 Entrada de dados}

a) Título: Lê um título com até 80 caracteres.

b) Dados iniciais, lidos em formato livre: KEYF, NND, NDOUB, NE, NIP, FESCH, FESCV, GE,XNU, TE, GAMMA, TOL.

- KEYF é uma chave. Se $\mathrm{KEYF}=0 \Rightarrow$ problema de elasticidade; $\mathrm{KEYF}=1$ $\Rightarrow$ problema de fratura

. NND é o número total de nós do contorno. Cada nó duplo conta como dois.

. NDOUB é o número de pares de nós duplos

. NE. é o número de elementos de contorno

. NIP é o número de pontos internos, onde tensão e deslocamento são calculados. Se o problema é de elasticidade, as coordenadas dos pontos internos são fornecidas ao programa. Se o problema é de fratura, as coordenadas dos pontos internos são geradas. Nesse último caso, NIP tem de ser igual ao numero de pontos de Gauss usados na sub-rotina INTEGJ. No caso, está fixado em 48.

. XNU será o coeficiente de Poisson, v, se o estado plano for de deformação. Se o problema é de estado plano de tensão, entrar com $\mathrm{XNU}=\mathrm{v} /(1+\mathrm{v})$

. TE é a espessura da chapa.

. FESCH é um fator de escala geométrico horizontal : altera todas as coordenadas horizontais, por multiplicação

. FESCV é um fator de escala vertical: altera todas as coordenadas verticais, por multiplicação 
. GE é o módulo de elasticidade transversal

. GAMMA é um número real positivo qualquer

- TOL é a tolerância, para o processo iterativo que busca o valor limite de $G_{\text {t }}$ Pode ser dado como um número muito pequeno (abaixo de $10^{-3}$, por exemplo)

c) Lê pares de nós duplos: Lê os números dos nós duplos, aos pares. Em qualquer vértice contido no contorno, deve-se sempre colocar nó duplo. Deve-se também colocar um nó duplo, em cada ponto de descontinuidade de traction.

d) Lê incidências dos elementos: Lê o número do elemento e os números de seus dois nós, no sentido anti-horário.

e) Lê as coordenadas do vértice do entalhe, XF, YF. De fato, podem ser as coordenadas de um ponto qualquer, em relação ao qual queira-se ter uma distância. Só é útil quando KEYF=0, isto é, quando o problema não é de fratura.

f) Lêe, em qualquer ordem, os números dos nós do contorno, cada qual seguido de suas respectivas duas coordenadas.

g) OPCIONAL. Se o problema é de elasticidade $(\mathrm{KEYF}=0)$, lê os números dos nós internos, cada qual seguido de suas duas coordenadas. A numeração dos nós internos deve ser em seqüência à dos nós do contorno.

h) OPCIONAL. Se o problema é de fratura, isto é, KEYF=1, lê os seguintes dados, em formato livre: X0, Y0, CX1, CY1, CX2, CY2 e ELIPSY.

. X0, Y0: coordenadas cartesianas do centro do circuito elíptico situada o no plano médio da chapa. 
. CX1, CY1: coordenadas do ponto de intercessão do caminho elíptico com a face lateral do entalhe que corresponde ao início do processo de integração numérica, que deve ser realizado no sentido anti-horário.

. CX2, CY2: coordenadas do ponto de intercessão do caminho elíptico com a face lateral do entalhe que corresponde ao final do processo de integração numérica.

. ELIPSY: semi-eixo da elipse, na direção de $x_{2}$.

\section{E.1.3 Saída do valor da integral $J$, do valor limite de $G_{t}$ e do ângulo formado pela direção do avanço da fissura com o eixo $x_{1}$}

Abaixo, mostra-se o trecho final da saída de resultados do programa ELCFRAT, no intuito de interpretar-se, no caso do exemplo processado, o fato de saírem duas soluções, tanto para o valor limite de $G_{t}$, quanto para o ângulo da direção do avanço da fissura. De fato, o programa reflete o resultado teórico, contido no Capítulo 4, segundo o qual o problema da determinação do valor desse ângulo poderia ter: duas, uma, ou nenhuma solução. A última hipótese torna-se sem sentido, porque o processo iterativo, em busca do valor limite de $G_{\mathrm{t}}$, sempre segue em frente, quando verifica que o programa indica que a fissura não avança. Em síntese, o que ele busca determinar é o valor limite de $G_{t}$, isto é, o menor valor do parâmetro termodinâmico, para que a fissura avance.

O caso em que a solução é única não oferece novidade. Já no caso em que são duas as soluções, verificou-se que, quanto menor o valor da tolerância fornecida inicialmente, para o processo iterativo, mais as duas soluções tendem a convergir, uma para a outra. Para um mesmo valor de $G_{\mathrm{t}}$ limite, por um lado, e para um mesmo valor do ângulo $\theta$, por outro lado, como ilustra a saída de resultados abaixo:

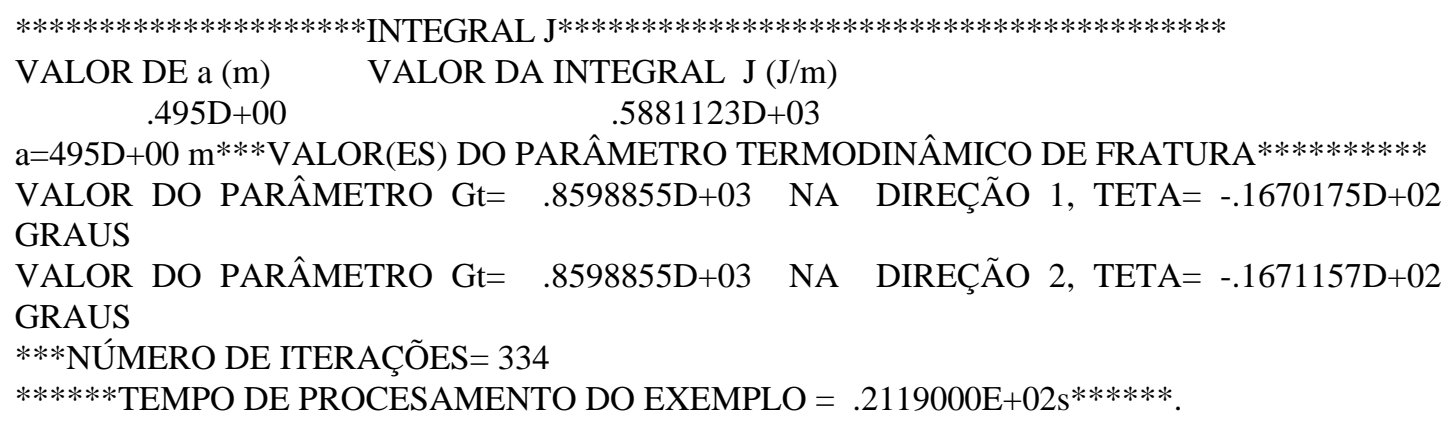




\section{REFERÊNCIAS BIBLIOGRÁFICAS}

BARENBLATT, G. I. (1959). Equilibrium cracks formed during brittle fracture rectilinear cracks in plane plates. Appl. Math. Mech. (PMM), v.23, n.4, p.706-21.

BARENBLATT, G. I. (1960). On finiteness conditions in the mechanics of continuous media. Static problems of the theory of elasticity. Appl. Math. Mec, (PMM), v.24, n. 2, p.316-22.

BARENBLATT, G. I. (1964). On some general concepts of the mathematical theory of brittle fracture. Appl. Math. Mech (PMM), v.28, n.4, p.630-43.

BEREMIN, F. M. (1983). A local criterion for cleavage fracture of a nuclear pressure vessel steeel. Metallurgical Transactions, v.14 A, p.2277-87.

BREBBIA, C. A.; DOMINGUEZ, J. (1989). Boundary elements: an introductory course. New York, McGraw-Hill Book.

BROPHY, J. H.; ROSE, R. M.; WULFF, J. (1972). Ciência dos Materiais, Propriedades Termodinâmicas, v. Rio de Janeiro, Livros Técnicos Científicos Editora Ltda.

CIMINI JR., C. A.; TAROCO, E. O.; LAS CASAS, E. B. (1991). Fatores de intensidade de tensão em componentes estruturais mediante avaliação numérica da integral J. Rio de Janeiro. / Relatório de Pesquisa $n^{0}$ 020/91, do Laboratório Nacional de Computação Científica /. 
CUNHA, D. J. S.; TAROCO,E.; FEIJÓO, R. A. (1995). Avaliação numérica da integral J para estados planos de tensão e de deformação. Rio de Janeiro. / Relatório de Pesquisa n ${ }^{0}$ 02/95, do Laboratório Nacional de Computação Científica /

EFTIS, J.; LIEBOWITZ, H. (1976). On surface energy and the continuum thermodynamics of brittle fracture. Engineering Fracture, v.8, p.459-85.

ESHELBY, J. D. (1956). The continuum theory of lattice defects. In: Solid State Physics. New York, Academic Press. v.3, p. 79-114.

FAUCHER, B. (1994). Crack lenght and $J$-integral expresions for especimens loaded in tension. Journal of Testing and Evaluation, v.22, n.1, p.30-35.

FEIJÓO, R. A. (1972). Introduccion a Mecanica del Continuo. Rio de Janeiro, CBPF.

GALILEI, G. (1945). Diálogos acerca de dos nuevas ciencias, Trad. do original Discorsi intorno a due nuove scienze, por José San Román Vilassante. Buenos Aires, Editorial Losada.

GRIFFITH, A. A. (1920). The phenomena of rupture and flow in solids. Philosophical Transactions of the Royal Society, v.A 221, p.163-98.

GRIFFITH, A. A. (1924). The theory of rupture. In. First International Congress of Applied Mechanics, Delft, 1995. Proceedings. Delft, 1924, p.55-63.

GURTIN, N. E. (1979). On the energy release rate in quasi-static elastic crack propagation, Journal of Elasticity, v.9, n.2, p.187-195.

GURTIN, N. E. (1981). An introduction to continuum mechanics. Mathematics in Science and Engineering, Academic Press, New York.

HILLERBORG, A. (1991). Application of the fictitious crack model to different types of materials. International Journal of Fracture, 51, p.95-102. 
INGLIS, C. E. (1913). Stresses in a plate due to the presence of cracks and sharp corners. Transactions of the Royal Institution of Naval Architects, v. 60, p.219-41.

IRWIN, G. R. (1957). Analysis of stress and strains near the end of a crack traversing a plate. Journal of Applied Mechanics, v.24, p. 361-64.

KNOTT, J. F. (1993). The Science and Engineering of Fracture. In: Advances in Fracture Resistence and Structural Integrity: Select papers from $8^{\text {th }}$ Int. Conf. On Fracture (ICF8). Ukraine, 08-14 jun. 1993, p.13-50.

KNOWLES, J. K.; STERNBERG, E. (1972). On a class of conservation laws in linearized and finite elastostatics. Archiv. Rat. Mech. Anal. ,v.44, p.187-211.

LEMAITRE, J.; J-L. CHABOCHE. (1990). Mechanics of solid material. Cambridge, Cambridge University Press,

LEWIS, G. N.; RANDALL, M. (1961). Thermodynamics. 2.ed. New York, McGrawHill Inc.

MINAMI, F.; BRÜCKNER-FOIT, A; MUNNZ, D.; TROLLDENIER, B. (1992). Estimation procedure for Weibull parameters used in the local approach. International Journal of Fracture, v.54, p.197-210.

NUSSENZVEIG, H. M. (1990). Curso de Física Básica. v.2. São Paulo, Edgard Blücher.

OROWAN, E. Fundamentals of brittle behavior in metals. In: MIT Symposium, New York, June 1950. Proceedings. John Wiley \& Sons, Inc., p. 154.

OWEN, D. R. J.; FAWKES, A. J. (1983). Engineering Fracture Mechanics: numerical methods and applications. Swansea, U. K., Pineridge Press Ltda. 
PIAN, T. H. H., PIN TONG e LUK, C. (1971). Elastic crack analysis by a finite element hybrid method, In: Proc. Third Air Force Conf. on Matrix Methods in Structural Mechanics, Daytona, Ohio,1971.

RICE, J. F.; THOMSON, R. M. (1974). Ductile vs Brittle Behaviour of Crystals, Phil. Mag., v.29, p.73-97.

RICE, J. R. (1968). A path independent and the approximate analysis of strain concentration by notches and cracks. Journal of Applied Mechanics, v.35, p.379-86.

ROCHA J. A. de L.; PROENÇA, S. P. B. (1997). On the necessary condition for the validity of the Continuum Mechanics' principles in Fracture Mechanics. In: Fifth International Conference on Computational Plasticity, Barcelona, 1997. Proceedings. CIMNE, Barcelona, 1997, p.381-6.

ROCHA J. A. de L.; VENTURINI, W. S. (1997).Critério termodinamicamente consistente para previsão de início de fratura. CONGRESSO LATINOAMERICANO SOBRE MÉTODOS COMPUTACIONAIS (CILAMCE), 18., Brasília, 1997. Anais. Brasília, UNB, v.3, p.1137-45.

RUGGIERI, C. et al. (1997). Transferability of elastic-plastic fracture toughness $\left(J_{\mathrm{c}}\right)$ using the Weibull stress approach. Publicação técnica (BT-PNV-34) do Departamento de Arquitetura Naval e Engenharia Oceânica da USP

RUGGIERI, C.; DODDS , R. H. (1996b). A transferability model for brittle fracture including constraint and ductile tearing effects: a probabilistic approach. International Journal of Fracture, 79, p.309-40.

RUGGIERI, C.; DODDS, R. H. (1996a). Probabilistic modeling of brittle fracture including 3-D effects on constraint loss and ductile tearing. Journal de Physique, v. 1996. 
TAROCO, E. \& FEIJÓO, R. A. (1997) Rate of change of J-Rice integral in elastic fractured membranes. Fifth Pan American Congress of Applied Mechanics PACAM V, Puerto Rico, 1997.

TAROCO, E. (1996). Variational formulations in shape sensivity analysis and fracture mechanics. In: Symposium dedicated to the 70th Birthday of Wolf Altman, Laboratório Nacional de Computação Científica/CNPq, Rio de Janeiro, 1996. Recent developments in Solid Mechanics. Rio de Janeiro, 1996, p. 61-9.

TIMOSHENKO, S. P. (1953). History of the Strength of Materials. New York, McGraw-Hill Book.

VENTURINI, W. S. (1995a). Dual reciprocity BEM for non-linear problems. Boundary Elements Communications, 6, p.259-63

VENTURINI, W. S. (1995b). Análise de problemas de fratura coesiva usando o Método dos elementos de Contorno. In: CONGRESSO LATINO-AMERICANO SOBRE MÉTODOS COMPUTACIONAIS (CILAMCE), 16.,Curitiba,1995. Anais, p.112118.

VOLTERRA, V. (1907) Sur l'équilibre de corps élastique multiplement connexes. Ann. Éc. Norm., (Sér 8), 24, p.401-517.

WEIBULL, W. (1939). The Phenomenon of Rupture in Solids, Ingeniors Vetenskaps

WESTERGAARD, H. M. (1939). Bearing pressures and cracks. Journal of Applied Mechanics, 6, p.49-53.

ZHANG, C.; KARIHALOO, B.L. (1993). A thermodynamic framework of fracture mechanics. Engineering Fracture Mechanics, v.46, n.6, p.1023-30. 


\section{BIBLIOGRAFIA COMPLEMENTAR}

ARORA, J. S. (1993). An exposition of the material derivative appproach for structural shape sensitivity analysis. Computer Methods in Applied Mechanics and Engineering, v.105, p.41-62

BAZANT, Z. P. (1997). Scaling of quasibrittle fracture: hypothesis of invasive and lacunar fractality, their critique and Weibull connection. International Journal of Fracture, 83, p. 41-65.

BAZANT, Z. P.; KAZEMI, T. K. (1991). Size dependence of concret fracture energy determined by RILEM work-of-fracture method. International Journal of Fracture, 51, pp. 121-138.

BELYTSCHKO, T.; LU, Y. Y. ; GU, L. (1994). Element-free Galerkin methods. International Journal for Numerical Methods in Engineering, v.37, p.229-56.

BETEGON, C.; HANCOCK, J. W. (1991). Two-parameter characteriztion of elasticplastic crack tip fields, Journal of Applied Mechanics, v. 58, p. 104-113.

BILLARDON, R.; ADAM, C.; LEMAITRE, J. (1986). Study of the non-uniform growth of a plane crack in a three-dimensional body subjected to nonproportional loadings. Int. J. Solids Strrctures, v.22, n.7, p.677-92.

BISKOV, E. (1970). The calculation of stress intensity factors using the finite element method with cracked elements. International Journal of Fracture Mechanics, v.6, n.2, p.159-67. 
BONNET, M.; XIAO, H. (1995). Computation of energy release rate using material diferentiation of elastic BIE for 3-D elastic fracture. Engineering Analysis with Boundary Elements, 15, p.137-49.

BUDIANSKY, B.; RICE, J. R. (1973). Conservation laws and energy release rates. Journal of Applied Mechanics, Mar. 1973.

CARDOSO, J. B. (1997). Um princípio variacional de sensibilidades de $1^{\mathrm{a}}$ e $2^{\mathrm{a}}$ ordens para o projeto de estruturas não lineares. V Encontro Nacional de Mecânica Computacional, Universidade do Minho, Guimarães, Portugal, 20 a 22 out. 1997.

CARDOSO, J. B.; ARORA, J.S. (1988). Variational method for design sensitivity analysis in nonlinear structural mechanics. AIAA Journal, v.26, n.5, p.595-603.

CARPINTERI, A. (1991). Size-scale transition ductile to brittle failure: structural response vs. crack growth resistance curve. International Journal of Fracture, v.51, p.151-86.

CISILINO, A. P.; ALIABADI, M. H. (1998). Three-dimensional elastoplastic analysis of cracked bodies using the dual boundary element method. IV WCCM, Buenos Aires, June,29 - July, 02. Proceedings (CD ROM).

CUNHA, D. J. S.; RANGEL, M. S.; TAROCO, E. O.; FEIJÓO, R. A. (1996). Decréscimo de energia potencial em Mecanica da Fratura de sólidos axisimétricos mediante cálculo numérico das integrais $J$ e $M$. Rio de Janeiro./ Relatório de Pesquisa n ${ }^{\circ}$ 05/96, do Laboratório Nacional de Computação Científica /.

CUNHA, D. J. S.; TAROCO, E. O. (1996). Lei de invariância e a integral $J$ em sólidos de revolução. Rio de Janeiro. / Relatório de Pesquisa $n^{0}$ 04/96, do Laboratório Nacional de Computação Científica /.

DIAO, X. (1995). A statistical equation of damage evolution. Engineering Fracture Mechanics, v.52, n.1, p.33-42. 
DODDS, R. H.; SHIH, C. F.; ANDERSON, T. L. (1993), Continuum and micromechanics treatment of constraint in fracture, International Journal of Fracture, v. 64, p.101-133.

EFTIS, J. (1987). Load biaxiality and fracture: a two-sided history of complementing errors. Engineering Fracture Mechanics, v.26, n.4, p.567-592.

EFTIS, J.; SUBRAMONIAN, N.; LIEBOWITZ, H. (1977). Crack border stress and displacement equations revisited. Engineering Fracture Mechanics, v. 9, p. 189210.

ENGLAND, A. (1971). On stress singularities in linear elasticity. Int. J. Engng. Sci., v.9, p.571-85.

ESHELBY, J. D. (1970). The energy-momentum tensor in Continuum Mechanics. In: Inelastic Behavior of Solids. ed. KANNINEN, M. F. et al., eds. New York, McGraw-Hill.

ESHELBY, J. D. (1975) The elastic energy-momentum tensor. Journal of Elasticity, v. 5, ns. 3-4, p. 321-35.

GUIMARÃES, S.; TELLES, J. C. F. (1994). On the hyper-singular boundaryelement formulation for fracture-mechanics applications. Engineering Analysis with Boundary Elements, v. 13, p.353-63.

HERNÁNDEZ-GÓMEZ, L. H.; RUIZ, C. (1993). Assessment data for dynamic crack initiation under shock presure loading: Part 1 - Experiment. Theoretical and Applied Fracture Mechanics, 19, p. 75-83.

JEULIN, D. (1995). Modèles probabilistes de rupture des materiaux hétérogènes: efetts de taille et effets d'échelle. Annales des Ponts et Chaussées, n.74.

KEUM, D. J.; KWAK, B. M. (1992). Energy release rates of crack kinking by boundary condition sensitivity analysis. Engineering Fracture Mechanics, v.41, n.6, p.833-41. 
KOLEDNIK, O.; TURNER, C.E. (1994). Application of energy dissipation rate arguments to ductile instability. Fatigue Fract. Engng. Mater. Struct., v.17, n.10, p.1129-45.

KRAJCINOVIC, D.; MASTILOVIC, S. (1995). Some fundamental issues of damage mechanics. Mechanics of Materials, v.21, p.217-30.

KRÄMER, D. (1993). On the applicability of the $I$-integral in Fracture Mechanics. Archive of Applied Mechanics, v. 163, p.551-55.

LANDES, J. D.; ZHOU, Z.; LEE, K.; HERERA, R. (1991). Normalization method for developing J-R curves with the LMN function. Journal Testing and Evaluation, v.19, n.4, p. 305-11.

LAVIT, I. M. (1994). Boundary integral equation for a curvilinear boundary crack. $J$. Appl. Maths. Mechs., v.58, n.1, p.161-70.

LIEBOWITZ, H.; SANDHU, J. S.; LEE, J. D.; MENANDRO, F. C. M. (1995). Computational fracture mechanics: research and asppplication. Engineering Fracture Mechanics, v.50, n.5/6, p.653-70.

LIU, H. W. (1991). A review of fatigue crack growth analysis. Theoretical and Applied Fracture Mechanics, v.16, p.91-108.

MAITI, S. K. (1990). Finite element computation of the strain energy release rate for kinking of a crack. International Journal of Fracture, v.43, p.161-174.

MALVERN, L. E. (1969) Introduction to the mechanics of a continuous medium. Englewood Cliffs, N.J, Prentice-Hall, Inc.

MATSUO, Y. (1981). Statistical theory for multiaxial stress states using Weibull's three-parameter function, Engineering Fracture Mechanics, v. 14, p. 527-538.

MINDLIN, R. D. (1936). Force at a point in the interior of a semi-infinite solid. Physics, v.7, p.195-202. 
MIRENKOV, V. E. (1994). Finite stress in fracture mechanics. Engineering Fracture Mechanics, v. 48, n.1, p.63-8.

MÜLLER, W. H.; HERRMANN, G.; GAO, H. (1993). Elementary theory of cracked beams. Theoretical and Applied Fracture Mechanics, v.18, p.163-67.

NGUYEN, Q. S. (1987). Bifurcation and post-bifurcation analysis in plasticity and brittle fracture. J. Mech. Phys. Solids, v.35, n.3, p.303-24.

NOGUCHI, H.; SMITH, R. A. (1995). An analysis of a semi-infinite solid with three dimensional cracks. Engineering Fracture Mechanics, v.52, n.1, p.1-14.

OLIVER, J. (1995). Continuum modelling of strong discontinuities in solid mechanics using damage models. Computational Mechanics, v.17, p.49-61.

PIAN, T. H. H.; TONG, P.; LUK,C. H. (1971). Elastic crack analysis by a finite element hybrid method.

PLANAS, J.; ELICES, M. (1991). Nonlinear fracture coesive materials. International Journal of Fracture, v.51, p.139-57.

PLANAS, J.; ELICES, M.; GUINEA, G. V. (1991). Cohesive cracks versus nonlocal models: closing the gap. International Journal of Fracture, v.63, p.173-87.

RICE, J. R.; SORENSEN, E. P. (1978). Cotinuing crack-tip deformation and fracture for plane-strain crack growth in elastic-plastic solids. J. Mech. Phys. Solids, v.26, p.163-86.

RIGBY, R. H.; ALIABADI, M. H. (1993). Mixed-mode $J$-integral method for analysis of 3D fracture problems using BEM. Engineering Analysis with Boundary Elements, v. 11, p.239-56.

ROCHA, J. A. de L.; BARREIRO, J. C.; PROENÇA, S. P. B. (1996). Condição fundamental para a compatibilização da Mecânica da Fratura com a Mecânica do Contínuo. In: SIMPÓSIO BRASILEIRO SOBRE TUBULAÇÕES E VASOS DE PRESSÃO, $9^{\mathrm{O}}$., Rio de Janeiro, 1996. Anais. Rio de Janeiro, p.177-81. 
RUGGIERI, C.; DODDS, R. H. (1992). The local approach to the effect of notch depth on fracture toughness. In: European Conference on Fracture (ECF9), 9, Varna, Bulgária. Anais. Varna, v. 1.I, p. 621-26.

RUGGIERI, C.; DODDS, R. H. (1997). Transferability of elastic-plastic fracture toughness $\left(J_{c}\right)$ using the Weibull stress approach. São Paulo. / Relatório Técnico, BT-PNV-34 EPUSP /

SHE, S.; LANDES, J. D.; BOULET, J. A. M.; STONEKING, J. E. (1991). Statistical theory for predicting the failure of brittle materials. Journal of Applied Mechanics, Mar. 1991, v.58, p.43-9.

SPENCER, A. J. M. (1965). On the energy of the Griffith crack. Int. J. Engng. Sci., v.3, p.441-49.

STEVENS, R. N. ;GUIU, F. (1991). Energy balance concepts in the physics of fracture. Proc. R. Soc. Lond. A (1991), 435, p.169-83.

SCHÜTZ, W. (1996). A History of fatigue. Engineering Fracture Mechanics, v.54, n.2, p.263-300.

TAROCO, E.; CIMINI, C. A.; LAS CASAS, E. (1994). Fracture Mechanics via Sensitivity Analysis and Numerical Evaluation of $\mathrm{J}$ integral in cracked sheets. Journal of Constructional Steel Research, v. 28N2, p. 153-66.

TURNER, C. E.; KOLEDNIK, O. (1994). Application of energy dissipation rate arguments to stable crack growth. Fatigue Fract. Engng. Mater. Struct., v.17, n.10, p.1109-27.

VALENTE, S. (1993). Heuristic softening strip model in the prediction of crack trajectories. Theoretical and Applied Fracture Mechanics, 19, p.119-25

WANG, B.; HWANG, K-C. (1994). $J_{1}$-integral for non-J-controlled crack growth. Engineering Fracture Mechanics, v.47, n.1, p.49-57.

WANG, G. S. (1993). The plasticity aspect of fatigue crack growth. Engineering Fracture Mechanics, v.46,n.6, p.909-30. 
WEIBULL, W (1951). A statistical distribution function of wide applicability. Journal of Applied Mechanics, Sept. 1951, p.293-7.

WEICHERT, R.; SCHÖNERT, K. (1978). Heat generation at the tip of a moving crack. J. Mech. Phys. Solids, vol.26, p.151-61.

WILLIS, J. R. (1967). A comparison of the fracture criteria of Griffith and Barenblatt. J. Mech. Phys. Solids, v.15, p.151-62.

ZAMANI, N. G.; SUN, W. (1993). A direct method for calculating the stress intensity factor in BEM. Engineering Analysis with Boundary Elements, 11, p.285-92. 